NAVAL PETROLEUM RESERVES IN CALIFORNIA

\title{
MITIGATION ACTION PLAN
}

FOR THE

JOINT ENVIRONMENTAL ASSESSMENT 1997-2001

\author{
OF THE \\ CALIFORNIA DEPARTMENT OF FOOD AND AGRICULTURE \\ CURLY TOP VIRUS CONTROL PROGRAM \\ FOR \\ BUREAU OF LAND MANAGEMENT \\ AND DEPARTMENT OF ENERGY
}

(DOE/EA-1011)

NAVAL PETROLEUM RESERVES IN CALIFORNIA

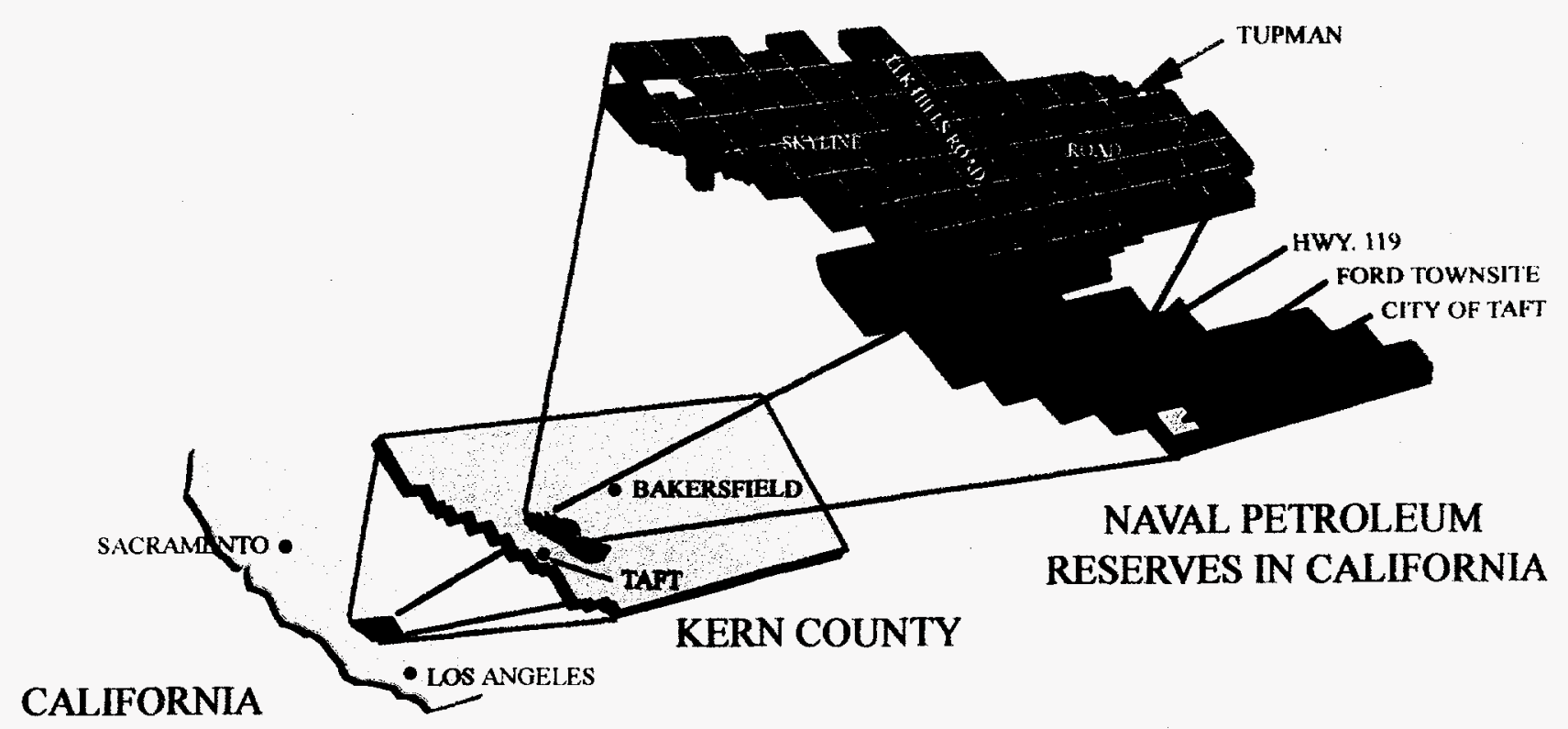

MARCH 1997 


\section{MITIGATION ACTION PLAN \\ For The Curly Top Virus Control Program \\ As Performed within the Naval Petroleum Reserves in California}

\section{EXECUTIVE SUMMARY}

Since 1987, the California Department of Food and Agriculture (CDFA) has conducted annual Malathion spraying in selected areas of southern and central California to control the beet leafhopper, which is a vector for the curly top virus. The beet leafhopper migrates onto lands in both the Naval Petroleum Reserves Number 1 and 2 from agricultural areas surrounding the reserves, which are collectively referred to as the Naval Petroleum Reserves in California (NPRC). The effects of the CDFA spraying operations have been evaluated in the Joint Environmental Assessment 1997-2001 (DOE/EA-1011) for the CDFA Curly Top Virus Control Program (CTVCP). The CTCVP would continue to be conducted at NPRC in accordance with the Cooperative Agreement and the Supplements signed by DOE/NPRC and CDFA.

DOE-NPRC and CDFA have executed another amendment to extend the term of the Agreement from 1997 through 2001.

As specified in 40 CFR 1021.331(b), "National Environmental Policy Act Compliance Program", a mitigation action plan (MAP) is required that provides for the implementation of any mitigation commitments made in a DOE Environmental Assessment and the associated Finding of No Significant Impact (FONSI). This MAP focuses on mitigation commitments stated in the EA and FONSI. 


\section{DISCLAIMER}

Portions of this document may be illegible in electronic image products. Images are produced from the best available original docoment. 
This MAP outlines the mitigative actions necessary to alleviate any impacts resulting from the CDFA Malathion spraying operations on Naval Petroleum Reserves Number 1 and 2 (NPR-1 and NPR-2).

NPR-1 is a large oil and gas field owned and operated by the Federal government and Chevron U.S.S. Inc. (CUSA), pursuant to a Unit Plan Contract that became effective in 1944. The government's interest is approximately $78 \%$ and CUSA's interest is approximately $22 \%$. NPR-1 contains approximately 47,409 areas (74 square miles) located in western Kern County, California, about 25 miles southwest of Bakersfield and 100 miles north of Los Angeles.

Under the CTVCP, Malathion would be applied at the rate of 0.583 pounds of active ingredient per acre. This compares to recommended dosages ranging from 0.292 to 1.166 pounds of active ingredient per acre for insect pests on various agricultural crops. Treatment of NPRC lands with Malathion would be limited to no more than one treatment per any given area within a calendar year. Additionally, the application of Malathion will consist solely of aerial spraying over NPR-1 and NPR-2 lands, either by fixed-wing or rotary-wing (helicopter) aircraft. As described in the EA, agreements have been achieved between DOE/NPRC and CDFA to ensure compliance with environmental protection, appropriate notification, monitoring and reporting, as well as requirements for human health and safety during the spraying operations. The Cooperative Agreement, the Supplement, and The Amendment proposed for DOE/NPRC signature will remain in effect through December 31, 2001 or until such time that either NPR-1 or NPR-2 are sold or transferred by the federal government.

It is expected that approximately 330 acres on Naval Petroleum Reserve Number 1 (NPR-1) and approximately 9,603 acres on Naval Petroleum Reserve Number 2 (NPR-2) will be treated with Malathion annually by CDFA during the course of this program. The actual acreage subject to treatment can vary from year to year. This document sets forth the actions required to mitigate any potential environmental impacts resulting from the proposed action.

\section{ENVIRONMENTAL IMPACTS:}

The impacts of aerial spraying would be localized and temporary. Activities conducted for beet leafhopper control are highly mobile, move through an area quickly, and are performed during daylight hours only away from populated areas. Malathion has a low vapor pressure and is essentially non-volatile. It is not among the substances identified by the U.S. Environmental Protection Agency as a hazardous air pollutant to be regulated under Section 112 of the Clean Air Act. Small amounts of soil compaction and dust from observer vehicles and aircraft would be created.

Malathion degrades relatively rapidly by hydrolysis and the action of soil mechanisms, and does 
not adsorb well onto inorganic soil particles, but does bind tightly to organic matter.

Consequently, Malathion is not expected to leach into groundwater, especially in areas with high organic content soils. Malaoxon, a degradation product of Malathion in soil, has a similar toxicity level and is itself degraded by hydrolysis with a half-life of 3.9 to 5 days. Populations of soil microorganisms are not expected to be significantly altered.

Indirect effects of temporarily reducing numbers of insects utilized as food for other animals is not expected to be significant because of the large foraging area, movement of prey insects to adjacent non-treated areas, and reduced impact to nocturnal flying prey insects from daytime treatments. For more than 30 years, Malathion has been used in rangeland and cultivated fallow fields to control the beet leafhopper, which is the target vector for the Curly Top Virus Control Program. No visual evidence of significant impact to vegetation or wildlife has been observed during post-treatment surveys.

Malathion may enter aquatic streams in runoff, if isolated thundershowers occur over treated areas before complete degradation of Malathion has taken place. However, the relatively quick degradation of Malathion by ultraviolet light and hydrolysis reduces the potential for residues in run-off waters or soils.

Pursuant to the requirements of Section 7 of the Endangered Species Act, a formal biological consultation was completed for this program with the U.S. Fish and Wildlife Service (FWS) and resulted in a biological opinion dated January 28,1997 . The biological opinion, entitled "Renewal of a Five-year Pesticide Use Permit to the California Department of Food and Agriculture For Use of Malathion to Control Curly Top Virus," concludes that the proposed action is not likely to jeopardize the continued existence of threatened or endangered species under the conditions set forth therein.

\subsection{MITIGATION MEASURES}

The January 1997 Biological Opinion contains all mitigation measures for the protection of federal or state listed threatened/endangered species throughout California that may be affected by the CTVCP activities. Terms and conditions contained in the Biological Opinion will be incorporated into the Amendment to the Cooperative Agreement between DOE/NPRC and CDFA. The following items are specific to the protection of listed species at the NPRC.

2.1 The following avoidance criteria table for the listed wildlife resources and conditions will be followed by all Curly Top Virus Control Project vehicles. Within the NPRC, Malathion will only be applied using either fixed wing or rotary wing aircraft, ground rigs will not be used for applications of the Malathion. 


\begin{tabular}{|c|c|}
\hline \multicolumn{2}{|c|}{ AVOIDANCE CRUTERIA } \\
\hline Type of Sensitive Area & $\begin{array}{l}\text { Radius of } \\
\text { Bunffer } \\
\text { Zone in Feet } \\
\end{array}$ \\
\hline Occupied kit fox den & 100 \\
\hline Known kit fox den & 100 \\
\hline Known kit fox natal den & 150 \\
\hline Occupied kit fox natal den & 200 \\
\hline Potential kit fox den & 50 \\
\hline Giant kangaroo rat burrows & 50 \\
\hline San Joaquin antelope squirrel dens & 30 \\
\hline Occupied blunt-nosed leopard lizard burrows & 30 \\
\hline Badger dens & 30 \\
\hline Burrowing owl burrows & 50 \\
\hline
\end{tabular}

2.2 Prior to the initiation of the project, a NPRC environmental specialist shall brief all project personnel on the occurrence and distribution of listed species in the project area, measures being implemented to protect these species during project actions, reporting requirements should incidental take occur, and applicable definitions and prohibitions under the Act.

2.3 All food-related trash such as wrappers, cans, bottles, and food scraps shall be disposed of in closed containers only and regularly removed from the project site.

2.4 All spills of hazardous materials shall be cleaned up immediately in accordance with the NPRC Spill Prevention, Control, and Countermeasures Plan.

2.5 All project-related vehicles shall observe a speed limit of $20 \mathrm{mph}$ or less on all routes that traverse endangered species habitat, except as posted on State and County highways and roads.

2.6 Water bodies are strictly avoided during the program and adequate buffer areas are provided to prevent drift of materials into any bodies of water. Additionally, spraying operations will be discontinued if more than 0.25 inch of precipitation is forecasted within 48 hours of the time of application. 
2.7 No applications of Malathion will take place when wind velocities exceed $5 \mathrm{mph}$ or air temperatures exceed $80^{\circ} \mathrm{F}$.

2.8 A qualified biologist shall be present during all spray operations. The biological monitor shall be responsible for the protection of biological resources, and shall have the authority to terminate spraying operations at any time a listed species may be threatened.

2.9 Measures to protect San Joaquin kit fox, giant kangaroo rat, and Tipton kangaroo rat:

2.9.1 No off-road vehicle travel is permitted within NPRC.

2.9.2 All known and potential San Joaquin kit fox dens will be avoided during ground surveys.

2.10 Measures to protect blunt-nosed leopard lizard (BNLL) during CTVCP Malathion spraying operations at NPRC:

2.10.1 In areas with known BNLL populations, no more that $50 \%$ of the infested area will be treated, by alternating treated swaths and untreated swaths to facilitate quick recovery of prey species.

2.10.2 Spraying will be limited to a single annual application.

2.11 An annual program report shall be provided to NPRC by December 31 of each year and shall contain at least the following: (1) a full account of any incidental take of listed species that occurred on NPRC lands as a result of CTVCP operations, (2) a map showing areas treated, (3) a table showing the number of acres of NPRC lands treated, (4) a summary of beet leafhopper populations pre- and post-control, (5) an account of all sightings of listed species, including date and time, location, and other circumstances, (6) a summary of all integrated pest management efforts, including parasite introductions, (7) the total weight of Malathion used on DOE lands, and (8) any other pertinent information not previously reported.

Other plant and animal species addressed in the January 1997 biological opinion for the CTVCP are not considered in this mitigation action plan because:

a. Those species do not exist at NPR-1;

b. Hoover's wooly star was withdrawn from the Federal Pesticide Permit (issued by the Bureau of Land Management for the CTVCP) list of plants to be avoided. 
One species of concern is the oil neststraw (citroleum stylocline) plant. A review of the literature (Morefield, Madroño, vol. 39, no. 2, p. 114) indicates the plant is self-pollinating. Consequently, aerial application of Malathion is not considered to have a negative impact on oil neststraw, and therefore avoidances of extant populations is not warranted. 
Finding of No Significant Impact

Curly Top Virus Control Program in California

AGENCY: U.S. Department of Energy (DOE)

ACTION: Finding of No Significant Impact (FONSI)

\section{SUMMARY:}

The DOE, Naval Petroleum Reserves in California (NPRC), proposes to sign an Amendment to the Cooperative Agreement and Supplement with the California Department of Food and Agriculture (CDFA) to extend the term of the Curly Top Virus Control Program (CTVCP) in California. This program involves Malathion spraying on NPRC lands to control the beet leafhopper, over a five year period from 1997 through 2001. It is expected that approximately 330 acres on Naval Petroleum Reserve Number 1 (NPR-1) and approximately 9,603 acres on Naval Petroleum Reserve Number 2 (NPR-2) will be treated with Malathion annually by CDFA during the course of this program. The actual acreage subject to treatment can vary from year to year.

Pursuant to the requirements of the National Environmental Policy Act of 1969 (NEPA), as amended, the potential impacts of the proposed action were analyzed in a Joint Environmental Assessment (DOE/EA-1011) with the U.S. Department of Interior, Bureau of Land Management (BLM) acting as lead agency, in consultation with the CDFA, and the DOE acting as a cooperating agency. Based on the analysis in the EA, DOE has determined that the conduct of the Curly Top Virus Control Program in California is not a major Federal action significantly affecting the quality of the human environment, within the meaning of the NEPA. Therefore, the preparation of an Environmental Impact Statement is not required and DOE is consequently issuing a FONSI.

\section{COPIES OF THE EA ARE AVAILABLE FROM:}

\section{O. J. Williams}

Director

Naval Petroleum Reserves in California

P. O. Box 11

Tupman, CA 93276

(805) 763-6011 


\section{FOR FURTHER INFORMATION CONTACT:}

Carol Borgstrom, EH-25

Director

Office of National Environmental Policy Act Policy and Assistance

U.S. Department of Energy

1000 Independence Avenue, S.W., 3E-080

Washington, D.C. 20585

(202) $586-4600$ or (800) $472-2756$

\section{BACKGROUND:}

NPRC has cooperated since 1987 with the CDFA's aerial spraying of the insecticide Malathion on portions of NPR-1 and NPR-2. This action is part of a much larger Malathion spraying program conducted annually by CDFA throughout the southern and central portions of California. Malathion applications control populations of the beet leafhopper, an insect that threatens many commercial agricultural by transmitting the curly top virus.

\section{DESCRIPTION OF THE PROPOSED ACTION:}

Annual Malathion spraying would continue to be conducted at NPRC as it has been each year since 1987, in accordance with the Cooperative Agreement and the Supplements signed by DOE/NPRC and CDFA. Since the term of the existing Agreement and the Supplement has expired, DOE NPRC and CDFA will execute another amendment to extend the term of the Agreement from 1997 through 2001. Malathion would be applied at the rate of 0.583 pounds of active ingredient per acre. This compares to recommended dosages ranging from 0.292 to 1.166 pounds of active ingredient per acre for insect pests on various agricultural crops. Treatment of NPRC lands with Malathion would be limited to no more than one treatment per any given area within a calendar year. Additionally, the application of Malathion will consist solely of aerial spraying over NPR-1 and NPR-2 lands. As described in the EA, agreements have been achieved between DOE/NPRC and CDFA to ensure compliance with environmental protection, appropriate notification, monitoring and reporting, as well as requirements for human health and safety during the spraying operations. The Cooperative Agreement, the Supplement, and The Amendment proposed for DOE/NPRC signature will remain in effect through December 31 , 2001 or until such time that either NPR-1 or NPR-2 are sold or transferred by the federal government.

\section{ENVIRONMENTAL IMPACTS:}

The impacts of aerial spraying would be localized and temporary. Activities conducted for beet leafhopper control are highly mobile, move through an area quickly, and are performed during daylight hours only away from populated areas. Malathion has a low vapor pressure and is essentially non-volatile. It is not among the substances identified by the U.S. Environmental Protection Agency as a hazardous air pollutant to be regulated under Section 112 of the Clean Air Act. Small amounts of soil compaction and dust from observer vehicles and aircraft would be created. 
Malathion degrades relatively rapidly by hydrolysis and the action of soil mechanisms, and does not adsorb well onto inorganic soil particles, but does bind tightly to organic matter.

Consequently, Malathion is not expected to leach into groundwater, especially in areas with high organic content soils. Malaoxon, a degradation product of Malathion in soil, has a similar toxicity level and is itself degraded by hydrolysis with a half-life of 3.9 to 5 days. Populations of soil microorganisms are not expected to be significantly altered.

Indirect effects of temporarily reducing numbers of insects utilized as food for other animals is not expected to be significant because of the large foraging area, movement of prey insects to adjacent non-treated areas, and reduced impact to nocturnal flying prey insects from daytime treatments. For more than 30 years, Malathion has been used in rangeland and cultivated fallow fields to control the beet leafhopper, which is the target vector for the Curly Top Virus Control Program. No visual evidence of significant impact to vegetation or wildlife has been observed during post-treatment surveys.

Malathion may enter aquatic streams in runoff, if isolated thundershowers occur over treated areas before complete degradation of Malathion has taken place. However, the relatively quick degradation of Malathion by ultraviolet light and hydrolysis reduces the potential for residues in run-off waters or soils. Water bodies are strictly avoided during the program and adequate buffer areas are provided to prevent drift of materials into any bodies of water. Additionally, spraying operations will be discontinued if more than 0.25 inch of precipitation is forecasted within 48 hours of the time of application.

Pursuant to the requirements of Section 7 of the Endangered Species Act, a formal biological consultation was completed for this program with the U.S. Fish and Wildlife Service (FWS) and resulted in a biological opinion dated January 28, 1997. The biological opinion, entitled "Renewal of a Five-year Pesticide Use Permit to the California Department of Food and Agriculture For Use of Malathion to Control Curly Top Virus," concludes that the proposed action is not likely to jeopardize the continued existence of threatened or endangered species under the conditions set forth therein. Upon approval of this FONSI, an amendment to the existing cooperative agreement between CDFA and DOE will be issued subject to the conditions set forth in the biological opinion.

\section{ALTERNATIVES CONSIDERED:}

Alternatives to the proposed action considered in the EA, including a reduced project alternative involving only private lands and the no action alternative. The no action alternative and use only on private lands were determined to be unacceptable because neither would meet the public need to control the curly top virus and thereby prevent loss of agricultural products in California.

Other alternatives considered but rejected were the use of an alternative pesticide, the eradication of all beet leafhopper host plant species in rangeland areas, local eradication of a single host plant species, biological control only, and the use of ground vehicles for application. Because 
Malathion is considered one of the safest pesticides and no other pesticide is registered for use in California for control of the beet leafhopper, the use of alternative pesticides was considered but rejected. The eradication of host species alternatives were rejected due to the overwhelming costs and the impacts to the ecosystem and wildlife dependence on the host plants. The ground vehicle application alternative was rejected due the impacts to habitat and the restrictions against off-road vehicle travel that are imposed by the public land agencies participating in the CTVCP.

Recommendations regarding alternatives were received from individuals, groups, and agencies in response to the EA and the proposed project. Mitigation measures were developed as terms and conditions to the proposed action in response to public and agency comments on the EA. Specific areas identified in the Coast/Valley Resource Management Plan were eliminated from the treatment area. Concern for cumulative effects identified the need to limit the number of applications. Further limitations and additional monitoring were found necessary in order to minimize impacts to several protected species under the Endangered Species Act. Public notification prior to spraying would be given to safeguard public and land use activities. In particular, owners and operators of apiary sites and livestock would be notified. A detailed spill contingency plan would be implemented to prevent or reduce adverse consequences of any spills.

Specific mitgation measures necessary to render the impacts of the proposed action at NPR-1 and NPR-2 not significant include treating only $50 \%$ of areas of known blunt nosed leopard lizard habitat by alternating treated and untreated swaths and restricting ground vehicle travel to established roads. The mitigation measures are contained in the Mitigation Action Plan that has been prepared by the DOE, pursuant to 40CFR 1021.331(b). Copies of the Mitigation Action Plan are available from the Director, Naval Petroleum Reserves in California at the above address.

\section{DETERMINATION:}

The proposed Curly Top Virus Control Program in California at the NPRC does not constitute a major Federal action significantly affecting the quality of the human environment within the meaning of the National Environmental Policy Act. This finding is based on the analyses in the EA. Therefore, an Environmental Impact Statement for the proposed action is not required.

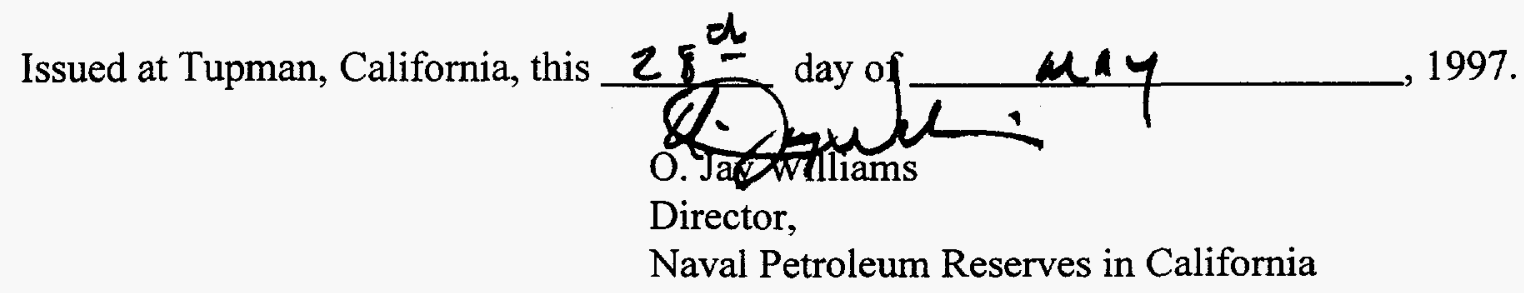




\section{TABLE OF CONTENTS}

Page No

I. INTRODUCTION 8

A. Purpose and Need............................................... 9

B. Background...................................................... $9-10$

\section{PROPOSED ACTIONS AND ALTERNATTVES}

Alternative 1 - Proposed Action......................................

General Program.

Program Specifics.

Public Health and Environmental Considerations:

Public Health and Safety.

Notification.

18

Avoidance of Non-target Sites.

19

Run-off and Drift Prevention.

20

Biological Control of Beet leafhopper

$20-22$

Key Features of Proposed Action

Measures to Avoid Potentially Major Effects

to Species of Special Concern.

Altemative 2 - Reduced Project Alternative.

Alternative 3 - No Action.

Altematives Considered but Rejected.

\section{DESCRIPTION OF EXISTING ENVIRONMENT}

A. San Joaquin and Inter-Coastal Valleys

1. Physical Components.

2. Living Component. 
3. Miscellaneous Components.
a. Natural Resources
b. Naval Petroleum Reserve in the Elk Hills
c. Cultural Components
d. Wilderness
e. Ground-rig Only Areas
f. Critical Habitat

B. Imperial and Eastern Riverside Counties

1. Physical Components.

2. Living Components.

3. Miscellaneous Components.
a. Imperial Sand Dunes
b. Cultural Components
c. Wilderness
d. Ground-rig Only Areas
e. Critical Habitat

C. Western Riverside County (Hemet)

1. Living components.

2. Critical Habitat.

D. Southern Kern and Northeastern Los Angeles Counties (Palmdale-Lancaster)

1. Living Components.

2. Critical Habitat 
Page No

\section{ENVIRONMENTAL CONSEQUENCES}

A. Assumptions for Impact Analysis........................... $\quad 61-62$

B. Impact Topics:

1. Impact Topics Dismissed from Detailed Analysis.....

2. Impacts Discussed in Detail:

a. Proposed Action

1. Impacts to Soil.

$65-66$

2. Impacts to Air Quality.

3. Impacts to Water

4. Impacts to Aquatic Life

$67-69$

5. Impacts to Vegetation:

General.

$69-70$

Plant Species of Special Concern.

$70-72$

6. Impacts to Animals:

General...

$72-74$

Animal Species of Special Concern.

74-89

7. Impacts to Curly Top Susceptible Crops.

90

8. Cumulative Impacts

$90-93$

b. Alternative 2 - Reduced Project Alternative.

93-95

c. Alternative 3 - No Action

95

V. CONSULTATION/COORDINATION.

$96-97$

VI. REFERENCES CITED.

$98-103$

VII. REFERENCES REVIEWED BUT NOT CITED

$104-108$

Appendix A Description of BLM Land Involved

Al-A8

Appendix B Malathion Labels

B1-B6 
Page No

Appendix C Correspondence cited: Hastey (BLM) to Clark

(CDFA) 3/30/93 - Hoover's woolly-star;

Pierce (USFWS) to Hastey (BLM) 11/8/93 -

Spontaneous Abortion Relating to Kangaroo

Rats; USFWS to G. Walker (UCR) $9 / 6 / 94$ \&

8/23/96 - BLH Parasite Evaluations

$\mathrm{C} 1-\mathrm{C} 9$

Appendix D Summary of Measures (a-1) to Avoid BNLL Impacts

Maps of CTVCP Designated BNLL Conservation Areas;

"High Virus-Intensive Control" Areas.

D1-D10

Appendix E Potential Treatment Maps; Chart of Probable

Treatment; Acres Sprayed (1979-1995); Ground-

rig Frequency and Application (1985-1995)

E1-E22

Appendix F Control Strategies - San Joaquin Valley, Imperial and Eastern Riverside Counties, Westem

Riverside County and Monterey County.

F1-F4

Appendix G Plants and Animals of the San Joaquin Valley, Imperial and Eastern Riverside Counties and Western Riverside County within or Near CTVCP Potential Control Boundaries.

Appendix $\mathbf{H}$ Harvester Ant Monitoring.

$\mathrm{H} 1-\mathrm{H} 2$

Appendix I Pesticide Spill Contingency Plan

II-I4

Appendix J Summary of Toxicology Data and Toxicology

Study Evaluation Work Sheet (reproduction)

for Malathion as Evaluated by the Medical

Toxicology Branch, Cal EPA

J1-J19

Appendix K Harvester Ant Survey, 1991

$\mathrm{K} 1-\mathrm{K} 25$

Appendix L Checklist of Species within or Near CTVCP

Control Boundaries for which Critical Habitat has been Designated. 


\section{LIST OF ACRONYMS}

$\begin{array}{ll}\text { ADSB } & \text { Andrew's Dune Beetle } \\ \text { APCS } & \text { Agricultural Pest Control Specialist } \\ \text { APHIS } & \text { Animal Plant Health Inspection Service (USDA) } \\ \text { BLH } & \text { Beet Leafhopper } \\ \text { BLM } & \text { Bureau of Land Management } \\ \text { BNLL } & \text { Blunt-nosed Leopard Lizard } \\ \text { CAC } & \text { County Agriculture Commissioner } \\ \text { CASB } & \text { Ciervo Aegialian Scarab Beetle } \\ \text { CBR } & \text { California Black Rail } \\ \text { CEQA } & \text { California Environmental Quality Act } \\ \text { CDFA } & \text { California Department of Food and Agriculture } \\ \text { CDFG } & \text { Califormia Department of Fish and Game } \\ \text { CRF } & \text { California Red-legged Frog } \\ \text { CTV } & \text { Curly Top Virus } \\ \text { CTVCP } & \text { Curly Top Virus Control Program } \\ \text { EA } & \text { Environmental Assessment } \\ \text { DOE } & \text { Department of Energy } \\ \text { FTHL } & \text { Flat-tailed Horned Lizard } \\ \text { GGS } & \text { Giant Garter Snake } \\ \text { GKR } & \text { Giant Kangaroo Rat } \\ \text { LDSO } & \text { Lethal dose found to cause mortality in 50\% of a } \\ & \text { test animal population } \\ \text { L\&M } & \text { Limited and Moderate } \\ \text { NEPA } & \text { National Environmental Policy Act } \\ \text { NPR } & \text { Naval Petroleum Reserve } \\ \text { OTW } & \text { Orange-throated Whiptail } \\ \text { PUP } & \text { Pesticide Use Permit } \\ \text { SKR } & \text { Stephen's Kangaroo Rat } \\ \text { SJAS } & \text { San Joaquin Antelope Squirrel } \\ \text { SJDB } & \text { San Joaquin Dune Beetle } \\ \text { SJKF } & \text { San Joaquin Kit Fox } \\ \text { TKR } & \text { Tipton Kangaroo Rat } \\ \text { UCR } & \text { University of California, Riverside } \\ \text { USFWS } & \text { U.S. Fish and Wildlife Service } \\ \text { USDA } & \text { U.S. Department of Agriculture } \\ \text { VELB } & \text { Valley Elderberry Longhom Beetle } \\ \text { WSA } & \text { Wilderness Study Area } \\ \text { YCR } & \text { Yuma Clapper Rail } \\ & \end{array}$




\section{PREFACE}

This environmental assessment (EA) is a joint document for both the Bureau of Land Management (BLM) and the Department of Energy (DOE) for the review and fulfillment of National Environmental Policy Act (NEPA) requirements and issuance of necessary permits as proposed by the California Department of Food and Agriculture (CDFA). The BLM, as lead agency, has cooperated with DOE in developing this document to assure compliance with NEPA. In addition, this EA will be used to satisfy Section 7 requirements of the Federal Endangered Species Act of 1973, the California Endangered Species Act and the California Native Plant Protection Act.

Although federal lands are highlighted throughout the document, unless otherwise specified, the descriptions and impact analysis will pertain to private as well as public lands.

A Pesticide Use Permit (PUP), issued by the BLM, authorized the CDFA to conduct this program on public lands. The current 5 -year permit will be considered for reauthorization upon its expiration, December 31, 1996. In addition, the Curly Top Virus Control Program (CTVCP) is currently operating under a cooperative agreement between the DOE and the CDFA for control of the BLH in Naval Petroleum Reserve \#1 \& \#2. Agreements between DOE and CDFA ensure compliance with requirements for notification, health and safety, environmental protection and endangered species. To facilitate the needs of both cooperating agencies, BLM and DOE will independently prepare a decision record and a PUP for the 1997-2001 permit period.

A Biological Opinion from the Sacramento Field Office of the U. S. Fish and Wildlife Service (USFWS) regarding CTVCP activities is pending. However, faced with the expiration of the current PUP, this document will be submitted for Public Review reflecting only that portion of the Biological Opinion (southern California) rendered to date, (1-6-96-F-32), Carlsbad Field Office. 


\title{
ENVIRONMENTAL ASSESSMENT
}

\author{
Curly Top Virus Control Program
}

\section{INTRODUCTION}

Curly top virus (CTV) is a viral disease of sugar beets, tomatoes, melons, peppers, beans, cucumbers, squash, pumpkins, spinach, vine seed and other commercially important crops, including ornamentals. CTV not only infects commercial crops, but at times devastates backyard vegetable and flower gardens. The only known vector of CTV is Circulifer tenellus (Baker), commonly known as the sugar beet leafhopper (BLH).

Control of BLH may take place at various locations in the San Joaquin, Salinas, Cuyama, Antelope, San Jacinto, Imperial and Palo Verde Valley including portions of Stanislaus, San Joaquin, Merced, Fresno, Kings, Kern, San Luis Obispo, Monterey, Santa Barbara, Los Angeles, Riverside and Imperial Counties. (See Appendix "E" for maps.)

The size of the control program is totally dependent on the location, size, and distribution of the BLH population. In years with above normal rainfall, BLH populations are generally limited. Lush rangeland vegetation reduces optimum breeding acreage and concentrates BLH populations into smaller areas. In years with below normal precipitation, BLH populations have the potential to be large and widespread. Sparse rangeland vegetation increases optimum breeding acreage and the possibility of developing a large BLH population. In periods of drought (successive years of below normal rainfall) a significant reduction in rangeland vegetation in some areas led to a decline in BLH populations and a reduction in treatments.

In a year with a low population, 80,000 acres or less, in western Fresno, Kings, and Kern Counties may require treatment. In years with below normal rainfall, the treatment required may increase to more than 200,000 acres and may include acreage in several inter-coastal valleys including the Cuyama and Salinas Valleys.

Not all areas require treatment on an annual basis. The mode and probability of treatment vary within the potential treatment area. (See Treatment of Probability Chart, Appendix "E", page 20.)

The CTVCP was instrumental in supporting research which developed an antisera allowing the use of Enzyme-Linked Immunosorbent Assay to determine the presence, on a percentage basis, of CTV. Thus, the amount of virus found in a given area lends weight to treatment priorities. 


\section{A. Purpose and Need for the "Proposed Action"}

The purpose of the "Proposed Action" is to control the sugar beet leafhopper, Circulifer tenellus (Baker), the only known vector of CTV. Without the control of BLH, the CTV would threaten well over three billion dollars of susceptible crops and home gardens.

With only a $1 \%$ loss from CTV in California, it is estimated that during the period 1974-1976, California suffered annual losses of $\$ 9.75$ million in commercial crops alone. A $\$ 2.68$ million loss in home gardens can be extrapolated from a 1974 value of $\$ 268,199,643$ using a $1 \%$ infection rate (Yokomi, 1979). Without control where required, BLH is capable of an infliction rate of $10-40 \%$ or more. Infection rates as high as $80 \%$ were observed near Huron, CA in 1977.

Were it not for the Program's effective control of BLH and the support of the affected industries, the state and nation would lose a substantial portion of its tomato, sugar beet, melon, bean, squash, pumpkin, cucumber, pepper and spinach crops valued in excess of $\$ 1.2$ billion annually.

\section{B. Background}

A brief review of the Program's history and development will aid in understanding the purpose and objectives of the CTVCP.

In the early part of the 20th century, large areas in California and the western United States, were cleared of natural vegetation to plant grain. In succeeding years, price fluctuation led to alternate use and abandonment of much of this land. At the same time, unrestricted grazing of cattle and sheep denuded what was once lush grazing land. The long-range result has been an enormous increase in areas ideal for BLH reproduction where natural vegetation was replaced by mustards, Brassica spp., Russian thistle, Salsola spp. and other annual BLH host plants. A study by Piemeisel and Chamberlain (1936) found well managed grazing land does not produce economically important numbers of BLH.

$\mathrm{BLH}$ is a desert insect introduced from the Middle East, probably in the late 1800's. Years with below normal precipitation provide favorable environmental conditions for the insect causing CTV to be devastating to the agricultural economy. The year 1919 was such a year and nearly ended the then young sugar beet industry in California. Out of the near disaster of 1919 emerged a concerted effort by private, state and federal researchers to design control methods that would minimize CTV incidence. After extensive research over a period of several years, it was found that in California BLH migrated between the valleys and the foothills and at times concentrated on particular host plants (Severin, 1933). It was apparent that once breeding grounds and migration patterns were determined, control efforts could be economically carried out with a minimum of expense. 
Control was originally carried out by the sugar companies until the realization that a number of other important crops were susceptible to infection. As the other susceptible crops such as tomatoes, melons, and beans increased in acreage, growers found control work becoming futile because of the migratory nature of BLH and the fact that the main breeding grounds were in uncultivated foothill areas under control of disinterested parties. Private growers and industry could not pursue the insect into the breeding grounds where control was most effective.

In 1943, the State of California, Department of Food \& Agriculture, assumed full responsibility for the control of BLH. In the first years the annual control budget was only $\$ 15,000$; however, as the effectiveness and cost of the Program increased, the State Legislature enacted a law requiring grower assessments totaling $65 \%$ of the budget. In 1986, in response to growers' request, the CTVCP extended survey and treatment activities into the Blythe and Hemet areas of Riverside County.

Recent shortfalls in state budget have eliminated the General Fund portion (35\%) of the annual CTVCP budget. The Program is now $100 \%$ funded by individual grower assessments. 


\title{
II. PROPOSED ACTIONS AND ALTERNATIVES
}

\author{
ALTERNATIVE 1 - PROPOSED ACTION
}

\section{General Program}

The "Proposed Action" alternative of CTVCP represents an overall strategy for the control of the BLH statewide where the infection of susceptible crops and backyard gardens is likely. Control is performed within rangeland habitat on both public and private lands; and along ditch banks, roadsides and fallow fields in cultivation adjacent to rangeland. (Appendix "E" comprises, [1] Maps of Potential CTVCP Treatment Areas [2] Treatment Probability Chart [3] Acres Sprayed (1979-1995) [4] Ground-rig Frequency and Application Totals.)

In the State of California, there are approximately 2,506,240 total acres of rangeland which have the potential for developing BLH populations. Of the 2,506,240 acres, approximately 628,480 acres or $25 \%$ are public land. (See Appendix "A" for detailed descriptions of potential public lands.) An average of 86,601 acres per year has been treated during the past 18 years. (See "Acres Sprayed Chart" in Appendix "E", page 21.) The 18-year average includes groundrig applications to roadsides and ditch banks within intensive agricultural areas; and, aerial applications to rangeland and cultivated fallow fields. Treatments performed exclusively in rangeland represent approximately $70 \%-80 \%$ of the total acreage treated annually.

Potential treatment areas are not denoted by rigid boundaries but represent generalized zones where BLH populations have historically developed. BLH development in rangeland is influenced by annual variations in weather patterns, fires, and grazing. Variations in cultural practices within intensive agriculture largely influence the development of BLH populations in cultivated fallow fields.

In any given year, the CTVCP may treat between 5,000-20,000 acres of public land depending on the frequency of treatments in Imperial County. Between 1991 and 1995, the CTVCP annually treated an average of 3,051 acres of public lands administered by the BLM and an average of 10,075 acres of public lands administered by the DOE. (See Appendix "E", page 21.) The total acres treated in any given year varies depending on rainfall patterns and BLH density and may occur at any location within the potential treatment areas mapped.

Throughout California, BLH populations develop on host plants in rangeland, cultivated fallow fields and roadsides at various times of the year and possess the potential for vectoring CTV to susceptible crops. Control is a year-round effort. As with most pest insects, control is linked to the life cycle and directed at disrupting its continuity. Aerial treatments (helicopter or fixedwing) are employed to control $\mathrm{BLH}$ populations in rangeland habitat and in large cultivated fallow fields, while ground-rigs are utilized to spot treat BLH populations within intensive agriculture adjacent to rangeland breeding grounds and CTV susceptible crops. 
San Joaquin Valley - In the San Joaquin Valley, the CTVCP usually conducts three aerial campaigns annually which closely coincide with the reproductive biology of BLH. The winter, spring and fall control periods in the San Joaquin Valley are performed on the west side and southern end of the Valley and are generally performed within three separate geographical areas. A single treatment per calendar year for any given area is generally sufficient to control BLH populations. A second San Joaquin Valley treatment per calendar year over the same geographic area may be necessary to control BLH populations if;

1) fall populations of BLH are developing in Russian thistle on rangelands previously treated in the spring, or

Approximately 17,000 acres of historical spring breeding grounds in the Pleasant Valley, Fresno County, have the potential to produce Russian thistle populations. Approximately 100-3,000 of the 17,000 acres may need a second fall treatment in any one calendar year. Appendix D, pages D3-DS illustrate potential overlap of spring and fall control areas in the San Joaquin Valley.

2) late spring rains rejuvenate drying rangeland vegetation and a second generation of BLH develops on rangeland treated earlier in the spring. Late spring rains have historically developed a second spring generation of BLH in the San Joaquin Valley every 5 or 6 years involving an estimated 1,000 to 10,000 acres of rangeland.

Imperial Valley - In the Imperial Valley, the CTVCP conducts a single aerial treatment when necessary, in the winter or spring, depending on weather patterns. Historically, treatments in the Imperial Valley are necessary one out of every three years. The treatment acreage varies from one-hundred to several thousand acres and the specific locations receiving treatments vary from treatment period to treatment period. Many years may pass between treatments to any specific location. A second treatment per calendar year, over the same geographical area, due to additional rain in the Imperial Valley has never been necessary and is not anticipated in the future.

Salinas Valley - The last aerial treatment was performed in the Salinas Valley during the spring of 1977. Aerial treatment in the Salinas Valley has been rare but could be performed as frequently as once every $7-10$ years.

Ground-rig Treatments - While aerial treatments are employed to control BLH populations in rangeland habitat and large fallow fields, ground-rigs are used to spot treat BLH populations along roadsides or ditch banks within intensive agriculture adjacent to both rangeland breeding grounds and CTV susceptible crops. Ground-rig treatments target BLH host weeds in areas where ongoing weed control activities are prevalent and may be subject to frequent discing, mowing and herbicide use. On rare occasions, ground-rigs are used to treat BLH populations in small cultivated fallow fields too small or isolated to be economically treated by aircraft. Small fallow fields, subject to ground-rig applications, range from 1-20 acres and are usually 
located at the periphery of larger cultivated fields isolated by the intersection of roads, ditches, power lines, equipment yards, or dry washes.

A ground-rig is typically a four-wheel drive pickup truck with an engine powered blower in the bed. Insecticide is injected into the air stream of the blower nozzle which is movable. Although a ground-rig can treat a swath as wide as 50 feet, the swath width is constantly adjusted to the width of the area containing roadside host plants and averages 20 to 25 feet wide. The blower is equipped with dripless nozzles and electric cutoff for precise control of spray. All controls are inside the cab where the operator can start and stop the blower engine, turn the spray off and on and control the direction of the blower.

The malathion is mixed in a 100-gallon tank mounted in the bed of the truck and applied at the same rate as an aerial application. Ground-rig vehicles are generally driven on roads accessed by agricultural vehicles and equipment within intensive agriculture.

The size and locations of ground-rig treatments in cultivated areas are related to the size and location of BLH populations in adjacent rangeland habitat. Ground-rig applications are performed immediately following aerial treatments. Spring ground-rig applications are performed for a duration of one to two weeks and target BLH populations migrating from rangeland. Fall ground-rig applications are generally one week in duration and target BLH populations developing through the summer. In most locations, one ground-rig treatment per year is generally sufficient to control roadside and ditch bank BLH populations.

Ground-rigs Only -The CTVCP personnel use ground-rigs exclusively to control BLH populations in five distinct control areas. These areas are designated "ground-rig only" and include the (1) Cuyama Valley, (2) Palmdale-Lancaster, (3) Blythe, and (4) Hemet control areas; and a portion of the (5) San Joaquin Valley including sections of Stanislaus, Merced, San Joaquin and Fresno Counties (see maps in Appendix "E").

Both spring and or fall treatments are possible in the Hemet, Antelope Valley, and San Joaquin Valley "ground-rig only" control areas. (See "Treatment Probability Chart", Appendix "E", page 20, and "Frequency of Ground-rig Treatments", Appendix " $E$ ", page 22.)

\section{Program Specifics}

\section{Fall Treatments}

Fall control operations in the San Joaquin Valley are the culmination of monitoring the BLH population on Russian thistle (Salsola spp.). Beginning in June, Russian thistle is mapped where it is growing on fallow ground, oil fields or rangeland. Maps are updated weekly and the BLH populations are monitored with sweep net surveys. By mid or late September, the Russian thistle harboring the largest populations of BLH has been delimited and the emergence of nymphs, which will be the overwintering generation, has begun. The overwintering 
generation will be the adults that migrate from the Russian thistle to the hills on the west side of the San Joaquin Valley to seek out sunny south-facing slopes on which they produce the spring generation of BLH. A percentage of the overwintering BLH carry CTV to winter annuals where the disease multiplies and is carried back to cultivated crops by the spring generation of BLH. The only differences between the spring and winter treatments are the time of year and the phase of the life cycle of the BLH that is targeted. In winter, the adult female is targeted prior to egg deposition, whereas, spring operations target adults and nymphs of the first spring generation. (See Appendix "F" for detailed control strategies.)

Once the CTVCP personnel, Entomologists and Agricultural Pest Control Specialists (APCS), determine that the probability of achieving maximum population reduction is high, pre-treatment counts of the BLH populations are made and control operations are started.

BLH control is accomplished by insecticidal application. Malathion is mixed with buffered water at a rate of $7.7 \mathrm{oz}$. (.583 lbs./ acre a.i.) of $95 \%$ malathion in $120.3 \mathrm{oz}$. of water equaling one gallon, which is applied to each acre treated. Malathion is routinely sampled by CTVCP and tested by the Center for Analytical Chemistry, CDFA, to assure quality and absence of contaminants.

Fixed-wing aircraft or helicopters are used to apply malathion in $100 \mathrm{ft}$. swaths. In order to keep the aircraft in line, flaggers (people hired and trained to direct aircraft), are placed at each end of the swath and at intervals in the swath line, as necessary. The flaggers keep the aircraft in line by waving a flag or providing the pilot a bright flash of light from either a signal mirror or powerful spotlight. Once the aircraft approaches one flagger and is sighted on the next, the flagger moves 100 feet to direct the next swath. Since the flaggers are on foot, communications are maintained by hand held radio. Supervisors are in constant contact with the pilot and flaggers by radio to give directions, where needed. To further aid in the accuracy of the application, all aircraft are required to have SAT-LOC GPS (Global Positioning System) equipment.

Concentrated malathion and water are transported to the aircraft loading site as near to the control area as practical. Mixing is accomplished by metering water, buffered to a $\mathrm{pH}$ of 6.5 , into a mix tank then metering the prescribed ratio of malathion into the mix tank under agitation. The helicopter is loaded by connecting a hose with a drip proof connector between the mix tank and the helicopter. Each load transferred to the helicopter is metered and checked against the known area treated to assure proper application rate. Spray booms are calibrated on site under the supervision of the CDFA supervisor before application is started and periodically re-checked during the course of the operation. T-Jet, D-4 nozzles with \# 45 spinners are utilized on helicopter booms while fixed-wing aircraft are equipped with T-Jet, D-4 nozzles with \# 56 spinners. Separate spinners allow for the different operating speeds of the two aircraft while delivering a droplet size averaging 350 microns. 
The aircraft and pilots are under contract to CDFA and meet or exceed all FAA standards. In addition, CDFA requires that the pilot, licensed as a journeyman agricultural pilot, has a minimum of 1,000 hours in the type and model aircraft being used.

Equipment used in conjunction with aerial control operations normally consists of one helicopter or airplane and fuel truck furnished by the contractor, two CDFA trucks with water, mix tank and malathion tank and three or four passenger vehicles for the supervisors and flaggers. Flaggers are put out and picked up via the passenger vehicle where roads are available. If no roads are available, flaggers are put out and picked up by helicopter.

If a fixed-wing aircraft is used, the fuel truck and mixing vehicles are located at a landing strip which is frequently remote to the treatment area. This effectively reduces the number of offroad vehicles supporting treatment activities within the immediate treatment area.

The number of CTVCP personnel needed to support a single helicopter during treatment operations varies from 8-12 people. More people are utilized in areas where constant surveillance with extra passenger vehicles is necessary to minimize accidental exposure to people, water sources or to assist in flagging sensitive habitat boundaries. Within 72 hours after application is completed in an area, post-treatment checks are made to assure positive depopulation of BLH has been achieved.

Both pre and post-treatment surveys in Russian thistle are conducted by using a heavy duty sweep net with shallow net bag of CTVCP design. The net frame consists of a stiff $15^{\prime \prime}$ round hoop constructed of $3 / 16^{\prime \prime}$ steel attached to a hardwood handle $7 / 8^{\prime \prime}$ round by 25 " long. During survey, the net is vigorously swung horizontally in order to contact the Russian thistle plant in such a manner as to enter the foliage several inches and sweep through with sufficient velocity to dislodge BLH and collect them in the attached net bag. The bag is 16" deep and 15" in diameter, constructed to form a shallow cone. Once captured, the BLH begin migrating from the base of the net towards the open top where they are counted as they attempt to exit.

BLH counts are averaged by the number of BLH per net sweep. The single net sweep method is directly related to actual counts from enclosed trap studies conducted over several decades.

If during actual pre-treatment survey, counts on Russian thistle averaged 100 BLH per net sweep and post-treatment counts taken 72 hours after treatment averaged three BLH per net sweep in the same area, the population is considered to have been reduced by $97 \%$. A $97 \%$ reduction is considered excellent control since malathion at $7.7 \mathrm{oz}$. per acre cannot fully penetrate the canopy of moderate sized (24"-30") Russian thistle. However, most treatments result in a 90 percentile plus mortality because of BLH movement to the outer perimeter of the plants where contact with the malathion is assured. 


\section{Winter/Spring Treatments}

Survey and treatment of BLH populations in winter/spring differs from fall control strategies. BLH overwintering and spring breeding sites in the San Joaquin Valley are located on south to southwestern facing slopes within the upland foothill terrain of western Kern, Kings, Fresno and Merced Counties. Breeding sites are located where dense growing wild oats, red brome, foxtail dominated rangeland gives way to slopes harboring sparsely populated, stressed plant communities, including filaree (Erodium), peppergrass (Lepidium) and Plantago.

Soils are typically low in organic matter and are unable to retain moisture necessary for robust plant development. The BLH, being a desert insect, benefits from these sparse and stunted plant zones. The slope, sun angle and sparse growth provides heat necessary for egg and nymph development at a time of year when the vast portion of the San Joaquin Valley is influenced by fog and cool temperatures. BLH migrate and concentrate in these micro-habitats during the winter and early spring months. In addition, the sparse plant growth and poor soils are subject to rapid dehydration and are usually the first rangeland areas to show moisture stress in the spring while rangeland on north and east facing slopes and flats remain green.

BLH treatments target these sparsely vegetated breeding areas after a majority of the nymphs have hatched but prior to the adult migrations.

A different net and sweeping technique is used during winter/spring survey. The net bag is the same; however, the stiff $15^{\prime \prime}$ hoop is replaced with a flexible hoop made of flat stainless steel attached to a 30" handle. In sweeping, the net is held against the ground and swiftly moved in a horizontal arc approximately $150^{\circ}$ from side to side. As it passes over the tops of host plants, BLH attempting to escape, are caught in the cone of the net. Both pre and post-treatment surveys are conducted and daily evaluations of populations are made in order to alert growers of susceptible crops as to the threat level posed by CTV infection in various areas.

Due to the early drying of sparsely vegetative breeding habitat, pilots can easily discern BLH breeding areas from other rangeland vegetation. Flaggers are used to direct the aircraft to pre-designated slopes where concentrations of BLH have been located. Mixing and loading of aircraft is identical to fall treatment.

In contrast to BLH breeding sites in the San Joaquin Valley, historical spring breeding sites in the Imperial Valley develop across the desert floor where seasonal rainfall patterns influence the random growth of host plant populations. (Further information regarding control strategies can be found in Appendix " $F$ ".) 


\section{Public Health and Environmental Considerations}

\section{Public Health and Safety}

Malathion has been used for 50 years on commercial food crops, home gardens, landscaping, pets, livestock, mosquito abatement and fruit fly eradication projects. The relatively small quantity of $.58 \mathrm{lbs}$. of malathion per acre, as specified in the "Proposed Action", limits potential exposure for people living in or near the treatment areas. It is the policy of the CTVCP to prevent accidental exposure of the general public or persons incidentally working in the area treated.

Malathion has been extensively evaluated and there is no convincing evidence that it is a carcinogen, teratogen, reproductive toxin, or that it damages nerves (CDFA, 1994). Detailed discussions of risk and hazard assessments of malathion can be found in Exotic Fruit Fly Eradication Program-Final EIR, Appendix "A" (CDFA, 1994) and in the Health Risk Assessment of Aerial Application of Malathion-bait (CDHS, 1991).

All personnel working on the CTVCP are trained in the safe handling and application of pesticides and are provided with required safety equipment.

Prior to treating an area by air, the pilot is informed of local non-target sites including water sources, endangered species sites, livestock, and any people working or passing through the treatment area. Where vehicles are able to travel, CTVCP personnel patrol ahead of the aircraft to alert anyone who may not have been notified. When feasible, entry points into the treatment area are restricted by stationing a person to notify people of the pesticide application in progress.

Supervisors are in constant contact with the aircraft and ground crews by radio. Wind direction and velocity is monitored to prevent pesticide drift out of the target area. Pilots are instructed to turn off spray when people or vehicles are encountered in the treatment area.

\section{Pesticide Training - Project Personnel}

CTVCP personnel are trained in the safe and proper mixing, loading and application of malathion in compliance with both federal and state pesticide regulations and the product label. Each full time employee maintains and updates a CTVCP Safety/Pesticide Training Manual consisting of general safety rules and the written pesticide training program. Each employee attends a documented pesticide training session annually or prior to working with malathion. In addition members of the CTVCP staff maintain a Qualified Applicator Certificate, issued by the California Department of Pesticide Regulation. To maintain a certificate, 20 hours of continuing education courses must be completed every two years. 


\section{Notification}

The notification of property owners prior to survey and BLH control, is a fundamental part of the program. Written permission for continued survey and potential treatment is solicited from the owners or lessees of public and private lands where BLH host plants have been mapped. County property plat books are used to locate names and addresses of property owners. Within winter and spring treatment areas, where large tracks of rangeland are held by small numbers

of oil companies or ranchers, the landholders are notified in person. The written waiver informs the owner of the presence of BLH host plant populations and the potential for harboring BLH on their property. Comments or special instructions are requested from the landowners in an effort to minimize the impact of the Program on their daily activities. Special concerns of property owners and the CTVCP may include honeybees, livestock, endangered species, water sources, work crews, recreational uses or pre-existing medical conditions of landowners. Copies of both the malathion label and material safety data sheet are made available on request for more detailed and specific information.

A special effort is made to give a $24 / 48$-hour notice of treatment, if requested by property owners. The one to two-day notice is more commonly requested by the various oil companies to inform company personnel and private contractors within the oil fields, where BLH control will be performed.

Public agencies, such as the BLM, DOE, California Department of Water Resources and California Department of Parks and Recreation, have requested a substantial prior notice of treatment, coordination meetings, or a temporary permit prior to survey or treatment. Pretreatment meetings and temporary permits generally highlight safety concerns, the notification of local field supervisors, descriptions of the potential treatment area and known endangered species locations.

\section{Honeybees}

Due to the susceptibility of honeybees to malathion, care is taken to locate apiaries during pretreatment survey activities. The County Agricultural Commissioners (CAC) offices and the Kern Agricuitural Chemical Association are utilized by the CTVCP to notify beekeepers prior to BLH treatment activities.

Beekeepers are required to register apiary locations with $\mathrm{CAC}$ offices and may register with the Kem Agricultural Chemical Association. Comparisons of CTVCP potential treatment maps to current bee locations at both the CAC and the bee notification service are made prior to treatment. Locations are noted and follow-up field surveys are performed to confirm the presence of bees. The beekeeper is contacted if BLH control must be performed within one mile of the apiary. Pre-treatment contact with the CAC and the bee service also alerts beekeepers, looking for new apiary locations, of the potential treatment areas and approximate time frame. CTVCP staff attempt to contact owners of unregistered apiaries, found during pre- 
treatment surveys, using the owner information stenciled on the hive boxes. If the owner's name and phone number does not appear on the hives, the $\mathrm{CAC}$ is contacted in an effort to locate the owner.

\section{Avoidance of Non-target Sites}

Program personnel, through extensive field experience, become intimately acquainted with all physical characteristics of the terrain within their assigned districts. This includes familiarity with non-target sites and situations such as human activity, livestock, water sources, endangered species locations and riparian zones.

Riparian habitats are not conducive to the growth and development of BLH host plants and therefore are not treated. The area of riparian influence or "green belt" is in stark contrast to drying rangeland vegetation where treatments are conducted. Buffer areas of at least 100 yards are left untreated near riparian water courses. The buffers extend from the outer edge of the influence of the water course (green belt) into arid areas of drying rangeland vegetation. Buffer zones are widened sufficiently to compensate for the curvature of stream beds and current wind direction.

BLH breeding habitat, in close proximity to riparian water courses, are most often located on the north side where the slope direction and host plant growth is suitable for BLH development. The slope and sun angle in rangeland habitat on the immediate south side of water courses is not conducive to BLH development and when left untreated, functions as a buffer of 400 to 600 yards or more.

The close familiarity with treatment areas and continual BLH delimitation surveys performed during the 4-5 week period prior to the commencement of aerial applications, enables Program personnel to predict where non-target sites and situations are likely to occur. Maps provided by private parties, the BLM, National Resource Conservation Service and the U.S. Geological Survey are utilized to record the locations of BLH populations and the position of non-target sites.

Prior to the treatment of each area, the aerial applicator is briefed and given a map of nontarget sites, treatment restrictions and potential aviation hazards within areas to be treated. On occasion, reconnaissance flights are performed to point out non-target areas and potential aviation hazards to pilots unfamiliar with a particular treatment area.

The aerial applicators and Program personnel performing ground-rig applications leave at least a 50-100 yard buffer around non-target sites within the potential treatment area. To aid the aerial applicator in this task, Program personnel routinely place flag persons or position vehicles, as cutoff points, between the non-target sites and the flight path of the aircraft, assuring a proper buffer. In addition, field supervisors are in constant radio contact with the pilot to aid and direct the pilot in locating and avoiding non-target sites. 


\section{Runoff and Drift Prevention}

Weather conditions within potential treatment areas are important factors in determining the effectiveness of control applications. Each canyon is different with respect to weather patterns, precipitation, propensity for fog and winds. A great deal of time and money is invested in the survey, delimitation and treatment of BLH populations. It makes little sense to apply expensive materials by expensive methods when windy or inclement weather conditions could nullify control efforts and increase the potential for drift or runoff into non-target areas. Listed below are guidelines employed by the CTVCP to reduce the potential for drit and runoff from the influences of weather.

1. Prior to and during treatment activities, the local weather forecasts are consulted on a daily basis to ascertain the likelihood of rain and wind. During control operations, wind speed and direction is constantly monitored to eliminate drift into non-target areas. Constant communication is maintained with aircraft to alert the pilot should weather conditions change. When necessary, buffer zones are enlarged to compensate for wind direction.

2. When plant cover is moist due to recent rain, dew, or frost, the CTVCP delays the application of malathion until the plant cover is nearly dry.

3. When there is a high probability $(80 \%)$ of local moderate rain, .25 inch or less within 24 hours, we closely watch the possibility of precipitation within the treatment area allowing applied materials sufficient time to dry (at least four hours) before anticipated rainfall. Light showers of 10 inch or less appears to have little affect on the applied insecticide once dried on the plant surface.

4. If rainfall of more than a moderate amount (.25 inch or more) is predicted locally within 48 hours, we will discontinue applications until predictable local conditions improve.

\section{Biological Control of Beet Leafhopper}

In an on-going effort to reduce the amount of insecticide used, the CTVCP is currently funding research to explore the prospects for utilizing egg parasites to control BLH. The University of California at Riverside is in its third year under contract to the CTVCP, to explore and develop a viable bio-control program. It is the intent of the CTVCP to integrate the use of BLH parasites with current control strategies when the effectiveness of a parasite or parasites have been demonstrated. Research efforts have concentrated on improving rearing techniques for the augmentation of Anagrus giraulti (a native BLH egg parasite) and foreign exploration for other BLH egg parasites. 
Anagrus giraulti (Crawford), is a native of California and can be found parasitizing eggs of Empoasca leafhopper and BLH eggs on sugar beets. Techniques for mass rearing Anagrus giraulti have been developed and augmentation releases have been progressing for several years in several study sites in the San Joaquin Valley.

In 1993, an undescribed egg parasite of BLH was discovered in Turkmenistan, a state in the former Soviet Union. The new parasite, in the family Trichogrammatidae, was described and given the name, Aphelinoidea turanica. On September 6, 1994 and August 23, 1996, the USFWS determined that the "Proposed Action" of releasing parasites for the biological control of BLH will not adversely affect federally listed threatened and endangered species. (See Appendix "C" for USFWS correspondence.) Due to the host specificity of other parasites in the family Trichogrammatidae, we anticipate parasitation to occur exclusively in BLH eggs. Aphelinoidea turanica has been successively recovered two years in a row from a study site near Oildale and represents a promising prospect. Further intensive field studies will be performed to evaluate the effectiveness of the parasite.

A second exploratory trip to Turkmenistan during the summer of 1994 was unsuccessful in recovering a viable population of potential BLH egg parasites.

In 1995 an exploratory trip was made to three geographic regions of Iran. Six or possibly seven species (some may be undescribed) of parasites from two different families were recovered. The parasites were processed through the quarantine facility at the University of California at Riverside. Nine cultures of nine different species were established, but only seven survived and are listed below:

\section{Mymaridae}

1) Gonatocerus sp. 1

2) Gonatocerus sp. 2

3) Polynema sp. 1

4) Polynema sp. 2

\section{Trichogrammatidae}
5) Aphelinoidea turanica
6) Aphelinoidea anatolica
7) Oligosita sp.

The population of Aphelinoidea turanica collected in Iran will be evaluated separately from the population collected in Turkmenistan as potentially different biotypes.

All cultures were moved out of quarantine, and into the insectary facility shortly after obtaining permits from USDA and CDFA for field release for all species. Due to the small size of the cultures, only small and intermittent releases of parasites have been possible. Between December 13, 1995 and July 7, 1996, approximately 17,115 parasites have been released in 9 locations in the greater Coalinga area of Fresno County. Field sampling of release sites was performed to check for establishment of all parasites and to date, none of the latest group of parasites have been recovered from wild vegetation. 
Research through 1997 will focus on:

1. The continued release and establishment of BLH parasites throughout the state and on public lands.

2. Determine basic biological parameters on the development rate and longevity of the new parasites and to determine their host plant preferences.

3. Disseminate Aphelinoidea turanica, established near Bakersfield, into other areas.

4. Assess the impact of all parasites on BLH populations.

5. Determine if the host plant preferences of the parasites can be modified by conditioning.

\section{Key Features of "Proposed Action"}

1. BLH population levels are assessed within historical breeding sites prior to undertaking control measures. CTVCP personnel monitor BLH populations in historical breeding grounds from as far north as Red Bluff south to the international border between the United States and Mexico.

2. The state is divided into five control districts with an APCS assigned to each district, depending on workload in the particular area. Program entomologists coordinate workload and evaluate BLH population levels statewide based on predator/prey relationships, virus analysis, weather trends and available host plants.

3. Control of the BLH will be accomplished through the application of malathion by aircraft or ground-rigs where and when the CTVCP determines that BLH populations pose a threat to adjacent croplands.

4. When helicopters are used, they are serviced by a specially built tanker equipped with a closed mixing system and landing pad on the top of the truck. If two treatment crews are needed simultaneously, a second water truck (without landing pad) and an additional vehicle carrying malathion and a mixing tank is employed to service the second helicopter. Service vehicles utilize the nearest existing roads to be as close as possible to the application site.

5. If the use of fixed-wing aircraft is deemed necessary, the aircraft will use established runways in close proximity to the treatment areas.

6. CTVCP aerial operations can take place during pre-dawn hours, but only when sufficient light exists to safely navigate and observe obstacles such as power poles, wires and structures. Rarely can CTVCP aerial treatments begin earlier than 30 to 45 minutes before sunrise. CTVCP aerial operations are terminated when wind speeds exceed label requirements and/or air temperatures exceed approximately $80^{\circ} \mathrm{F}$. 
7. Ground-rigs are generally used to treat BLH host plants along roadsides and in cultivated fallow fields. (Ground-rigs consist of a mist blower mounted in the bed of a pickup.)

a. The ground-rigs are calibrated to deliver $7.7 \mathrm{oz}$. of $95 \%$ malathion per acre while treating a 50-foot maximum swath, at approximately $10 \mathrm{mph}$, along roadsides where the CTVCP determines that population levels warrant treatment. The treatment swath is adjusted to match the width of the target area.

b. Ground-rigs generally use established roads when treating roadside host plants in areas where CTV susceptible crops are grown. Ground-rig treatments target $\mathrm{BLH}$ host weeds in areas where intensive weed control activities are ongoing and may be subject to frequent discing, mowing and herbicide use.

8. The ground-rigs will also be used to treat small fallow fields where the size or location of the fallow field, if treated by aircraft, would not be cost effective.

a. The fallow fields will be covered by driving a ground-rig in parallel lines, 50 feet apart, across the length of the field with a 50-foot treatment swath.

b. The majority of ground-rig use within cultivated fallow fields is adjacent to rangeland breeding grounds and slows BLH migration toward susceptible crops.

9. Aircraft and ground-rigs are calibrated and monitored during treatment to assure a rate of $7.7 \mathrm{oz}$. of $95 \%$ malathion per acre.

\section{a. Exact formulation:}

7.7 oz. +120.22 oz. water +.08 oz. BAC Spred Stik $=128$ oz. mixture per acre (water is buffered as needed)

10. After treatment is completed, post-spray kill checks are taken by CTVCP personnel in all areas at 24,48 or 72 -hour intervals. Sampling is the same as pre-treatment sampling. These post-spray checks give a means of measuring effectiveness of the control work. The areas that were not sprayed are also sampled, both to check for possible build-up of the BLH population and predator population, and as a control to measure against areas sprayed.

11. The use of a totally closed mixing system reduces the possibility of chemical spill at the loading site. 
12. All vehicles will be restricted to existing roads to prevent soil compaction and damage to flora and fauna. BLM vehicle designations will be adhered to where applicable. Survey and flagging activities are performed on foot.

13. Where no roads exist, flaggers walk to the proper position or are placed and retrieved by helicopter.

14. Aircraft landing sites will be watered to reduce dust.

15. All malathion applications are monitored constantly to ensure proper placement of insecticide.

16. Wind speed and direction is continually monitored to ensure that the insecticide does not drift into non-target areas.

17. To minimize drift, no application of malathion will take place when sustained wind velocities exceed $5 \mathrm{mph}$.

18. Great care and effort is taken to ensure that natural or man-made bodies of water, sufficient to support any kind of wildlife, are not contaminated by runoff, drift, or by direct application. These areas include; springs, wildlife guzzlers, alkali sumps, vernal pools, ephemeral pools, stock ponds, reservoirs, streams and riparian zones. (See "Avoidance of Non-target Sites", page 19.)

a. Permanent and ephemeral water sources are located prior to treatments during delimitation survey.

b. Adjacent to all bodies of water, a 50-100 yard buffer zone is left untreated to ensure water quality.

c. A 100 yards radius buffer zone will remain untreated adjacent to riparian habitat and water courses to assure water quality and reduce impacts to sensitive wildlife.

d. Weather forecasts are consulted prior to and during treatment operations to reduce the potential for runoff (page 20).

19. All beekeepers are notified by the CTVCP within a minimum of 48 -hours of pending pesticide application. (See "Honeybees" under "Notification", pages 18 and 19.)

20. CTVCP personnel are trained to be observant of and avoid wildlife on roads within the areas of operation. The speed of off-road vehicles vary and are commensurate with the quality and condition of the road. 
21. Managers of camps and recreation areas are notified prior to treatment.

22. All Program personnel have been trained to minimize contamination in the event of a pesticide spell (See "Pesticide Spill Contingency Plan", Appendix "I".)

23. Application contractors are required to furnish journey level pilots who have a minimum of 1,000 hours experience flying the type of aircraft used in pesticide application. The pilot must possess all licenses required by the county and state.

24. Malathion is routinely sampled by CTVCP and tested by the Center for Analytical Chemistry, CDFA, to assure quality and absence of contaminants.

25. Aircraft carry a maximum of 24 gallons active ingredient (a.i.) for helicopter and 50 gallons for fixed-wing to minimize contamination in the unlikely event of an aircraft accident.

26. All vehicles carry fire fighting equipment including: 1) a chemical fire extinguisher, type A-B-C, of at least one pound minimum capacity of a type approved by the California Department of Forestry, and 2) a shovel in good condition with a handle not less than three feet in length and a blade width not less than 7-3/4 inches. When helicopters are utilized, the tanker truck usually has several hundred gallons of clean water that can be applied by high pressure to control fire, if needed.

\section{Measures to Avoid Potentially Major Effects to Species of Special Concern}

Measures to avoid potentially major effects to species of special concern have been adopted directly from terms and conditions, and conservation recommendations outlined in USFWS biological opinions and stipulated as terms and conditions of CTVCP's Federal PUP. Measures were also adopted from formal and informal consultations with CDFG. Measures for candidate dune beetle species were stipulated within the current Federal PUP by BLM.

\section{SAN JOAQUIN VALLEY}

\section{Blunt-nosed Leopard Lizard (BNLL)}

Measures to minimize impacts to BNLL involves a conservation strategy which focuses on efforts to eliminate or severely restrict malathion treatments within habitat important for the recovery and maintenance of the BNLL while allowing control of BLH, when necessary, in historical high CTV virus areas. (See "Summary of Measures and Maps" in Appendix " $D$ ".) The strategy includes the following: 
- Identification of BNLL conservation habitat;

- Align the BNLL conservation habitat with conservation objectives contained within the Kern County Valley Floor Habitat Conservation Plan, the Pleasant Valley Habitat Conservation Plan and BLM's Listed Species Conservation Strategy. The BNLL conservation areas can be amended to reflect the most current BNLL survey information.

- Identification of historical intensive CTVCP treatment areas;

- The integration of BLH egg parasites within BNLL conservation habitat reducing the need for treatments;

- The reduction of favorable BLH host plants by encouraging grazing standards.

\section{Measures Taken within Non-BNLL Habitat}

a. All malathion applications will be aerial. No off-road vehicle use within spray areas will be permitted.

b. Application rates of malathion for treatment areas will not exceed the prescribed rate addressed in the CTVCP EA.

c. No applications of malathion will take place when sustained wind velocities exceed $5 \mathrm{mph}$ to minimize insecticide drift into non-target areas.

d. The CTVCP will attempt to reduce BLH host plants including Russian thistle by encouraging rangeland management practices as a third priority.

\section{Measures Taken within Presumed BNLL Habitat}

Presumed BNLL habitat is based on known locations and site characteristics outside the CTVCP designated BNLL conservation areas (see Appendix " $D$ ").

e. Same measures as in a, b, and c for non-BNLL habitat plus,

f. With the exception of $g$ below, malathion will not be applied more than once per calendar year within each treatment area that is "presumed" BNLL habitat with up to $100 \%$ coverage of delimited BLH populations, based on pre-treatment surveys.

g. Intensive spring treatment areas which overlap intensive fall treatment areas, highlighted in Appendix " $\mathrm{D}$ ", will have the option of an additional annual treatment, up to $100 \%$ coverage, of delimited BLH populations on Russian thistle. (These intensive control areas, approximately 17,000 acres, have the potential of developing large BLH populations in Russian thistle on rangeland where a single spring treatment 
may have been performed. The majority of these areas are located on the west side of Fresno County in the Pleasant Valley. Approximately 100-3,000 acres may need treatment in any one year.)

h. The CTVCP, as a second priority, will attempt to reduce the necessity for a second fall treatment in "Intensive Fall Treatment" areas by encouraging rangeland management practices that reduce the development of Russian thistle.

\section{Measures Taken within BNLL Conservation Areas}

BNLL conservation areas are based on best available knowledge and preliminary recovery planning. BNLL conservation areas are estimated to cover approximately 154,060 acres (67,060 in San Joaquin Valley; 87,000 in the Carrizo Plain). BNLL conservation areas are highlighted in Appendix " $D$ ".

i. Malathion will not be applied in areas designated as BNLL conservation area \# 10 in the Carrizo and Elkhorn Plains.

j. Malathion will not be applied in areas designated as conservation areas $1,2,3,4,8$, 9 in the San Joaquin Valley. Malathion may only be applied in areas designated as BNLL conservation areas 5, 6, 7 in the San Joaquin Valley under the following conditions:

1. If a critically large BLH population is found during pre-treatment surveys, averaging 15 BLH's per 10 net sweeps. BLH control will be restricted to a single annual treatment. No more than $50 \%$ of the area will be treated by alternating a treated swath with an untreated swath to facilitate the quick establishment of insect prey species and spot applications will not cover contiguous parcels exceeding 20 acres; or

2. If BLH control is necessary within designated "High Virus-Intensive Control" areas, highlighted in Appendix " $\mathrm{D}$ ". Treatments will be restricted to one per year up to $50 \%$ coverage of delimited BLH populations by alternating a treated swath with an untreated swath to facilitate the quick establishment of insect prey species. Spot applications will not cover contiguous parcels exceeding 20 acres.

k. The CTVCP, as a first priority, will attempt to reduce the need for treatments within BNLL conservation habitat by encouraging rangeland management practices that reduce the development of BLH host plant populations.

1. The CTVCP will target BNLL conservation habitat, outside "High Virus-Intensive Control" areas, for initial release and establishment of BLH egg parasites in BNLL 
conservation areas 2, 5, 6 and 7 as a first priority and the remaining conservation areas as a second priority.

m. On an annual basis, the CTVCP will consult informally with BLM, USFWS and CDFG, if necessary, to modify designated BNLL conservation habitat areas and review the status of the BNLL conservation strategy and research.

NOTE: Additional restrictions to CTVCP activities within potential BNLL habitat exist due to the exclusion of CTVCP's treatment activities from "Specialty Preserves" (as defined within habitat conservation plans), various national and state preserves and refuges, Nature Conservancy lands, wetlands and lands populated by several listed plant species during the spring bloom periods.

The CTVCP will support collaboration on the following list of additional informational needs.

- Further definition of BNLL conservation habitat areas with driving surveys.

- Long-term studies to determine post-treatment invertebrate response, recovery and BNLL population/reproductive responses to treatments of $50 \%$, and no treatments.

- Resolve any questions regarding dermal exposure of BNLL to malathion.

- Review and assessment of previous BNLL survey data generated by the CTVCP.

\section{Tipton Kangaroo Rat and Giant Kangaroo Rats (TKR \& GKR)}

a. All malathion applications in the vicinity of known TKR or GKR habitat shall be aerial. No off-road vehicle use will take place in known TKR or GKR habitat.

\section{San Joaquin Kit Fox (SJKF)}

a. Known and potential dens of SJKF will be avoided during ground surveys. No off-road vehicle use will take place within know SJKF habitat.

\section{San Joaquin Dune Beetle and Ciervo Aegialian Scarab Beetle}

a. Application of malathion is strictly avoided within $1 / 4$ mile of known habitat of the San Joaquin dune beetle and the Ciervo Aegialian scarab beetle.

b. Additional potential dune habitat for each species will be inventoried. Malathion application in such areas, which are found to be occupied, is strictly avoided.

c. Aerial application of malathion within one mile of known and probable population sites are curtailed when sustained wind velocity exceeds $5 \mathrm{mph}$. 


\section{San Joaquin and Intercostal Valley Plants of Concern}

Locations of extant populations of listed plants are gathered from the California Natural Diversity Database and information gathered by state and federal resource agencies prior to treatments. Maps prepared and maintained by Enterprise Advisory Service are consulted to determine the locations of extant populations of listed plants within NPR \#1 and \#2. The CTVCP on an annual basis will consult plant maps prepared and maintained by the CDFG, DOE and the BLM to update known plant locations.

a. Malathion is not applied in areas with extant populations California jewelflower, Bakersfield cactus, Kern mallow, Monterey spineflower and robust spineflower during the flowering periods.

b. Specific avoidance measures, previously adopted by the CTVCP for Hoover's woolly-star and San Joaquin woolly-threads, have been removed from the "Proposed Action" due to:

- the modification of BLM Federal Pesticide Permit 91-CA-93-0001, withdrawing Hoover's woolly-star from the list of plants to be avoided by CTVCP during the bloom period. (See letter dated March 30, Appendix " $\mathrm{C}^{\prime \prime}$.)

- recent pollination exclusion experiments were performed on San Joaquin woolly-threads (Mazer \& Hendrickson, July, 1993). Although inconclusive, San Joaquin woolly-threads showed and ability to set seed in the absence of insect pollinators as previously speculated by USFWS (USFWS, Sept. 1991). Previously adopted avoidance measures would therefore, have no significant relevance on the ability of the San Joaquin woolly-threads to produce seed in areas left untreated by the CTVCP.

\section{San Joaquin Antelope Squirrel (SJAS)}

a. All malathion applications in the vicinity of known SJAS habitat shall be aerial.

b. No off-road vehicle use will take place in known SJAS habitat. 


\section{California Red-legged Frog}

a. An aerial and ground-rig buffer of at least 100 yards will remain untreated near aquatic or ripirian areas suitable as potential habitat for the California red-legged frog.

b. An aerial buffer of at least $1 / 4$ mile radius will remain untreated near known occurances of California red-legged frog as defined by the National Diversity Data Base or other available data base sources.

\section{Giant Garter Snake}

a. An aerial or ground-rig buffer of at least 100 yards will remain untreated near aquatic or ripirian areas suitable as potential habitat for the giant garter snake.

\section{Valley Elderberry Longhorn Beetle}

a. CTVCP personnel operating ground-rigs will be trained to recognize elderberry plants. An aerial or ground-rig buffer of at least 100 yards will remain untreated near riparian areas suitable as potential habitat for Elderberry.

b. During the time when adult beetles are active (March through June), a buffer of at least $1 / 4$ mile radius will remain untreated near known occurrences of valley elderberry longhorn beetle as defined by the National Diversity Data Base or other available data base sources.

10. Conservancy Fairy Shrimp. Longhorn Fairy Shrimp. Vernal Pool Fairy Shrimn. Vernal Pool Tadoole Shrimn

a. The CTVCP, with the assistance of federal and state resource agencies, will identify and inventory vernal pools known to be habitat for listed fairy shrimp within potential CTVCP treatment areas.

b. No aerial or ground application of malathion will be made within a $1 / 2$ mile of known listed fairy shrimp habitat.

\section{Specialty Preserves}

The CTVCP recognizes "Specialty Preserves" as defined in the Pleasant Valley Habitat Conservation Plan (Hopkins, 1994). Three small areas, categorized as sand dune or stabilized sand dunes, have been identified near Coalinga within the potential 
winter CTVCP treatment area. These areas are potential habitat for the San Joaquin dune beetle (Coelus gracilis), ciervo aegelian scarab beetle (Aegialia concinna) or the red-headed sphecid wasp (Euceris ruficeps).

a. All malathion treatments will be eliminated from within the specialty preserves.

b. No off-road vehicle use will take place within the specialty preserves.

\section{Nature Conservancy Lands}

Nature Conservancy lands are generally dedicated to threatened and endangered species management and habitat preservation.

a. The CTVCP will not treat Nature Conservancy lands.

b. The CTVCP will seek to establish BLH egg parasites on Nature Conservancy lands as development of biological control agents prove effectual.

\section{SOUTHERN CALIFORNIA}

\section{Least Bells' vireo and Southwestern Willow Flvcatcher}

a. Ground-rig treatments in the Hemet area will not be carried out in riparian habitats which may be used for nesting by the least Bell's vireo and southwestern willow flycatcher.

b. A buffer of 200 feet will be left untreated around all such habitats which may be used for nesting by the least Bell's vireo (March-September) and southwestern willow flycatcher (May-September).

\section{Coastal California Gnatcatcher}

a. Ground-rig treatments in the Hemet area will not be carried out in coastal sage scrub areas which may be habitat for the coastal California gnatcatcher.

b. A buffer of 200 feet will be left untreated around all such habitats.

\section{Stephens' Kangaroo Rat (SKR)}

a. Malathion will not be applied within any proposed SKR preserves. Locations of such preserves are shown in Riverside County's Short-term Habitat Conservation Plan for the SKR. 
b. Vehicles will not be driven on cultivated fallow fields currently occupied by the Stephens' kangaroo rat.

\section{Desert Tortoise}

a. Vehicles used in the CTVCP will not exceed $15 \mathrm{mph}$ while conducting surveys or treatment activities within desert tortoise habitat.

b. Desert tortoises encountered by vehicles used in the CTVCP will be avoided. If a tortoise cannot be avoided without moving the animal out of harm's way, the following procedure will be followed. Stationary tortoises (i.e. those in the path of a survey vehicle) may not be moved out of harm's way until 10 minutes have elapsed from the time of first encounter. Such tortoises may be handled (i.e. moved out of the way) after 10 minutes have elapsed only by personnel who have received instruction in the appropriate procedures for handling tortoises from trained BLM personnel prior to the commencement of surveys.

c. Trash will be removed daily from within desert tortoise habitat to avoid attracting ravens and other predators.

\section{Yuma Clapper Rail (YCR)}

a. No aerial applications of malathion will be made within 300 yards of potential YCR habitat. Potential YCR habitat is defined as any wetland, including agricultural drains with suitable vegetative cover, in the areas shown on Spring Treatment Maps, pages E-13 or E-14 of Appendix “E”.

b. Areas containing BLH host material that are between 100 yards and 300 yards from potential YCR habitat will be treated with ground equipment only.

c. Areas containing BLH host material that are less than 100 yards from potential YCR habitat may be treated only with equipment that can deliver the malathion specifically to the target plants harboring the BLH population.

d. Malathion will not be applied within 5 miles of occupied YCR habitat if rain is expected within 72 hours of treatment.

\section{Desert Punfish}

a. Application of malathion will not be carried out within a $1 / 2$ mile of occupied desert pupfish habitat. 
b. Application of malathion within one mile of the designated critical habitat boundaries will not take place when sustained wind velocities exceed $5 \mathrm{mph}$.

c. Application of malathion within five miles of designated critical habitat will be curtailed if weather conditions indicate a moderate to high possibility for precipitation within 72 hours of planned treatment.

\section{Ouino Checkersnot Butterfly}

a. Treatments will not be performed in known quino checkerspot butterfly habitat. The USFWS and the California Natural Diversity Database will be consulted for location information prior to treatments.

b. A $1 / 2$ mile buffer will remain untreated around all quino checkerspot habitat that the USFWS has mapped or any other known locations gathered from the California Natural Diversity Database.

c. Areas that harbor host plants for the quino checkerspot butterfly (Plantago erecta and/or Castilleja exserta) will not be treated.

\section{Andrew's Dune Scarab Beetle (ADSB)}

a. Malathion application will be curtailed within the geographic range of the ADSB between the months of February through May to prevent mortality of adult beetles during the breeding season.

b. Prior to an application in January and June, a field examination of proposed treatment areas will be conducted to determine if adult scarabs are active. If present, the malathion application will be postponed until the beetle flight was completed.

\section{Flat-tailed Horned Lizard (FTHL)}

a. Application of malathion within the geographic range of the FTHL will consist of no more than a single treatment per given area per year.

b. All application will be aerial. No spraying from off-road vehicles or use of off-road vehicles on other than designated roads will be used within FTHL habitat.

c. The application of malathion will be closely associated with ant activity. Pre and post-treatment surveys of harvester ant colonies will be conducted to gauge affects of treatments on ant activity. (See Appendix " $H$ " for survey methods.) 


\section{Peirson's Milk-vetch}

a. Applications of malathion will not be made within known extant populations of Peirson's milk-vetch.

\section{Riverside Fairy Shrimp and Vernal Pool Fairy Shrimp}

a. Treatments will not be performed in known vernal pool habitat. The USFWS and the California Natural Diversity Database shall be consulted for location information prior to treatments.

b. A $1 / 2$ mile buffer will remain untreated around all known vernal pool habitat mapped by USFWS or other locations found in the California Natural Diversity Database.

c. Treatments in other areas which include depressions that may potentially harbor vernal pool fairy shrimp will be conducted when no standing water is present.

\section{ALTERNATTVE 2 - REDUCED PROJECT ALTERNATIVE}

Under the Reduced Project alternative, the CTVCP would not treat public lands.

The CTVCP would control BLH populations where necessary on adjoining private lands using the same procedures as in the "Proposed Action".

\section{ALTERNATUVE 3 - NO ACTION}

Under the No Action alternative, the CTVCP would not use any of the above actions. Pesticide treatments would not be performed by the CTVCP to control BLH.

\section{ALTERNATIVES CONSIDERED BUT REJECTED}

1. The use of an alternative pesticide in conjunction with the "Proposed Action".

\section{Reasons for Rejection}

a. Malathion is considered one of the safest pesticides. It is used extensively and safely as demonstrated by extracts from the Initial Scientific and Minieconomic Review of Malathion (E.P.A., 1975) and toxicological evaluation by Cal-EPA (Appendix “ $J$ "). 
b. No other pesticide is registered for use in California for control of BLH in rangeland.

2. The eradication of all BLH hosts plant species in rangeland areas.

\section{Reasons for Rejection}

a. The BLH utilizes many species of host plants for food and/or ovi-position sites. The elimination of all host plant species would include native and introduced species, and would have a major impact on the ecosystem and wildlife dependent on the many BLH host plants.

b. Distribution and diversity of host plant species would make the eradication of BLH hosts practically impossible and extremely costly.

3. The local eradication of a single plant species used by BLH almost exclusively during specific times of the year.

\section{Reason for Rejection}

a. During 1940-1965, the CTVCP endeavored to eradicate localized populations of Russian thistle to reduce the large acreages found on the west side of the San Joaquin Valley. The Project utilized hoeing crews to eliminate young Russian thistle plants prior to seed production. The project was terminated due to high costs and a persistent seed bed making even local eradication of Russian thistle nearly impossible. Considerations of eradicating a single introduced BLH host plant, other than Russian thistle, include the following:

1. Financial costs to implement and maintain.

2. Environmental impacts to dependent wildlife.

3. The need for $100 \%$ cooperation from every property owner within a given area.

4. Controlling re-infestation from outside the eradication area. Excluding the environmental impacts, the financial commitment for such a project is well beyond the ability of the CTVCP's present budget.

4. Biological Control Only

Reason for Rejection

At this time, there is no proven effective bio-control agents available to control the $\mathrm{BLH}$ in rangeland habitat. 
In an on-going effort to reduce the amount of insecticide used, the CTVCP is currently funding research to determine the viability of using biological agents as an alternative. Presently, researchers from the University of California, Riverside are exploring foreign countries for effective egg parasites (see pages 20-22).

This research is being performed on an experimental basis and has not yet developed scientifically to consider full-scale development of this alternative as a viable option.

If, through continued research, biological control agents are found to be effective in controlling BLH, the CTVCP will seek to develop and integrate the use of biological control as a practical alternative.

5. Control the sugar beet leafhopper, Circulifer tenellus, using a combination of minimal aircraft and mostly ground spray rigs: $O R$ ground-rigs only - no aircraft.

This action allows the use of aircraft with malathion, in areas inaccessible by wheeled vehicles and the use of spray-rigs using malathion mounted on wheeled vehicles, in areas where they are able to negotiate the terrain.

Ground-rig treatments would include roadsides, fallow fields and rangeland where accessible. Treatment of rangeland would be performed using the same methods as ground-rig use in fallow fields (see page 12).

Aircraft use would be limited to areas inaccessible by wheeled vehicles, or not used at all.

\section{Reason for Rejection}

An increase in damage to habitat important to listed species on public and private lands would most likely result from the use of ground-rigs to treat rangeland where ground-rigs are able to negotiate the terrain.

There are large tracts of public and state lands with strict restrictions pertaining to the use of cross-country motorized vehicles. In the desert areas, large tracks of BLM land is designated Limited and Moderate (L\&M) use in which cross-country travel is prohibited. Within the Carrizo Plain Natural Area and on NPR-\#1 \& \#2, motorized vehicle use is limited to designated routes of travel. Lands administered by the State of California including the Department of Water Resources, Department of Parks and Recreation and the Department of Fish and Game, place restrictions on motorized vehicles use. 


\section{DESCRIPTION OF EXISTING ENVIRONMENT}

The following describes the existing environment in all areas where CTVCP activities take place.

\section{A. SAN JOAQUIN AND INTER-COASTAL VALLEYS}

\section{Phrsical Components}

a. Soils

The soils of the west side of the San Joaquin Valley and inter-coastal valleys are generally alkaline, ranging from very fine powdery gypsum to gravelly. Many areas have exposed hardpan or hardpan under very shallow (1-5") overburden.

b. Water

Water is scarce except where irrigation canals such as the California Aqueduct wind along the west side of the Valley, generally following the line of low foothills of the Coast Range.

Seasonal streams drain from west to east carrying runoff in arroyos and canyons during wet periods. This runoff is carried to the Valley floor where it is absorbed or becomes associated with wildlife guzzlers, alkali sumps, vernal pools, stock ponds or into one of several small reservoirs in the region. Runoff can be carried directly into streams or rivers during periods of heavy rains.

There are numerous seeps, both natural and created by petroleum production, in the Coalinga area, Kettleman Hills, Lost Hills, Elk Hills and McKittrick area. These seeps support small numbers of aquatic organisms and marsh plants. Oily sumps are screened to reduce access to wildlife.

c. Topography

The elevation of the area where control work takes place is 300 feet to 2,000 feet above sea level. The area varies from flat to gently sloping, to steep hills deeply cut by washes and canyons.

d. Air

The air quality in the west side of the San Joaquin Valley is variable and depending on the inversion layers and coastal intrusion, ranges from good to poor. 
There are many factors that can contribute to the accumulation of chemicals and particulates in the air:

a. Growing urban centers with increases in automobile and truck traffic;

b. Agricultural chemicals, pesticides, herbicides and agricultural vehicles;

c. Dust from cultivation;

d. Oil fields (local influence);

e. Agricultural burning; and

f. Pollution from population centers in the Sacramento Valley and Bay area driven by prevailing winds.

\section{Living components}

\section{A. Flora of Western San Joaquin Valley}

The southern and west side of the San Joaquin Valley is dominated by Valley Grassland and Valley Saltbush plant communities. Important annual BLH hosts include filaree (Erodium spp.), peppergrass (Lepidium spp.), and Plantain (Plantago sp.).

Valley grasslands were originally dominated by bunch grasses such as Stipa pulchra, Stipa cermua, and Poa scabrella. The grasslands are now dominated by annual species of Bromus, Festuca, Lepidium, Erodium, and various flowers. Valley grasslands grow and set seed during a winter/spring growing season of 711 months and die during the arid summer season. Seed dormancy is broken at the onset of late fall or winter rains.

The San Joaquin Valley is separated from the influences of the ocean by a series of parallel mountain ranges and inter-coastal valleys. Generally, the San Joaquin Valley has winters that are warm and relatively short. The summers are long and hot with low humidity (Twisselman, 1967).

Annual rainfall ranges from 6 inches, in southwestern Kern County, to 10 inches in western Merced County. Large floral displays are observed in years with wet springs. Approximately $90 \%$ of the rains fall between December and April. Dense ground fog persists for days and sometimes for weeks in late November, December and January (Twissleman, 1967).

The Valley Saltbush Scrub plant community occurs in the southern and western San Joaquin Valley in poorly drained alkali soils on gently sloped alluvial plains or moderately steep to rolling terrain. The more prominent plants in the Valley Saltbush Scrub community are saltbush (Atriplex polycarpa), iodine bush 
(Allenrolfea occidentalis), Lepidospartum squamatum and snakeweed (Gutierrezia spp.) along with large disturbed areas covered with Russian thistle, (Salsola spp.).

Although the boundaries are not always distinct, a secession of vegetation zones are generally observed from the Valley floor; west, into the hills. The Valley Grassland plant community will give way to Valley Saltbush Scrub plant community, which in turn gives way to a mixed chaparral in the higher elevations. It is common to find Valley grassland plants such as Lasthenia, Erodium, Bromus, Vulpia and Lepidium species as understory growth in Valley Saltbush Scrub. Within the potential treatment area, annual grasses dominate the northern slopes, while Erodium, Lepidium, and Plantago are found on the sparsely vegetated, south-facing slopes. The tops of some hills and sides of canyons at times support a combination of Atriplex and Gutierrezia.

Small, isolated, areas of riparian habitat are found along major drainage areas and creeks on the west side of the San Joaquin Valley. Primary tree species within riparian habitats include cotton wood (Populus fremontii) and tamarisk (Tamarix ramosissima). In the northern portions of the San Joaquin Valley, Lepidospartum squamatum and Baccharis vininea can be found growing as understory plants within these riparian habitats.

In washes and relatively moist areas, occasional small stands of tree tobacco (Nicotiana glauca) occur. Where buildings or homesteads once stood, plantings of tamarisk are evident, providing shade or windbreaks.

\section{B. Elora of the Inter-Coastal Valleys}

The Inter-Costal Valleys including the Salinas Valley area, are classified generally with the Great Central Valley. They are dominated in the lower elevations by the Valley grasslands which extend into oak woodland chaparral in higher elevations. The Salinas Valley is dominated by the Salinas River and its riparian habitat composed of an occasional cottonwood (Populus fremontii) and Red willow (Salix laevigata), box elder (Acer negundo var. californicum), blue elderberry (Sambucus mexicana) and western red dogwood (Cormus douglasii). In the upper Salinas Valley and other more arid inter-coastal valleys, the grasslands give way to an oak savanna dominated by blue oak (Quercus douglasii). The climate of the inter-costal valleys are influenced by the ocean to a greater degree than the Central Valley. 
Listed. Threatened and Endangered Species Which May Occur within CTVCP Potential Treatment Area:

Several candidates for listing are also highlighted because of special interest. A further list of candidate species and species of special concern can be found in Appendix " $G$ ".

$\begin{array}{llr}\text { FT } & \text { Federal Threatened } & \text { ST CA State Threatened } \\ \text { FE } & \text { Federal Endangered } & \text { SE CA State Endangered } \\ \text { FC } & \text { Federal Candidate } & \text { SC CA State Candidate } \\ \text { FPE } & \text { Federal Proposed Endangered }\end{array}$

\section{PLANTS}

\section{California Jewelflower (Caulanthus californicus) (FE,SE)}

The Califomia jewelflower is a member of the mustard family. The stems rise out of a basal rosette of leaves to a height of one foot and may produce several flowering branches. This species historically occurs in slightly alkaline sandy loam in native grasslands of the southern San Joaquin Valley. The bloom period is February through May.

Kern Mallow (Eremalche kernensis) (FE,SC)

The Kern mallow occurs in western Kern County and blooms during April and May. It is endemic to Valley Sink Scrub, Valley Saltbush Scrub and adjacent grassland. This species is a small annual herb of the mallow family and ranges from McKittrick to near Buttonwillow.

\section{San Joaquin Woolly-threads (Lembertia congdonii) (FE,SC)}

San Joaquin woolly-threads occurs within many operational areas of the CTVCP. It's name is taken from the white, multi branched stems that grow to a length of 8-10 inches. The annual herb is a member of the sunflower family and blooms from March through May. San Joaquin woolly-threads are endemic to the southern San Joaquin Valley within the Valley Saltbush Scrub or Valley Grassland plant communities.

\section{Bakersfield Cactus (Opuntia basilaris var. treleasei) (FE,SE)}

The Bakersfield cactus is a prickly pear type of cactus. It occurs on coarse well-drained granite sand on the grasslands of Kern County and blooms from April through May. It is currently known from five general areas in the southeastern San Joaquin Valley. 
The Hoover's woolly-star is a short ( 3 inches) greyish annual herb of the phlox family. It is found within the Valley Saltbush Scrub and Valley Sink Scrub plant communities from Fresno County, south through the southern San Joaquin Valley and into the Cuyama Valley. The bloom period of Hoover's woolly-star extends from March through July.

\section{Bakersfield-saltbush (Atriplex tularensis) (SE,FC)}

The Bakersfield-saltbush is a member of the family Chenopodiaceae and is an erect annual with a scaly surface on the stems. This salt-tolerant species has only been reported from Kern County as part of the Kern Lake Preserve. Population size of this annual species fluctuates with local rainfall patterns and blooms from June through October.

\section{Palmate Bracted Birds Beak (Cordylanthus palmatus) (FE,SE)}

This plant has soft hairy gray-green leaves with five lobes. It grows from 10 to $30 \mathrm{~cm}$ tall and is a parasite of salt grass. Floral spikes, 50 to $150 \mathrm{~mm}$ tall, hold whitish to pale lavender flowers which appear May through October. This plant can be found inhabiting alkaline flats in Colusa, Alameda, San Joaquin, Madera and Fresno Counties.

\section{Large-Flowering Fiddleneck (Amsinckia grandiflora) (FE,SE)}

The large-flowing fiddleneck is an annual herb, green in color, hairy with linear to narrowly ovate leafs. Red-orange flowers, $10-15 \mathrm{~mm}$ wide, bloom from April through May. The plant inhabits grassy slopes and is known from just three native populations near Corral Hollow in San Joaquin County. Some apparently successful reintroductions have been attempted.

\section{Monterey Spineflower (Chorizanthe pungens var. pungens) (FT) and Robust} Spineflower (Chorizanthe robusta var. robusta) (FE)

The Monterey and robust spineflowers are members of the buckwheat family (Polygonaceae). The plants grow to $50 \mathrm{~cm}$ in height with greyish soft hair. The flowers are 2-4 mm and contain 9 stamens. Both species are found growing in the Coastal Sage Scrub plant community. Occurrences of these plants, near the potential treatment area in the Salinas Valley, are represented by a few old records and may be extrapolated from those locations. 


\section{ANIMALS}

San Joaquin Kit Fox (Vulpes macrotis mutica) (FE,ST)

This kit fox is the smallest canine species ranging throughout the San Joaquin Valley from San Joaquin County south through southern Kern County. Portions of Monterey, Santa Clara, San Benito and Santa Barbara Counties are included in the kit fox range. They eat a varied diet of small rodents, lizards and insects. One kit fox per square mile has been estimated as the average density throughout the San Joaquin kit fox range.

\section{Giant Kangaroo Rat (Dipodomys ingens) (FE,SE)}

The Giant kangaroo rats (GKR) are small mammals with elongated hind limbs for hopping and external cheek pouches for carrying food. The GKR is the largest of all kangaroo rats and feed almost entirely on the seeds of annual plants. Colonies are found in western Kern County and on the Elkhorn and Carrizo Plains in eastern San Luis Obispo and western Fresno and Kings Counties. They prefer sparsely vegetated Valley Grassland plant communities with sandy loam soils.

\section{Tipton Kangaroo Rat (Dipodomys nitratoides nitratoides) (FE,SE)}

The Tipton kangaroo rat (TKR) is a small mammal with specialized hind limbs and external cheek pouches. The TKR feeds almost entirely on seeds. They live in arid, open land where they dig burrows for shelter and food storage. The range has been reduced to approximately 6,400 acres among five separate parcels and supports low to moderate population levels.

San Joaquin Antelope Squirrel (Ammospermophilus nelsoni) (ST,FC)

The San Joaquin antelope squirrel is about 10 inches long with a white stripe on each side of the body. It has an omnivorous diet consisting of grass, seeds and insects. They are generally active at temperatures between $68^{\circ}$ to $86^{\circ} \mathrm{F}$. Significant populations exist in the Elk Hills and portions of the Carrizo and Elkhorn Plains in western Kern and eastern San Luis Obispo Counties; also, in the Kettleman, Quijarral and Panoche Hills in western Fresno and Kings Counties.

\section{Blunt-nosed Leopard Lizard (Gambelia silus) (FE,SE)}

The blunt-nosed leopard lizard is a large lizard with dark blotches on the back and tail. Breeding females have orange or reddish spots on their sides. It inhabits sparsely vegetative plains, alkali flats, foothills and canyon floors from San Joaquin County south through Kern County and into eastern San Luis Obispo County. Their diet consists of a wide variety of insects and small lizards. 
The western yellow-billed cuckoo is a slender brown bird with white underparts. Its natural nesting habitat is in deciduous riparian forest in primarily cottonwoods and willow trees. Food consists of grasshoppers, katydids, tree frogs and caterpillars. Breeding pairs are found along the Sacramento River in Butte, Glenn, Colusa Counties, the south fork of the Kern River, and along the Santa Ana, Amargosa and lower Colorado Rivers.

\section{Swainson's Hawk (Buteo swainsoni)}

The Swainson's hawk is a medium-sized hawk with long pointed wings and a long square tail. The Swainson's hawk often nests in riparian systems of the Central Valley adjacent to open grasslands and annual agricultural row crops. The California vole is an important staple in their varied diet.

\section{Peregrine Falcon (Falco peregrinus anatum) (FE,SE)}

The peregrine falcon is about the size of a crow with slate gray color above and lighter color below. The range includes most of California during migrations and in winter, except in deserts. Nesting sites are typically on ledges of cliff faces. The peregrine falcon eats a variety of birds.

\section{Bald Eagle (Haliaeetus leucocephalus) (FT,SE)}

The bald eagle is a large brown bird of prey with a white head and tail. It occurs widely in North America and winters at lakes, reservoirs, river systems and some rangelands and coastal wetlands. The bald eagle eats rabbits and large rodents, but chiefly consumes dead or dying fish.

\section{California Condor (Gymnogyps californianus) (FE,SE)}

Formerly widespread in North America from Baja California to British Columbia, the California condor declined in number during the 1970's and 1980's. In 1987 the remaining birds were trapped and placed in a captive breeding program. The number of birds were increased in captivity until the reintroduction of two birds in January 1992. Subsequent releases were made in December 1992 and December 1993. Five condors currently occupy a range adjacent to the Sierra Madre Ridge, south of the Cuyama Valley.

\section{Aleutian Canada Goose (Branta canadensis leucopaveia) (FT)}

The Aleutian Canada goose is one of the smaller races of $B$. canadensis. External markings are consistent with the greater Canada goose, but the neck and bill are relatively shorter and 
check patches are slightly smaller. Breeding occurs in the western Aleutian Islands. The goose winters in the Central Valley of California and arrives as far south as Merced County in December.

\section{Giant Garter Snake (Thamnophis gigas) (FT,ST)}

The giant garter snake (GGS) inhabits marshes and swamps and basks near water in the spring and fall. Adult GGS can reach 64 inches in length. The color of the GGS is dull brown with black spots on the dorsal side, separated by a yellow dorsal stripe and two lateral stripes. Thirteen population clusters have been identified in the Central Valley and coincide with historical flood basins in the Central Valley. The GGS occupies waterways and agricultural wetlands and water delivery systems. Surveys in the San Joaquin Valley during 1986 and 1992 failed to discover any GGS although a few remnant populations may still occur in the northern San Joaquin Valley.

\section{California Red-legged Frog (Rana aurora draytonii) (FT)}

The Califomia red-legged frog (CRF) occurs in lakes, reservoirs, ponds, marshes, streams and other mostly permanent water sources. CRF are attracted to cattails or other plant cover in or near water. May disperse after rains and may appear on roads at night. When not breeding, may be found in damp woods.

San Joaquin Dune Beetle (Coelus gracilis) (FC), Ciervo Aegialian Scarab Beetle (Aegialia concinna) (FC)

The San Joaquin dune beetle (SJDB) and the Ciervo Aegoalian scarab beetle (CASB) appear to be endemic to dune systems along the west side of the San Joaquin Valley. The SJDB restricted to five locations along the western edge of the San Joaquin Valley. The CASB is found north of Coaling in the Ciervo dunes. The dunes are generally not isolated from other San Joaquin Valley coastal dunes by great distances and display uniform vegetation over brood areas. Larvae are thought to feed on the roots of dune vegetation.

\section{Conservancy Fairy Shrimp (Branchinecta conservatio) (FE)}

The Conservancy fairy shrimp inhabits vernal pools with highly clouded water and is known from six separate populations within the Counties of Tehama, Solano (Sacramento Natural Wildlife Refuge), Glenn, Merced and Ventura. The Conservancy fairy shrimp are found in rather large pools and have been observed from November to early April.

\section{Longhorn Fairy Shrimp (Branchinecta longinatenna) (FE)}

The longhorn fairy shrimp is found inhabiting vernal pool depressions in grasslands and sandstone and is known from four separate populations within the counties of Contra Costa 
(Altamont Pass), San Luis Obispo (Soda Lake), Merced (Kesterson National Wildlife Refuge). The longhorn fairy shrimp have been observed from late December until late April.

\section{Vernal Pool Tadpole Shrimp (Lepidurus packardi) (FE)}

The vernal pool tadpole shrimp is known from 18 populations ranging from Shasta County, south to Merced County (San Luis National Wildlife Refuge); and a single population in Alameda County (San Francisco Bay National Wildlife Refuge). Winter rains break diapausing eggs in dry pool sediments. Vernal pool tadpole shrimp have been reported to mature within three weeks. Adults are present until the pools dry up in the spring.

\section{Vernal Pool Fairy Shrimp (Branchinecta lynchi) (FT)}

The vernal pool fairy shrimp is known from 32 populations distributed sporadically from Shasta County in the north through most of the length of the Central Valley to Pixley in Tulare County; along the central coast range from northern Solano County, south to San Benito County. Additional populations have been found in San Luis Obispo County (Soda Lake), northern Santa Barbara County, and on the Santa Rosa Plateau and near Rancho California in Riverside County. They feed on algae, and other aquatic microorganisms as adults. The eggs lay dormant in the soil until rainwater replenishes the vernal pool.

\section{Valley Elderberry Longhorn Beetle (Desmocerus californicus dimorphus) (FT)}

The elderberry longhom beetle is found in elderberry plants associated with valley oak woodlands along the borders of streams and their tributaries including the Sacramento, Cosumnes, Mokelumne and northern San Joaquin Rivers.

\section{Western Snowy Plover (Charadrius alexandrimus) (FT,SSC)}

The western snowy plover is a small inhabitant of sandy seashores, alkali flats and sand flats. they consume shellfish, marine invertebrates and worms. The western snowy plover is a migratory bird which breeds along the Pacific Coast from Washington, south to Baja California and inland along riverbanks, sand dunes and alkali flats.

\section{Miscellaneous Components}

\section{a. Natural Resources}

Numerous oil fields are found within the CTVCP potential treatment areas from Maricopa north to Coalinga on the west side of the San Joaquin Valley. Many oil and gas leases have been issued on public lands within these areas. The oil fields 
have been active for many years and represent some of the first settlements in the southern San Joaquin Valley:

b. Naval Petroleum Reserve in the Elk Hills

The CTVCP operates under cooperative agreement with the DOE for the control of the BLH in NPR \#1 \& \#2. Agreements between DOE and CDFA ensures compliance with environmental protection, notification and requirements for human health and safety as well as protection of endangered species.

c. Cultural Components

There are many historical and archeological sites throughout the west side of the San Joaquin Valley. They include prehistoric sites from American Indians and more recent artifacts from the early oil exploration and settlements (1911-1912).

d. Wildẹrness

Wilderness study areas (WSA) \#301a, \#301b (Panoche Hills) and \#309 (San Benito Mt.) lie within or near CTVCP potential treatment areas on the west side of the San Joaquin Valley.

e. Ground-rig ONLY areas, Cuyama Valley and a portion of the San Joaquin Valley.

If treatments are necessary in designated "ground-rig only" areas in the Cuyama or a portion of the San Joaquin Valleys, only ground-rigs will be used to control BLH populations along roadsides, ditch banks and small cultivated fallow fields adjacent to CTV susceptible crops within intensive agriculture. (See Appendix "E", pages E-3 and E-10, for "ground-rig only" Control Regions within the Cuyama and San Joaquin Valleys.)

\section{f. Critical Habitat}

Habitat determined to be essential to the conservation of threatened or endangered plants or animals, has been established by USFWS for several California species. Appendix " $L$ " contains a checklist of species for which critical habitat has been designated. Species residing in or frequenting the San Joaquin and inter-coastal valleys near CTVCP control boundaries include the American peregrine falcon, California condor, Fresno kangaroo rat, large-flowered fiddleneck, southwestern willow flycatcher and valley elderberry longhorn beetle. 


\section{B. IMPERIAL VALLEY AND EASTERN RIVERSIDE COUNTIES}

\section{Physical Components}

a. Soils

The soils of the desert are typical of low desert, being high in sedimentary mineral deposits, clays and sand. Most desert cobble covered by fine drift sand from a few inches to several hundred feet in depth.

b. Topography

The general topography is undulating with small rises cut by water eroded gullies varying in depth from a few inches to many feet.

Wind storms and flash floods move large amounts of desert soils where they are not held by scrub brush.

The desert area is high in minerals. It is subject to mining or quarrying operations, and the vast open area attracts large numbers of off-road vehicle enthusiasts, contributing to erosion where they concentrate.

c. Water

Water on the desert is scarce. The irrigated portions of the county are crisscrossed by canal systems and the desert is crossed by larger man-made canals such as the All-American and Coachella Canals.

The Salton Sea is the major body of water fed by runoff from streams and irrigation. Since there is no outlet for the Salton Sea, the water is highly saline, but harbors an abundance of fish and aquatic invertebrates, plus it is frequented by vast numbers of migratory waterfowl.

The Colorado River is the largest source of fresh water in the region and is the main source for the All-American and the Coachella Canals.

Annual precipitation averages approximately two inches. Rainfall is extremely varied within localized areas due to periodic thundershowers. 


\section{d. Temperatures}

Daytime temperatures during the summer often exceed $100^{\circ} \mathrm{F}$. and may climb to $120^{\circ} \mathrm{F}$. During the winter, daytime maximum temperatures range from 60 to $80^{\circ} \mathrm{F}$.

e. Air

The air quality in the Imperial Valley and eastern Riverside Counties varies with weather, temperature and inversions. Winds frequently move through the Imperial Valley creating dust storms which constantly shift loose top soil. Man-caused pollutants from the Riverside-San Bernardino Basin frequently move into the Imperial Valley through Beaumont Pass when cooler coastal air responds to inland temperature gradients. When Santa Ana wind conditions exist, pollutants can move out of the Imperial Valley towards the coast.

\section{Living Components}

The major plant community inhabiting well drained soils of low alkalinity is the Creosote Bush Scrub. The co-dominant plants are creosote bush (Larrea tridentata) and ragweed (Ambrosia dumosa), interspersed with Coldenia palmeri, Croton californicus, smoke tree (Parosela spinosa), Mexican tea (Ephedra trifurca), and galleta (Hilaria rigida).

In the arroyos or washes that cross the Creosote bush community there is a relatively dense wash woodland community dominated by coyote brush (Baccharis sarathroides), Palo Verde (Cercidium floridum, desert willow (Chilopsis linearis), Condaliopsis lycioidea, smoke tree (Parosela spinosa), water jacket (Lyciumandersonii), desert ironwood (Olneya tesota), and honey mesquite (Prosopis glandulosa).

Where soils grade into sandy loam with a higher salinity range, the saltbush scrub community is evident with saltbush Atriplex polycarpa, Atriplex canescens, Haplopappus acradenius and Prosopis glandulosa as the dominant perennial plants.

Along the edge of the Salton Sea and in areas where there are heavy, wet soils with high salt content, Iodine bush (Allenrolfea occidentalis, Atriplex lentiformus, Baccaris glutinosa, screw-bean mesquite (Prosopis pubesens), cottonwood (Populus fremontii), arrow-weed (Pluchea sericea), willow (Salix gooddingii), and tamerisk (Tamarix spp.) form the Alkali Sink plant community.

Along rocky hillsides or where the soils are gravelly, cactus species are found including; Opuntia, Ferocactys and Echinocereus. Water in both the Coachella and 
All-American Canals have influenced vegetation along their banks. The vegetation along the Coachella Canal was almost eliminated when it was lined with concrete in 1980. The All-American Canal contains the majority of canal influenced vegetation which is dominated by Carrizo cane.

The Colorado River influences vegetation along its shores through the Colorado River Valley region of the Sonoran Desert. The plant community consists of tamarisk, arrow-weed, cottonwood, mesquite, bulrushes, cattails, coyote bush (Bacchaus spp.), willow, sedges and various composites. Throughout the above perennial plant communities, when rainfall is sufficient to germinate seeds, BLH host plants emerge. The more common BLH hosts are: chinch-weed (Pectus papposa), filaree (Erodium spp.), plantain (Plantago spp.), Mignonette (Oligomeris linifolia), mustard (Brassica spp.), peppergrass, spectacle pod, lense pod, sand verbena (Abronia villosa) and dune primrose (Oenothera deltoides). Russian thistle, Bassia and wild mustards are also found along roadsides and in cultivated fallow fields.

Listed, Threatened and Endangered Species which May Occur within CTVCP Potential Treatment Area

Several candidates for listing are also highlighted because of special interest. A further list of candidate species and species of special concern can be found in Appendix " $G$ ".

FT Federal Threatened $\quad$ ST CA State Threatened
FE Federal Endangered $\quad$ SE CA State Endangered
FC Federal Candidate
FPE Federal Proposed Endangered
FPT Federal Proposed Threatened

\section{PLANTS}

Giant Spanish Needle (Palafoxia arida var. gigantea) (FC)

The giant spanish needle is scattered throughout the dunes east of the Coachella Canal. Its total range is within the Imperial Sand Dunes.

Peirson's Milk-vetch (Astragalus magdalenae var. peirsonii) (SE,FPE)

Peirson's milk-vetch is known from the Imperial Dunes and areas west of the Salton Sea. The highest concentrations are in the North Algodones Dunes Wilderness Area. It is a stout herbaceous perennial with leaves divided into oval leaflets. 
Silver-leaved Dune Sunflower (Helianthus niveus tephrodes) (SE,FC)

The silver-leaved dune sunflower is known from the Imperial Dunes and other dune systems in the Southwest. A dense covering of fine hairs which protect the plant from extreme heat and light, gives the leaves a silvery appearance.

Wiggins' Croton (Croton wigginsii) (ST,FC)

Wiggins' croton is common on the west side of the Imperial Sand Dunes and found occasionally on the east side. It is a multi-branched perennial shrub with silvery hairs producing male and female flowers on different plants.

\section{ANIMALS}

Desert Tortoise (Gopherus agassizii) (FT,ST)

In California, the desert tortoise occurs in northeastern Los Angeles, eastern Kern, southeastern Inyo and most of San Bernardino, Riverside and Imperial Counties, as well as parts of Arizona and Utah. The desert tortoise can be found in washes, rocky hillsides and flat desert. Adult tortoises grow to 8 to 14 inches long. Creosote bush, burro bush, salt bush, Joshua tree, and Mojave yucca are often present in areas inhabited by the tortoise. They eat a variety of annual and perennial plants. The desert tortoise are active during spring and retreat into burrows during severe winter and summer weather.

\section{Flat-tailed Horned Lizard (Phrynosoma mcallii) (FPT)}

The present distribution of the flat-tailed horned lizard ranges from the Coachella Valley in Riverside County, south along both sides of the Saiton Sea into Imperial County. The most favorable habitats are areas of low relief with surface soils of packed sand, overlain with loose, fine sand, and associated with Creosote bush and bur-sage. The flat-tailed horned lizard is insectivorous with harvester ants accounting for the majority of its prey.

\section{Western Yellow-billed Cuckoo (Coccyzus americanus occidentalis) (SE)}

The western yellow-billed cuckoo is a slender brown bird with white underparts. Its natural nesting habitat is in deciduous riparian forest in primarily cottonwoods and willow trees. Food consists of grasshoppers, katydids, tree frogs and caterpillars. Breeding pairs are found along the Sacramento River in Butte, Glenn, Colusa Counties, the south fork of the Kern River, and along the Santa Ana, Amargosa and lower Colorado Rivers. 


\section{Yuma Clapper Rail (Rallus longirostris) (FE,ST)}

The Yuma clapper rail (YCR) is a resident of the shallow, freshwater marshes along the lower Colorado River and the Salton Sea and prefers dense growths of cattail, bulrush and reeds to forage and nest. The YCR eats mostly crayfish; also small fish, isopods, insects, clams and seeds. The YCR is gray-brown and grows to the size of a chicken.

\section{Least Bell's Vireo (Vireo bellii pusillus) (FE,SE)}

The least Bell's vireo is a small migratory songbird with a drab-gray color on top and whitish below with sides of grayish olive-yellow. The vireo is insectivorous and is a summer resident of the cottonwood-willow thickets and dry washes. Its breeding range is restricted to primarily Santa Barbara, Riverside and San Diego Counties and into northwestern Baja California.

\section{Arizona Bell's Vireo (Vireo bellii arizonae) (SE)}

The Arizona Bell's vireo is very similar in habitats and appearance as the least Bell's vireo. The Arizona Bell's vireo is only found at a few sites on the California side of the Colorado River near Needles and Laguna Dam.

\section{California Black Rail (Laterallus jamaicensis coturniculus)}

The California black rail is about the size of a sparrow. It is blackish in color with nape of deep chestnut. They eat a variety of insects, frogs, crustaceans and mollusks. It is known to inhabit saltwater, brackish and fresh water marshes in California, particularly the Salton Sea and lower Colorado River, north of Yuma.

\section{Elf Owl (Micranthene whitneyi) (SE)}

The elf owl is the smallest owl in North America. The plumage is spotted with buff and white on a gray or brown base. The species is migratory and spends the breeding season in California. The diet of the elf owl consists almost entirely of large insects, centipedes and scorpions. Small birds and amphibians are occasionally taken. The elf owl is limited to the cottonwood, willow and mesquite riparian zone along the lower Colorado River and Corn Springs in Riverside County.

\section{Gilded Northern Flicker (Colaptes auratus chrysoides) (SE)}

The Gilded northern flicker has a brown-barred back, white rump, yellow wing and tailings and a brown crown. This woodpecker nests in mature cottonwood, willow trees along the lower Colorado River and eats ants, other insects, wild fruits and berries. The bird is found only at several sites on the California side of the Colorado River north of Blythe. 


\section{Gila Woodpecker (Melanerpes uropygialis) (SE)}

This is a large woodpecker with a grayish-brown head, neck and underparts. Its back is narrowly barred with black and white. Food items include insects, mistletoe berries, cactus pulp, bird eggs, and fruit. The Gila woodpecker is a primary cavity nester of the mature cottonwood, willow riparian forest. The woodpecker is now only found in scattered locations along the California side of the river between Needles and Yuma.

\section{Southwestern Willow Flycatcher (Empidomax traillii extimus) (ST,FE)}

The southwestern willow flycatcher is an insectivorous transient bird and is found from the middle of May through the middle of June in the deserts of southern California. They are found along rivers and streams in dense growing riparian habitat, canyon woodlands, desert washes and desert oases. Southwestern willow flycatchers breed in late spring and are generally gone form breeding grounds in southern California by September. Habitat destruction and the parasitism by brown-headed cowbirds have been proposed as causes of population decline.

\section{Desert Pupfish (Cyprinodon macularius) (FE,SE)}

The desert pupfish is a small pupfish with a tan to olive coloration with lateral vertical bars. This species occurs in the San Felipe Creek, Salt Creek, Carrizo Wash, Fish Wash, the mouths of agricultural drains and shoreline pools along the edge of the Salton Sea. The desert pupfish forage on invertebrates, algae and detritus. Exotic fish and habitat destruction have contributed to the decline of the species.

\section{Bonytail Chub (Gila elegans) (FE,SE)}

The bonytail is a large chub, 12-14 inches long with a gray or olive back and white sides and belly. There is usually a conspicuous hump behind the head. The bonytail are bottom feeders and are presently very rare. The bonytail historically occurred in the mainstream of the Colorado River and lower-gradient portions of its major tributaries.

\section{Humpback (Razorback) Sucker (Xyrauchen texamus) (SE,FE)}

The humpback sucker has a sharp hump or keel on the back which elevates the dorsal region of the body above the head. Its back is a brown to olive and its belly is yellowish. The fish was known from the mainstream of the Colorado River and major tributaries. Recent records of occurrence on the lower basin are sporadic and isolated. 
Colorado Squawfish (Ptychocheilus lucius) (FE,SE)

The Colorado squawfish is the top carnivore of the Colorado river system. The fish is a dusky green on top and yellowish to white below, with silver sides. The head is long, slender and depressed. The eyes are small and the mouth is large and toothless.

The Colorado squawfish has not been seen below the Glen Canyon Dam since 1968. Habitat alteration is cited as a direct cause of extirpation in the lower Colorado River basin (CDFG, 1992).

\section{Andrew's Dune Scarab Beetle (Pseudocotalpa andrewsi) (FC)}

This scarab species appears to be endemic to the Algdodones Dunes in Imperial County and possibly portions of the same dune system in Baja California Norte, Mexico. Activity may start as early as February but typically, ADSB activity ranges from mid-April through the first week of May. ADSB emerge from the sand in late afternoon, but before dark, with a brief activity period. Flights of beetles numbering 3-20 have been observed in "clouds" around Creosote and occasionally Palo Verde and Eriogonum spp. during this short dusk activity period. From first emergence until last disappearance ranges from 10-30 minutes. After the flight individuals can be seen burying themselves rapidly in the sand within 1-2 minutes of landing on the surface (Hardy and Andrews, 1979).

\section{Miscellaneous Components}

a. Imperial Sand Dunes

The Imperial Sand Dunes are one of the largest dune systems in North America forming a band 40 miles long and five miles wide. The dune system extends across the border into Mexico and runs northwest to southeast. The dune system is home for many specialized plants and animals.

b. Cultural Components

There are many archeological and historical sites throughout the Imperial Valley and eastern Riverside County. There are three historical cemeteries (from 1880-1930) at the railroad townsites of Amos, Glamis and Ogilby. Remnants of the Plank Road, utilized by vehicles between 1914 and 1926, can be seen fenced at Greys Well. Remnants of native American pottery and signs of ancient trails are evident around the edge of the Ancient Lake beach line. 
c. Wilderness

The North Algodones Dunes Wilderness Area is located on the Algodones sand dune system and covers approximately 32,240 acres including both state and private lands. The primary and secondary dunes supports a variety of desert plant and animal species. The Imperial Sand Hills National Natural Landmark and the Algodones Outstanding Natural Area are specially areas found within this wilderness.

d. Ground-rig ONLY area, Blythe (Eastern Riverside County)

If treatments are necessary in the Blythe region, only ground-rigs will be used to control BLH populations on roadsides, ditch banks and in small cultivated fallow fields adjacent to CTV susceptible crops within intensive agriculture. (Appendix "E", page 13, illustrates the potential treatment area near Blythe.)

e. Critical Habitat

Habitat determined to be essential to the conservation of threatened or endangered plants or animals, has been established by USFWS for several California species. Appendix " $L$ " contains a checklist of species for which critical habitat has been designated. Species residing in or frequenting the Imperial Valley near CTVCP control boundaries include the bonytail chub, Coachella Valley fringed-toed lizard, Colorado squawfish, desert pupfish, desert tortoise, least Bell's vireo, razorback sucker and southwestern willow flycatcher.

\section{Western Riverside County (Hemet)}

In the Hemet area, CTVCP will use ground-rigs only to control BLH populations on roadsides and in cultivated fallow fields. No rangeland will be treated. The area indicated in Appendix "E", page 12, designates the potential growing region for CTV host crops. In recent years there has been a steady decline in agricultural production and an increase in urban development. When treatments are necessary, only roadsides, ditch banks and small cultivated fallow fields adjacent to cultivation are treated. (For additional information see Appendix "E", page 20, "Treatment Probability Chart" and Appendix "E", page 22, "Frequency of Ground-rig Only Treatments".)

\section{Living Components}

The vegetation in the San Jacinto Valley is closely related to the Coastal Sage Scrub mixed with some Valley grasslands. California mugwort (Atremisia californica), mint (Salvia apiana), flat-top (Eriogonu fasciculatum), Lemonaide-berry (Rhus 
integrifolia), Encelia californica, Horkelia cuneata are typical of the plants that may be found in the area.

\section{Species of Special Significance in or Near the Greater Hemet Region}

Several candidates for listing are also highlighted because of special interest. A further list of candidate species and species of special concern can be found in Appendix " $G$ ".
FT Federal Threatened
ST CA State Threatened
FE Federal Endangered
SE CA State Endangered
FC Federal Candidate
FPT Federal Proposed Threatened
FPE Federal Proposed Endangered

\section{PLANTS}

\section{Slender-horned Spine Flower (Dodecahema leptoceras) (FE)}

The slender-horned spine flower is a small, low growing member of the Polygonaceae family. The bloom period for this annual plant varies between April through June and is dependent on rain intervals. The slender-horned spineflower is associated with sandy places within the Coastal Sage Scrub plant community.

\section{California Orcutt Grass (Orcuttia californica) (SE,FE)}

California orcutt grass is a member of the grass family (Poaceae). It is bright green, sticky and an aromatic annual plant. It was once found in the volcanic terrace and valley vernal pool systems of Los Angeles, Riverside and San Diego Counties. Most occurrences today are found associated with vernal pools habitat on Otay Mesa, Nature Conservancy's Santa Rosa Plateau Preserve, and various locations in Riverside County on private property.

\section{Munz's Onion (Allium munzii) (ST,FC)}

Munz's onion is a small, bulb-bearing, white flowered perennial herb in the family Liliaceae. Munz's onion is restricted to clay soils and shares its range and habitat with a similar onion species (Allium haematochiton) in open coastal sage scrub and grasslands. Munz's onion has diminished rapidly from the grasslands of western Riverside County and is currently known from 12 populations. 
The San Jacinto saltbush is an annual herb with an erect stiff branches ascending from the base. The stems are grey to straw in color with grey scaly elliptic leaf blades eight to twenty millimeters $(8-20 \mathrm{~mm})$ long. The San Jacinto saltbush is associated with highly alkaline, silty-clay soils. Only 10 populations are known to exist in the San Jacinto Valley of Riverside County.

Spreading Navarreta (Navarretia fossalis) (FPT)

This spreading annual herb inhabits assorted shallow freshwater vernal pools, marshes and swamps within the Chenopodium (saltbush) scrub lands in Riverside and San Diego Counties. It may also be seen in ditches or artificial depressions associated with degraded vernal pool habitat. The stems grow to $15 \mathrm{~cm}$ long with white to lavender white flowering corollas appearing from April to June.

Thread-Leaved Brodiaea (Brobiaea filiforia) (FPT,SE)

The thread-leaved brodiaea is a perennial bulbiferous herb from the family Liliaceae and inhabits clay soils near vernal pools complexes in the Costal Scrub and the Aalkali Grassland plant communities of San Diego, Orange and Riverside Counties. Violet to red flowers bloom from March to June. This species is thought to be extirpated from Los Angeles and San Bernardino Counties and is currently only known from 27 populations, the majority of which are located in Riverside and northwestern San Diego Counties.

\section{ANIMALS}

Stephens' Kangaroo Rat (Dipodomys stephensi) (FE,ST)

The Stephens' kangaroo rat (SKR) has long hind legs, short front legs and feet with a white belly. It is nocturnal and forages for seeds and probably fruits, leaves, stems, buds and insects. The SKR constructs burrows in areas with sandy soils and will use existing gopher or ground squirrel burrows in areas with compacted soils. The present range of the SKR includes the Anza, Perris and San Jacinto Valleys and are associated with specific soil types and patchy herbaceous plant communities.

\section{Orange-throated Whiptail (Cnemidophorus hyperythrus beldingi) (FC)}

The orange-throated whiptail (OTW) is a striped unspotted whiptail with an orange throat. It inhabits washes and other sandy areas where there are rocks and patches of brush. OTW feed on insects, mainly termites, and other arthropods, some of which they dig out of the ground and evidently detect by odor. 
The San Diego horned lizard is yellowish, brown, reddish or gray and usually resembles the prevailing soil color. They are most common in the lowlands along sandy washes with low vegetation. They eat a large volume of ants and occasionally other insects.

\section{Black-tailed Gnatcatcher (Polioptila melanura) (FC)}

The Black-tailed gnatcatcher is similar to the Blue-gray gnatcatcher, but the male has a black cap and much less white on the tail. It is a resident of southwestern U. S. and northern Mexico. It frequents desert brush in ravine and dry washes and is generally insectivorous.

\section{Least Bell's Vireo (Vireo bellii pusillus) (FE,SE)}

The least Bell's vireo is a small migratory songbird with a drab-gray color on top and whitish below with sides of grayish olive-yellow. The vireo is insectivorous and is a summer resident of the cottonwood-willow thickets and dry washes. Its breeding range is restricted to primarily Santa Barbara, Riverside and San Diego Counties and into northwestern Baja California.

\section{Swạinson's Hawk (Buteo swainsoni) (ST)}

Swainson's hawk is a medium-sized hawk with long pointed wings and a long square tail. Swainson's hawks often nest in riparian systems of the Central Valley adjacent to open grasslands. The California vole is an important staple in their varied diet.

\section{Peregrine Falcon (Falco peregrimus anatum) (FE,SE)}

The peregrine falcon is about the size of a crow with slate gray color above and lighter color below. The range includes most of California during migrations and in winter, except in deserts. Nesting sites are typically on ledges of cliff faces. Peregrine falcons eat a variety of birds and rodents.

\section{Bald Eagle (Haliaeetus leucocephalus) (FT,SE)}

The bald eagle is a large brown bird of prey with a white head and tail. It occurs widely in North America and winters at lakes, reservoirs, river systems and some rangelands and coastal wetlands. The bald eagle eats rabbits and large rodents, but chiefly consumes dead or dying fish. 
The coastal California gnat catcher is approximately $11 \mathrm{~cm}$ long. The top of the bird is a dark blue-gray while the bottom is dull gray. The dark cap in the males is somewhat lighter than the caps of male black tailed gnat catchers and black caped gnat catchers. The tail is long and black with almost no white on the underside. The bird inhabits coastal sage scrub from Los Angeles County, south through Riverside and San Diego Counties. The coastal gnat catcher is threate: : d by habitat destruction due to urbanization.

\section{Western Yellow-billed Cuckoo (Coccyzus americanus occidentalis) (SE)}

The western yellow-billed cuckoo is a slender brown bird with white underparts. Its natural nesting habitat is in deciduous riparian forest in primarily cottonwoods and willow trees. Food consists of grasshoppers, katydids, tree frogs and caterpillars. Breeding pairs are found along the Sacramento River in Butte, Glenn, Colusa Counties, the south fork of the Kern River, and along the Santa Ana, Amargosa and lower Colorado Rivers.

\section{Quino Checkerspot Butterfly (Euphydrya editha quino) (FPE)}

The quino checkerspot butterfly can be distinguished from the 11 other recognized subspecies of $E$. deitha by its wing coloration pattern and overall body size. The quino checkerspot tends to be larger with redder wings. Light spots on the wings tend to be fewer and more distinct. The butterfly is restricted to sunny openings on clay soils within scrubland habitats. Only six small populations are known to exist in Riverside and San Diego Counties. Adult butterflies live 4-8 weeks and fly from mid January through late April.

\section{Riverside Fairy Shrimp (Streptocephalos wootoni) (FE)}

The Riverside fairy shrimp is the most restricted of the Californian Anostracans and is only known from five vernal pools in western Riverside County. Mature males measure 14-23 $\mathrm{mm}$ in length, females measure $14-21 \mathrm{~mm}$ in length. This species is threatened by urban development and local agriculture.

\section{Vernal Pool Fairy Shrimp (Branchinecta lynchi) (FT)}

The vernal pool fairy shrimp is known from 32 populations distributed sporadically from Shasta County in the north through most of the length of the Central Valley to Pixley in Tulare County; along the central coast range from northern Solano County, south to San Benito County. Additional populations have been found in San Luis Obispo County (Soda Lake), northern Santa Barbara County, and on the Santa Rosa Plateau and near Rancho California in Riverside County. They feed on algae, and other aquatic microorganisms as adults. The eggs lay dormant in the soil until rainwater replenishes the vernal pool. 


\title{
2. Critical Habitat
}

Habitat determined to be essential to the conservation of threatened or endangered plants or animals, has been established by USFWS for several California species. Appendix " $L$ " contains a checklist species for which critical habitat has been designated. Species residing in or frequenting the San Jocund Valley (Hemet) near CTVCP "ground-rig only" boundaries include the American peregrine falcon, least Bell's vireo and southwestern willow flycatcher.

\section{Southern Kern and Northeastern Los Angeles Counties (Palmdale -Lancaster)}

The Palmdale-Lancaster potential treatment area is one of five "ground-rig only" treatment areas. The region outlined in Appendix " $E$ ", page 9, designates the potential growing region for CTV susceptible crops. Although the potential for CTV susceptible crops has been widespread in the past, recent years have shown a tendency toward decreasing agricultural production and an acceleration in urban development. If treatments are necessary, only roadsides, ditch banks and small cultivated fallow fields, adjacent to CTV susceptible crops in intensive agriculture, are potential treatment sites. Rangeland is not treated. (For additional information, see Appendix "E", page 20, "Treatment Probability Chart" and Appendix "E", page 22, "Frequency of Ground-rig Only Treatments".)

\section{Living Components}

\section{Species of Special Significance in the Greater Palmdale-Lancaster Region}

\author{
FE Federal Endangered $\quad$ FC Federal Candidate
}

ST CA State Threatened

\section{Desert Tortoise (Gopherus agassizi) (FE,ST)}

In California the desert tortoise occurs in northeastern Los Angeles, eastern Kern, southeastern Inyo and most of San Bernardino, Riverside and Imperial Counties, as well as parts of Arizona and Utah. The desert tortoise can be found in washes, rocky hillsides and flat desert. Adult tortoises grow to 8 to 14 inches long. Creosote bush, burro bush, salt bush, Joshua tree, Mojave yucca are often present in areas inhabited by the tortoise. They eat a variety of annual and perennial plants. The desert tortoise are active during spring and retreat into burrows during severe winter and summer weather. 
The Mojave ground squirrel is cinnamon-gray in color with white undersides. The squirrel lives in underground burrows and eats fruits and seeds of desert plants. The Mojave ground squirrel occurs in southwestern Inyo County, eastern Kern County, northwestern San Bernardino County, and northeastern Los Angeles County. This squirrel inhabits the Creosote Bush-Joshua Tree-Shad-Scale plant community.

\section{Critical Habitat}

Habitat determined to be essential to the conservation of threatened or endangered plants or animals, has been established by USFWS for several California species. Appendix "L" contains a checklist of species for which critical habitat has been designated. The desert tortoise resides in or near CTVCP Antelope Valley "ground-rig only" boundaries. 


\section{ENVIRONMENTAL CONSEQUENCES}

\section{A. Assumptions for Impact Analysis}

Malathion will be applied at the rate of .58 pounds of active ingredient (a.i.) per acre. This compares to recommended dosages ranging from $.292-1.166$ pounds a.i./acre for insect pests on various agricultural crops.

1. Malathion has a relatively short half-life and degrades quickly in ultraviolet light (EPA, 1975). Malathion is effective in controlling BLH for only 1-4 days after application. Malathion has particular chemical properties which reduces leaching and presents small risks to ground water. Malathion is broken down relatively fast by hydrolysis and by the action of soil microorganisms (Matsumura and Boush, 1966). Malathion is not generally phytotoxic and is registered for use on a variety of vegetation, crops and livestock.

2. Conclusions drawn in this EA are based in part on toxicological evaluation of laboratory and domestic animals and on professional judgment of BLM, USFWS, CDFG and CDFA personnel. This is necessary because few studies have been performed to determine the effects of malathion on wildlife species. However, there have been many studies performed on the effects of malathion on laboratory and domestic animals. (See Appendix "J" for the Summary of Toxicology Data for Malathion Evaluated by the Medical Toxicology Branch, Cal EPA.) Correlations have been drawn from those laboratory studies on possible affects to wildlife populations.

3. The control of the BLH with malathion in rangeland and cultivated fallow fields has been performed for over 25 years (only the last 10 years in Riverside County). No major impacts to vegetation or wildlife has been observed during CTVCP post-treatment surveys.

4. The CTVCP has cooperated with the following federal, state and local agencies in the control of BLH in California: Department of the Navy, DOE, Department of the Interior, USFWS, BLM, CDFG, Department of Water Resources and the CAC within the counties where BLH control work is performed. No major impacts to vegetation or wildlife has been observed and documented by cooperating governmental agencies from CTVCP activities.

5. Accidental spillage or treatment of malathion on non-target areas is possible due to vehicle or aircraft accidents, equipment malfunction, drift and mis-communication. While the possibility of accidents are recognized, they would be infrequent and isolated. The CTVCP has maintained a good safety use record throughout the life of the Program; therefore, the likelihood of major adverse impacts to the environment 
from accidents would be low. (See Appendix " $\mathrm{I}$ " for "Pesticide Spill Contingency Plan".)

\section{B. Impact Topics}

\section{Impact Topics Dismissed from Detailed Analysis}

\section{a. Wilderness Areas}

Any proposals to apply the control procedures within wilderness study areas or designated wilderness areas will be analyzed and authorized separately, following the terms of the Bureau's Interim Management Policy for Wilderness Study Areas or Wilderness Management Policies for designated Wilderness Areas and not be considered within the scope of this document.

\section{b. Cultural Components}

The prehistoric and historic sites within treatment areas are quite varied. the CTVCP will continue to consult with federal, state or local agencies to identify and avoid sensitive cultural resources throughout the potential treatment areas. The restricted use of vehicles on existing roads during CTVCP treatments will eliminate impacts to unknown cultural resources.

c. Noise

The potential impacts of the CTVCP on noise levels will be the greatest when aircraft are used to apply malathion or to set flaggers. Equipment for ground-rig applications will also increase noise levels. Impacts from noise to the environment are temporary due to the relatively rapid movements of CTVCP treatments performed away from populated areas.

\section{d. Visual Impacts}

The impacts on visual resources of aerial and ground equipment are localized and temporary. CTVCP activities are quite mobile and move through a given area quickly and are performed away from populated areas.

\section{e. Bats}

There are a number of bat species which may occur within potential BLH treatment areas. Direct exposure of malathion to bats and nesting sites from daytime treatment activities is not likely due to the nocturnal foraging habits and 
nesting behavior of bats. Indirect effects of temporarily reducing insects utilized as food by bats is not expected to be significant because:

1. The large foraging range of bats;

2. The movement of prey insects and bats within treated and adjacent nontreated areas.

\section{f. Birds of Prey - Hawks, Eagles, Falcons, California Condor}

The bald eagle, peregrine falcon, Swainson's hawk and California condor are listed as threatened or endangered by the State of California, and/or the Federal Government and may occur within the potential BLH treatment areas. No major impacts to birds of prey and condors are anticipated due to BLH treatment activities due to:

1. The large foraging range within and outside of potential treatment areas;

2. The minimal indirect impacts to food supplies other than insects, including small and medium-sized mammals, birds, reptiles, fish; and

3. Riparian systems or cliff faces used for nesting sites are not treated during CTVCP operations.

\section{g. Fish}

The bonytail chub, humpback sucker and the Colorado squawfish may occur in the Colorado River adjacent to BLH potential treatment areas. No major impacts to fish or fish species of concern is expected due to the avoidance of aquatic situations during treatment operations. (See "Key Points of Proposed Action", pages 22-25.)

Malathion may enter aquatic water systems in runoff if isolated thundershowers occur over treated areas before the complete degradation of malathion has taken place. (Discussion on the effects of malathion in runoff is on page 68.) Small residues of malathion washed into the Colorado River or Salton Sea from runoff would be exposed to absorbing organic particles and be diluted by the large bodies of water. Residues of malathion in runoff resulting from isolated thunderstorms is not expected to have a major impact to fish species of special concern. 


\section{h. Desert Pupfish}

Due to the potential impacts of malathion on the desert pupfish, specific measures have been adopted to avoid impacts (see pages 32-33). Adherence to the procedures, within the proximity of desert pupfish habitat is anticipated to eliminate impacts of CTVCP treatments to desert pupfish populations.

I. San Joaquin Dune Beetle (SJDB); Andrew's Dune Scarab Beetle (ADSB) and Ciervo Aegialian Scarab Beetle (CASB):

Potential impacts to the SJDB, ADSB and CASB would be expected if adult beetles were exposed to malathion during their brief flight periods. On rare occasions, BLH hosts may be in close proximity to dune systems in the Imperial or San Joaquin Valleys.

Due to potential adverse impacts of CTVCP activities, specific measures have been adopted to minimize impacts (page 28 and 33 ). Adherence to measures will reduce potential adverse impacts of CTVCP treatments to dune beetle species.

\section{j. Aleutian Canada Goose}

The migratory patterns of the Aleutian Canada goose place the goose within the periphery of CTVCP control boundaries during a time of year when malathion applications, for the control of BLH, are very rare (USFWS 1994). The "Treatment Probability Chart", Appendix "E", page 20, indicates potential ground-rig activities in or near overwintering grounds to be completed prior to the first of December. Since 1985, ground-rig treatments have not been performed in either San Joaquin or Stanislaus Counties (Appendix "E", 22, "Ground-rig Frequency and Application Totals"). Appendix "E-22" also indicates the frequency of Merced County treatments during October and November to be low. Due to the seasonal application of malathion, low volume of malathion used, the low frequency of use and the restricted application of malathion to roadsides and ditch banks by "ground-rigs only"; no major impacts to Aleutian Canada geese is expected.

\section{k. Palmate-bracted Bird's Beak and Large-flowered Fiddleneck}

The palmate-bracted bird's beak and large-flowered fiddleneck are known from relatively few occurrences outside potential CTVCP control boundaries. Both plants occupy specialized habitats not typically utilized by BLH host plants. Since very little, if any, natural habitat is expected to occur within the "ground-rig only" 
treatment region of the San Joaquin Valley, there will little chance that CTVCP ground-rig treatments would encounter unknown populations of palmate-bracted bird's beak or large-flowered fiddleneck.

1. Western Snowy Plover

Habitats utilized by the western snowy plover include sandy seashores, shorelines along rivers and alkali vernal pools. These habitats are generally not found within CTVCP potential treatment areas, and if present, are avoided as prescribed by the "Proposed Action".

m. Critical Habitat

Critical habitat has not been designated within any of the potential CTVCP control areas (USFWS, Oct., 1994 and USFWS, 1993). No impacts to critical habitat is anticipated by the "Proposed Action" (see Appendix "L").

n. The egg parasitization of insect species other than BLH by parasites being evaluated for biological control of the BLH.

Based on current scientific knowledge, all BLH parasites are specific parasites of BLH eggs only.

\section{Impacts Discussed in Detail}

\section{a. PROPOSED ACTION}

\section{Impacts to Soil}

Soil compaction is expected to be minimal from CTVCP operations and limited to existing roads or established airstrips. Vehicles, turning around on narrow dirt roads, would compact a small amount of soil to the edges of the road.

Small amounts of dust from vehicles and aircraft would be created from CTVCP activities with negligible impact. The amount of dust created by CTVCP activities would vary with the types of soils and vegetation present and be temporary due to the mobility of treatment procedures through a specific area. 
Malathion in Soil. Malathion is broken down relatively fast by hydrolysis and by the action of soil micro-organisms (Matsumura and Boush, 1966). Malathion does not absorb well to inorganic soil particles but binds tightly with organic matter.

Many values for malathion's half-life in soil have been reported:

a. 5 days (Curley and Donohue, 1986);

b. 1 day (EPA, 1986);

c. 7.5 to 11 days in soils with low organic content (Buckman and Brady, 1969).

The range of values depends on soil's alkalinity, organic content, microbial population and chemical degradation.

Malaoxon, a common degradation product of malathion in the soil, has a toxicity level similar to that of malathion. Degradation of malaoxon is primarily by basic hydrolysis and half-lives of 3.9 to 5 days were found for soils of $\mathrm{pH} 7.2$ to $\mathrm{pH} 8.2$ (Pascal and Neville, 1976 as cited in USDA, 1991). This indicates that basic hydrolysis will lead to rapid degradation of malaoxon under conditions found in soils in many CTVCP treatment areas.

There are indications malathion is mobile in loamy sand and loam soils, but based on its rapid degradation and reported octanol-water partition coefficient, malathion is not expected to leach to ground water, especially with high organic soils (NLM, 1988).

Soil Microorganisms: Malathion was slightly toxic to the bacterium Nitrobacter sp. (Bollen, 1961) but caused complete inhibition of the cerium Nitrosomonas sp. (Garretson and San Clemente, 1968). Bacteria and fungi degrade malathion rapidly (Murry and Guthrie, 1980; Paris and Lewis, 1974 and Bourquin, 1977). Malathion application to a forested watershed caused short-term effects on micro-arthropods and no observed effects on bacteria, fungi, earthworms, or snails. Some populations of soil arachnids and insects may be reduced by malathion; populations would not be significantly altered (Giles, 1970). No significant alteration of earthworm population density by aerial spraying of malathion was found in field studies (Giles, 1970).

\section{Impacts on Air Quality}

The potential impacts of CTVCP on air quality include light increases in dust, pollutants from internal combustion engines of vehicles and aircraft. Amounts 
of these pollutants should be negligible to air quality except on a local, temporary basis.

Increases in ozone concentrations from the volatilization of malathion is also expected to be negligible. Malathion has a low vapor pressure and is essentially non-volatile. Airborne particles of malathion are not expected to contribute significantly to the formation of photochemical smog (USDA, 1991).

Malathion has not been identified by the EPA as a hazardous air pollutant to be regulated under Section 112 of the Clean Air Act.

\section{Impacts to Water}

Water quality is related to the geography and geology of the surrounding area. Soil types, vegetative cover, precipitation and topography determine the quality of the ground and surface water in a drainage basin. The relatively quick degradation of malathion by ultraviolet light (EPA, 1975) and hydrolysis, reduces the potential for residues in soil or runoff. Malathion has particular chemical properties which reduces leaching and will then present extremely small risks to people and animals drinking ground water (USDA, 1991). A report from the California Department of Water Resources (1969) stated that no malathion residuals have been found in surface or sub-surface drain effluents. It is expected that extremely small quantities of malathion may leach from cultivated fallow fields and rangeland after major storms if the storms hit before complete degradation has taken place. Natural river water with a large amount of organic matter resulted in a half-life for malathion of 15 to 16 hours under sunlight photolysis (Wolfe et al., 1977 as cited in USDA, 1991). Malathion found dissolved in surface runoff would be available to bind with organic solids suspended in the water and would result in less malathion exposure to organisms living in or ingesting the water.

\section{Impacts to Aquatic Life}

Adverse phytotoxic effects from malathion have not been reported on aquatic plants. Algae metabolize malathion rapidly into non-toxic components (Mulla and Mian, 1981). Fogging or aerosol applications of malathion on salt marsh plants showed no adverse effects (Dobroski and Lambert, 1984).

Impacts to aquatic animals varies according to species, duration of exposure and the quality, temperature and flow rate of water. While malathion shows a moderate level of toxicity to several fish species (EPA 1975), aquatic invertebrates show the most sensitivity to malathion. The sensitivity of 
aquatic invertebrates to malathion in laboratory experiments differs with data gathered from actual field studies. Field applications of malathion, applied at levels sufficient to control mosquitoes, showed no effects on crustaceans and shrimp (Tagatz et al, 1974; Wall and Marganian, 1971); while, laboratory studies showed malathion to be highly sensitive to shrimp and daphnia (Hunsen et al, 1973; as cited in USDA, 1991). A wide area application of Technical-grade malathion was applied at $561 \mathrm{~g} /$ hectar $(.501 \mathrm{lbs} . / \mathrm{acre})$ in Dawson County, Nebraska. Treatments did not result in direct mortality of bluegill and native fish (Stucky, 1976). Two farm ponds repeatedly treated with 1 pound a.i./acre of malathion were studied in Texas. No mortality of fish species was observed (Fischer, 1966).

Should rain follow close behind a malathion application, or more critically, before the application can thoroughly dry, malathion may be washed from rangeland foliage and migrate toward small streams or ponds containing aquatic plants and wildlife. The potential for malathion in runoff is reduced if the application has sufficiently dried prior to a rain event and will continue to decline as the time between the application and the rain event increases.

The impacts malathion may have on aquatic life is a function of the following six variables (USDA, 1991):

1. Volume of precipitation produced by a storm;

2. Volume of rangeland runoff;

3. Insecticide concentration in rangeland runoff;

4. Quantity of insecticide washed into a stream or river;

5. The length of time the insecticides are in contact with the receiving organism; and

6. Stream volume and flow.

Additional environmental variables influencing potential malathion exposure to aquatic organisms in streams include; flow rate, volume of water in relation to surface area, subsurface recharge of stream flow, microscopic organism burden, temperature, shading, oxygenation, and bottom characteristics (Peterle and Giles, 1964).

Although the possibility exists for malathion to enter aquatic water systems in runoff, the occurrence of such an event would be rare and isolated. In addition, actual field studies indicate that malathion in runoff or drift would be subject to a wide variety of environmental factors; many of which can degrade and shorten the half-life of malathion under aquatic conditions. Measures to reduce potential runoff and drift into non-target areas are specified in the "Proposed Action" (pages 19-20). Treatment restrictions, in 
desert areas frequented by thunder showers, have been adopted to minimize the potential impacts of nunoff to desert pupfish habitat and Yuma clapper rail habitat (page 32).

Treatments near water are strictly avoided by CTVCP (See "Avoidance of Non-target Sites", page 19). Water is defined as any body of water, natural or man-made including; springs, wildlife guzzlers, alkali sumps, vernal pools, ephemeral pools stock ponds, reservoirs, streams, ditches and canals.

\section{Impacts to Vegetation}

\section{GENERAL}

The potential impacts of malathion on vegetation include effects on plant reproduction through the reduction of insect pollinators and direct toxicity to vegetation.

Phytotoxicity: Malathion is registered on a wide variety of vegetation and crops (see label in Appendix "B"): When used properly at appropriate concentrations, malathion does not appear to injure vegetation. Malathion is not generally phytotoxic. No phytotoxicity was observed in a forest watershed after several treatments of malathion at $.72 \mathrm{lb}$. a.i./ acre (Giles, 1970). (In the "Proposed Action" malathion rates are applied at $.58 \mathrm{lbs}$. a.i. per acre.)

Indirect Impacts Caused by Decline of Pollinators: If the populations of insect pollinators (flies, bees, ants, beetles, etc.) are reduced as a result of the use of malathion, propagation of plants within the treatment area could be affected for a short period of time.

Honeybees and groups of insects from the order Hymenoptera (ants, wasps, bees, etc.) are particularly susceptible to malathion exposure (Dobroski and Lambert, 1984). The depression of hymenopterous insects would be temporary because foraging bees, wasps and ants would continue to re-enter from adjacent non-treated areas. Honeybee and ant workers could be quickly replenished from beehives out of the treatment area and ant colonies under ground where the queen, brood and a large majority of workers are protected. Only a small percent of the nest's work force would be out at the time of the application. (See "Key Points of Proposed Action", Honeybee Notification Policy, pages 18-19.) 
Solitary bees and wasps are not members of colonies and foraging adults could not be replenished from a social insect structure. The depression of solitary Hymenoptera may be temporary due to re-entry of solitary species from adjacent non-treated areas (Manser and Bennett, 1962). Research indicates that insects of certain orders are more susceptible to malathion than others. Populations of flies, except mosquitos and beetles, were found not to be affected by low volumes of malathion (Hill, 1971).

\section{PLANT SPECIES OF SPECIAL CONCERN}

Plant species of special concern which may occur within the CTVCP's potential aerial treatment boundaries include: California jewelflower, Kern mallow, San Joaquin woolly-threads, Bakersfield cactus, Hoover's woolly-star, Bakersfield saltbush, giant Spanish needle, Peirson's milk-vetch, silver-leafed dune sunflower and Wiggins' croton, Monterey spineflower and robust spineflower.

The BLM notified CDFA by letter dated March 30, 1993, (Appendix "C") that recent data indicated Hoover's woolly-star to be much more widespread than originally believed. After discussions with USFWS, BLM concluded that avoiding treatment of areas occupied by the Hoover's woolly-star is no longer a reasonable or necessary conservation measure. BLM modified Federal PUP 91-CA-93-0001, withdrawing Hoover's woolly-star from the list of plants to be avoided by CTVCP during the bloom period.

We are assuming that the effects of direct exposure to malathion to plant species of special concern would be essentially the same as other general plant species in the environment covered previously in "Impacts to Vegetation General".

Little is known about the pollination strategies of many plant species of special concern. Of concern to USFWS are potential impacts to listed plant species exclusively dependent on insect pollinators to set seed, including vernal pool plants dependant on pollinators which range only a few meters and California jewelflower possibly dependent on bumblebee pollinators (USFWS, Sept., 1991). USFWS speculated that the death of pollinators within a limited range could significantly affect the plant's ability to produce seed for the next generation. The survival of an isolated population of plants could be crucial if a single year's seed production was eliminated.

As a small portion of a larger study, pollination exclusion experiments were performed on San Joaquin woolly-threads and California jewelflower; (Mazer 
\& Hendrickson, July, 1993) and (Mazer \& Hendrickson, Sept., 1993). While not conclusive, the San Joaquin woolly-threads exhibited an ability to set seed in the absence of pollinators while the California jewelflower showed a dependence on insect pollinators for seed production.

In the absence of pollinator exclusion studies for other plant species of concern, the indirect affects of malathion would be a combination of the following factors:

1. Was the plant or immediate area treated by CTVCP?

2 Mode of pollination for each species (wind, insect, self-pollinated);

3. Variety and quantity of insects utilized in pollination;

4. Foraging range of plant pollinators;

5. Time of year plant species bloom;

6. Duration of bloom period;

7. Persistence of seed bed within the environment; and

8. Time of year CTVCP treatment occurs.

Due to the avoidance of California jewelflower, Kern mallow, Bakersfield cactus and Peirson's milk-vetch, Monterey spineflower, robust spineflower as specified in the "Proposed Action" (page 29), no major impact to plant species of special concern is anticipated.

\section{Plants of Concern in the Hemet "Ground-rig Only" Treatment Area}

Plant species of concern found within or near potential treatment boundaries include: slender-homed spineflower, Munz's onion, San Jacinto saltbush, spreading navarretia, thread-leaved brodiaea, California orcutt grass. Direct phytotoxic impacts to these plants species of concern due to malathion exposure, is not expected due to the low phytotoxic properties of malathion.

Indirect impacts to insect pollinators may affect the reproductive abilities of these plant species. Because the California orcutt grass does not require an insect pollinator and the San Jacinto Saltbush is thought to be wind pollinated, indirect impacts of the "Proposed Action" would be minimized with respect to these two species (USFWS, July, 1996). In addition, the California orcutt grass occurs predominantly in vernal pool habitats avoided by the CTVCP to protect fairy shrimp species (USFWS, July, 1996).

USFWS also speculated that indirect impacts may occur as a result of suppressing predatory insects and parasitoids which control insect herbivores feeding on plant species of concern. USFWS concluded that plants within 
narrow treatment areas would be less subject to impacts because insects could re-enter the treated area from adjacent untreated areas; and, herbivory does not appear to be a problem for the San Jacinto saltbush (USFWS, July, 1996).

Direct and indirect impacts to the slender-horned spineflower from the "Proposed Action" would be minimized because core populations of the species are not located in the vicinity of planned treatment.

No major impacts to plant species of concern in the Hemet "ground-rig only" treatment area is expected because (USFWS, July, 1996):

1. Malathion has low phytotoxicity;

2. Treatments in the Hemet area will be largely composed of roadsides, ditch banks and small portions of fallow fields which will allow for rapid repopulation of these areas by insects from adjacent untreated areas;

3. Treated areas are anticipated to comprise a small portion of the available habitat.

\section{Impacts to Animals}

\section{GENERAL}

The potential impacts of malathion on animals, apart from removing non-target ectoparasites (some on the label), could include possible dermal and oral exposures.

Dermal exposure may result from the direct application of malathion during BLH treatment activities. Malathion is registered for the direct use on animals to control insects, mites and ticks. The animals include sheep, hogs, goats, dogs, cats, cattle, horses, ducks, geese and turkeys. (See Appendix "B" page $5 ; 57 \%$ emulsifiable concentrate.) The use of malathion for this wide range of animals indicates a favorable safety margin between target pests and non-target higher terrestrial animals.

Oral exposures may result from grooming, food and inhalation. Oral LD50's of malathion on laboratory and domestic animals varies widely.

Malathion's low solubility and low-octanol-water partition to efficiently contribute to a low bio-accumulation potential. Malathion has a low potential for accumulating in lipids (Dobroski and Lambert, 1984; as cited in USDA, 1991). A half-life for one hour was reported for retention after exposure to malathion (Kenaga and Goring, 1980; as cited in Dobroski and Lambert, 1984). 
Few field studies have been performed on the direct effects of malathion on wildlife. A review of the limited literature sources a general tolerance of wildlife to malathion applied at rates used to control insects. Based on a general comparison of field studies, malathion applied at the rate of $.58 \mathrm{lbs}$. of a.i./acre will not adversely affect wildlife populations.

Mammals: Possible impacts due to dermal or oral exposure by malathion in mammals include cholinesterase inhibition, but are dependant on dose and method of exposure. The lowest oral LD50 values for rabbits, rats, and mice are 250, 370 and $507 \mathrm{mg} / \mathrm{kg}$, respectively (NIOSH, 1987; as cited in USDA, 1991). A study in Michigan found no significant adverse effects on mammals and birds in areas treated with $1 \mathrm{lb}$. a.i./acre of malathion (DOI, 1963). In the "Proposed Action", malathion rates are applied at $.58 \mathrm{lbs}$. a.i./acre.

Reptiles and Amphibians: Impacts of malathion on reptiles and amphibians have not been widely studied and little information is available to aid in assessing impacts of CTVCP activities. Observations of the CTVCP staff during post-treatment surveys have found no evidence of major adverse impacts to reptiles or amphibians.

Both reptiles and amphibians were unaffected by the treatment of a watershed with malathion at the rate of $7 \mathrm{lb}$. a.i./acre (Giles, 1970). In the "Proposed Action", malathion rates are applied at $.58 \mathrm{lb}$. a.i./acre. Malathion was applied in seven low volume, high concentration sprays in the Presidio Valley in Texas. No malathion residues were detected in lizard tail muscle, brain tissue, ljver, coelom fat, and stomach contents (Culley and Applegate, 1967).

Birds: Oral exposure to malathion may result from grooming, feeding and inhalation. Such exposure would not cause major impacts. No major effects to birds and mammals were found in areas of Nebraska treated with $.5 \mathrm{lb}$. a.i./acre. Domestic turkeys held in cages in the treated area were allowed to eat insects and had slightly depressed plasma cholinesterase levels, but no external symptoms were noted (USDA, 1985). In the "Proposed Action", malathion is applied at $.58 \mathrm{lb}$. a.i./acre.

Dermal exposure may result from direct application of malathion to the environment. Malathion is registered for the control of mites and ticks on chickens, ducks, geese and turkeys. (See Appendix "B" - Malathion 57 label.)

Insects: Malathion is a broad spectrum pesticide and does not select between target and beneficial insects. Non-target insects and other, arthropods will be killed by malathion treatments. Because various insect groups vary in susceptibility to malathion, temporary changes in the composition of insect 
populations may occur within the treatment areas. Soft-winged flower beetles, ladybird beetles, green lace wings, crickets, grasshoppers, plant bugs and wasps have shown a greater susceptibility to malathion than other insect groups. This effect is expected to be temporary due to the rapid decomposition of malathion in the environment, high reproductive rates for insects and the migration of insects from adjacent non-treated areas. The rate at which insect populations re-colonize treated areas will depend on their biology and their densities in nearby untreated areas.

A one-year study of beneficial insect populations was performed using annual applications of malathion at .75 and $1 \mathrm{lb}$. a.i./acre. Adverse effects were noted on many insect species immediately after treatment, but no significant difference in populations of beneficial insects was noted the following spring (Huddleston et al., 1968). Long-term decline of insect populations from repeated annual treatments is not anticipated.

BLH control is accomplished because:

1. BLH's are generally found only in areas selected for treatment; and

2. Those BLH's not affected by treatment will be migratory toward green agricultural areas and are generally not a major part of the rangeland ecosystem after host plants have dried.

BLH Resistance to Malathion: Resistance to malathion by BLH in the field has not been observed by CTVCP personnel. The CTVCP is a control program; therefore, treatments are not continuous and are generally performed only once a year in a relatively small portion of the BLH's range. A tendency towards resistance to malathion would be predicted if all five to six annual BLH generations were exposed to malathion.

\section{IMPACTS TO ANIMAL SPECIES OF SPECIAL CONCERN}

\section{San Joaquin Kit Fox (SJKF) (Vulpes macrotis mutica)}

Impacts from direct dermal exposure of malathion to SJKF populations would be negligible. For the most part, the kit fox is nocturnal and CTVCP treatment operations are performed during daylight hours in the San Joaquin Valley. Any kit foxes, foraging during daylight in the vicinity of CTVCP operations, would most likely be dispersed by the activities into underground dens or out of the treatment area. 
Significant oral exposure of malathion to SJKF populations appears unlikely. The kit fox eats a variety of rodents, lizards and insects. There is no evidence that biomagnification of malathion in food chains occurs. Malathion is not accumulated in body fat (Metcalf, 1972) and was not found in various tissue samples after seven low-volume, high concentration sprays (Culley and Applegate, 1967).

CTVCP operations may directly affect the SJKF through the destruction of its den sites during ground monitoring surveys and ground spray applications (USFWS, Sept., 1991). In the "Proposed Action", vehicles are restricted to existing roads and potential den sites are avoided during ground survey activities (page 28). Minimal direct impacts to the SJKF from CTVCP operations is anticipated.

Malathion spray treatments could indirectly impact the food base of the SJKF due to potential effects on kangaroo rats and invertebrates (USFWS, Sept., 1991). Although the kit fox utilizes vertebrates for a majority of its food, invertebrates are ingested.

Indirect impacts of CTVCP treatments to kit fox vertebrate and invertebrate food base, as characterized by USFWS, would not be significant. These impacts are expected to be temporary due to the rapid degradation of malathion and the foraging mobility of both the kit fox and its prey within adjacent non-treated areas.

The USFWS postulates that because drought related reductions of vertebrate prey can be documented in the San Joaquin Valley and the Carizzo Plain, that further reductions in optional invertebrate food sources could affect the survival and recovery of the kit fox. Periods of drought may also result in a decline of BLH populations, thereby reducing the need to treat during these periods (USFWS, Sept., 1991).

Potential reproductive impacts from malathion treatments on rodent populations, cited in USFWS, Sept., 1991, and USFWS May, 1991, were re-evaluated by USFWS. (See discussion under "Impacts to GKR" and Appendix "C", correspondence dated Nov. 8, 1993). Malathion induced reproductive effects in rodent species and a corresponding reduction of kit fox food sources is not considered a likely potential impact.

\section{San Joaquin Antelope Squirrel (SJAS) (Ammospermophilus nelsoni)}

Potential impacts from dermal exposure of malathion to the SJAS may be separated into two areas: direct exposure to fur and/or skin and exposure to feet from treated ground or foliage. 
With the absence of dermal LD50 studies of malathion on SJAS in the literature, LD50's for laboratory rats are used for comparison. The dermal LD50 of malathion on rats is quite high at $4,444 \mathrm{mg} / \mathrm{kg}$ (Spiller, 1961). If we assumed the dermal LD50 for SJAS to be half that of the rats, the dermal LD50 would still be quite high. (CTVCP uses malathion at $.583 \mathrm{lb}$. a.i./acre and is equal to approximately $6.0 \mathrm{mg} / \mathrm{sq}$. ft.). It is unlikely that the SJAS would be exposed to significant concentrations of malathion during treatment operations. No significant dermal impacts to SJAS populations are expected.

Potential impacts from oral exposure of malathion to SJAS populations may result from grooming and the ingestion of treated foods. Impacts from grooming should be minor due to the concentrations of malathion in the environment coupled with the rapid degradation of malathion in ultraviolet light and organic matter in soils.

The potential impacts associated with the ingestion of food is a combination of the following:

1. Is the SJAS foraging within a treated area?

2. How long the treated vegetation persisted in the environment prior to ingestion;

3. Seed coats or skins exposed to malathion being discarded before ingestion of the seed;

4. Volume of treated food ingested/time; and

5. Type of food ingested (Gains, 1969).

Impacts to the pollination of seed producing plants utilized for food by SJAS is discussed generally in ("Indirect Impacts Caused by Decline of Pollinators", discussion on pages 69-70).

Impacts to SJAS habitat from CTVCP operations, besides the protection of SJAS seed producing plants from non-target phytophogus insects, may include concerns of potential phytotoxicity of malathion to seed producing plants and potential destruction of vegetation and burrow systems with vehicles.

Malathion's low degree of phytotoxicity coupled with the restricted use of CTVCP vehicles on existing roads greatly reduces impacts to SJAS habitat. In the spring, CTVCP treatments are applied to south-facing slopes in foothill terrain. This results in large areas of non-treated land on north and east-facing slopes. 
No major impacts to SJAS are expected as a result of the "Proposed Action".

\section{Mojave Ground Squirrel (Spermophilus mohavensis)}

It is expected that potential impacts to the Mojave ground squirrel, due to CTVCP activities, would be similar to the SJAS. In addition, potential impacts to the Mojave ground squirrel would be minimized due to the treatment of only ditch banks, roadsides, and small portions of fallow fields within the Palmdale/Lancaster treatment area by ground-rig.

No major impacts to the Mojave ground squirrel are expected as a result of the "Proposed Action".

\section{Giant Kangaroo Rat (GKR) (Dipodomys ingens)}

GKR are predominantly nocturnal; however, USFWS was concerned about potential direct exposure to GKR if CTVCP applications occur in their habitat during pre-dawn hours (USFWS, Sept. 1991). CTVCP operations in the San Joaquin Valley can take place during pre-dawn hours, but only when sufficient light exists to safely navigate and observe obstacles such as power poles, wires and structures. Rarely can CTVCP treatments begin longer than 30 to 45 minutes before sunrise leaving little pre-dawn treatment time. A percentage of GKR's foraging during daylight or pre-dawn hours would be expected to react to the presence of control operations and temporarily retreat into burrows, avoiding possible dermal exposure.

Impacts from dermal exposure of malathion to GKR populations are expected to be minimal. Malathion applications would have sufficient time to dry before $\mathrm{GKR}$, foraging during the following night, contact treated vegetation or soils with its feet or fur. Negligible dermal exposure to GKR is anticipated from treated vegetation carried in fur-lined cheek pouches.

The dermal LD50 of malathion in rats is quite high at $4,444 \mathrm{mg} / \mathrm{kg}$ (Spiller, 1961). If we assumed the dermal LD50 for GKR to be half that of laboratory rats, the dermal LD50 would still be quite high.

Potential impacts from oral exposure of malathion to GKR populations can be separated into two areas: exposure. from dry-tooth grooming of fur and the ingestion of sprayed vegetation such as peppergrass and red stem filaree (USFWS, Sept., 1991).

Impacts associated with dry-tooth grooming should have a minor impact on GKR populations because of the unlikely exposure of fur to direct applications. The 
potential for exposure to malathion from treated dirt used for dust baths is reduced greatly due to the rapid ultraviolet decomposition of malathion in sunlight and its absorption in organic matter. Malathion particles on the surface would not be expected to remain active for more than 4-6 days. The potential impacts associated with the ingestion of food is a combination of the following:

1. Is the GKR foraging within a treated area?

2. How long the treated vegetation persisted in the environment prior to ingestion;

3. Seed coats or skins exposed to malathion being discarded before ingesting of the seed;

4. Volume of food ingested/time; and

5. Type of food ingested.

In the absence of specific GKR oral toxicity studies, impacts may vary widely with changes or combinations of food sources in their diet (Gains, 1969).

USFWS acknowledged an oral LD50 of $4,445 \mathrm{mg} / \mathrm{kg}$ of malathion for laboratory rats but highlighted the difference in physiology and environmental stresses between laboratory rats and wildlife. USFWS, concerned with critical life stages, sighted a 1967 study in which ingestion rates as low as $.191 \mathrm{mg} / \mathrm{kg}$ over a 10-day period produced spontaneous abortions in laboratory rats. Based on the ingestion of malathion and a ten-fold safety factor, the USFWS concluded K-rats could ingest sufficient quantities to cause spontaneous abortions (USFWS, Sept. 1991).

Potential reproductive impacts from malathion treatments on kangaroo rat populations, cited in (USFWS, Sept., 1991) and (USFWS, May, 1991), were reevaluated by USFWS in 1993. In a memo to BLM dated November 8, 1993, (Appendix " $C$ "), the USFWS concluded; "sole use of the malathion toxicity data generated by the Dobbins (1967) study to calculate a risk assessment for kangaroo rats is not advisable. Other data generated in a more acceptable study did not indicate malathion caused reproductive effects in rats, and limited comparative toxicity data indicates kangaroo rats are not more sensitive than laboratory rats to another OP compound (Methyl Parathion)." The reduction of kangaroo rat populations from malathion induced reproductive effects is not considered a likely potential impact by USFWS.

Indirect potential impacts on seed producing plants utilized by GKR from CTVCP treatments may result from the reduction of insect pollinators and phytotoxic injury. The low phytotoxicity of malathion and decline of insect pollinators was previously discussed under "Impacts to Vegetation" (pages 69-70). 
CTVCP vehicles have the potential to impact food plants and burrow systems. The restricted use of CTVCP vehicles on existing roads greatly reduces impacts to individual GKR and its habitat.

Only minimal impacts to GKR are anticipated as a result of the "Proposed Action".

Tipton Kangaroo Rat (TKR) (Dipodomys nitratoides nitratoides)

It is expected that potential impacts to the TKR, due to CTVCP activities, would be similar to the GKR.

\section{Stephens' Kangaroo Rat (SKR) (Dipodomys stephensi)}

It is expected that potential impacts to SKR rat, due to CTVCP activities, would be similar to the GKR.

No major impacts to SKR are expected for the following reasons (USFWS, July, 1996):

1. The majority of the treatment area falls within an area where incidental take of SKR is currently allowed;

2. Large concentrations of SKR believed to be vital to the species survival are primarily in preserve areas outside the proposed treatment areas;

3. The best available evidence suggests that kangaroo rats are not particularly sensitive to malathion:

\section{Blunt-nosed Leopard Lizard (BNLL) (Gambelia silus)}

Seasonal fluctuations of BNLL activity are expected to reduce the impact of CTVCP operations to BNLL populations during the winter and fall treatments in the San Joaquin Valley. A graph of BNLL seasonal activity (Montanucci, 1965) shows no BNLL activity during the months of January and February and during the month of October, a small percentage of sub-adults comprise most of the activity. A majority of the potential impacts to BNLL would be expected from spring treatment activities.

Because little information is available to address the affects of malathion on $B N L L$, the affects of malathion on other lizard species was examined. 
Impacts from oral or dermal exposure to malathion are expected to be minimal. The acute oral LD50 to malathion for Anolis carolinensis, a lizard, is $2,324 \mathrm{mg} / \mathrm{kg}$ (Hall and Clark, 1982). The genius Anolis is in the same family (Iguanidae) as the genus Gambelia of which the BNLL belongs. Because of the close relationship of Anolis to the BNLL, impacts to BNLL are assumed to be similar.

Potential oral exposure may occur if insect prey species, exposed to malathion, are ingested. Disoriented and dying insect prey species may become easy prey for BNLL. Because insect prey species are in motion only a brief time prior to death, BNLL's are limited to this type of potential exposure. Exposure to disoriented prey species is further limited when spring CTVCP treatments are performed at temperatures below the BNLL activity threshold of $77^{\circ} \mathrm{F}$. Cool weather often accompanies spring treatment activities in late March or early April. Treatments are generally performed during the coolest part of the day, 30-40 minutes before sunrise until 1:00 p.m. During cooler spring weather, maximum daytime temperatures rarely exceed the BNLL activity threshold of $77^{\circ} \mathrm{F}$.

Direct exposure of malathion is not expected to adversely affect BNLL (USFWS, Sept., 1991).

USFWS opinion on potential impacts of malathion treatments on BNLL populations focused on the reduction of insect prey species utilized by BNLL. Grasshoppers and crickets make up approximately $74 \%$ of the BNLL diet. The reduction of insect prey species would take place during a time when overwintering fat reserves are low and food availability is important (USFWS, Sept., 1991).

Food of the BNLL consists primarily of invertebrates, including Orthroptera, Hymenoptera, Hemiptera, Coleoptera and smaller lizards (Kato, 1987; Snow, 1972). Stomach contents of BNLL, examined in May, contained crickets and Uta sp., a small lizard. The majority of the contents were crickets, but the lizards accounted for the greater bulk (Montanucci, 1965). Climate, location and availability of invertebrate prey species may contribute to conflicting food source data observed by Montanucci in 1965 and food source evaluations reported by Tollestrup (Tollestrup, 1972).

Grasshoppers, crickets and invertebrates, in general, are highly mobile and are expected to re-enter treated areas from adjacent non-treated areas. A rapidly changing rangeland habitat due to the maturing and drying of annual plants can also contribute to the movement or migration of invertebrate prey species during spring. 
With BNLL food reserves lowered during drought conditions, USFWS surmised that fewer insect prey species would be available in adjacent non-treated areas. Continued insect prey reductions during drought periods may adversely affect the BNLL's survival in the areas sprayed (USFWS, Sept., 1991).

Periods of drought also result in a decline of BLH populations, thereby reducing the need to treat during these periods (USFWS, Sept., 1991).

Moderate and temporary depression of insect food sources are anticipated during spring CTVCP activities due to:

- The varied diet and mobility of BNLL food sources;

- The relatively quick degradation of malathion in the environment; and

- Specific measures adopted to minimize impacts (pages 25-28).

Only minor impacts to BNLL burrows and habitat vegetation may be expected due to the restricted use of vehicles, and the use of a virtually non-phytotoxic treatment during CTVCP operations.

\section{Flat-tailed Horned Lizard (FTHL) (Phrynosoma mcallii)}

The use of malathion, in concentrations outlined in the "Proposed Action", is likely to have no direct adverse effect on the FTHL. Studies cited previously in this EA have shown various lizard species to have a high tolerance to malathion (Hall and Clark, 1982; Peterle and Giles, 1964; Giles, 1970).

Potential impacts to the FTHL prey food (harvester ants) was proposed by CDFG as perhaps a greater concern to the FTHL than the direct effects of malathion (Bolster and Nicol, 1989).

A moderate and temporary impact to insect food sources of the FTHL is expected from CTVCP treatments. The FTHL utilizes ants as a major portion of their diet. Foraging harvester ants (Veromessor pergandei) may be killed by malathion treatments.

A mature ant nest may contain up to 50,000 individuals and contain multiple queens (Wheeler \& Wheeler, 1973) of which only a small portion are foraging on the surface during a malathion application. The queen, eggs, larvae and a majority of the workers are underground, shielded from exposure to malathion. The majority of treatments will be conducted in early morning, or at night (Imperial County only), prior to peak ant activity. Ant foraging activity usually does not 
begin until the soil temperature reaches $13^{\circ} \mathrm{C}\left(55.4^{\circ} \mathrm{F}\right)$ (Snelling, 1979). In winter or early spring, this temperature isn't usually reached until about 12:00 noon P.S.T.

Because malathion treatments can occur until mid-morning with an average winter minimum temperature of $50^{\circ} \mathrm{C}\left(41^{\circ} \mathrm{F}\right)$, there is a possibility of ant foraging during spray activities (Bolster and Nicol, 1989).

Past monitoring required under the federal PUP has shown harvester ant colonies recover in areas following malathion spraying. (See "Harvester Ant Survey", Appendix " $\mathrm{K}$ ")

Historically, treatments are necessary one out of every three years. The last aerial application of malathion in the Imperial Valley was performed in 1991 (Appendix "E", page E-21). The treatment acreage can also vary from a few hundred to several thousand acres. Since the areas receiving treatments vary from treatment period to treatment period, many years may pass between treatments to any particular area.

Due to the random occurrence, size and location of CTVCP treatments in the Imperial Valley, no major impacts to harvester ant colonies are anticipated.

Destruction of FTHL habitat is expected to be minimal due to the restriction of CTVCP vehicles to existing roads and malathion's low phytotoxic properties.

No major impacts to FTHL are expected as a result of the "Proposed Action" because (USFWS, July, 1996):

1. Application of malathion will be limited to a single treatment per year in any given area and will likely be even less frequent;

2. Applications will be made aerially with no vehicle use on other than designated roads in FTHL habitat;

3. Treatments are not expected to be required in all areas or every year in the Imperial Valley;

4. Treatments will take place during the cooler hours of the day when ant activity is not at peak levels lessening the proportion of harvester ant colonies which are exposed to the treatments.

\section{Desert Tortoise (Gopherus agassizi)}

Potential impacts to the desert tortoise from CTVCP operations may result from direct exposure to malathion, oral exposure of malathion treated vegetation and habitat damage from vehicles. 
Few studies have been performed on exposure of reptiles and amphibians to malathion. Little information available on the affects of malathion on the desert tortoise to aid in assessing impacts of CTVCP operations.

Impacts from CTVCP treatments in the Imperial Valley during the months of January and February would be negligible due to the hibernation of the desert tortoise in underground burrows during the winter months. Potential impacts from malathion exposure are more likely if CTVCP treatments during March and April coincide with post-hibernation activities of the desert tortoise.

USFWS has concern for the potential of a foraging tortoise to ingest a substantial amount of malathion from food plants (USFWS, May, 1991). Indirect impacts could occur if insect pollinators are affected by the treatment program, and forage plants are unable to set seed for the following year's growth (USFWS, July, 1996).

Populations of desert tortoises would not necessarily be exposed to CTVCP treatments every year. Historical records show that treatments of any particular area in the Imperial Valley occur only once in every three to five years. Imperial Valley aerial treatments have been necessary only 6 years out of the last 18 with widely varying acreage totals. (See Appendix " $E$ " page 21.)

Direct dermal exposure of malathion from CTVCP treatments is expected to have minimal impacts on the desert tortoise. The desert tortoise has a small surface area in proportion to its body mass. The desert tortoise would not be expected to absorb enough malathion, before complete degradation, from a single direct treatment or from dermal contact with treated soils or vegetation to cause morbidity.

An occasional desert tortoise may migrate across roads and be in danger of being struck by CTVCP vehicles. In the "Proposed Action", ground-rigs and survey vehicles move at reduced speeds in desert tortoise habitat increasing the ability to avoid individual tortoises on road ways. The likelihood of hitting a desert tortoise with a CTVCP vehicle would be low.

Because malathion is generally non-phytotoxic, and vehicles are restricted to existing roads, minor to negligible impacts are anticipated to desert tortoise habitat.

No major impacts to the desert tortoise are expected for the following reasons: 1) The vast majority of proposed treatment area occurs on lands where desert tortoise would not be expected to occur; 2) potential treatment areas where desert tortoises are expected to occur is habitat characterized by low densities of desert 
tortoises; 3 ) the total area of tortoise habitat which could potentially be treated is extremely small in relation to the occupied desert tortoise habitat in this area (USFWS, July, 1996).

\section{California Red-legged Frog (CRF) (Rana aurora draytonii)}

Impacts to the CRF as a result of the "Proposed Action" included the potential for direct and indirect impacts. There is no specific data available on the direct toxicity of malathion to the CRF and little data available on amphibians in general. Several studies suggest that malathion in water, held at constant concentrations for 24- 96 hours, showed adverse effects to frog and toad larva at low concentrations; $0.56 \mathrm{mg} / \mathrm{L}(24 \mathrm{hrs}$.) \& $0.20 \mathrm{mg} / \mathrm{L}$ (96 hrs.) (Devillers \& Exbrayat, 1992). Risks of direct oral and dermal exposure to adult frogs would be significantly less critical. Frog brain cholinesterase has a greater resistance (100 times) to inhibitors than does cholinesterase in mammalian brain (Hall \& Kolbe, 1980). Huge doses of cholinesterase inhibitors are required to kill frogs (Tucker and Crabtree, 1970). The CTVCP maintains a standard 100-yard buffer from water and from riparian habitats (pages 19-20, "Avoidance of Non-target Sites") and maintains a $1 / 4$ mile aerial buffer from known CRF locations (page 30).

Field studies indicate a difference between laboratory conditions and those conditions found in the ecosystem. Natural and biological factors within aquatic situations influence the concentration, degradation and fate of malathion in aquatic environments (previously discussed pages 67-69).

There is a potential risk of indirect impacts due to the reduction of invertebrate prey species. This risk to terrestrial insect prey species would be greater during spring treatments and less of a factor during treatments in winter when rangeland invertebrate prey species are not active. The risk is further reduced by the standard buffers given to aquatic situations and to known CRF locations.

Only minimal impacts to CRF are anticipated because:

1. The CTVCP potential treatment areas are on the periphery of the CRF range as defined by the State Natural Diversity Database;

2. Standard treatment buffers in "Proposed Action" given to riparian and aquatic habitats, page 19 "Avoidance of Non-Target Sites";

3. Measures to avoid potential impacts to CRF, "Proposed Action", page 30;

4. Drift and runoff protection protocol, "Proposed Action", page 20. 


\section{Giant Garter Snake (GGS) (Thamnophis gigas)}

Impacts to the GGS as a result of the "Proposed Action" may include the potential for direct and indirect impacts. Research indicates reptile species have a high tolerance to malathion. The risk of impacts to populations of the GGS are not anticipated to be high as only CTVCP ground-rig treatments will be performed in proximity to habitats where remnant populations may exist. Aquatic habitats occupied by the GGS are not suitable habitats for the growth and development of BLH host plants and as such, are not surveyed and treated by the CTVCP. Ground-rig treatments within ground-rig only treatment areas (northern San Joaquin Valley) are small and infrequent (see Appendix "E", page 22, "Ground-rig Frequency and Application Totals"). Narrow treatment areas will allow invertebrate prey to re-enter from adjacent untreated areas, reducing indirect potential impacts. In addition, the standard treatment buffer given to aquatic habitats, potentially occupied by the GGS, will reduce direct and indirect potential impacts (page 19, "Proposed Action").

Only minimal impacts to giant garter snake are anticipated because:

1. The CTVCP potential treatment areas are on the periphery of the GGS range, only remnant populations may exist in proximity to the "Proposed Action";

2. Standard treatment buffers in "Proposed Action" given to riparian and aquatic habitats, page 19;

3. Measures to avoid potential impacts to GGR, "Proposed Action", page 30.

Orange-throated Whiptail (Cnemidophorus hyperythrus beldingi) and the San Diego Horned Lizard (Phrynosoma coronatum blainvillei)

Both direct and indirect impacts could occur if treatments are performed in areas occupied by the orange-throated whiptail and the San Diego Horned Lizard. Direct impacts to both lizard species as a result of the "Proposed Action" is not anticipated because research indicates lizard species have a high tolerance to malathion. Indirect impacts to invertebrate prey species is of greater potential. Treatments in the Hemet area are performed by ground-rig and are limited to roadsides, ditch banks and small portions of fallow fields. Lizard species within these narrow treatment areas would be less subject to impacts as invertebrate prey species would be expected to re-enter from adjacent untreated areas.

No major impacts to the orange-throated whiptail and the San Diego Horned Lizard are anticipated because:

1. Narrow treatment areas will allow invertebrate prey to re-enter from adjacent untreated areas; 
2. Treated areas are anticipated to comprise a small portion of the available habitat;

3. Measures adopted to avoid impacts (pages 31-34) to listed plant and animal species in the Hemet area reduces potential treatment acreage.

\section{Bird Species of Special Concern}

Potential direct impacts to bird species of special concern may result from both dermal and oral exposure to malathion. Potential indirect impacts may result if invertebrate prey are affected.

The USFWS believes the Yuma clapper rail (YCR) is susceptible to malathion both directly and indirectly. Of major concern to the USFWS was the potential for pesticide drift into occupied habitat. The reduction of available invertebrate food sources in a given area could force competition with other bird species in an environment already limited. Regions of concern included buffer zones between YCR habitat and treatment areas and agricultural drains (USFWS, May, 1991).

The YCR and the California black rail (CBR) would be impacted less than other bird species during CTVCP operations. Both birds move and forage along water systems of the Colorado River and Salton Sea and possess diets consisting largely of aquatic arthropods (crayfish and isopods). Direct application to aquatic habitat is strictly avoided by the CTVCP.

Minimal impacts to YCR and CBR are anticipated because: 1) Direct application of malathion to YCR habitat (wetlands) will be avoided by the "Proposed Action"; and 2) the amount of habitat which could be exposed to malathion is small in relation to the total amount of YCR and CBR habitat in the vicinity of the proposed treatment area.

On rare occasions, malathion may enter aquatic water systems in runoff when isolated thundershowers occur over treated areas before complete degradation has taken place. (See discussion of malathion in runoff, page 68). The small amount of malathion residue washed into the Colorado River or Salton Sea from runoff would be exposed to absorbing organic particles and be diluted by the large bodies of water. Residues of malathion in runoff resulting from isolated thunderstorms is expected to have minimal impacts to both the YCR and the CBR. Measures have been adopted to lessen impacts within potential YCR habitat (page 32).

Due to the use of ground-rigs only in the Blythe potential treatment region, impacts to YCR and CBR in the vicinity of Blythe will not be significant. 


\section{Riparian Bird Species of Concern}

The western yellow-billed cuckoo, southwestern willow fly-catcher, coastal California gnatcatcher, elf owl, gilded northern flicker, Gila woodpecker, black-tailed gnatcatcher, Arizona Bell's vireo and least Bell's vireo are generally associated during different times of the year within the willow-cottonwoodmesquite riparian forest along the Colorado River or other riparian systems in California.

Riparian systems are not treated by CTVCP due to the absence of BLH hosts. Nesting birds and hatchlings within riparian systems would not be exposed to direct applications of malathion during treatment operations.

All of the bird species of special concern are dependent on insects for all or part of their diets and could be indirectly impacted by the "Proposed Action". Indirect impacts to insect populations outside of riparian systems are expected to be temporary due to the high mobility of the birds, prey insects and the rapid degradation of malathion in the environment. Insects would be expected to re-enter treated areas from adjacent non-treated areas. Highly mobile bird species would be expected to easily move and forage in adjacent non-treated areas. Potential treatment areas adjacent to riparian habitat is small in relation to the total amount or riparian habitat occupied by bird species of concern.

The CTVCP will be minimally impacting riparian bird species of concern because:

1. Malathion degrades quickly in the environment;

2. Riparian habitat will not be treated in this program;

3. Potential treatment areas adjacent to riparian habitat are small in relation to the total habitat available;

4. Riparian bird species of concern fluctuate seasonably in their association with riparian habitat;

5. Buffers placed near riparian habitat in the San Joaquin Valley to protect the California red-legged frog, giant garter snake and the valley elderberry longhorn beetle will minimize impacts to bird species and

6. Specific measures adopted to minimize impacts to bird species of concern, pages $31-32$. 


\section{Fairy Shrimp Species of Concern}

Studies of malathion exposure to aquatic habitats from drift or runoff suggest the potential for significant risk to fish and aquatic invertebrates including fairy shrimp. The potential for impacts to aquatic habitats are reflected in the CTVCP's commitment to assure that no man-made or natural water sources are contaminated (pages 19-20).

The Conservancy fairy shrimp, longhom fairy shrimp, vernal pool tadpole shrimp, vernal pool fairy shrimp and the Riverside fairy shrimp are known from a limited number of locations distributed from Shasta County in the north, through parts of the Central Valley and the coast range into San Luis Obispo, Santa Barbara and Riverside Counties. Known locations of listed fairy shrimp are generally not found within CTVCP potential treatment areas (Eng, 1990; USFWS, Sept., 1994). In addition, the terrain and physical characteristics of the soils within historical $\mathrm{BLH}$ breeding grounds are generally not conducive to the formation of vernal pool habitat.

No major impacts to listed fairy shrimp species are anticipated from BLH control activities because:

1. The general scarcity of known listed fairy shrimp locations within CTVCP potential treatment areas.

2. The CTVCP avoids natural or man-made aquatic situations during control activities. (See "Avoidance of Non-target Sites" page 19.)

3. A relatively low risk of significant quantities of malathion leaching or migrating to vernal pools from treated rangeland due to post-treatment precipitation. (See "Impacts to Aquatic Life and Water", pages 67-69.)

4. Measures employed by the CTVCP to avoid potentially major effects to listed fairy shrimp (pages 30 and 34).

\section{Valley Elderberry Longhorn Beetle (VELB)}

Malathion could have a direct impact on adult VELB if CTVCP treatments are performed near woody riparian vegetation or water courses containing elderberry plants. No major impacts to the VELB are anticipated from the "Proposed Action" because:

1. Habitat conducive to the development of elderberry plants is generally not found within CTVCP potential treatment areas;

2. Woody riparian vegetation or watercourses with woody vegetation is not BLH habitat and is avoided in the "Proposed Action";

3. Measures to avoid major impacts to VELB, page 30. 


\section{Quino Checkerspot Butterfly (Euphydryas editha quino)}

Direct impacts to quino checkerspot butterfly could occur if host plants are sprayed during ground-rig treatments in the Hemet project area. Host plants are known to occupy and occur in fallow areas and roadsides within the boundaries of the potential treatment area.

USFWS believes the "Proposed Action" will not jeopardize the continued existence of the quino checkersopt butterfly because:

1. All known populations of quino checkerspot butterfly occur outside the proposed treatment area (USFWS, July, 1996).

2. Measures adopted to reduce potential impacts to quino checkerspot butterfly, page 33, will minimize potential impacts.

\section{Designated "Ground-rig Only" Treatment Areas}

Palmdale-Lancaster: Southeastern Kern, Northeastern Los Angeles Counties; Hemet-Blythe Regions: Western and eastern Riverside County; Cuyama Valley: Northwestern Ventura County, northeastern Santa Barbara and Southeastern San Luis Obispo Counties; San Joaquin Valley: Portions of western Stanislaus, Merced, Fresno, San Joaquin Counties.

In recent years the quantity and frequency of ground-rig applications within "ground-rig only" areas, near Hemet and in the Antelope Valley, has been in significant decline. The increased urban development and a decrease in farming has curtailed the need for BLH control in both areas. The frequency and quantity of applications in the Blythe, Cuyuma, and San Joaquin Valley "ground-rig only" areas have remained generally low. (See Appendix "E", page 22, "Frequency of Ground-rig Only Treatments" and Appendix "E", page 20, "Treatment Probability Chart".) There is every reason to conclude that the necessity for ground-rig applications in these designated control areas will continue at current levels or decline further.

When BLH treatments are necessary, the CTVCP spot treats roadsides and ditch banks with ground-rigs adjacent to CTV susceptible crops. Rangeland is not treated in these zones. Considering the small quantity of malathion presently utilized, the low frequency of ground-rig treatments and measures employed to reduce potential impacts to species of concern (pages 25-34); it is likely that plant or animal species of concem or their habitat would be minimally impacted by BLH treatments within "ground-rig only" areas. 


\section{Impacts to CTV Susceptible Host Crops}

Positive impacts to CTV host crops due to the "Proposed Action" may include the following:

a. Maintenance of a $1 \%$ or less CTV infection rate within host crops on a statewide basis;

b. Adequate supplies of CTV host crops and products;

c. Stable prices of CTV host crops and products;

d. Stability of jobs and investments in CTV host crop production and related product industries;

e. Minimum amounts of pesticides used to control BLH; and

f. Localized control and reduction of aphids and aphid vectored plant diseases and potential reduction of pesticide treatments in agricultural croplands adjacent to treatment areas.

\section{Cumulative Impacts}

Cumulative impacts are those impacts on the environment that results from the incremental impact of the action when added to other past, present, and reasonable foreseeable future actions regardless of the agency or person that performs such actions.

Adverse Effects of Past, Present and Reasonable Foreseeable Future Actions

A variety of actions have combined to affect ecosystems and sensitive species within potential CTVCP treatment areas. Destruction of natural ecosystems have been evident in urban sprawl, recreational activities such as off-road vehicle use, hunting, camping, various military uses, oil, gas, and mineral exploration, mining, livestock grazing, agriculture, industrial and vehicular air pollution, poaching, fire, drought, predation, disease, and competition from introduced species.

Agriculture in its many forms has the most wide reaching effects in changing the habitat for many sensitive, threatened and endangered species. The clearing of natural vegetation, the cultivation of soils and the use of herbicides, insecticides and rodenticides has affected the historical range of the blunt-nosed leopard lizard, desert tortoise, Tipton kangaroo rat, giant kangaroo rat, San Joaquin antelope squirrel, Mojave ground squirrel, flattailed horned lizard, San Joaquin kit fox, Bakersfield cactus, Kern mallow, San Joaquin woolly-threads, Bakersfield saltbush, California jewelflower, peregrine falcon, Swainson's hawk and the bald eagle. 
In addition to the application of malathion to rangeland for control of the BLH, additional pesticides may also be used to control grasshoppers, vertebrate pests and noxious weeds within the CTVCP potential treatment areas. The Cooperative Rangeland Grasshopper Management Program, administered by USDA, utilizes block or buffer treatments for the control of grasshopper infestations that threaten food, fiber and grasslands. The USDA works closely with state agencies and private landowners to control extremely large grasshopper populations on public and private lands. Grasshopper control within the potential CTVCP treatment area would be rare.

Avicides and rodenticide baits may be placed in rangeland to control vertebrate pests inflicting damage to adjacent cropland areas. The locations and amount of vertebrate pest control would be expected to fluctuate from year to year with changes in vertebrate pest populations.

Herbicides are utilized to control noxious weeds within the boundaries of CTVCP treatment areas. Small isolated acreages of tamarisk, arundo and yellow starthistle are routinely treated. Federal, state and county agencies may be involved in the survey and eradication of noxious weeds. The majority of weed eradication acreage is quite small and extremely localized. The quantity of herbicides used for control is also quite small and not significant. At this present time, Salsola vermiculata is the only weed under regulatory eradication within the CTVCP potential treatment area.

Urban sprawl and associated activities, causing permanent habitat destruction and changes in air and water quality, have affected many species throughout California. In the San Joaquin Valley, species such as the San Joaquin kit fox, western yellow-billed cuckoo, Bakersfield cactus, blunt-nosed leopard lizard and San Joaquin antelope squirrel have been subject to pressures resulting from urban growth. Uiban growth in southern California has had a significant impact on the environment. The black-tailed gnatcatcher, Munz's onion, slender-horned spineflower and California orcutt grass are being threatened by the continued urban expansion in the Hemet area.

A combination of urban sprawl and agriculture has impacted the ecosystems associated with the Colorado River. The development of flood control and the diversion of water from the Colorado River for urban and agriculture uses, has changed the lower Colorado River basin and impacted many sensitive species. The greatly reduced cottonwood-willow-mesquite riparian forest is the home for a large group of birds including the Gila woodpecker, gilded northern flicker, elf owl, California black rail, Arizona Bell's vireo and Yuma clapper rail. The bonytail chub and humpback sucker have also been impacted by changes in the Colorado River. 
Oil, gas and mineral exploration or production have profoundly modified, over a limited area, the habitat of San Joaquin kit fox, blunt-nosed leopard lizard and Bakersfield cactus.

Off-road vehicle use, whether in commercial racing events or casual weekend family activities, have posed a clear threat to some desert species, including the desert tortoise, flat-tailed horned lizard, Algodones dunes sunflower, Wiggins' croton and silver-leafed dune sunflower.

The impacts of predation, poaching, and disease are impacting the desert tortoise, flat-tailed horned lizard, blunt-nosed leopard lizard, San Joaquin kit fox, peregrine falcon and bald eagle.

\section{Beneficial Actions}

Although many factors are contributing to the degradation of natural habitat in California, efforts are being made to reverse trends of habitat disruption and the decline of species. Protection for sensitive, threatened or endangered species is provided by federal and state legislation. Habitat, identified by federal, state or local agencies to be crucial to the survival of endangered species, may be recommended for acquisition and set aside as wildlife preserves; national, state, county or city parks; national wildlife areas and ecological preserves. Critical habitat for some species has been defined and officially designated by the USFWS. Tax check-off monies, off-site habitat protection to compensate for development, wildlife bond monies and private donations are being used to set aside more land.

Recovery plans have been adopted to enhance the recovery of many endangered species such as the BNLL, San Joaquin kit fox, bald eagle and the peregrine falcon. Both the bald eagle and the peregrine falcon are on the road to recovery as their numbers have increased in response to management programs. The bald eagle was downgraded from "Endangered" to "Threatened" status as of July 1, 1994.

Management plans, developed by resource agencies, provide guidance to for the management of a sufficient portion of habitat to maintain viable populations of species in decline.

Non-profit conservation organizations such as the Nature Conservancy, Audubon Society and the Sierra Club are promoting research and habitat improvement which will greatly improve the survival of many species, including those listed as endangered or threatened. 


\section{Conclusion}

The direct and indirect effects of the "Proposed Action" are minor and should not significantly add to or increase impacts of other actions. Malathion breaks down within $1-4$ days of application, residue build up is not anticipated from single annual treatments. Studies have shown that insect populations re-establish rapidly within several months of treatment and would not experience long-term decline from repeated annual treatments. Therefore, the "Proposed Action" will have little or no cumulative effect, beyond what is occurring as a result of other actions, within the treatment areas.

\section{B. ALTERNATIVE 2-REDUCED PROJECT ALTERNATIVE}

Under the Reduced Project alternative, the CTVCP would not treat public lands and would control BLH populations where necessary on adjoining private lands. This alternative would eliminate treatments from an estimated 10,000-20,000 acres of rangeland per year. In years when treatments are necessary in the Imperial Valley, an additional 3,000-20,000 acres would be eliminated from treatment.

The Reduced Project alternative would eliminate all negative and positive impacts to public lands previously discussed in the "Proposed Action".

\section{Impacts to Soil}

Same as "Proposed Action"

2. Impacts on Air Ouality

Same as "Proposed Action"

3. Impacts to Water

Same as "Proposed Action"

4. Impacts to Aquatic Life

Same as "Proposed Action" 
5. Impacts to Vegetation

\section{GENERAL}

Same as "Proposed Action"

PLANT SPECEES OF SPECIAL CONCERN

Same as "Proposed Action"

6. Impacts te Animals

\section{GENERAL}

Same as "Proposed Action"

\section{ANIMAL SPECIES OF SPECIAL CONCERN}

Same as "Proposed Action"

7. Impacts to CTV Susceptible Crops

Impacts to CTV susceptible host crops are expected to be similar to the "Proposed Action" with the addition of:

a. Increased potential for small to medium CTV outbreaks from BLH populations migrating from important historical breeding grounds located on untreated public lands in the San Joaquin Valley. Due to the high ratio of public to private lands in the Imperial Valley, large CTV outbreaks in Imperial Valley host crops would be expected;

b. The increased use of foliar and systemic pesticides to control BLH migrating from public lands;

c. Potential localized crop loss; and

d. Untreated public lands could act as a reservoir for CTV and the BLH; increasing the potential for re-infesting adjacent treated lands.

Where treatment of BLH populations is determined by the CTVCP to be necessary and no treatment is allowed by the agency or persons in control of such land harboring these pest populations, abatement orders could be issued under authority of Chapter 6, Article 1 of the Food and Agricultural Code of the State of California. Under the abatement order, the agency or person in charge of land, harboring such a pest, could bear all cost of controlling the pest. 
The agency or persons controlling lands harboring pest could also be held liable for crop losses attributed to failure to control this pest.

\section{Cumulative Impact}

The overall cumulative impact of this alternative is expected to be the same as the "Proposed Action".

\section{ALTERNATIVE 3-NO ACTION}

Under the No Action alternative, the CTVCP would not use any of the above actions. No pesticide treatment for BLH control would take place in California by the CTVCP.

'Where no treatment occurred, both BLH populations and CTV would increase and become a threat to a wide range of agricultural crops and home gardens, statewide, valued at well over three billion dollars worth annually. Losses could be astronomical. A large portion of the produce consumed in the United States comes from California, and a major outbreak of CTV could affect consumers nationally.

Potential impacts of No Action are expected to be:

a. Unstable prices for CTV susceptible crops and products;

b. Inadequate supplies of CTV susceptible crops and products;

c. Loss of jobs and investments in CTV susceptible crop production and related industries;

d. A large increase in pesticide use to control migrating BLH populations within cultivated crops;

e. Increased potential for pesticide residue on produce; and,

f. Potential increases in air and ground water contamination from increased use of pesticides in crops.

Without the control of BLH, CTV infection would threaten over three billion susceptible crops and home gardens annually. Susceptible crops and gardens growing in California would be subject to the same devastating losses experienced in agricultural history prior to the establishment of the CTVCP.

\section{Cumulative Impact}

The absence of BLH control in California would have little cumulative impact beyond what is occurring as a result of other actions and be similar to the "Proposed Action". 



\section{CONSULTATION/COORDINATION}

1. California Department of Food and Agriculture

\section{A. Division of Plant Industry}

1. Dell O. Clark - Program Supervisor, Integrated Pest Control Branch

2. G. Doug Barbe - Plant Taxonomist, Analysis \& Identification Branch

3. Thomas K. Palmer - Area Manager, Integrated Pest Control Branch (retired)

4. Robin Reynolds - Senior Environmental Planner

5. Peter H. Kurtz, M.D. - Medical Coordinator

6. Robert L. Peterson - Project Leader, Curly Top Virus Control Program

7. Rodney A. Clark - Associate Entomologist, Curly Top Virus Control Program

2. California Department of Fish and Game

\section{A. Region 4}

1. Gail Presly - Associate Wildlife Biologist

2. Jeff Single - Environmental Specialist III

3. Donna Daniels - Environmental Specialist III

4. Gene Coolie - Botanist

5. Rod Goss - Botanist

3. United States Department of the Interior

\section{A. Bureau of Land Management}

California State Office:

1. Jim Morrison - State Rangeland Conservationist

2. Jack Mills - Environmental Coordinator

3. Ed Lorentzen - Natural Resource Specialist

4. John Willoughby - Botanist

\section{California Desert District:}

1. Larry Foreman - District Wildlife Biologist

El Centro Resource Area:

1. Nancy Nicolai - Wildlife Biologist

\section{Caliente Resource Area:}

1. Amy Kuritsubo - Wildlife Management Biologist

2. Susan E. Carter - Botanist

3. Larry Saslaw - Natural Resource Specialist 
Hollister Resource Area:

1. Sam Fitton - Wildlife Management Biologist

Palm Springs Resource Area:

1. Roland DeGouvenain - Botanist/Rangeland Conservationist

B. U. S. Fish and Wildlife Service

Carlsbad Field Office:

1. Carol Roberts - USFWS Biologist

Sacramento Field Office:

1. Don Hovik - USFWS Biologist

2. David Wright - USFWS Biologist

3. Kirsten Tarp - Botanist

4. Alison Willy - Endangered Species Coordinator

4. United States Department of Energy (Elk Hills)

A. Bechtel Petroleum Operations, Inc.

1. Robb Fishman - Environmental Services

B. Enterprise Advisory Service (Environmental Studies Contractor to DOE)

1. Ken Spencer - Scientist

2. Thomas T. Kato - Manager, Endangered Species \& Cultural Resources

3. Mike Phillips - Project Manager

5. University of California, Riverside

A. Department of Entomology

1. Dr. Gregory P. Walker - Entomologist

2. Dr. Imad M. Bayoun - Entomologist 


\title{
United States Department of the Interior
}

\author{
FISH AND WILDLIFE SERVICE \\ Ecological Services \\ Sacramento Field Office \\ 3310 El Camino Avenue, Suite 130 \\ Sacramento, California 95821
}

IN REPLY REFER TO

In Reply Refer To:

1-1-95-F-141

January 23, 1997

\section{Memorandum}

To:

State Director, Bureau of Land Management, Sacramento, California

From:

Field Supervisor, Ecological Services, Sacramento Field office, Sacramento, California (ES)

Subject: Formal Section 7 Consultation on Renewal of a Five Year Pesticide Use Permit to the California Department of Food and Agriculture For Use of Malathion to Control Curly Top Virus in Fresno, Kings, Kern, Los Angeles, Merced, Monterey, San Luis Obispo, San Joaquin, Santa Barbara, Stanislaus, and Ventura Counties, California

This is in response to a June 23, 1995, request from Mr. Ed Hastey of the Bureau of Land Management (Bureau) for formal consultation pursuant to section 7 of the Endangered Species Act of 1973, as amended (Act), on the renewal of a five-year pesticide use permit to the California Department of Food and Agriculture (Department) for use of malathion to control curly-top virus in the above listed counties in California. Ine Bureau has the lead role regarding this request. The Department of Energy (DOE) is also involved because malathion will also be applied on DOE lands.

At issue are the effects of the proposed activity on the following federally endangered species:

San Joaquin kit fox (Vulpes macrotis mutica)
Tipton kangaroo rat (Dipodomys nitratoides nitratoides)
giant kangaroo rat (Dipodomys ingens)
Aleutian Canada goose (Branta canadensis leucopareia)
American peregrine falcon (Falco peregrinus anatum)
California condor (Gymogyps californianus)
blunt-nosed leopard lizard (Gambelia silus)
Conservancy fairy shrimp (Branchinecta conservatio)
longhorn fairy shrimp (Branchinecta longinatenna)
vernal pool tadpole shrimp (Lepidurus packardi)
California jewelflower (Caulanthus californicus)
Kern mallow (Eremalche kernensis)
San Joaquin woolly-threads (Lembertia congdonii)
Bakersfield cactus (Opuntia treleasei)
large-flowered fiddleneck (Amsinckia grandiflora)
palmate-bracted bird's beak (Cordylanthus palmatus)
robust spineflower (Chorizanthe robusta)

plus the following federally threatened species:

western snowy plover (Charadrius alexandrinus)

bald eagle (Haliaeetus leucocephalus)

California red-legged frog (Rana aurora draytonii)

giant garter snake (Thamnophis gigas)

vernal pool fairy shrimp (Branchinecta lynchi)

valley elderberry longhorn beetle (Desmocerus californicus dimorphus? 
Hoover's woolly-star (Eriastrum hooveri)

Monterey spineflower (Chorizanthe pungens var. pungens)

This document transmits the U.S. Fish and Wildlife Service's (Service)

biological opinion based on the Service's review of the proposed Curly-Top Virus Control Program (CTVCP), 1997-2001, located in the above counties, and its effects on the above listed species, in accordance with section 7 of the Endangered Species Act of 1973, as amended (16 U.S.C. 1531 et seq.). Your June 23, 1995, request for formal consultation was received on July 12, 1995.

This biological opinion is based on information provided in the joint environmental assessment (joint EA) for the program (BLM \& DOE 1995), a January 12, 1996, memo from the California state Director of the Bureau to the Field Supervisor of the Service's Sacramento Field Office, meetings held on July 30, August 7, and October 25 1996, an amendment to the proposed action dated August 19, 1996 (CDFA 1996), faxes from the CTVCP to the service on August 23, 27 and 29 and October 3 (two faxes, amending the proposed action), 1996, and other sources of information. A complete administrative record of this consultation is on file in the Service's Sacramento and Carlsbad Field offices. Listed species in Riverside and Imperial Counties are addressed in a biological opinion prepared by the Carlsbad Field office (1-6-96-F-32).

The Service has determined that the proposed action is not likely to adversely affect the federally endangered American peregrine falcon, California condor, Conservancy fairy shrimp, large-flowered fiddleneck, palmate-bracted bird's beak, robust spineflower, and the federally threatened western snowy plover, bald eagle, and Monterey spineflower (see Appendix B). These species will not be addressed further in this biological opinion.

\section{BIOLOGICAL OPINION}

Description of the Proposed Action

\section{General Program}

The Bureau/DOE proposes to authorize a five-year pesticide use permit to the California Department of Food and Agriculture for continued CTVCP use of malathion on selected Bureau and DOE public lands in California, to control curly top virus. The Department's program also applies malathion on private lands. The lands proposed for treatment are located in San Joaquin, Stanislaus, Merced, Fresno, Kings, Monterey, Kern, San Luis Obispo, Santa Barbara, Ventura, Riverside, and Los Angeles counties. Potential treatment areas total over 2.5 million acres, of which about $25 \%$ is public land. Only about $3 \%$ of the total potential treatment area is sprayed in an average year (Appendix A).

This treatment is proposed as part of a continuing program to control the beet leaf-hopper (BLH), Circulifer tenellus (Baker) (Homoptera: Cicadellidae), an introduced species and the only known vector of curly-top virus. Without control of BLH, curly-top virus (CTV) could threaten over 1.2 billion dollars of crops and a similar or larger value of home garden production (BLM \& DOE 1995; see also Appendix A).

The beet leafhopper is a migratory insect that may undergo several generations per year. In summer or early fall, BLH moves from crops to weeds, especially Russian thistle (tumbleweed: Salsola tragus), where it feeds and reproduces. It then migrates to the western foothills of the San Joaquin Valley where it seeks out south to west-facing slopes. The sun exposure, xeric soils, and sparse plant growth of these slopes benefit the desert-adapted leafhopper. Another generation, or two, of BLH is produced on annual plants and weeds on 
sparse plant growth of these slopes benefit the desert-adapted leafhopper. Another generation, or two, of BLH is produced on annual plants and weeds on these slopes before the leafhopper migrates back to croplands in late spring or early summer. The CTVCP conducts distinct treatment efforts targeted at different BLH generations in three seasons: fall, winter, and spring.

The CTVCP uses monitoring and targeted aerial and ground-based spraying of malathion to control BLH populations. Spraying is conducted in areas where monitoring has identified concentrations of BLH. Aerial treatments are used in rangeland habitat and large fallow fields; ground-rigs are used along roadsides or ditch banks within cultivated areas adjacent to rangeland breeding grounds of BLH. On rare occasions; ground-rigs are used to treat BLH populations in cultivated fallow fields too small or isolated to be treated economically by aircraft. In both aerial and ground spraying, malathion is mixed with water and applied at a rate of 7.7 fluid ounces of $95 \%$ malathion per acre (65 mg of active ingredient per square meter). The program aims for a typical droplet size of $350 \mathrm{um}$.

Most aerial spraying for the program is done from helicopters and fixed-wing aircraft, which spray swaths 100 feet wide. Flaggers on foot help the pilot to orient. Supervisors are in contact with the pilot and flaggers by radio to direct the spraying operation.

Ground-rigs are used exclusively to control BLH populations in five distinct areas. These areas, which are designated "ground-rig only" include the Cuyama Valley, Palmdale-Lancaster, Blythe, and Hemet control areas; and a portion of western San Joaquin, Stanislaus and Merced Counties (maps in Appendix " $E$ " of the Joint Environmental Assessment, BLM \& DOE 1995). The size and locations of ground-rig treatments in cultivated areas are related to the size and location of BLH populations in adjacent rangeland habitat. One treatment per year is generally sufficient to control BLH populations on roadsides and ditch bank weed hosts.

A ground-rig is typically a four-wheel drive pickup truck with an enginepowered blower in the bed. Malathion mixed with water is injected into the air stream of the blower nozzle which is movable. All controls are inside the cab where the operator can start and stop the blower engine, turn the spray off and on, and control the direction of the blower. Ground-rig vehicles are driven primarily on roads accessed by agricultural vehicles and equipment.

San Joaquin Valley

In the San Joaquin Valley, the CTVCP usually conducts aerial campaigns which closely coincide with the reproductive biology of BLH. Winter, spring, and fall control campaigns are performed on the west side and southern end of the Valley; each is generally performed in a separate geographical area. A single treatment per calendar year for any given area is generally sufficient to control. BLH populations. A second treatment may be necessary if:

(1) fall populations of BLH are developing in Russian thistle on rangelands previously treated in the spring period. Approximately 17,000 acres of historical spring breeding grounds in the Pleasant Valley, Fresno County, have the potential to produce Russian thistle populations. Approximately 100 to 3,000 of the 17,000 acres may need a second fall treatment in any one calendar year; or,

(2) late spring rains rejuvenate drying rangeland vegetation and a second generation of BLH develops on rangeland treated earlier in the spring. Late spring rains have historically developed a second spring generation of BLH in the San Joaquin Valley every 5 or 6 years on an estimated 1,000 to 10,000 acres of rangeland. 
Salinas Valley

Aerial treatments in the Salinas Valley (Monterey County) are infrequent; historically, they have been performed every $7-10$ years. The last aerial treatment in the Salinas Valley was during the spring of 1977.

Proposed Action Measures to Avoid Potentially Significant Effects to SpecialStatus Species

Measures to avoid potentially significant effects to listed, proposed, and candidate species have been adopted from the terms and conditions and conservation recommendations outlined in previous Service biological opinions $(1-6-91-F-20$ and $1-1-91-F-6)$ and stipulated as terms and conditions of CTVCP's Federal pesticide use permit (BLM 1991). Measures were also adopted from label restrictions on the use of malathion, and formal and informal consultations with the California Department of Fish and Game (CDFG).

1. General measures to minimize environmental impacts:

a. Application rates of malathion for treatment areas will not exceed the prescribed rate ( $7.7 \mathrm{oz}$. of $95 \%$ malathion per acre).

b. No applications of malathion will take place when wind velocities exceed $5 \mathrm{mph}$ or air temperatures exceed $80^{\circ} \mathrm{F}$.

c. No applications of malathion will be made within 100 yards of surface waters, natural or impounded, or areas of riparian influence. According to the CTVCP, "Riparian habitats are not conducive to the growth and development of beet leafhopper populations and therefore are not treated. The area of riparian influence or 'green belt' is in stark contrast to drying rangeland vegetation where [spring] treatments are conducted. Buffer areas of at least 100 yards are left untreated near riparian water courses. The buffers extend from the outer edge of the influence of the water course (green belt) into arid areas of drying rangeland vegetation. Buffer zones are widened sufficiently to compensate for the curvature of stream beds and current wind direction." (CDFA, fax, August 23, 1996; the text "[spring]" has been added)

d. The following protocols will be followed to minimize the chance of contamination of runoff by malathion:

1. Weather will be constantly monitored for wind and rain.

2. When there is a high probability ( $80 \%$ chance) of local moderate rain- -0.25 inches or less within 24 hours - the CTVCP will spray only when it is anticipated that there will be sufficient time for the application to dry before rainfall occurs (at least four hours).

3. If rainfall of more than a moderate amount (more than 0.25 inches) is predicted locally within 48 hours, applications are discontinued until predictable local conditions improve.

4. When plant cover is wet from recent rain, heavy dew or frost, the CTVCP waits until nearly dry before applying insecticide.

e. The CTVCP will attempt to reduce BLH host plants, including Russian thistle, by encouraging the use of appropriate rangeland management practices (e.g., BLM or USDA Cooperative Extension guidelines).

2. Measures to protect San Joaquin kit fox, giant kangaroo-rat, and Tipton kangaroo-rat: 
No off-road vehicle use will take place within known habitat of these species. Known and potential dens of San Joaquin kit fox will be avoided during ground surveys.

3. Measures to protect blunt-nosed leopard lizard (BNLL):

a. Identification of BNLL conservation habitat. Ten BNLL "conservation areas," based on available knowledge and consistent with current conservation plans--including the developing Kern County Valley Floor and Pleasant Valley Habitat Conservation Plans and Bureau resource management plans--were identified by the CTVCP [Appendix D of the joint environmental assessment (BLM \& DOE 1995) and revised in the amended proposed action (CDFA 1996), included here as Figures 1-8]. These BNLL conservation areas are estimated to cover approximately 154,000 acres (67,000 in the San Joaquin Valley; 87,000 in the Carrizo Plain). On an annual basis, the CTVCP will consult informally with the Bureau, the Service, and California Department of Fish and Game (CDFG), if necessary, to modify designated BNLL conservation habitat areas and review the status of the BNLL conservation strategy and research (see chart of measures $a-1$ in joint EA Appendix " $D$ ").

b. The following measures will be taken within presumed BNLL habitat. Presumed BNLL habitat is based on known locations and site

characteristics outside the CTVCP-designated BNLL conservation areas. All measures followed outside of BNLL habitat will apply ( $1 \mathrm{a}, \mathrm{b}, \mathrm{c}$, and d, above), plus:

1) No off-road vehicle use within spray areas will be permitted.

2) Reduction of Russian thistle and other BLH host plant populations by encouraging appropriate rangeland management practices will have a higher priority.

3) In the Cuyama Valley spring ground-rig spray area, spraying will be along existing roads, and when the spray corridor is adjacent to suitable habitat for BNLL, the ground-rig operator will direct the spray application to roadside weeds only.

4) Malathion will not be applied more than once per calendar year within each treatment area that is "presumed" BNLL habitat, with up to $100 \%$ coverage of delimited BLH populations, based on pretreatment surveys; except that,

5) Intensive spring treatment areas which overlap intensive fall treatment areas, highlighted in Appendix " $D$ " of the joint environmental assessment (BLM \& DOE 1995), may receive an additional fall treatment, with up to $100 \%$ coverage of delimited BLH populations on Russian thistle. These intensive control areas, approximately 17,000 acres, have the potential of developing large BLH populations in Russian thistle on rangeland where a single spring treatment may have been performed. The majority of these areas are located on the west side of Fresno County in the Pleasant Valley. Approximately 100 to 3,000 acres may need treatment in any one year.

Additional restrictions to CTVCP activities within potential BNLL habitat exist due to the exclusion of CTVCP treatment activities from proposed "Specialty Preserves" (as defined within habitat conservation plans), various national and state preserves and refuges, lands of The Nature Conservancy, wetlands, and lands populated by several 1 isted plant species during the spring bloom periods (see below). 
c. The following measures will be taken within the designated BNLL conservation areas:

1) The CTVCP, as a first priority, will attempt to reduce the need for insecticide treatments within BNLL conservation habitat by encouraging rangeland management practices that reduce the development of BLH host plant populations.

2) Malathion will not be applied in BNLL conservation area 110 in the Carrizo and Elkhorn Plains, or in BNLL conservation areas 1 , $2,3,4,8$, and 9 in the San Joaquin Valley.

3) Malathion will not be applied in BNLL conservation areas 5, 6, and 7 in the San Joaquin Valley unless a critically large BLH population is found during pre-treatment surveys--averaging at least 15 leafhoppers per 10 net sweeps. Malathion spraying for BLH control will be restricted to a single annual treatment. No more than $50 z$ of the infested area will be treated, by alternating treated swaths with untreated swaths, to facilitate the quick reestablishment of insect prey species. Spot applications will not exceed 20 contiguous acres.

4) The CTVCP will target BNLL conservation habitat, outside "High Virus-Intensive Control" areas, for initial release and establishment of BLH egg parasites. Releases will take place in BNLL conservation areas $2,5,6$, and 7 as a first priority and the remaining conservation areas as a second priority.

d. The CTVCP will support collaboration on fufilling the following BNLL informational needs:

1) Further definition of BNLL conservation areas with driving surveys

2) Long-term studies to determine post-treatment invertebrate response and recovery and BNLL population/reproductive responses to treatments of $50 \%, 100 \%$, and no treatments. In particular, the CTVCP has offered to provide aircraft and malathion for such a study (fax dated August 27, 1996).

3) Resolve any questions regarding dermal exposure of BNLL to malathion

4) Review and assessment of previous BNLL survey data generated by the CTVCP

4. Measures to protect San Joaquin Valley endangered plants:

a. Malathion will not be applied during the flowering period(s) in areas with extant populations of the California jewelflower, Bakersfield cactus, Kern mallow, Monterey spineflower, or robust spineflower. Maps prepared by the CTVCP will be used to determine the known location of extant populations of these listed plants prior to spring treatments. Maps prepared and maintained by EASI (formerly EG\&G) will be consulted to determine the locations of extant populations of listed plants within Naval Petroleum Reserves (NPR) \#1 and \#2. The CTVCP will update their plant maps annually based on maps prepared and maintained by the CDFG, DOE, and the Bureau.

b. Specific avoidance measures, previously adopted by the CTVCP, for Hoover's woolly-star and San Joaquin woolly-threads have been removed from the "Proposed Action," due to: 
- the modification of Federal Pesticide Permit 91-CA-93-0001 (issued by the Bureau to the CDFA), withdrawing Hoover's woolly-star from the list of plants to be avoided by CTVCP (letter dated March 30 , 1993, see joint EA Appendix " $C^{\text {") }}$

- recent experiments showing San Joaquin woolly-threads to be capable of self-fertilization (Mazer \& Hendrickson 1993)

5. Measures to protect longhorn fairy shrimp, vernal pool fairy shrimp, Conservancy fairy shrimp, and vernal pool tadpole shrimp:

a. The CTVCP, with the assistance of Federal and State resource agencies, will identify and inventory vernal pools known to be habitat for listed vernal pool crustaceans within potential CTVCP treatment areas.

b. No aerial or ground application of malathion will be made within $1 / 2$ mile of known habitat of listed vernal pool crustaceans.

6. Measures to protect the valley elderberry longhorn beetle:

a. The CTVCP will train ground-rig operators to recognize elderberry plants. Ground rigs will not spray within 100 yards of elderberry plants. Aerial operations will not spray within 100 yards of riparian areas suitable as habitat for elderberries.

b. During the time when adult beetles are active (March through June), a buffer of at least $1 / 4$ mile radius will remain untreated around known occurrences of valley elderberry longhorn beetle, as determined from the CDFG Natural Diversity Data Base or other available database sources.

7. Measures to protect the California red-legged frog:

a. In the western San Joaquin County and western Stanislaus County spring ground-rig spray area, no spraying will be done west of I-5 along Corral Hollow, or west of I-5 west of Gustine.

b. There will be no aerial spraying of malathion within one-quarter mile of habitat known to be occupied by the California red-legged frog, as determined from the CDFG Natural Diversity Data Base or other available database sources.

8. Measures to protect the giant garter snake:

An aerial or ground-rig buffer of at least 100 yards will remain untreated near aquatic or riparian areas suitable as habitat for the giant garter snake.

9. Specialty Preserves: The CTVCP recognizes "Specialty Preserves" as defined in the draft Pleasant Valley Habitat Conservation Plan (Hopkins \& Assoc. 1994). Three small areas, categorized as sand dune or stabilized sand dunes, have been identified near Coalinga within the potential CTVCP winter treatment area. These areas are known habitat or potential habitat for the San Joaquin dune beetle (Coelus gracilis), Ciervo aegelian scarab beetle (Aegialia concinna), or the red-headed sphecid wasp (Euceris ruficeps). Measures for candidate dune beetle species were stipulated within the CTVCP's previous federal Pesticide Use Permit by the Bureau, including a $1 / 4$ mile buffer around potential dune beetle habitat within which no spraying would be done. In addition to this buffer, the following measures are proposed:

a. All malathion treatments will be eliminated from within the specialty preserves. 
b. No off-road vehicle use will take place within the specialty preserves.

10. The Nature Conservancy Lands/Center for Natural Lands Management: The Nature Conservancy lands are generally dedicated to threatened and endangered species management and habitat preservation.
a. The CTVCP will not treat The Nature Conservancy lands.
b. The CTVCP will seek to establish BLH egg parasites on The Nature Conservancy lands as development of biological control agents prove effectual.

These proposed measures are considered part of the project evaluated by the Service in this biological opinion. Any change in these measures that might affect listed threatened or endangered species requires reinitiation of consultation with the Service, as set forth in the final paragraphs of this letter.

\section{Species Accounts/Environmental Baseline}

\section{San Joaquin Woolly-Threads (Lembertia congdonii)}

San Joaquin woolly-threads is an annual herb in the sunflower family (Asteraceae). It produces several white-woolly, many-branched stems up to about 10 inches long that tend to trail on the ground. It is the only species in the genus Lembertia, which is readily distinguished from Eatonella, its closest relative, by differences in growth habit, flower and seed morphology, and geographic range (Taylor 1987; SE. FR [139]:29361-29370, July 19, 1990).

Historical and Current Distribution. San Joaquin woolly-threads is endemic to the southern San Joaquin Valley and surrounding hills. Its original range extended from southern Fresno and Tulare Counties (excluding the Tulare lakebed) to Bakersfield and Cuyama Valley (Taylor 1987). Only 12 small, disjunct populations remain in the San Joaquin Valley and adjoining foothills from the vicinity of Panoche Pass to Caliente Creek, southeast of Bakersfield. Another seven populations are scattered in the Cuyama Valley and Carrizo Plain (Natural Diversity Data Base 1994; 55 FR [139]:29361-29370, July 19, 1990).

Habitat Requirements and Reasons for Decline. San Joaquin woolly-threads grows in annual grasslands with sparse cover of saltbush on alluvial fans, often in sandy soil.

Over $60 \%$ of historically known populations have been eliminated by conversion of habitat to agricultural uses. The remaining unprotected populations are threatened by agricultural land conversion, urbanization, heavy grazing (especially by sheep), oilfield development, gravel and sand extraction, ORV use, and possibly air pollution (Taylor 1987; 55 FR [139]:29361-29370, July 19,1990 ). San Joaquin woolly-threads was listed on July 19, 1990 (SS FR $29370)$.

\section{California Jewelflower (Caulanthus californicus)}

California jewelflower is an annual herb of the mustard family (Brassicaceae). Its stems are erect, up to about 1 foot tall, and produce several flowering branches. The leaves are wavy-margined and most are in a basal rosette. The flowers are translucent white with purple to green tips. Fruit, stem, and foliar hair characteristics distinguish this species from other jewelf lowers (Taylor and Davilla 1986; S5 FR [139]:29361-29370, July 19, 1990).

Historical and Current Distribution. California jewelflower is endemic to the southern San Joaquin Valley. It originally occurred throughout much of the 
Tulare Basin from Coalinga and Fresno in Fresno County to the Cuyama Valley in Santa Barbara County and Bakersfield in Kern County. Historical collections document its occurrence at 47 sites and an early collector described the plant as "abundant on the plains of the San Joaquin from Tulare southward" (Taylor and Davilla 1986; 55 FR [139]:29361-29370, July 19, 1990).

In 1990, California jewelflower was known to occur in only 10 populations, primarily in three areas: the mouth of Santa Barbara Canyon in Santa Barbara County, the southern portion of the Carrizo Plain in San Luis Obispo County, and at The Nature Conservancy's Paul Paine Preserve in Kern County (a small colony of introduced plants). Since 1990, several more populations have been discovered following wet winters (Skinner and Pavlik 1994; Natural Diversity Data Base 1993; 55 FR [139]:29361-29370, July 19, 1990).

Habitat Requirements and Reasons for Decline. California jewelflower occurs in grassland and mixed grassland-scrub habitats, often on sandy soils. All of the previously known and recently discovered populations occur in remnants of mixed native/non-native grassland habitat (Taylor and Davilla 1986; 55 FR [139]:29361-29370, July 19, 1990).

Habitat loss resulting from agricultural land conversion, increased livestock grazing and trampling associated with the development of summer water sources, oil and gas development, other human activities; and competition with aggressive non-native annual grasses probably eliminated California

jewelflower from Fresno, Kings, and Tulare Counties and reduced its range in Kern and Santa Barbara Counties. These factors continue to threaten many of the remaining populations (Taylor and Davilla 1986; S5 FR [139]:29361-29370, July 19, 1990). The California jewelflower was listed on July i9, 1990 (55 'FR 29370).

\section{Hoover's woolly-star (Eriastrum hooveri)}

Hoover's woolly-star is a small annual herb in the phlox family

(Polemoniaceae): The plant is 2-3 inches tall and has grayish, fuzzy stems, slender branches, and small white flowers about $0.25 \mathrm{inch}$ across. It is distinguished from other species of Eriastrum by flower size, relative dimensions of the petals and sepals, and stamen characteristics (55 FR [139]:29361-29370, July 19, 1990).

Historical and Current Distribution. Hoover's woolly-star was historically distributed in the Temblor Range (Kern and San Luis Obispo Counties), Cuyama Valley (San Luis Obispo and Santa Barbara Counties), and discontinuously in the San Joaquin Valley from Fresno County south, excluding the vicinity of Tulare Lake. Field surveys conducted throughout the southern San Joaquin Valley by Federal agencies and private consultants since 1992 have documented numerous occurrences of Hoover's woolly-star (BLM 1992, BLM 1994). Surveys have shown that Hoover's woolly-star populations range from the upper Cuyama Valley near Ventucopa, Santa Barbara County, northward to the Panoche Hills in San Benito County, a distance of approximately 140 miles. Hoover's

woolly-star occurs in 42 USGS 7 - minute quadrangles within Kings, Kern, San Luis Obispo, Santa Barbara, San Benito, and Fresno counties. Hoover's woolly-star occurrences primarily are located within four areas. The four areas from largest to smallest are: (1) the Kettleman Hills area, (2) the Carrizo Plain-Elkhorn Plain-Temblor Range-Caliente Mountains-Cuyama Valley-Sierra Madre Mountains area, (3) the Lokern-Elk Hills-Buena Vista Hills-Coles Levee-Maricopa-Taft area, and (4) the Antelope Plain-Lost Hills-Semitropic area. Additional, more isolated populations occur throughout the region. An intra-agency draft recovery plan has been developed for Hoover's woolly-star. Hoover's woolly-star is now known from Fresno, Kings, San Luis Obispo, and Santa Barbara Counties at scattered locations spanning a 
distance of 100 miles in the inner southern Coast Range of central California. The species is now documented from over 600 sites that cover some 2,200 acres.

Habitat Requirements and Reasons for Decline. Hoover's woolly-star grows in scrub-grassland habitats with moderate cover of saltbush. Hoover's woolly-star appears to prefer slightly sandy, sometimes silty soils that often exhibit cryptogamic crusts and is found on ridgetops, hillsides, benches, alluvial fans, and level areas at elevations from 280 to 2,770 feet. It often grows among cryptogamic soil crusts (i.e., mats of moss, lichen, and algae) that reduce competition from annual grasses (Taylor and Davilla 1986).

Hoover's woolly-star has declined mainly as a result of habitat conversion to agricultural and urban uses. An estimated $92 \%$ of known extant populations are threatened by future conversions to agricultural use, groundwater recharge basins, and oil and gas development (Taylor and Davilia 1986). Although some sites contain substantial populations $(5,000$ to 40,000 individuals), most of the remaining sites on the valley floor are at risk because they are isolated from one another, range in size from approximately 1 acre to less than 400 acres, and contain fewer than 1,000 individuals (55 FR [139]:29361-29370, July 19,1990 ). The Hoover's woolly-star was listed on July 19, 1990 (55 FR 29370).

\section{Kern Ma1low (Eremalche kernensis)}

Historical and Current Distribution. Kern mallow was first described as Eremalche kernesis (Wolf 1938). The most recent treatments (Bates 1992, 1993) assign Kern mallow the name Eremalche parryi (Greene) Greene ssp. parryi. Bates' treatment of Kern mallow, which includes both white- and purple-flowered gynodioecious plants, has not widely been accepted by the scientific community. Due to the debate within the scientific community over the newest treatment, the Service intends to undertake a status review to solicit available scientific information on which to base a determination of the appropriate taxonomic circumscription of Kern mallow. In the interim, the Service shall continue to consider the listed entity to be $E$. kernensis $C$. B. Wolf, which was the circumscription used when Kern mallow was listed in 1990. The endangered Kern mallow is a small annual herb of the mallow family 2 to 4-inches in height primarily with white flowers (USFWS 1989). The endangered Kern mallow typically develops an erect stem about 2 to 4 inches in height. The Kern mallow was first collected in Temblor Valley about 7 miles northwest of McKittrick along the Lost Hill Road in Kern County in 1937. This plant is restricted to the base of the Temblor Range in Kern County. The species ranges from the vicinity of McKittrick to near Buttonwillow within valley saltbush scrub. Kern mallow historical range includes portions of San Luis Obispo County.

Habitat Requirements and Reasons for Decline. The Kern mallow occurs on eroded hillsides and alkali flats with shadscale ranging from 100 to 1,000 meters in elevation. 0 il and gas development likely extirpated the species at the type locality, while agricultural conversion has eliminated habitat throughout most of the remainder of the species historic range. The remaining four small populations exist near active oil and gas fields or in the vicinity of transmission corridors and, thus, are highly vulnerable to extirpation. Conversion of habitat to irrigated agriculture, livestock overgrazing, exotic plant competition, telecommunication and electric line construction, and offroad vehicle activity present additional imminent threats. Kern mallow was listed on July 19, 1990 ( 55 FR 29370).

Bakersfield Cactus (Opuntia basilaris var. treleasei)

Bakersfield cactus is a succulent, spiny member of the cactus family (Cactaceae). It is a spreading perennial plant with gray-green stems that form flat pads or "joints". It has large, showy, magenta flowers that bloom 
from March through June. It is a close relative of the familiar beavertail cactus of the southern California deserts. Bakersfield cactus is a distinct member of the beavertail group that is endemic to the southern Tulare Basin in Kern County (55 FR [139]:29361-29370, July 19, 1990).

Historical and Current Distribution. Bakersfield cactus once formed extensive colonies around Bakersfield, along the bluffs of the Kern River, along the Caliente Creek drainage and nearby foothills of the Tehachapi Mountains, and south to the Tejon Hills. Its current distribution is very fragmented and much reduced, with remnant populations in five areas: the oilfields northeast of Oildale, Kern River bluffs northeast of Bakersfield, the bluffs and rolling hills west of north Caliente Creek east of Bakersfield, Comanche Point on the Tejon Ranch southeast of Arvin, and northwest of the community of Wheeler Ridge (55 FR [139]:29361-29370, July 19, 1990).

Habitat Requirements and Reasons for Decline. Bakersfield cactus occurs in grassland on bluffs, low hills, toe slopes, drainages, and flats. It prefers substrates of coarse cobble and well-drained sand. Substantial decline has resulted from urbanization, agricultural conversion (primarily for production of potatoes and cotton), oilfield development, overgrazing, dumping, sand mining, and invasion of weedy grasses (CDFG 1992). These activities plus ORV use, telecommunication and electrical line construction, and proposed flood control basins continue to threaten the remaining sites (55 FR [139]:2936129370, July 19, 1990). Agricultural conversion remains the most pervasive threat to this species. The Bakersfield cactus was listed on July 19, 1990 (55 FR 29370).

\section{San Joaquin Kit Fox (Vulpes macrotis mutica)}

Historical and Current Distribution. Prior to 1930, San Joaquin kit foxes occupied much of the San Joaquin Valley. They occurred from as far north as San Joaquin County (west side) and Stanislaus County (east side) south to Kern County. By the 1930s, however, their range had been reduced to the southern and western portions of the Central Valley (Grinnell et al. 1937).

Surveys conducted between 1969 and 1975 extended the known range of the kit fox back into portions of its historic range in the northern $S a n$ Joaquin Valley, including Contra Costa, Alameda, and San Joaquin counties (Orloff et a1. 1986). Additionally, kit foxes were found in three counties outside the originally defined historic range: Monterey, Santa Clara, and Santa Barbara (Orloff et al 1986).

The original range of the kit fox was estimated to encompass approximately 8,670 square miles, supporting between 8,670 and 12,135 adult foxes. By 1975 , an estimated 42 percent of suitable habitat had been lost to development, particularly irrigated agriculture, with the kit fox population size estimated at 7,000 individuals (USFWS $1983 ;$ CDFG 1989). Most of the range defined in 1975 still supports kit foxes (CDFG 1989), although populations are declining (CDFG 1988) and populations in the northern portion of the species' range are small and isolated (USFWS 1983).

Habitat Requirements and Reasons for Decline. San Joaquin kit foxes inhabit arid grasslands, seasonal wetlands, alkali desert scrub, and valley foothill hardwood habitats. Prior to the rapid expansion of irrigated agriculture in the San Joaquin Valley, the alkali desert scrub association was probably the species' prime habitat' (Grinnell et al. 1937).

Kit foxes are primarily nocturnal and carnivorous. Major prey includes kangaroo rats, black-tailed hares, desert cottontails, deer mice, and California ground squirrels. While kangaroo rats are a dominant prey item in the San Joaquin Valley (USFWS 1983), California ground squirrels are the most important prey item in some other portions of the kit fox's range (Balestreri 
1981; Hall 1983; O'Farrell et al. 1987; and Clifton 1989). Kit foxes apparently do not require drinking water (Egoscue 1956; Morrell 1972).

Kit fox home range sizes vary from 640 to 1,280 acres, with substantial overlap among individuals (Morrell 1972; Zoellick et al. 1987). The foxes usually inhabit areas with loose-textured soils suitable for den excavation (USFWS, 1983). Where soils make digging difficult, the foxes frequently use and modify burrows built by ground squirrels and other aigging animals (Orloff et al. 1986). Structures such as culverts, abandoned pipelines, and well casings may also be used as den sites (USFWS 1983).

San Joaquin kit foxes occupy many dens during their lifetime, and individuals will change den sites frequently in a season, especially in the summer. Morrel1 (1971) observed a family of kit fox using at least 41 different den sites over a 15 -month period. Transient dens are used throughout the year and may continue to be used until the prey base in the area is depleted or until fleas become intolerable (Egoscue 1956).

Pairs are formed during winter, with young being born in late winter and spring (Morrell 1972). Natal dens are used from December through May, with the same natal dens often used in subsequent years (USFWS 1983). The natal or pupping den entrances range from two to 18 , with an average of six, while transient dens typically have fewer openings (USFWS 1983). Natal or pupping dens are also distinguished by the presence of prey remains, scat, and extensive matted vegetation around their multiple entrances (USFWS 1983).

The San Joaquin kit fox population has declined primarily because of habitat loss to agricultural, urban, industrial, and oil and gas development in the San Joaquin Valley (USFWS 1983). In 1979 , only 6.7 percent of the native habitats in the San Joaquin Valiey south of Stanislaus County remained untilled or undeveloped (O'Farrell et al. 1981).

Berry et al. (1987) conducted studies of kit fox mortality in western Kern County from 1980 until 1986 of 270 radio-collared animals, approximately $54 \%$ were killed by predators, $11 \%$ were killed by vehicles, $4 \%$ died from causes other than predation, and $31 \%$ died from unknown causes. Natural mortality factors include predation by coyotes, red foxes, golden eagles, and feral dogs (Grinnell et al. 1937, Hall 1983), and starvation (Morrell 1975). Road kills, illegal shooting and trapping, and secondary poisoning and prey reduction from rodent control programs may be significant factors in the species' decline (USFWS 1983). The San Joaquin kit fox was listed on March 11, 1967 (32 FR 4001).

\section{Blunt-Nosed Leopard Lizard (Gambelia silus)}

Historical and Current. Distribution. The blunt-nosed leopard lizard once occurred throughout the San Joaquin Valley and surrounding plains and foothills (Montanucci 1965). Its historical range extended from San Joaquin County south to San Luis Obispo, Santa Barbara, and Ventura Counties (CDFG 1980).

Agricultural, urban, and oil and gas development has resulted in extensive losses of habitat suitable for this lizard (Chesemore 1980, Stebbins 1954). Approximately $50 \%$ of the blunt-nosed leopard lizard's historical range had been lost by the late 1950s, and O'Farrell et al. (1981) estimated that approximately $7 \%$ of the San Joaquin Valley remained as potential habitat for blunt-nosed leopard lizards. Present populations are restricted to fragmented patches of native habitats in Merced, Madera, Fresno, Kings, Tulare, Kern, San Luis Obispo, and Santa Barbara Counties.

Habitat Requirements and Reasons for Decline. Blunt-nosed leopard lizards occur from the valley floor up to 2,400 feet elevation in the surrounding 
foothills (Stebbins 1985). They inhabit sparsely vegetated grasslands, canyon floors, gently sloping hills, large washes, and alkali desert scrub habitats dominated by iodine bush, bush seepweed, and saltbush. Areas with native shrubs and from $30 \%$ to $50 \%$ bare ground provide optimum habitat for this species (Chesemore 1980).

The lizards prefer sandy soil but also occur in coarse, gravelly soil and hardpan areas (Montanucci 1965). Bare ground is preferred for courtship and escape, while shrub cover is needed for foraging and shade (USFWS 1985). Soils that have been disturbed by plowing or disking typically support small and discontinuous populations of this species, and they are often displaced from such areas (USFWS 1985).

In optimal habitats, blunt-nosed leopard lizards typically occur at low densities, reaching densities of up to only one lizard per acre (Tollestrup 1978). Higher densities of 24-50 lizards per 20 acre plot have been found on the Elkhorn Plain and Pixley National Wildlife Refuge during the period from 1989 through 1991. With the characteristic fluctuation in conditions in the San Joaquin Valley, even prime habitat will only support relatively low and variable densities of leopard lizards. Consequently, blunt-nosed leopard lizards may require large areas of habitat to sustain reproductively viable populations (Chesemore 1980).

Blunt-nosed leopard lizards are predatory: their diet includes insects and small vertebrates (Stebbins 1985). A study of scat collected on Naval Petroleum Reserves $\# 1$ and $\# 2$ in Kern County showed the 1 izards to be feeding primarily on orthopterans (grasshoppers and crickets: 54\%), non-formicine hymenopterans (bees and wasps: 18\%), and true bugs (17\%) (Kato et al. 1987). Small lizards are occasionally consumed (Montanucci 1967, Tollestrup 1979, Kato et al. 1987). During drought periods, when herbaceous production and arthropod populations (especially grasshoppers) are low, adult blunt-nosed leopard lizards spend less time above ground and may not reproduce at all (Germano et al. 1994). Kato et al. (1987) speculated that CTVCP malathion spraying may adversely impact leopard lizards in the spring through effects on their insect prey, since this is a time when the lizards' energy reserves are stressed: fat reserves are depleted from the winter dormancy, courtship and breeding are approaching, and females are producing eggs. Sustained periods of poor conditions would be expected to depress leopard lizard populations. Likewise, other factors that have the potential to affect grasshopper numbers could similarly affect leopard lizard populations.

The lizards commonly use small mammal (e.g., kangaroo rat, ground squirrel, and gopher) burrows, and, in some areas, the abundance of the lizard may be correlated with the availability of burrows (Montanucci 1965, Dorff 1981). The burrows are used for shade, escape, winter hibernation, and egg-laying. In areas where burrows are scarce, the lizards construct simple-chambered tunnels under exposed rocks or along banks of earth.

Timing of spring emergence from hibernation strongly depends on temperature, as does daily timing of activity. Individual lizards emerge from hibernation as early as late March, with most lizards active by mid-April. Courtship occurs from early May to mid-June, and egg-laying occurs from early June to mid-July. An average of two eggs are laid in a chamber excavated by the female lizards in the back of a rodent burrow. This species is most active during spring, and hibernation usually begins in October.

The timing of daily emergence is strongly temperature-dependent. Generally, there are two periods of daily activity, the morning and late afternoon. Most blunt-nosed leopard lizard surface activity takes place at air temperatures between $25^{\circ}$ and $35^{\circ} \mathrm{C}\left(77-95^{\circ} \mathrm{F}\right)$, and at soil temperatures between $30^{\circ}$ and $50^{\circ} \mathrm{C}$ $\left(86-122^{\circ} \mathrm{F}\right.$ ). Thus, on cold mornings (i.e., below $25^{\circ} \mathrm{C}$ ) the lizards may not be 
active and if afternoon air temperatures exceed about $35^{\circ} \mathrm{C}$, they may not emerge from their burrows until early evening.

Agricultural development and urbanization in the San Joaquin Valley have reduced the amount of native habitat available for blunt-nosed leopard lizards. Intensive livestock grazing may have contributed to the decline of this species by compacting soils, damaging rodent burrows, and denuding grasses and shrubs that support its prey base. ORV use and oil and gas development may degrade the habitat, and rodent-control programs that reduce the number of available small mammals reduce the availability of their burrows to the blunt-nosed leopard lizard. Montanucci (1965) suggested that agricultural pest control, especially spraying for leafhoppers, may have contributed to the decline of this species.

Habitat losses for this species are continuing. For example, the 1980 Recovery Plan (USFWS 1980a) reported 176,604 acres of priority blunt-nosed leopard lizard habitat in 1977. By 1980, the remaining priority habitat had declined to 128,530 acres, and by 1985 , habitat losses reduced that to 102,460 acres, only $40 \%$ of the habitat available in 1977 . Unpublished maps prepared by the California Energy Commission in 1991 indicated that habitat losses for this species are continuing (CEC 1991). The blunt-nosed leopard lizard was listed on March 11, 1967 ( 32 FR 4001).

\section{California red-legged frog (Rana aurora draytonii)}

The California red-legged frog is the largest native frog in the western United States (Wright and Wright 1949), ranging from 1.5 to 5.1 inches in length (Stebbins 1985). The abdomen and hind legs of adults are largely red; the back is characterized by small black flecks and larger irregular dark blotches with indistinct outlines on a brown, gray, olive, or reddish background color. Dorsal spots usually have light centers (Stebbins 1985). Dorsolateral folds are prominent on the back. Larvae (tadpoles) range from 0.6 to 3.1 inches in length, and the background color of the body is dark brown and yellow with darker spots (Storer 1925).

Historical and Current Distribution. Historically, this species was found in suitable habitat throughout the Central Valley, Sierra Nevada foothills, central California coast and coast ranges, but has been extirpated from approximately 70 percent of its former range. It exists in small, fragmented, and often threatened populations in the remainder. Within the action area, populations of the frog are known from (from north to south): Corral Hollow, Lone Tree Creek, Del Puerto Creek, Orestimba Creek, Cottonwood Creek (near San Luis Reservoir), Los Banos Creek, Ortigalita Creek (including Piedra Azul Creek), Mine Creek (Little Panoche Creek watershed), Bitterwater Creek, the Salinas River watershed, including the San Antonio River and Nacimiento River, and in the Cuyama River. Undiscovered populations of the species may exist in the project area, such as in unsurveyed drainages and ponds.

Habitat Requirements and Reasons for Decline. California red-legged frog adults prefer dense, shrubby or emergent riparian vegetation closely associated with deep ( $>0.7$ meters), still or slow moving water (Hayes and Jennings 1988, Jennings 1988). The greatest densities of California redlegged frogs are found in deep-water pools with dense stands of overhanging willows (Salix spp.) and an intermixed fringe of cattails (Typha latifolia) (Jennings 1988). Despite these preferences, California red-legged frogs are capable of surviving in and around a variety of permanent or long-lived seasonal aquatic habitats, including stock ponds and streams with little overhanging vegetation.

Well-vegetated terrestrial areas near the riparian corridor may provide important sheltering habitat for the frog during winter. California redlegged frogs sometimes estivate in small mammal burrows or in moist leaf 
litter, up to 300 feet from breeding habitat. During mid-winter rains the frogs move extensively throughout watersheds, including upland areas, and have been found up to one mile from permanent water (Mike Westphal, pers. comm., Galen Rathbun, pers. comm., Alison Willy, pers. comm.).

The California red-legged frog breeds from November through March, with earlier breeding records in southern localities (Storer 1925). Larvae undergo metamorphosis 3.5 to 7 months after hatching (Storer 1925, Wright and Wright 1949 , Jennings and Hayes 1990). The diet of both juvenile and adult California red-legged frogs is highly variable. Hayes and Tennant (1985) found invertebrates to be the most common food items, and represent nearly half the volume of prey consumed even by large adult's (Hayes and Tennant 1985).

The California red-legged frog has been extirpated from 70 percent of its former range, and is threatened throughout its remaining range by a wide variety of human impacts including urban encroachment, construction of reservoirs and water diversions, and introduction of predators and competitors (Jennings et al. 1992). Several researchers in Central California have noted the decline and eventual disappearance of California red-legged frogs once bullfrogs (Rana catesbeiana) become established at the same site (L. Hunt, in litt. 1993; S. Barry, in 1itt., 1992; S. Sweet, in litt.1993.) Bulifrogs prey on California red-legged frogs (Twedt 1993; S. Sweet, in litt. 1993) and interfere with California red-legged frog reproduction (Jennings and Hayes 1990; Twedt 1993; M. Jennings, in litt. 1993; $\mathrm{R}$. Stebbins in litt. 1993). California red-legged frog population numbers are not precisely known, although the Service estimates that populations are declining throughout the range of the sub-species.

The final rule listing the California rad-legged frog as threatened identifies recovery units--five geographic areas, each of which the Service considers vital to the conservation and recovery of the species. The CTVCP action area lies within the Central Valley Hydrographic Basin recovery unit. Only 14 drainages in the Central Valley recovery unit--one in the Sierran foothills and the rest in the western foothills of the San Joaquin Valley and--are now known to support red-legged frogs, compared to over 60 historic locality records for this basin (more than a 75 percent reduction). About $25 \%$ of the land in the action area is public, and many streams and ponds with potential habitat for California red-legged frog have not been surveyed. The California red-legged frog was listed as threatened on May 23, 1996 (61 FR 25813); the rule became effective June 24, 1996.

\section{Giant Garter Snake (Thamophis gigas)}

On October 20, 1993, the giant garter snake was listed as a threatened species (58 FR 54053). The giant garter snake is one of the largest garter snakes, reaching a total length of at least $160 \mathrm{~cm}$. Females tend to be slightly longer and stouter than males. Adult female giant garter snakes typically weigh $500-700 \mathrm{~g}$. Dorsal background coloration varies from brownish to olive with a checkered pattern of black spots, separated by a yellow dorsal stripe and two light colored lateral stripes. Background coloration, prominence of the black-checkered pattern, and the three yellow stripes are geographically and individually variable (Hansen 1980). The ventral surface is cream to olive or brown and sometimes infused with orange, especially in northern populations.

Endemic to valley floor wetlands in the Sacramento and San Joaquin valleys, the giant garter snake inhabits marshes, sloughs, ponds, small lakes, low gradient streams, and other waterways and agricuitural wetlands, such as irrigation and drainage canals and rice fields. Giant garter snakes feed on small fish, tadpoles, and frogs (Fitch 1941, Hansen 1980, Hansen 1988).

Habitat needs consist of (1) adequate water during the snake's active season 
(early-spring through mid-fall) to provide food and cover; (2) emergent, herbaceous wetland vegetation, such as cattails and bulrushes, for escape cover and foraging habitat during the active season; ( 3 ) grassy banks and openings in waterside vegetation for basking; and (4) higher elevation uplands for cover and refuge from flood waters during the snake's dormant season in the winter (Hansen 1980). Giant garter snakes are absent from larger rivers and other water bodies that support introduced populations of large, predatory fish, and from wetlands with sand, gravel, or rock substrates (Hansen 1980, Rossman and Stewart 1987, Brode 1988, Hansen 1988). Riparian woodlands do not provide suitable habitat because of excessive shade, lack of basking sites, and absence of prey populations (Hansen 1980).

The giant garter snake inhabits small mammal burrows and other soil crevices above prevailing flood elevations throughout its winter dormancy period (November to mid-March). Giant garter snakes typically select burrows with sunny aspects along south and west facing slopes. The breeding season extends through March and April, and females give birth to live young from late July through early September (Hansen and Hansen 1990). Brood size is variable, ranging from 10 to 46 young, with a mean of 23 (Hansen and Hansen 1990). Young immediately scatter into dense cover and absorb their yolk sacs, after which they begin feeding on their own. Although growth rates are variable, young typically more than double in size by one year of age (G. Hansen, pers. comm.). Sexual maturity averages three years in males and 5 years for females (G. Hansen, pers. comm.).

Fitch (1940) described the historical range of the species as extending from the vicinity of Sacramento and Contra Costa Counties southward to Buena Vista Lake, near Bakersfield in Kern County. Prior to 1970, the giant garter snake was recorded historically from 17 localities (Ha.isen and Brode 1980). Five of these localities were clustered in and around Los Banos. Merced County, and the paucity of information makes it difficult to determine precisely the species' former range. These records coincide with the historical distribution of large flood basins, fresh water marshes, and tributary streams.

A number of land use practices and other human activities currently threaten the survival of the giant garter snake throughout the remainder of its range. Although some giant garter snake populations have persisted at low levels in artificial wetlands associated with agricultural and flood control activities, many of these altered wetlands are now threatened with urban development. In addition, several cities within the current range of the giant garter snake are expanding. Rapidly expanding urban areas within or near the historic range of the giant garter snake include: Chico, Yuba City, Sacramento, Galt, Stockton, Gustine, and Los Banos.

The giant garter snake is currently known only from a small number of populations. The status of these populations and the threats to these snakes and their habitats are detailed in the final rule that listed the giant garter snake as threatened ( 58 FR 54053).

\section{Glant Rangaroo Rat (Dipodomys ingens)}

Historical and Current Distribution. Historically, the giant kangaroo rat occurred in the Tulare Basin and in the adjacent Carrizo Basin and Cuyama and Panoche Valleys. This distribution closely coincides with the distribution of marine sediment-derived solls on the southern and western edges of the San Joaquin Valley (Williams 1992). Conversion of valley grasslands to agriculture and other land uses has resulted in a $98 \%$ loss of habitats suitable for the giant kangaroo rat (Williams 1992). The species is found in less than $2 \%$ of its historical range, in small, widely scattered colonies in areas such as the Panoche and Cuyama Valleys, Carrizo and Elkhorn Plains, and the upper Buena Vista Valley in the Elk Hills (WiIliams 1980). 
Habitat Requirements and Reasons for Decline. Giant kangaroo rats prefer sparsely vegetated grasslands that are characterized by good drainage, fine sandy-loam soils, and a gentle slope of less than 10\% (Grinnell 1922). Populations are limited to areas with less than 6 inches of rain and are generally found at elevations of less than 3,000 feet (Williams 1980, 1992). Areas with halophytic vegetation, dense shrub cover, or excessively rocky or gravelly terrain are typically avoided (Williams 1980).

Giant kangaroo rat burrow systems, or precincts, are distinctive because of the size and orientation of the holes and because they clear vegetation for about 18 feet around their burrows (Williams 1980). Each precinct has an average of about seven holes, each measuring 2.5 to 3.5 inches in diameter (O'Farrell and Scrivner 1987). Other characteristics of giant kangaroo rat precincts include the tracks of their distinctively large feet and dragging tails, "haystacks" of seeds drying near the burrows, and large scat near the burrow entrances. Individual precincts are usually connected with other precincts by well-worn paths and are relatively easy to spot from a distance (Williams 1980).

These nocturnal rodents forage for seeds and sprouts and cache the seeds just below the surface of the soil; food caches are later transferred to their underground burrows. Their food-caching habits may account for the giant kangaroo rats' affinity for arid sites; if rainwater penetrated and spoiled these stores, giant kangaroo rats could lose their fall and winter food supplies. (Williams 1980.)

The species feeds almost exclusively on the seeds of annual plants, such as brome grasses and filarees. Individuals harvest, stack, and dry the grasses and forbs near the entrance of their burrows (CDFG 1992). Historically, the colonies of giant kangaroo rat precincts were so dense as to exclude all other rodent species.

Giant kangaroo rats often occupy habitats in secondary stages of succession. Williams (1992) noted that they occur in areas with heavy grazing pressure, found increased densities after fires destroyed shrublands, and observed that individuals will colonize fallow fields where there are populations nearby on uncultivated ground.

Loss of habitat to agriculture and other land-modifying actions is the primary reason for the giant kangaroo rat population decline. This decline is apparently continuing, with habitat loss still the main threat to this species (CDFG 1987). Intensive livestock grazing and the use of rodenticides may contribute to the continued decline of this species (Williams 1980). The remaining giant kangaroo rat populations are susceptible to becoming genetically isolated because of habitat fragmentation (52 FR [2]:28.3-288, January 5, 1987). The giant kangaroo rat was listed on January 5, 1987 (52 FR 288).

\section{Tipton Kangaroo Rat (Dipodomys nitratoides nitratoides)}

Historical and Current Distribution. The Tipton kangaroo rat was originally described as a subspecies of the widely distributed species Dipodomys merriami (Merriam 1884). Its taxonomy was later revised by Grinnel1 (1920, 1921) who regarded it as a subspecies of the Fresno kangaroo rat.

The Tipton kangaroo rat historically occurred in the Tulare Lake Basin, from Lemoore and Hanford in Kings County to Tipton and Bakersfield on the east, and to the edge of the alkali desert scrub on the west (Uptain 1990; Williams $1985,1986)$. The historical range of this subspecies encompassed approximateiy $1,716,500$ acres (53 FR [131] :25608-25611, July 8, 1988). 
In 1985 , it was estimated that less than $4 \%(63,367$ acres $)$ of the Tipton kangaroo rat's habitat remained undeveloped, primarily in small blocks that were not large enough to support viable populations (Williams 1985).

Presently, only 1\% of the historical population may survive (CDFG 1992). Approximately 6,434 acres of remaining suitable habitat are preserved in five separate parcels (Williams 1986, CDFG 1992). These areas include the federally administered Pixley National Wildlife Refuge, the state-owned Allensworth Ecological Preserve, and TNC's Paine Wildflower Preserve.

Habitat Requirements and Reasons for Decline. The Tipton kangaroo rat occurs in valley saltbush scrub and valley sink scrub habitats between the 200 and 300 foot elevations in the Tulare Lake Basin (Williams 1985, 1986; CDFG 1992). Areas with friable soils are their preferred substrates to excavate shallow burrow systems. These systems are typically located on slightly elevated mounds, such as alluvial fans, or around the bases of shrubs, where winddeposited soils have accumulated. The Tipton Kangaroo rat's use of elevated sites for burrowing reduces the possibility of drowning during seasonal flooding.

Tipton kangaroo rats feed primarily on seeds and has an important role in seed dispersal; for this reason, it can influence the local distribution of its food plants (53 FR [131]:25608-25611, July 8, 1988). This subspecies is preyed upon by carnivores such as American badgers, coyotes, and San Joaquin kit foxes (a species federally and state listed as endangered). The Tipton kangaroo rat's burrow systems provide refuge to other animals, including blunt-nosed leopard lizards, and also serve to aerate soils and increase vegetative productivity (53 FR [131]:25608-25611, July 8, 1988).

Conversion of native habitats to agricultural production is considered the primary reason for the Tipton kangaroo rat's population decline (53 FR [131]:25608-25611, July 8, 1988). Construction of canals, roads, highways, railroads, and buildings and the use of rodenticides have probably also accelerated this subspecies' population decline. Because of the small, isolated nature of many remaining populations, their lack of genetic diversity, and limited dispersal, Tipton kangaroo rats are especially vulnerable to extinction from random environmental events such as flooding or unpredictable land use changes. The Tipton kangaroo rat was listed on July 8 , 1988 ( 53 FR 25611).

\section{Aleutian Canada Goose (Branta canadensis leucopareia)}

Historical and Current Distribution. Historically, Aleutian Canada geese wintered from British Columbia to California and northwestern Mexico (Delacour 1954). Although they occurred throughout California, the greatest concentrations were found in the Sacramento and San Joaquin Valleys (Grinnell and Miller 1944).

The subspecies nested throughout the Aleutian Islands and into Russia (Springer 1977). Predation by introduced arctic foxes eliminated most breeding colonies of the Aleutian Canada goose, and by 1962 the subspecies was nearly extinct, with only one breeding colony remaining on the tiny island of Buldir. This island was one of the few to escape the introduction of arctic foxes (USFWS 1982). In 1982, a new or remnant breeding population of Aleutian Canada geese of unknown size was discovered on Chagulak Island in the Islands of the Four Mountains (USFWS 1982).

The present population of Aleutian Canada geese migrates along the northern California coast and winters in the Central Valley near Colusa, and on scattered feeding and roosting sites along the San Joaquin River from Modesto to Los Banos (Jones \& Stokes Associates and CH2M Hill 1986, Nelson et al. 1984). Fall migration usually begins in late August or early September, with birds arriving in the Central valley between October and early November (USFWS 
1980b). Spring migration usually occurs from mid-February to early March (USFWS 1980b).

Habitat Requirements and Reasons for Decline. Aleutian Canada geese forage in harvested corn fields, newly planted or grazed pastures, or other agricultural fields (e.g., rice stubble and green barley). Lakes, reservoirs, ponds, large marshes, and flooded fields are used for roosting and loafing (Grinnell' and Miller 1944, USFWS 1982).

Predation by introduced arctic foxes on the breeding islands is the primary reason for the population decline (Yparraguirre pers. comm.). Avian cholera is currently a major threat to the concentrations of Aleutian Canada geese in the Central valley. This subspecies is particularly vulnerable to cholera outbreaks because most of the population overwinters in a small geographical area. Sport hunting on its wintering grounds in California and by natives on the nesting grounds also contributed to the species' decline (USFWS 1982). The Aleutian Canada goose was listed on March 11, 1967 (32 FR 4001).

\section{Valley Elderberry Longhorn Beetle (Desmocerus californicus dimorphus)}

Historical and Current Distribution. Little is known about the valley elderberry longhorn beetle's historical distribution. Based on museum specimens and survey data, the Service considers the Central Valley hydrographic basin, to an elevation of $3000 \mathrm{feet}$, to be the historical range of the beetle.

Extensive destruction of California's Central Valley riparian habitats has occurred during the last 150 years (Katibah 1984, Katibah et al. 1984, Smith 1977. Thompson 1961). Based on a 1979 aerial survey, only about 102,000 acres out of an estimated 922,000 acres of Central valley riparian forest remain (Katibah et al. 1981). The range of the beetle is still quite broad, but its remaining popuiations are few, disjunct, and scattered (Barr 1991). The beetle also occurs in upland habitats where elderberries are found, though apparently less abundantly, and loss of non-riparian habitat has further reduced the beetle's range and fragmented its habitat. Undiscovered populations of the beetle may exist in the project area, notably in unsurveyed drainages of the western foothills of the Central valley.

Habitat Requirements and Reasons for Decline. The valley elderberry longhorn beetle is dependent on its host plant, elderberry shrubs (Sambucus species), which are a common component of remaining riparian vegetation throughout the Central Valley. The beetle itself, a wood borer, is rarely observed. Frequently, the only evidence of the beetle are exit holes in larger elderberry'stems. The Valley Elderberry Longhorn Beetle Recovery Plan (USFWS 1984) and Barr (1991) contain further details on the beetle's life history.

Loss of habitat and the resulting decline of the beetle have primarily been due to agricultural and urban development in the Central valley. Widespread pesticide use could also be implicated.

The valley elderberry longhorn beetle was federally listed as a threatened species on August 8, 1980 (45 FR 52803).

Vernal Pool Fairy Shrimp (Branchinecta lynchi), Longhorn Fairy Shrimp ( $B$. longiantenna), and Vernal Pool Tadpole Shrimp (Lepidurus packardi)

Descriptions of the vernal pool fairy shrimp, the longhorn fairy shrimp, and the vernal pool tadpole shrimp are given in 59 FR 48136, the publication of the final rule listing these species. These freshwater crustaceans are restricted to vernal pools and swales and other seasonal aquatic habitats in California. When their habitats fill with water during California's winter rains, and when specific environmental conditions are right, these species 
emerge and develop rapidly to adulthood. Eventually these seasonal wetlands dry up, and fairy and tadpole shrimp survive the long dry season as resting eggs, or cysts, in the dried mud at the bottom of the pools. Eng et al. (1990) and Simovich et al. (1992) provide further details on the life history and ecology of these three species.

Historical and Current Distribution. There are approximately 50 known locations of pools occupied by Branchinecta lynchi, extending from Stillwater Plain in Shasta County through most of the length of the Central Valley to Pixley in Tulare County, and along the central Coast Range from northern Solano County to Pinnacles National Monument in San Benito County. Four additional, disjunct populations exist: one near Soda Lake in San Luis Obispo County, one in the mountain grasslands of northern Santa Barbara County, one on the Santa Rosa Plateau in Riverside County, and one near Rancho California in Riverside County. The vernal pool tadpole shrimp, Lepidurus packardi, is known from about 20 populations, in the Central Valley from east of Redding in Shasta County south to the Sequoia Airfield in Tulare County, and a vernal pool complex on and around the San Francisco Bay National Wildidfe Refuge in Fremont, Alameda County. The longhorn fairy shrimp is known from fewer than 10 locations, including sites in Alameda and Contra Costa counties, the Kesterson-Los Banos complex in Merced County, and the Carrizo Plain in San Luis Obispo County.

The historical distribution of these three species is unknown, but is presumed to include areas of the Central Valley and valleys of the Coast Range on suitable soils that have since been altered, primarily for agriculture and urban uses ((Holland and Jain 1988, USFWS 1994).

Habitat Requirements and Reasons for Decline. The vernal pool fairy shrimp, Branchinecta lynchi, inhabits vernal pools with tea-colored water, most commonly in grass or mud bottomed swales, or basalt flow depression pools in unplowed grasslands. Adults of $B$. Iynchi have been collected from early December to late May. The vernal pool tadpole shrimp, Lepidurus packardi, requires at least four weeks to develop from egg to adult, and inhabits moderately long-lived vernal pools. These pools contain clear to highly turbid water, and range in size from 54 square feet in the Mather Air Force Base area of Sacramento County to the 89 acre Olcott Lake at Jepson Prairie in Solano County. The longhorn fairy shrimp, $B$. Iongiantenna, has been found in pools ranging from shallow, short-lived pools in rock outcrops of the Coast Ranges to large pools at the Kesterson wildlife Refuge, Merced County, and the Carrizo Plain, San Luis Obispo County.

The vernal pool fairy shrimp, longhorn fairy shrimp, and the vernal pool tadpole shrimp are imperiled by habitat loss caused by a variety of human activities, primarily urban development, water supply and flood control projects, and conversion of land to agricultural use. Only a small fraction of the habitat of these crustaceans is protected from these threats. Holland estimated that between 60 and 85 per cent of the habitat that once supported vernal pools had been destroyed by 1973 (USFWS 1994). In the ensuing twentyone years, a substantial amount of remaining habitat has been converted for human uses. The rate of loss of vernal pool habitat in the state has been estimated at two to three per cent per year (Holland and Jain 1988). The Sacramento District of the U. S. Army Corps of Engineers has severai thousand vernal pools under its jurisdiction (Coe 1988), including most of the known populations of the vernal pool fairy shrimp. It is estimated that within 20 years, 60 to 70 per cent of these will be destroyed by human activities (Coe 1988).

\section{Effects of the Action}

Malathion is a broad-spectrum, organophosphate insecticide and acaricide that acts through acetylcholinesterase inhibition (Cornacchia 1984). It shows 
little or no tendency to bioaccumulate (Culley and Applegate 1967, Metcalf 1972, Cornacchia 1984), and degrades relatively rapidly under most environmental conditions. Half lives from 0.1 to 10 days are commonly reported, and half lives decrease by a factor of about 3 with each unit increase in $\mathrm{pH}$ over 4.5 (see Figure 2 of Cornacchia 1984). Miles (1991) reported that the half-life of malathion in river, ground, and seawater is 4.7 \pm 0.7 days. The CTVCP has found that their malathion applications continue to have some effect against beet leafhopper for 3-4 days (fax dated August 27 , 1996).

Soils in the project area are generally neutral to mildly alkaline (pH 6.68.4 ), and low in organic matter (less than $1 \%$ ) that could bind malathion (USDA-SCS Soil Survey data). In the absence of site-specific data on water chemistry, the Service anticipates that surface waters in the winter and spring aerial spraying areas will be near neutral in $\mathrm{pH}$.

Malathion (and its degradation product malaoxon) is highly toxic to aquatic arthropods and gill-bearing vertebrates (fish, amphibian larvae) (USEPA 1975). Half of stonefly nymphs are reported to die at concentrations from 7 to 50 $\mathrm{ug} / \mathrm{L}$ (-ppb) (Muirhead-Thomson 1987). Concentrations as low as $35 \mathrm{ug} / \mathrm{L}$ are lethal to bay shrimp and aquatic insects (Cornacchia 1984). Bookhout and Costlow (1976) found that the development of 2 species of crab larvae was adversely affected at concentrations from 11 to $110 \mathrm{ug} / \mathrm{L}$, showing longer development times and morphological abnormalities. Lockhart and Metner (1987; reported in Zinkl et al. 1991) observed mortality and low cholinesterase activities in northern pike following a heavy rainfall event that apparently washed malathion from trees on the bank into a river. The California Department of Fish and Game has recommended an acute criterion of $3.54 \mathrm{ug} / \mathrm{L}$ for malathion in freshwaters (Finlayson 1982, cited in Segawa et al. 1991).

Applied directly to water $1 \mathrm{dm}$ (decimeter: 4 inches) deep, the CTVCP malathion application rate $\left(65 \mathrm{mg} / \mathrm{m}^{2}\right)$ would produce a concentration of $650 \mathrm{ug} / \mathrm{L}$ ( $\mathrm{ppb}$ ). Application directly to water $1 \mathrm{~m}$ deep ( 39 inches) would produce a concentration of $65 \mathrm{ug} / \mathrm{L}$. The CTVCP takes precautions to prevent applications directly to water, but some off-target drift of malathion can be expected. Deposition from drift generally declines exponentially with distance from the source, but is strongly dependent on wind speed. Studies of pesticide drift indicate that, in most cases, aerial applications under conditions similar to those proposed for the CTVCP can be expected to result in concentrations from $0.1-7.3 \%$ of the target application rate being deposited at a distance of 100 yards from the application area (median value $0.4 \%$ ) (Akesson \& Yates 1964, Maybank et al. 1978, Ware et al. 1984, Riley et al. 1989). This would result in concentrations of malathion from CTVCP spraying from $0.5-37$ ug/L (median 2 $\mathrm{ug} / \mathrm{L}$ ) in water 1 dm deep. Limited data from ground rig applications show deposited concentrations from $0.1-2.1 \%$ of the target application rate at 100 yards from the application area (Akesson \& Yates 1964, Maybank et al. 1978, Payne et al. 1988), which would result in concentrations of malathion from 0.5-11 ug/L in water $1 \mathrm{dm}$ deep. Concentrations on the higher sides of these ranges would be toxic to significant numbers of aquatic arthropods, and could approach acute toxicity for sensitive species of gill-bearing vertebrates.

The potential of malathion to contaminate runoff is moderate to high if rainfall occurs near the time of application. Malathion has an organic carbon partition coefficient, $K_{O C}$, equal to 1800 (Miles 1991), an intermediate value, and a solubility of $145 \mathrm{mg} / \mathrm{L}$ (Bowman \& Sans 1983), a low value in absolute terms but high relative to concentrations that are toxic to aquatic life. $k_{O C}$ values of various chemicals range from 1 to $10,000,000$ : the higher the $k_{\infty C}$ the greater the tendency of the compound to adhere to organic matter in soil, and the lower the $K_{\infty c}$ the greater its potential to be washed out in runoff. Miles (1991) states, with respect to malathion, "Surface water contamination is likely, however, since runoff may release sorbed malathion". In an extensive review of pesticide runoff experiments, Wauchope (1978) Iisted 
results showing maximum observed runoff concentrations of up to or exceeding $1000 \mathrm{ug} / \mathrm{L}$ for low-solubility pesticides (solubilities $<250 \mathrm{mg} / \mathrm{L}$; malathion was not studied). Wauchope catalogued losses up to or exceeding $20 x$ of the total amount applied in single "catastrophic" storm events, but the highest concentrations in runoff came in smaller rains shortly after pesticide application. A calculation by the Service, assuming $10 \%$ of a watershed sprayed, followed within a day or two by a storm producing $1 \mathrm{~cm}$ of runoff $(0.4$ in) carrying malathion equal to $10 \%$ of the amount sprayed, indicated that CTVCP activities have the potential to result in localized, temporary concentrations of approximately $65 \mathrm{ug} / \mathrm{L}$ of malathion in runoff. Such concentrations would be acutely toxic to many aquatic arthropods and some gill-breathing vertebrates. Runoff coming directly from sprayed areas, before mixing with uncontaminated runoff, would have concentrations as high as 650 $\mathrm{ug} / \mathrm{L}\left(6.5 \mathrm{mg}\right.$ of malathion in $10 \mathrm{~L}$ of runoff per $\left.\mathrm{m}^{2}\right)$.

When spraying either closely preceded or closely followed rain, monitoring of surface waters in the San Diego, Los Angeles, and San Francisco medfly control areas has repeatedly found levels of malathion in runoff that are potentially toxic to aquatic life (Oshima et al. 1982, Cornacchia 1984, Segawa et al. 1991, Turner et al. 1991). High concentrations of both malathion and the more toxic malaoxon were found (up to and exceeding $1000 \mathrm{ug} / \mathrm{L}$ ), and fish kills were observed on occasion. Turner et al. (1991) report finding a concentration of $80 \mathrm{ug} / \mathrm{L}$ of malathion in runoff collected a mile from the treated area five days after an application. Cornacchia (1984) concluded that "Aerial

applications of malathion during the rainy season pose a significant hazard to water quality and aquatic life;" and "... Secondary effects may include temporary reduction of microcrustaceans and aquatic insects, a food source...." Risks of contamination of runoff by CTVCP spraying are reduced by their runoff prevention protocols, single spray events mostly in spring and fall (less exposure to a potential storm event), and by the buffers. provided around surface waters.

Among terrestrial insects, hymenopterans (bees, wasps and ants) and orthopterans (grasshoppers, crickets) are known to be especially sensitive to malathion. The toxicity of malathion to plants and terrestrial vertebrates is generally low (USEPA 1975, BLM \& DOE 1995).

\section{Plants}

Listed plant species which may be affected by CTVCP treatments include California jewelflower, Kern mallow, San Joaquin woolly-threads, Bakersfield cactus, and Hoover's woolly-star.

\section{Phytotoxicity:}

Malathion is registered for use on a wide variety of vegetation and crops. When used properly at appropriate concentrations, malathion does not appear to injure vegetation. Malathion is not generally phytotoxic. No phytotoxicity was observed in a forest watershed after several treatments of malathion at 0.72 lb./acre (Giles 1970). In the proposed action malathion would be applied at $0.46 \mathrm{lb}$./acre.

\section{Indirect Effects Caused by Decline of Pollinators:}

If the populations of insect pollinators (e.g., bees, flies, and beetles) are reduced as a result of the use of malathion, propagation of plants within the treatment area could be affected for a short period of time. Insects of certain orders are more susceptible to malathion than others. Honeybees and other hymenopterans (ants, wasps, bees, etc.) are particularly susceptible to malathion exposure (Dobroski and Lambert 1984). Populations of flies--except mosquitos--and beetles were found not to be affected by low volumes of malathion (Hill 1971). 
The depression of social insects may be temporary because foraging honeybees and ants could re-enter from adjacent, non-treated areas. Honeybee and ant workers could be replenished from colonies outside the treatment area, and ant colonies from underground where the queen, brood, and some workers would be protected. The CTVCP takes steps to avoid and protect managed honeybee colonies (honeybee notification policy, page 18 of the joint EA). Bumblebees also establish colonies, often underground, and are faithful to their nest sites once established, rarely foraging more than few kilometers away. Most bumblebee workers are foragers (D. Wright, pers. observ.), and malathion spraying would result locally in substantially reduced bumblebee visitation for several weeks, until surviving colonies or queens newly emerging from hibernation could rear new brood.

Solitary bees and wasps are not members of colonies, and foraging adults would not be replenished easily. Solitary bees usually forage within a few tens or hundreds of yards from a central burrow or nest where they stock larval cells, and are faithful to this site. Many solitary bee species are narrow in their visitation of flower species and seasonal in their life cycles. Malathion spraying could substantially reduce local pollination and seed set of plants pollinated primarily by solitary bees or wasps, subject to the following risk factors:

1. The pollinator population is seasonal, and abundant during spraying

2. The contiguous area sprayed is larger than the typical foraging area of an individual pollinator

3. Annual plants would be especially at risk

Little is known about the pollination strategies of many plant species of special concern. Of concern to the Service are the potential impacts to listed plant species exclusively dependent on insect pollinators to set seed, including species pollinated by solitary bees and wasps, and the California jewelflower and Kern mallow (pollinated by bumblebees: Ellen Cypher, pers. comm., March 8, 1996). Death of these pollinators, which are site-faithful and forage within a limited range, could significantly affect the plants' ability to produce seed. The survival of an isolated population of plants could be threatened if a single year's seed production was eliminated.

Pollination exclusion experiments were performed on San Joaquin woolly-threads and California jewelflower (Mazer \& Hendrickson 1993). California jewelflower was found to be dependent on insect pollinators for seed production. Although San Joaquin woolly-threads was found to have the ability to set seed in the absence of pollinators, it is not known what proportion of outcrossing occurs, or the importance of outcrossing to San Joaquin woolly-thread's long-term survival. In the absence of pollinator exclusion studies for other plant species of concern, the indirect affects of malathion would be a combination of the following factors:

1. Was the plant or immediate area treated by CTVCP?

2. Mode of pollination for each species (wind, insect, self-pollinated);

3. Variety and quantity of insects utilized in pollination;

4. Foraging range of plant pollinators;

5. Time of year plant species bloom;

6. Duration of bloom period;

7. Persistence of seed bed within the environment; 
8. Time of year CTVCP treatment occurs; and

9. Repetition of treatments between years, after the bloom period, after pollination has been completed.

Timing of malathion application:

Malathion is not applied in areas with extant populations of the California jewelflower, Bakersfield cactus, and Kern mallow during the flowering period. Maps prepared by the CTVCP are used to determine the known locations of extant populations of these 3 plants prior to spring treatments. Maps prepared by the DOE contractor are consulted to determine the extant locations of these 3 listed plants on Naval Petroleum Reserve land. The CTVCP annually consults plant maps prepared by the CDFG, DOE, and the Bureau to update known plant locations. Pollination and seed production in California jewelflower. Bakersfield cactus, and Kern mallow populations would continue to occur because malathion is not applied during the flowering period.

The Bureau notified the Department by letter dated March 30, 1993 (join EA Appendix (), that recent data indicated Hoover's woolly-star to be much more widespread than originally believed. After discussions with USFWS, the Bureau concluded that avoiding treatment of areas occupied by the Hoover's woollystar is no longer a reasonable or necessary conservation measure. The Bureau modified Federal Pesticide Use Permit 91-CA-93-0001, withdrawing Hoover's woolly-star from the list of plants to be avoided by CTVCP during the bloom period.

\section{Animals}

\section{San Joaquin kit fox}

Impacts from direct dermal exposure of malathion to San Joaquin kit fox populations are expected to be negligible (BLM \& DOE 1995: "joint EA"). For the most part, the kit fox is nocturnal and CTVCP treatment operations are performed during daylight hours in the San Joaquin Valley. Some kit foxes could be sprayed during dawn hours, and during the spring pup-rearing season, adults and pups are sometimes active aboveground during daylight hours. Nevertheless, adverse effects to sprayed individuals are unlikely due to the low concentration of malathion $\left(65 \mathrm{mg} / \mathrm{m}^{2}\right)$ relative to mammalian toxicity. Acute LD50's for domestic dog range from about $500 \mathrm{mg} / \mathrm{kg}$ for intravenous injection to $1400 \mathrm{mg} / \mathrm{kg}$ orally (USEPA 1975)

Significant exposure of San Joaguin kit fox to malathion through the food chain would be unlikely. The kit fox eats a variety of lagomorphs, rodents, lizards and insects. There is no evidence that bio-magnification of malathion in food chains occurs. Malathion is not accumulated in body fat (Metcalf 1972) and was not found in various tissue samples of various animals after seven low-volume, high concentration sprays (Culley and Applegate 1967).

Although kit foxes use vertebrates for a majority of their food, invertebrates are frequently eaten. In the face of reductions of vertebrate prey in the San Joaquin Valley and the Carizzo Plain by drought or other causes, further reduction of invertebrate food sources could affect the survival and recovery of the kit fox. Indirect effects of CTVCP treatments to kit fox vertebrate and invertebrate food bases are expected to be temporary due to the rapid degradation of malathion, the mobility of both kit foxes and grasshoppers, and the relatively limited area of spraying operations. It is anticipated that, in most cases, a spraying operation would only cover a portion of the home ranges of most of the kit foxes in the area. 
CTVCP operations could directly affect San Joaquin kit foxes through the destruction of den sites during ground monitoring surveys and ground spray applications (USFWS 1991b). However, CTVCP vehicles are restricted to existing roads, and potential den sites are avoided during ground survey activities (page 24, joint EA). Project vehicles may strike and injure or kill kit foxes while driving on public or private roads. Some harrassment of foxes still active during CTVCP operating hours is expected due to passing vehicles, either trucks or aircraft, or by ground personnel unaware of their presence.

\section{Giant kangaroo rat}

Giant kangaroo rats are predominantly nocturnal, but they may be sprayed directly if CTVCP applications occur in their habitat during pre-dawn hours (USFWS 1991b). CTVCP treatments rarely begin earlier than 30 to 45 minutes before sunrise, leaving little pre-dawn treatment time.

Impacts from dermal exposure of giant kangaroo rats to malathion are expected to be minimal. Malathion applications would generally have sufficient time to dry before giant kangaroo rats, foraging the following night, contact treated vegetation or soils. Negligible dermal exposure to giant kangaroo rats is anticipated from treated vegetation carried in fur-lined cheek pouches.

The dermal LDSO of malathion in laboratory rats is near $4,000 \mathrm{mg} / \mathrm{kg}$ (Spiller 1961). If the dermal LD50 for giant kangaroo rats ( $D$ ipodomys) is assumed to be one-tenth that of laboratory rats (Rattus), the dermal LD50 would still be high relative to the CTVCP application rate of $65 \mathrm{mg} / \mathrm{m}^{2}$.

Potential oral exposure of giant kangaroo rats to malathion can be separated into two pathways: from dry-tooth grooming of fur, and from ingestion of sprayed vegetation such as peppergrass and red stem filaree (USFWS 1991b). At the proposed rate of application and given that oral toxicity of malathion to most rodents tested is of the order of several hundred to low thousands of $\mathrm{mg} / \mathrm{kg}$ (USEPA 1975), toxic oral exposure of giant kangaroo rats to malathion from CTVCP spraying is unlikely by either pathway.

The U.S. Fish and Wildlife Service (USFWS 1991b) highlighted the difference in physiology and environmental stresses between laboratory rats and wildlife, and cited a 1967 study suggesting that ingestion rates as $10 \mathrm{w}$ as $0.191 \mathrm{mg} / \mathrm{kg}$ over a 10-day period could produce spontaneous abortions in laboratory rats. Based on a ten-fold safely factor, the Service concluded that kangaroo rats could ingest sufficient quantities of malathion to cause spontaneous abortions (USFWS 1991b). This conclusion was subsequently re-evaluated: in a memo to the Bureau dated November 8,1993 (file 1-1-91-F-6(R), reproduced in joint EA Appendix $C$ ), the Service concluded "Sole use of the malathion toxicity data generated by the Dobbins's (1967) study to calculate a risk assessment for kangaroo rats is not advisable. Other data generated in a more acceptable study did not indicate malathion caused reproductive effects in rats, and limited comparative toxicity data indicates kangaroo rats are not more sensitive than laboratory rats to another OP compound (methyl parathion)." Therefore, the reduction of kangaroo rat populations from malathion-induced reproductive effects is considered unlikely by the Service.

Potential indirect impacts on seed producing plants utilized by giant kangaroo rats from CTVCP treatments may result from the reduction of insect pollinators. Effects on insect pollinators were previously discussed under "Effects of the Action," "Plants," above.

CTVCP vehicles could crush giant kangaroo rat food plants and burrow systems. However, CTVCP vehicles are restricted to existing roads in giant kangaroo rat habitat, reducing the potential for such impacts. Project vehicles may strike and injure or kill kangaroo rats while driving on public or private roads, 
especially since kangaroo rats are apparently attracted to the open space provided by roads. Vehicular strikes would be most likely at dusk or dawn. Some harrassment of kangaroo rats still active during CTVCP operating hours is expected due to passing vehicles, either trucks or aircraft, or ground personnel.

\section{Tipton kangaroo rat}

It is expected that impacts to the Tipton kangaroo rat due to CTVCP activities would be similar to impacts to the giant kangaroo rat.

\section{Aleutian Canada goose}

Most cultivated fallow fields range from one to twenty acres and are usually located at the ends or corners of fields. Ground applications to small cultivated fallow fields are rare as indicated on page 11 of the joint EA. Potential exposure of Aleutian Canada geese (ACG) to malathion would be most likely where roadside application occurs.

Ingestion of malathion-contaminated grain by ACG would depend on a combination of the conditions listed below. Potentially toxic exposure to malathion would occur only under a combination of rare circumstances.

1. Very early fall or late spring migrations of geese.

2 A very early spring or extremely late fall ground-rig treatment.

3. A year in which ground-rig treatments were necessary.

4. A goose foraging within leafhopper host plants on roadsides or ditch banks rather than in the interior of the field.

5. Quantity of roadsides treated or number of gallons applied.

6. Length of time between the application and the consumption of the grain (malathion has a short half life).

7. Quantity and rate of ingestion of contaminated food.

\section{Blunt-nosed leopard lizard}

Seasonal fluctuations of blunt-nosed leopard lizard (BNLL) activity are expected to reduce the impact of CTVCP operations to BNLL populations during the winter and fall treatments in the San Joaquin Valley. A graph of BNLL seasonal activity (Montanucci 1965) shows no BNLL activity during the months of January and February. During the month of October, a small percentage of sub-adults comprise most of the activity. The greatest potential for impacts to BNLL would be expected from spring treatment activities.

No information is available on the acute effects of malathion on BNLL; therefore, the limited toxicological information on species other than BNLL was examined. The acute oral LD50 of malathion for Anolis carolinensis, a lizard in the same family as BNLL (Iguanidae), is over $2,000 \mathrm{mg} / \mathrm{kg}$ (Hali and Clark 1982). Even if the LD50 of malathion to BNLL is assumed to be one tenth of this dose, it is unlikely that CTVCP spraying, at $65 \mathrm{mg} / \mathrm{m}^{2}$, would result in substantial acute dermal or oral toxicity to BNLL. No information is available on sublethal effects, such as on reproduction, development, or behavior. However, opportunities for malathion exposure would be further limited when spring CTVCP treatments are performed at temperatures below the BNLL activity threshold of $77^{\circ} \mathrm{F}$. Cool weather often accompanies spring treatment activities in late March or early April, and treatments are 
generally performed during the coolest portion of daylight hours: from $30-40$ minutes before sunrise until 1:00 p.m.

Previous biological opinions focused on the reduction of insect prey species utilized by BNLL. Grasshoppers and crickets make up approximately 50-75\% of the BNLL diet, and bees and wasps also make up a sizeable fraction. Both orthopterans and hymenopterans tend to be especially sensitive to malathion. Spring reduction of insect prey species would take place during a time when the lizards' fat reserves are low and food availability is important (USFWS 1991b). Spraying large areas or during periods when insect abundance is naturally low (such as during drought) may adversely affect BNLL survival in the areas sprayed (USFWS 1991b).

Even though many grasshoppers and other insects will re-enter sprayed areas shortly after treatment, a general reduction in insect density in the area can be expected for a period ranging from a few days to a few weeks. Spring and early summer migratory movements of grasshoppers and other insect prey species due to the maturing and drying of rangeland vegetation could obscure this effect in some locations and years.

Since at least 1985 , the Service has been seeking more information about CTVCP effects on BNLL or their prey. Our 1985 biological opinion on the program (file 非-1-85-F-38) stated that "Investigations of indirect effects of malathion spraying for beet leafhopper control on BNLL populations are necessary for management of the beet leafhopper program in compliance with State and Federal endangered species legislation" (p. 9), and provided a conservation recommendation that the Bureau should require CDFA to study the level of indirect effects of malathion spraying for beet leafhopper control on BNLL populations ( $p .13$ ). Such an effort was begun but encountered setbacks due to severe drought. In the Proposed Action section of our 1991 biological

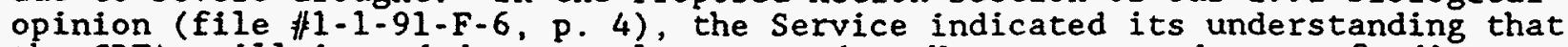
the CDFA still intended to complete a study. However, no adequate funding was arranged, and no reliable study of program effects on either BNLL or their prey has been reported to the Service. This lack of information seriously limits our ability to evaluate the nature and trend of the population baseline for the lizard, as well as whether continued CTVCP activities might jeopardize the species. The Service will continue to insist on this information under the provisions of 50 CFR $402.14(\mathrm{k})(3)$, which governs incremental consultations on ongoing projects. This information is needed for any future consultation on the program.

In the current proposal, the potential impacts of the CTVCP on the prey base of BNLL are somewhat moderated by the measures adopted to minimize impacts (Proposed Action section, above), and by the relatively quick degradation of malathion in the environment. However, the present proposal represents an increase of spray operations over CTVCP activities in the recent past in BNLL habitat not designated as conservation areas. For the period 1991-1995, in this habitat, CTVCP spraying was limited to 50x coverage, one, spraying per year, and spot applications not exceeding 20 acres (CDFA 1991, p. 16). Some populations of the lizard outside of the designated conservation areas could be adversely affected even by slight reductions in rates of survival or reproductive success resulting from increased impacts to their prey base.

Only minor effects of CTVCP operations on BNLL burrows and habitat vegetation are expected, due to the restricted use of vehicles and the limited phytotoxic effects of malathion. Project vehicles may strike and injure or kill BNLL while driving on pubiic or private roads, especially during fall and spring periods of warmer temperatures. Some minor harassment of lizards from passing vehicles or ground personnel is expected. 


\section{Giant garter snake}

Risk of direct oral or dermal toxicity of CTVCP malathion spraying to giant garter snakes is likely to be very slight. Effects on prey base are unlikely, but could occur if malathion contamination of surface waters occurs and results in prey mortality. Restriction of CTVCP vehicles to existing roads should protect giant garter snake hibernacula (hibernation burrows) and basking snakes. Project vehicles may strike and injure or kill giant garter snakes while driving on public or private roads, especially during spring periods of warmer temperatures. Some harassment of snakes from passing vehicles is possible but insignificant.

\section{California red-legged frog}

The June 14, 1989 Nationwide Biological Opinion provided to the EPA on registration of malathion (and other pesticides: file FWS/EHC/BFA/EPA-9-89-1) determined jeopardy for 3 of 3 species of toads, 3 of 3 salamanders, and 4 of 10 crustaceans. No conference opinion on California red-legged frog was provided. The reasonable and prudent alternative action for the Houston and Wyoming toads was: "prohibit use of the chemical within 100 yards of occupied habitat for ground applications and $1 / 4$ mile for aerial application." For the Puerto Rican crested toad, there was an alternative that restricted malathion use after periods of heavy rain (when breeding pools are full). Reasonable and prudent alternatives for salamanders ranged from 20-100 yard buffers for ground application and 100 yard to $1 / 4$ mile buffers for aerial, a 1 mile buffer for ultra-low volume (ULV) applications, and a $1 / 2$ mile upstream buffer. This nationwide biological opinion is in the process of being amended to cover the California red-legged frog.

No data are available on the toxicity of malathion to the red-legged frog, but malathion in water poses a serious threat to tadpoles of related species. Chorus frog tadpoles (Pseudacris triseriata) showed $50 \%$ mortality in response to malathion at concentrations of $560 \mathrm{ug} / \mathrm{L}$, with 24 hour exposure, or 200 ug/L, at $96 \mathrm{~h}$ exposure (Devillers \& Exbrayat 1992). For tadpoles of a toad (Bufo woodhousei fowleri), LC50's were higher: $1900 \mathrm{ug} / \mathrm{L}$ at $24 \mathrm{~h} ; 420 \mathrm{ug} / \mathrm{L}$ at $96 \mathrm{~h}$. A study on Rana tigerina showed adverse effects on metamorphosis (Devillers \& Exbrayat 1992).

Adult frogs, in contrast, do not breathe with gills, and most species tested tolerate considerable doses of malathion. Therefore, the Service considers that adult California red-legged frogs are at little risk of direct mortality due to oral and dermal exposure from project spraying. Adult California redlegged frogs are strongly insectivorous, however, and there are likely to be temporary adverse impacts of CTVCP spraying on the prey base of the frog, both in aquatic and terrestrial habitats. Tadpoles of the California red-legged frog graze on the "scum" coating debris and aquatic plants (M. Westphal, personal observation). Since this scum is largely composed of algae and detritus, which are not sensitive to malathion, we anticipate little effect of program spraying on the food base of the tadpoles.

The CTVCP proposes to protect known populations of California red-legged frog in the project area with $1 / 4$ mile buffers, within which no aerial spraying would take place. However, the Service's analysis of potential runoff and drift of malathion from CTVCP spraying (beginning of Effects section, above) suggests that undiscovered populations of the frog (populations in unsurveyed habitat) would be reasonably likely to suffer adverse effects due to the project. Indirect effects due to reduction of the prey base of adult frogs would be most likely. If tadpoles of the species are highly sensitive to malathion, an unusual drift or runoff event in the immediate vicinity of an unsurveyed breeding pond could cause some level of direct mortality. 
Based on 1:24,000 color aerial photos, National Wetlands Inventory maps, GIS vegetation maps, and a reconnaissance-level field survey by Service and Bureau personnel on November 6,1996 , the Service believes that there is very little potential habitat for California red-legged frog within the program's mapped winter spray area around Coalinga, California. Natural water sources are even more limited to the south, especially at the lower elevations targeted for spraying. North of Coalinga, portions of many streams with potential habitat have been surveyed, and several populations of the frog are known (see Species Account, above). Nevertheless, the Service cautions that some exceptional populations of the frog may yet be found in the program spray area.

Project vehicles may strike and injure or kill California red-legged frogs while driving on public or private roads, especially during winter periods of moist conditions.

\section{Valley elderberry longhorn beetle}

Malathion has the potential to directly kill valley elderberry longhorn beetles, particularly during spring spraying. Adults emerge and are active from March through early June, when they feed on elderberry leaves and flowers, mate, and lay eggs on elderberry plants. The eggs hatch shortly afterwards, and the larvae bore into the stem. Once inside the stem, the larvae, and subsequently the pupae, are less vulnerable to exposure to malathion. Beetles on elderberry plants outside of riparian areas, and beetles in riparian areas where substantial drift occurred despite precautions, would be most at risk from CTVCP spraying as proposed. Any impacts from a single spray or drift event would be limited to a few days' duration, so that surviving or later-emerging beetles would be unaffected.

Elderberry plants arc uncommon at lower elevations in the western San Joaquin and Tulare basin foothills, and at these elevations are more restricted to riparian habitats than in moister climate zones. The Service and the Bureau found no elderberries in field reconnaissance of Los Gatos, Warthan, and OiI Creeks and limited portions of their tributaries within the proposed winter spray area around Coalinga. Aerial photographs suggest that, at the lower elevations targeted for spraying, riparian habitats elsewhere in the project area are similar or less hospitable to the beetle's host plant.

The subspecific status of elderberry longhorn beetles in the western San Joaquin Valley has not been studied in any detail. The non-listed subspecies Desmocerus californicus californicus occurs further to the west, but the exact location and nature of the boundary between the subspecies is unknown in this region.

Vernal pool fairy shrimp. longhorn fairy shrimp, and vernal pool tadpole shrimp

No toxicity data on fairy or tadpole shrimp are available, but freshwater crustaceans are generally very sensitive to malathion. Behavioral changes (immobility) are observed in cladocerans at concentrations from $0.2-6.2 \mathrm{ug} / \mathrm{L}$ (ppb), and death occurs in $50 \%$ of the amphipods Gammarus lacustris at concentrations from $1-4 \mathrm{ug} / \mathrm{L}$ (USEPA 1975). In San Francisco Bay, mortality of shrimp has been associated with concentrations of malathion of $35 \mathrm{ug} / \mathrm{L}$ (Cornacchia 1984).

Thus, exposure to drift or runoff of CTVCP malathion applications appears to pose a significant threat to the listed species. The project would provide a $1 / 2$ mile buffer ( 880 yards) around waters where 1 isted species are known to occur. However, listed species inhabiting unsurveyed habitat would fall outside of this protocol and receive only the minimum 100 yard buffer for surface waters. The Service's calculations indicate that malathion drift is likely to cause injury and mortality to any listed crustaceans living in these waters in a substantial fraction of instances. 
Vernal pools are seasonal. Spraying of malathion on these habitats when they do not contain water is unlikely to adversely affect fairy or tadpole shrimp.

Cumulative Effects

Cumulative effects include the effects of future State, Tribal, local or private actions that are reasonably certain to occur in the action area considered in this biological opinion. Future Federal actions that are unrelated to the proposed action are not considered in this section because they require separate consultation pursuant to section 7 of the Act.

The Service is aware of other projects currently under review by State, county, and local authorities where biological surveys have documented the occurrence of the above federally listed species. These projects include oil and gas development on private lands, urban expansion, new city development, water banking projects that may not be a Federal action, and continued agricultural development.

The current strategy for recovery of listed species in the San Joaquin Valley is to secure large contiguous blocks of habitat to support core populations. In addition, lands connecting the large core areas would be managed to support scattered populations and to serve as corridors between the core areas. Rehabilitation of disturbed lands also may be necessary to provide sufficient habitat to support populations that will remain stable in perpetuity.

Agencies and organizations such as the CDFG and The Nature Conservancy have begun to secure some of the core lands identified as important for recovery for San Joaquin Valley species. Several local planning efforts which are focused on reducing the imfacts of urbanization and industrialization on listed species are also under way. These positive actions may assist with the recovery of these species.

\section{Conclusion}

The cumulative effects of present and future actions pose a significant threat to the eventual recovery of the species addressed in this biological opinion. However, we do not anticipate that the Curly Top Virus Control Program, considered together with other non-Federal actions, will appreciably reduce the likelihood of survival and recovery of these threatened and endangered species. Furthermore, most effects of the CTVCP are not persistent, and if a jeopardy threshold was reached for any species, discontinuing spraying would be expected to allow the species to begin rebounding almost immediately.

After reviewing the current status of the above federally listed species, the environmental baseline for the action area, the effects of the proposed action and cumulative effects, it is the Service's biological opinion that the Curly Top Virus Control Program, 1997-2001, as proposed, is not likely to jeopardize the continued existence of the San Joaquin kit fox, Tipton kangaroo rat, giant kangaroo rat, blunt-nosed leopard lizard, giant garter snake, California redlegged frog, Aleutian Canada goose, valley elderberry longhorn beetle, vernal pool fairy shrimp, longhorn fairy shrimp, vernal pool tadpole shrimp, California jewelflower, Kern mallow, San Joaquin woolly-threads, Bakersfield cactus, and Hoover's woolly-star, and is not likely to destroy or adversely modify statutory critical habitat. 


\section{INCIDENTAL TAKE STATEMENT}

Section 9 of the Act and Federal regulations pursuant to section 4 (d) of the Act prohibit the take of endangered and threatened species, respectively, without special exemption. Take is defined as to harass, harm, pursue, hunt, shoot, wound, kill, trap, capture or collect, or attempt to engage in any such conduct. Harass is defined by the Service as actions that create the likelihood of injury to a listed species by annoying it to such an extent as to significantly disrupt normal behavioral patterns which include, but are not limited to, breeding, feeding, or sheltering. Harm is defined by the Service to include significant habitat modification or degradation that results in death or injury to listed species by impairing behavioral patterns including breeding, feeding, or sheltering. Incidental take is defined as take that is incidental to, and not the purpose of, the carrying out of an otherwise lawful activity. Under the terms of section $7(b)(4)$ and section $7(0)(2)$, taking that is incidental to and not intended as part of the agency action is not considered to be prohibited taking provided that such taking under the Act is in compliance with this Incidental Take Statement.

If 1 isted plant species are present in the action area, the following special incidental take provisions apply: Sections $7(b)(4)$ and $7(0)(2)$ of the Act do not apply to the incidental take of listed plant species. However, protection of listed plants is provided to the extent that the Act requires a Federal permit for removal or reduction to possession of Federally listed endangered plants from areas under Federal jurisdiction, or for any act that would remove, cut, dig up, or damage or destroy any such species on any other area in knowing violation of any regulation of the respective state or in the course of any violation of that State's criminal trespass law.

The measures described below are non-discretionary, and must be undertaken by the Bureau of Land Management and Department of Energy (DOE) so that they become binding conditions of any grant or permit issued to the applicant in order for the exemption in section $7(0)(2)$ to apply. The Bureau and DOE have a continuing duty to regulate the activity covered by this incidental take statement. If the Bureau or DOE (1) fails to require the applicant to adhere to the terms and conditions of the incidental take statement through enforceable terms that are added to the permit or grant document, or (2) fails to retain oversight to ensure compliance with these terms and conditions, the protective coverage of section $7(0)(2)$ may lapse.

To clarify the options and duties of the Bureau and DOE in "implementing" the terms and conditions of this incidental take statement, the Service offers the following comments. If, as allowed under section $7(0)(2)$ of the Act, the Bureau--or DOE--is to be exempt from the section 9 prohibition of take, so that it may act to authorize, fund, or carry out a project expected to result in incidental take, it must be "in compliance" with the terms and conditions of this incidental take statement. This does not mean that the Bureau or DOE must themselves perform the activities specified in the terms and conditions, below. Instead, for example, it is appropriate to incorporate the terms and conditions as binding and enforceable provisions of the grant or permit to be issued to the applicant. Alternatively, the Bureau or DOE may wish to pursue a separate agreement with the applicant that guarantees the implementation of the terms and conditions. In any case, the Bureau and DOE must retain oversight of such implementation in order to remain exempt from the prohibition against take.

Amount or Extent of Incidental Take

With regard to animals, the Service anticipates that San Joaquin kit fox, Tipton kangaroo rat, giant kangaroo rat, blunt-nosed leopard lizard, giant garter snake, California red-legged frog, Aleutian Canada goose, valley elderberry longhorn beetle, vernal pool fairy shrimp, longhorn fairy shrimp, 
and vernal pool tadpole shrimp may be taken incidentally as a result of implementation of the proposed California Department of Food and Agriculture (CDFA) Curly Top Virus Control Program, 1997-2001, on Bureau of Land Management, Department of Energy, and other lands. Protective measures proposed by CDFA, the Bureau of Land Management, and the Department of Energy will substantialiy reduce but not eliminate the potential for incidental taking of these species during the project.

For San Joaquin kit foxes, Tipton kangaroo rats, giant kangaroo rats, bluntnosed leopard lizards, California red-legged frogs, valley elderberry longhorn beetles, vernal pool fairy shrimp, longhorn fairy shrimp, and vernal pool tadpole shrimp, incidental take may be in the form of mortality, through onroad vehicular strikes, loss of prey (including plant seeds, in the case of the kangaroo rats), and, in the case of the California red-iegged frog and the invertebrate species, poisoning. The amount of take likely to result from the project is difficult to assess for most of these species, because they are rare, secretive, or difficult to observe, dead bodies are rarely found, or the take would require comparative study to quantify--such as impacts on biuntnosed leopard lizard fecundity. Further adding to the difficulty of assessing take, the CTVCP sprays different locations in different years, with different total acreages, but permanent habitat damage is negligible.

Therefore, while acknowledging that greater but less easily measured take may occur, the Service here limits the more readily observable take authorized for the project, in the form of mortality, to the following: no more than two (2) San Joaquin kit foxes, two (2) Tipton kangaroo rats, two (2) giant kangaroo rats, two (2) blunt-nosed leopard lizards, two (2) valley elderberry longhorn beeties, two (2) adults or twenty (20) tadpoles of the California red-legged frog, 200 vernal pool fairy shrimp, fifty (50) longhorn fairy shrimp, and fifty (50) vernal pool tadpole shrimp. The Service anticipates no mortality of Aleutian Canada geese nor giant garter snakes, therefore none is

authorized. No off-road vehicular kills are authorized for any species, nor is incidental death from poisoning authorized for any terrestrial vertebrate. No take of habitat is authorized for any species.

The Service finds that an unknown number of all of the above species may be harassed during the conduct of normal project activities as proposed. Such harassment is fundamentally unpredictable, since it depends on the simultaneous co-occurrence of project activities and the presence of a rare species; but the Service estimates that in all cases less than one percent (17) of a listed species' population will be harassed for a very limited time in any given year.

Effect of the Take

In the accompanying biological opinion, the Service determined that this level of anticipated take is not likely to result in jeopardy to the above-listed species or destruction or adverse modification of critical habitat.

Reasonable and Prudent Measures

Section $7(b)(4)$ of the Act mandates that the Service specify reasonable and prudent measures to the federal agency and the applicant, to minimize the impacts of any incidental taking due to the project. The Service believes the following measures are necessary and appropriate:

(1) Provide additional protective measures for the San Joaquin kit fox, Tipton and giant kangaroo rats, blunt-nosed leopard lizard, giant garter snake, California red-legged frog, and fairy and tadpole shrimp.

Monitor effects of the project on Iisted species and the environment. 
Terms and Conditions

In order to be exempt from the prohibitions of section 9 of the Act, the Bureau of Land Management and Department of Energy must comply with the following terms and conditions, which implement the reasonable and prudent measures described above. These terms and conditions are non-discretionary.

1. A. Speed limit to reduce risk of road kills

Project vehicles driving on unpaved roads with no posted speed 1 imit shall drive at a maximum speed of 25 miles per hour and avoid striking wildlife species.

B. Blunt-nosed leopard lizard

(1) Restrict malathion spraying in presumed blunt-nosed leopard lizard (BNLL) habitat outside of the designated BNLL conservation areas to the levels described in the 1991-1995 CTVCP proposed action (CDFA 1991, p. 16), namely, 50\% coverage (every other swath untreated), one treatment per year, and spot applications not to exceed 20 acres. This term and condition will be void if a Service-approved study demonstrates that malathion spraying at $100 \%$ coverage does not affect the availability of insect prey to BNLL (see Conservation Recommendations).

(2) Increase biocontrol and integrated pest management efforts by expanding the amount of effort and funding allocated to nonmalathion-based control of crop damage due to curly top virus. Give areas of BNLL habitat higher priority in receiving these efforts. Report the amount of increase in funding effort in the annual program report to the Service (see term and condition 2B).

C. California red-legged frog

(1) Provide an untreated buffer of at least $1 / 4$ mile radius around all potential aquatic habitat for the frog in watersheds where the species is known to occur.

(2) Using aerial photographs or other means, map unsurveyed aquatic habitat that could support breeding of the frog within the CIVCP spring aerial spray areas, and either survey it according to Service protocol, or provide it with a 300 yard unsprayed buffer.

(3) If surveys or other sources show any aquatic habitat to support the frog, its aerial spray buffer will be extended to $1 / 4$ mile.

(4) If surveys fail to find the frog, the buffer for the wetland may be reduced to 100 yards.

D. Listed vernal pool crustaceans--The Service has provided maps to the CTVCP of areas that contain potential habitat for vernal pool crustaceans in the western San Joaquin Valley and Tulare Basin (letter with maps dated November 4, 1996, file \#1-1-97-TA-114). CTVCP ground and aerial applicators wili leave an untreated one-half mile buffer around habitat suitable for 1 isted vernal pool crustaceans that lies within the vernal pool areas delineated on these maps. These maps - showing "USFWSVP" data (also referred to as the Holland vernal pool GIS data layer, for Dr. Robert Holland, who performed the mapping study) -are available from CDFG. The CTVCP should check with CDFG each year and obtain new maps if there has been a change in the data. 
2. A. Biological Monitor--A qualified biologist shall be present during all spray operations. The biological monitor shall be responsible for the protection of biological resources, and shall have the authority to halt operations if listed species are threatened. The biological monitor shall carry a copy of this biological opinion during all spray operations.

B. Annual Program Report--An annual report shall be provided to the Service on treatments conducted during the previous year. The report ${ }^{\circ}$ shall be provided by December 31 of each year; and shall contain (at minimum): (1) a full account of any incidental take of listed species that occurred because of the program, (2) a map showing the areas treated, (3) a table showing the number of acres treated, (3) a summary of beet leafhopper populations pre- and post-control, (4) an account of all sightings of listed species, including the date and time, location, and other circumstances, (5) a summary of all integrated pest management efforts, including range management improvement, Russian thistle and other host plant control, and parasite introductions, (6) copies of the annual budget of the CTVCP for 1996 (baseline year) and the current year, showing the amounts dedicated to control methods other than malathion treatment, and, (7) any other pertinent information.

C. On-Site Review--If requested, the Bureau, DOE, or any designated contractor will accompany Service personnel on an on-site inspection. of sites to review project impacts to endangered species and their habitats.

The reasonable and prudent measures, with their implementing terms and conditions, are designed to minimize the impact of incidental take that might otherwise result from the proposed action. With implementation of these measures the Service believes that no more than 2 San Joaquin kit foxes, 2 Tipton kangaroo rats, 2 giant kangaroo rats, 2 blunt-nosed leopard lizards, 2 valley elderberry longhorn beetles, 2 adults and 20 tadpoles of the California red-legged frog, 200 vernal pool fairy shrimp, 50 longhorn fairy shrimp, and 50 vernal pool tadpole shrimp will be incidentally taken in the form of mortality. If during the course of the action this level of incidental take is exceeded, such incidental take represents new information requiring review of the reasunable and prudent measures provided. The Federal agency (Bureau, DOE) must immediately provide an explanation of the causes of the taking and review with the Service the need for possible modification of the reasonable and prudent measures or reinitiation of consultation.

The Service is to be notified in writing within three (3) working days of the accidental death or injury of any listed species, or the finding of any dead or injured listed species, or any unanticipated harm to the species addressed in this biological opinion, including any unanticipated harm to aquatic 1 ife or habitats. Notification must include the date, time, and location plus any other pertinent information. The Service contacts for this information are the Field Supervisor or Assistant Field Supervisor of the Sacramento Field office (916/979-2725), Carlsbad Field Office (619/431-9440), or Ventura Field office (805/644-1766): The Bureau or the DOE must notify the Assistant Field Supervisor immediately of any dead or sick individuals of listed species found in or adjacent to pesticide-treated areas. Cause of death or illness, if known, should also be conveyed to this office. The Service has provided a protocol for the handling of dead, injured or ill listed species for pesticide analysis (Appendix "F" and Attachments "1" and "2"). If the Bureau or DOE suspects a species has been taken in violation of label restrictions on the use of a pesticide, the incident shall be reported to the U.S. Fish and Wildife Service, Division of Law Enforcement, Sacramento office at (916)-9792987, which will provide instructions on the proper handling and disposition of such specimens. 
All observations of live, injured, or dead listed species shall be recorded on California Natural Diversity Data Base (NDDB) field survey forms and sent to NDDB, California Department of Fish and Game, 1416 Ninth Street, 12 th Floor, Sacramento, California 95814 (phone 916-324-3812), and to the Service at the letterhead address. Any dead or injured 1 isted vertebrates not required for pesticide analysis must be turned over to the California Department of Fish and Game, Environmental Services Division. The Department contact number at the Fresno Regional Headquarters is (209) 243-4005, ext. 0. Any dead or severely injured listed invertebrates not required for pesticide analysis shall be deposited in the Entomology Department of the California Academy of Sciences. The Academy's contact is the Senior Curator at (415) 750-7239.

\section{CONSERVATION RECOMONDATIONS}

Section $7(a)(1)$ of the Act directs Federal agencies to utilize their authorities to further the purposes of the Act by carrying out conservation programs for the benefit of endangered and threatened species. Conservation recommendations are discretionary agency activities to minimize or avoid adverse effects of a proposed action on listed species or critical habitat, to help implement recovery plans, or to develop information.

The recommendations provided here relate only to the proposed action and do not necessarily represent complete fulfillment of the agency's 7 (a) (1) responsibilities. The Service recommends the following actions to protect federally listed species and their habitats during the control program:

(1) In the past the CTVCP has avoided spraying malathion on quarter-sections where listed plants are known to occur (Rod Clark, personal communication, October 25,1996 ). The Service recommends that, for California jewelflower, Bakersfield cactus, and Kern mallow, the avoidance area be expanded to full sections (roughly 1 square mile) around known occurrences, since these plants are likely to be visited by pollinators such as bumblebees that are capable of foraging over long distances.

(2) The CDFA should annually reconfirm plant location maps with the appropriate regional plant ecologist of the California Department of Fish and Game, and locai Federal agency botanists from the Bureau of Land Management and DOE to ensure that they possess the most current information on listed, proposed, and sensitive plants.

(3) Malathion should not be applied within a quarter-section of extant populations of San Joaquin woolly-threads during the flowering period, unless a critically large leafhopper population is found during pretreatment surveys, averaging 15 beet leafhoppers per 10 net sweeps. If a critically large leafhopper population is found, control using malathion should be restricted to a single application every other year.

(4) For the following species, the Bureau, DOE, and/or CDFA should fund studies to a) identify the pollinator $(s), b)$ determine the effects, if any, to the pollinator $(s)$ and $(c)$ determine the amount of time for the pollinators to recover from being sprayed with malathion. Until these studies are completed, and show that CTVCP malathion spraying would not adversely affect reproductive success of the species, the CDFA should document the bloom period of each of the species listed below from a reliable source such as the California Native Plant Society and should not spray within a quarter-section of these plants during their bloom periods: 
Common Name

Lost Hills crownscale Slough thistle

Tejon poppy

Hall's tarplant

Pale-yellow layia

Munz's tidy-tips

Panoche pepper-grass

Jared's pepper-grass

Showy madia
Scientific Name

Atriplex vallicola

Cirsium crassicaule

Eschscholzia lemmonii ssp. kernensis

Hemizonia halliana

Layia heterotricha

Layia munzi i

Lepidium jaredii ssp. album

Lepidium jaredii ssp. jaredii

Madia radiata
(5)

We recommend that the Bureau, DOE, and CTVCP survey for or make note of the presence of elderberry plants within the program spray area. The plants should be examined for exit holes of the valley elderberry longhorn beetle, and, if present, the locality should be reported to the Service and to CDFG's Natural Diversity Data Base. Elderberry locations and areas surveyed should be mapped in any future environmental assessment for continuation of the program.

Databases maintained by the Service, the Bureau, DOE, CDFG, and the California Native Plant Society should be checked regarding the location of vernal pool and sensitive species habitats prior to annual implementation of the proposed action.

The Service recommends that CDFA develop and implement a monitoring protocol, to assess the amount of malathion reaching non-target habitats, especially surface waters. At CDFA's request, the Service will assist in reviewing a draft protocol. A copy of any program report on malathion monitoring should be provided to the Service prior to any future consultation.

Designate additional BNLI conservation area within the CTVCP potential treatment area. We recommend that this designation be effective as soon as possible, and suggest a target date of February 28,1997 and a target amount of 25,000 acres (about 40 sections). We are willing to work with the Bureau, DOE, and CDFA in developing and reviewing the designation.

Areas that should be considered for status as BNLL conservation areas include, but are not limited to: the vicinity of Mercey Hot Springs and Little Panoche Creek, Fresno County (Mercey Hot Springs USGS 7.5 minute quadrangle); the vicinity of Panoche Pass, Fresno County (Chounet Ranch and Tumey Hills quads); portions of the Pleasant Valley and Kettleman Hills, Fresno and Kings counties (Avenal quad), additional portions of Naval Petroleum Reserve Number 1, Kern County; and the upper Cuyama Valley, near the junction of Kern, San Luis Obispo, Santa Barbara, and Los Angeles counties. These areas show multiple observations of BNLL since 1970, and some since 1980, in the CDFG Natural Diversity Database.

Conduct a comprehensive survey of blunt-nosed leopard lizard population densities throughout the program area, to enable a rational delineation of conservation areas and other conservation needs.

Perform a replicated, controlled study of program effects on insect biomass in blunt-nosed leopard lizard habitat. The proposed study should be reviewed and approved by the Service, and should assess the effects of CTVCP spring aerial malathion spraying at $100 \%, 50 \%$, and $0 \%$ coverage. Provide annual progress reports to the Service, presenting and summarizing the data collected. The last report should present all data, analysis, and findings. A copy of the final report should be provided to the Service. This information is needed for future consultation. 
(11) The CTVCP should further develop and implement a comprehensive integrated pest-management (IPM) program for control of beet leafhopper. Possible elements of such a program might include:

a) an expanded biological control effort, assessing a greater variety of control organisms

b) developing pheromone traps or lures

c) incentives for planting of CTV-resistant or tolerant crops

d) modeling of beet leafhopper population dynamics, to assess optimal points of the life cycle for targeting control efforts

e) control of the leafhopper on crops, especially crops that support its reproduction (beets, spinach, cucumber). Recent control efforts have neglected this part of the life cycle.

f) a comprehensive IPM program for control of Russian thistle and other non-native plant hosts that support reproduction of the beet leafhopper.

In order for the Service to be kept informed of actions minimizing or avoiding adverse effects or benefitting listed species or their habitats, the Service requests notification of the implementation of any conservation

recommendations.

\section{REINITIATION - CLOSING STATEMENT}

This concludes formal consultation on the proposed Curly-Top Virus Control Program, 1997-2001. As provided in 50 CFR 402.16, reinitiation of formal consultation is required where discretionary Federal agency involvement or control over the action has been retained (or is authorized by 1 aw) and if: (1) the amount or extent of incidental take is exceeded; (2) new information reveals effects of the agency action that may affect listed species or critical habitat in a manner or to an extent not considered in this opinion; (3) the agency action is subsequently modified in a manner that causes an effect to the listed species or critical habitat not considered in this opinion; or (4) a new species is listed or critical habitat designated that may be affected by the action. In instances where the amount or extent or incidental take is exceeded, any operations causing such take must cease pending reinitiation.

We appreciate the cooperation of the Bureau of Land Management, the Department of Energy, and the California Department of Food and Agriculture throughout this consultation process. Please contact Mr. David Wright of my staff at the Sacramento Field office at (916) 979-2725, Ms. Carol Roberts at the Carlsbad Field Office at (619) 431-9440, or Mr. Ray Bransfield at the Ventura Field office at (805) 644-1766 if you have questions or comments on this biological opinion or further information concerning this project.

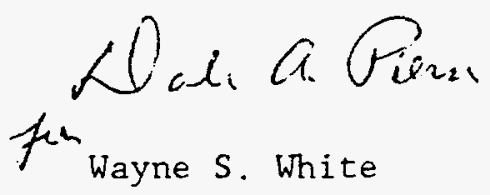

Attachments 
cc: AES-Portland, OR

Chief, ES, Washington, D.C.

SJVESRPP, Fresno, CA

DOE, Tupman, CA

BLM, Bakersfield, CA

BLM, Riverside, $C A$

FWS, Ventura, CA

FWS, Carlsbad, CA

Larry Salata, USFWS, Portland, OR 
Akesson, N.B. and W.E. Yates. 1964. Problems relating to application of agricultural chemicals and resulting drift residues. Ann. Rev. Entomol. 9:285-318.

BLM. 1991. Federal Pesticide Use Permit, 91-CA-93-0001. U.S. Bureau of Land Management, Washington, D.C.

BLM. 1992. Eriastrum hooveri field inventory. Conducted by R. Lewis, Caliente Resource Area, Bakersfield, California. (116 pp.)

BLM. 1994. Exiastrum hooveri field inventory. Conducted by R. Lewis, Caliente Resource Area, Bakersfield, California. (120 pp.)

BLM and DOE. 1995. Joint Environmental Assessment (1997-2001) of the California Department of Food and Agriculture Curly Top Virus Control Program. Prepared for the U.S. Bureau of Land Management and the U.S. Department of Energy by the California Department of Food and Agriculture, Pest Control Branch, Fresno, California. 87 pp. + Appendices.

Balestreri, A. N. 1981. Status of the San Joaquin kit fox at Camp Roberts, California. (Contract No. DAKF03-81-M-C736.) California Polytechnic State University, San Luis Obispo, CA. Prepared for U.S. Department of the Army, Directorate of Facilities Engineering, Environmental and Natural Resources, Fort Ord, CA.

Barr, C. B. 1991. The distribution, habitat, and status of the valley eiderberry ionghorn beetle Desmocerus californicus dimorphus. U.S. Fish and Wildife Service; Sacramento, California.

Berry, W. H. et al. 1987. Sources and rates of mortality of the San Joaquin kit fox, Naval Petroleum Reserve 非, Kern County, California, 1980-1986. (EGG 10282-2154, DE87 012332.) Energy Measurements Group. Goleta, CA. Prepared for U.S. Department of Energy, Naval Petroleum Reserves in California, Tupman, CA; and Chevron Corporation, through the Nevada Operations office.

Bookhout, C.G. and J.D. Costlow, Jr. 1976. Effects of mirex, methoxychlor, and malathion on development of crabs. Ecological Research Series EPA600/3-76-007. Office of Research and Development, U.S. Environmental Protection Agency, Gulf Breeze, FL.

Bowman, B.T. and W.W. Sans. 1983. Further water solubility determinations of insecticidal compounds. J. Environ. Sci. Health B18:221-227.

Brode, J. M. 1988. Natural history of the giant garter snake (Thamnophis couchi gigas). In Proceedings of the conference on California herpetology, H. F. Delisle, P.R. Brown, B. Kaufman, and B. M. McGurty (eds.). Southwestern Herpetologists Society, Special Publication No. $4: 25-28$.

CDFA 1996. Amended proposed action for blunt-nosed leopard lizard (BNLI). Letter from California Department of Food and Agriculture, Integrated Pest Control Branch, to U.S. Fish and Wildlife Service, Sacramento, CA. August 19, 1996.

CDFG. 1980. At the crossroads: a report on the status of California's endangered and rare $f i s h$ and wildlife. California Department of Fish and Game, Sacramento, CA.

1987. 1986 Annual report on the status of California's state-listed threatened and endangered plants and animals. California Department of Fish and Game, Sacramento, CA. 
1988. 1987 Annual report on the status of California's state-listed threatened and endangered plants and animals. California Department of Fish and Game, Sacramento, CA.

1989. 1988 Annual report on the status of California's state-listed threatened and endangered plants and animals. California Department of Fish and Game, Sacramento, CA.

1992. 1991 Annual report on the status of California state-1isted threatened and endangered animals and plants. California Department of Fish and Game, Sacramento, CA.

CEC. 1991. Southern San Joaquin Valley ecosystems protection program. California Energy Commission, Sacramento, CA.

Chesemore, D. 1980. Impact of oil and gas development on the blunt-nosed leopard lizard. (Contract YA-512-CT-118.) California State University. Fresno, CA. Prepared for U.S. Bureau of Land Management, Fresno, CA.

Clifton, S.D. 1989. Results of analysis of San Joaquin kit fox scats from Kellogg Creek watershed area, Contra Costa and Alameda counties, California. July 1988. Prepared for Jones \& Stokes Associates, Inc. (JSA 87-031.) Sacramento, CA.

Coe, T. 1988. The application of section 404 of the Clean Water Act to vernal pools. Pages 356.358 in J.A. Kusler, S. Daly, and G. Brooks, eds. Urban wetlands. Proceedings of the National Wetland Symposium, Dakland, California.

Cornacchia, J.W. 1984. Malathion. Water Quality and Pesticides, vol. 8. Special Projects Report 84-9SP, State Water Resources Control Board, Sacramento, GA.

Culley, D.C. and H.G. Applegate. 1967. Insecticide concentrations in wildlife at Presidio, Texas. Pest Monitoring Journal: 1 (2) 21-28.

Delacour, J. 1954. The waterfowl of the world, Vol. 1. Country Life, Ltd., London.

Devillers, J. and J.M. Exbrayat. 1992. Ecotoxicity of chemicals to amphibians. Handbooks of Ecotoxicological Data (ed. J. Devillers), Vol. 1. Gordon and Breach Science Publishers, Philadelphia.

Dorff, C. 1981. Comparison of small mammal populations with blunt-nosed leopard Iizard indices. Unpublished refuge report. U.S. Fish and Wildife Service, San Luis National Wildlife Refuge Complex, Los Banos, CA.

Dobroski, C.J. Jr. and W.P. Lambert, 1984. "Malathion: a Profile of its Behavior in the Environment." Submitted to U.S. Department of Agriculture, Animal and Plant Health Inspection Service, Plant Protection and Quarantine. Contract 53-6395-1-151.

Dobbins, P.K. 1967. Organic phosphate insecticides as tetratogens in the rat. J. Florida Medical Assoc. 54:452-456.

Eng, I.I., D. Belk, and C.H. Erickson. 1990. California anostraca: distribution, habitat, and status. J. Crustacean Biol. 10:247-277.

Egoscue, H. J. 1956. Preliminary studies of the kit fox in Utah. Journal of Mammalogy $37: 351-357$. 
Finlayson, B.J., B. Fagella, H. Jong, E. Littrell, and T. Lew. 1982. Impact on fish and wildife from broadscale aerial malathion applications in the south San Francisco Bay Region. Environmental Services report 82-2, California Department of Fish and Game, Rancho Cordova, CA.

Fitch, H. S. 1940. A biogeographical study of the Ordinoides artenkreis of garter snakes (genus Thamnophis). University of California Publications in Zoology $44(1): 1-50$.

1941. Geographic variation in garter snakes of the genus Thamnophis sirtalis in the Pacific coast region of North America. American Midland Naturalist 26:570-592.

Germano, D.J., D.F. Williams, and W. Tordoff III. 1994. Effect of drought on blunt-nosed leopard lizards (Gambelia sila). Northwestern Naturalist $75: 11-19$.

Giles, R.H., Jr., 1970. The ecology of a small forested watershed treated with the insecticide malathion-S35. Wild. Monogr., No. 24.

Grinnel1, J. 1920. A new kangaroo rat from the San Joaquin Valley, California. Journal of Mammalogy 1:78-179.

1921. Revised 1 ist of the species in the genua Dipodomys. Journal of Mammalogy 2:94-97.

1922. A geographical study of the kangaroo rats in California. University of California Publications in Zoology 24(1):1-124.

Grinnell, J., and A.H. Miller. 1944. The distribution of the birds of California. Casper Ornithological Club. Berkeley, CA.

Grinnel1, J., J.S. Dixon, and J.M. Linsdale. 1937. Fur-bearing mammals of California. Volume II. University of California Press. Berkeley, CA.

Ha11, F.A. 1983. Status of the kit fox (Vulpes macrotis mutica) at the Bethany Wind Turbine Generating (WTG) Project Site, Alameda, CA. The Resources Agency, California Department of Fish and Game. Sacramento, CA.

Hail, R.J. and D.R. Clark. 1982. Responses of the iguanid lizard Anolis carolinensis to four organophosphorus pesticides." Environmental Pollution (Series A) 28:45-52.

Hansen, R.W. 1980. Western aquatic garter snakes in central California: an ecological and evolutionary perspective. Master of Arts thesis, California State University, Fresno, California, 78 Pp.

1988. Review of the status of the giant garter snake (Thamnophis couchi gigas) and its supporting habitat during 1986-87. Final report to California Department of Fish and Game, Contract C-2060. 31 pp.

Hansen, G.E. and J.M. Brode. 1980. Status of the giant garter snake Thamnophis couchi gigas (Fitch). Inland Fisheries Endangered Species Program, Special Publication 80-5, California Department of Fish and Game, Sacramento, CA. 14 pp.

Hansen, R.W. and G.E. Hansen. 1990. Thamnophis gigas (giant garter snake) reproduction. Herpetological Review, 21(4): 93-94. 
Hayes, M.P., and M.R. Jennings. 1988. Habitat correlates of distribution of the California red-legged frog (Rana aurora draytonii) and the foothill yellow-legged frog (Rana boylii): implications for management. In: Management of Amphibians, Reptiles, and Small Mammals in North America Proceedings of the Symposium, July 19-21, 1988, Flagstaff, AZ. (General Technical Report RM-166.) U.S. Forest Service, Fort Collins, Co.

Hayes, M.P. and M.R. Tennant. 1985. Diet and feeding behavior of the California red-legged frog, Rana aurora draytonii (Ranidae). Southwestern Naturalist 30:601-605.

Hi11, E. F. 1971. Effects of ultra-low volume applications of malathion in Hale County, Texas. J. Med. Entomol., 8(2):173-179.

Jones and Stokes Associates and CH2M Hill. 1986. Biological assessment for endangered species, Kesterson program. (JSA 85-080.) Sacramento, CA. Prepared for U.S. Bureau of Reclamation, Sacramento, CA.

Holland, R. F., and S. Jain. 1988. Vernal pools. Pages 515-533 in M. E. Barbour and'J. Major, eds. Terrestrial vegetation of California, new expanded edition. California Native Plant Society, Special Publication Number 9, Sacramento, California.

Hopkins, Jean \& Associates, Inc., 1994. "Pleasant Valley Habitat Conservation Plan (administrative review draft). "Prepared for the Pleasant Valley HCP Steering Committee. September 11, 1994.

Jennings, M.R. 1988. Natural history and decline of native ranids in California. Pages 61-72 in H.F. Delisle, P.R. Brown, B. Kaufman, and B.M. McGurty, eds. Proceedings of the Conference on California Herpetology. Southwestern Herpetologists Society, Special Publication (4):1-143.

Jennings, M.R. and M.P. Hayes. 1990. Status of the California red-legged frog Rana aurora draytoni i in the Pescadero Marsh Natural Preserve. Report prepared for the California Department of Parks and Recreation, Sacramento, CA. $30 \mathrm{pp}$. + Tables and Figures.

Jennings, M.R., M.P. Hayes, and D.C. Holland. 1992. A petition to the U.S. Fish and Wildife Service to place the California red-legged frog (Rana aurora draytonii) and the western pond turtle (Clemmys marmorata) on the list of endangered and threatened wildlife and plants. 21 pP. U.S. Fish \& Wildlife Service, Sacramento, CA.

Katibah, E. F. 1984. A brief history of riparian forests in the Central Valley of California. In: Warner, R. E. and K. M. Hendrix (eds.). California riparian systems: ecology, conservation, and productive management. University of California Press, Berkeley. pp. 23-29.

Katibah, E. F., K. J. Dummer, and N. Nedeff. 1981. Evaluation of the riparian vegetation resource in the Great Central Valley of California using remote sensing techniques. Technical Papers of the American Society of Photogrammetry. ASP-ACSM Fail Tech. Mtg., San Francisco, Sept. 9-11 and Honolulu Sept. 14-16, 1981. pp. 234-246.

Katibah, E. F., K. J. Dummer, and N. Nedeff. 1984. Current condition of riparian resources in the Central Valley of California. In: Warner, $R$. $E$. and $K$. M. Hendrix (eds.). California riparian systems: ecology,

conservation, and productive management. University of California Press, Berkeley. pp. 314-321. 
Kato, T. T., B. R. Rose, and T. P. O'Farrell, 1987. "Diet of the Blunt-nosed Leopard Lizard, Gambelia silus, on Naval Petroleum Reserves 非 and 非, Kern County, California." E.G.\&G. Energy Measurements, Goleta, California.

Maybank, J., K. Yoshida, and R. Grover. 1978. Spray drift from agricultural pesticide applications. J. Air Poll. Control Assoc. 28:1009-1014.

Mazer, S. and B. Hendrickson. July, 1993. "Demography and Reproductive Biology of San Joaquin Woolly Threads (Lembertia congdoni i: Asteraceae)." Final report to California Department of Fish and Game, contract \# FG 1460. University of California, Santa Barbara.

Sept. 1993. "Demography, Ecology and Reproductive Biology of the California Jewelflower (Caulanthus californicus: Brassicaceae)." Final report to California Department of Fish and Game, contract \#⿰⿰三丨⿰丨三⿻三丨寸 1461 . Department of Biological Sciences, University of California, Santa Barbara.

Merriam, C. H., 1884. Preliminary description of eleven new kangaroo rats in the genera Dipodomys and Perodipus. Proc. Biol. Soc. Washington 9:109-116.

Metcalf, R. L. 1972. DDT Substitutes. Crit. Rev. Environ. Contr. 3(1):25-59, Ref. 110 .

Miles, C.J. 1991. Degradation products of sulfur-containing pesticides in soil and water. In: Somasundaram, L. and J.R. Coats (eds.), Pesticide Transformation Products-Fate and Significance in the Environment. ACS Symposium Series 459, American Chemical Society, Washington, DC.

Montanucci, R. R., 1965. "Observations on the San Joaquin leopard lizard, Crotophytus wislizenii Stejneger. Herpetologica 21:270-283.

1967. Further studies on leopard lizards, Crotaphytus wislizenii. Herpetologica 23:119-126.

Morrel1, S. H., 1971. Life history of the San Joaquin kit fox. Special Wildlife Investigations, Job II-11. Final report. California Department of Fish and Game. Sacramento, CA.

1972. Life history of the San Joaquin kit fox. California Fish and Game $58(3): 162-174$.

1975. San Joaquin kit fox distribution and abundance in 1975. (Administrative Report No. 75-3.) California Department of Fish and Game, Wildlife Management Branch, Sacramento, CA.

Muirhead-Thomson, R.C. 1987. Pesticide impact on stream fauna, with special reference to macroinvertebrates. Cambridge Univ. Press, Cambridge.

Natural Diversity Data Base. 1993. A database application for the California Department of Fish and Game, Natural Heritage Division, Sacramento, CA.

Natural Diversity Data Base. 1994. A database application for the California Department of $\mathrm{Fish}$ and Game, Natural Heritage Division, Sacramento, CA.

Nelsen, E. T., D. F. Springer, and D. R. Yparraguirre. 1984. Population, distribution and ecology of Aleutian Canada geese on their migration to wintering areas, 1983-1984. Humboldt State University. Arcata, CA. Prepared for U.S. Fish and Wildlife Service, Northern Prairie Wildlife Research Center, Jamestown, ND. 
O'Farre11, T. P., W. H. Berry, and G. D. Warrick. 1987. Distribution and status of the endangered San Joaquin kit fox, Vulpes macrotis mutica, on Fort Hunter Liggett and Camp Roberts, California. (EGG-10282-2194.) EG\&G Energy Measurements, Inc. Goleta, CA. Prepared for U.S. Department of the Army, Corps of Engineers, through the U.S. Department of Energy, Nevada Operations Office, Reno, NV.

O'Farrel1, T.P. and P. McCue. 1981. Inventory of the San Joaquin Kit Fox on BLM Lands in Western San Joaquin Valley. Final Report, Number EGG 1183 2416. Prepared by EG\&G Energy Measurements, Santa Barbara Operations, U.S. D.0.E., Goleta, CA. 135pp.

O'Farrell, T.P., P. McCue, and T. Kato. 1981. Potential of BLM lands in western Fresno and eastern San Benito and Monterey Counties, California, as critical habitats for the endangered San Joaquin kit fox (Vulpes microtus mutica) and blunt-nosed leopard lizard (Crotaphytus silus). U.S. Bureau of Land Management, Sacramento, CA.

O'Farrell T. P., and J. H. Scrivner. 1987. Wildlife management plan, Naval Petroleum Reserve 非, Kern County, California. (EGG-10282-2133, DE87 005864.) Energy Measurements Group. Goleta, CA. Prepared for U.S. Department of Energy, Office of Naval Petroleum and Oil Shale Reserves, and Chevron Corporation through the Nevada Operations office.

Orloff, S., F. Hall, and L. Spiegel. 1986. Distribution and habitat requirements of the San Joaquin kit fox in the northern extreme of their range. Transactions of the Western Section of the Wildlife Society $22: 60$. 70 .

Oshima, R.J., L.A. Neher, T.M. Mischke, D.J. Weaver, and O.S. Leifson. 1982. A characterization of sequential aerjal malathion applications in the Santa Clara Valley of California, 1981. Caiffornia Department of Food and Agriculture, Sacramento, CA.

Payne, N.J., B.V. Helson, K.M.S. Sundaram, and R.A. Fleming. 1988. Estimating buffer zone widths for pesticide applications. Pestic. Sci. $24: 147-161$.

Riley, C.M., C.J. Wiesner, and W.R. Ernst. 1989. Off-target deposition and drift of aerially applied agricultural sprays. Pestic. Sci. 26:159-166.

Rossman, D. A. and G. R. Stewart. 1987. Taxonomic reevaluation of Thamnophis couchi. Occasional Papers of the Museun of Zoology, Louisiana State University, No. 63.23 pp.

Segawa, R.T., J.A. Sitts, J.H. White, S.J. Marade, and S.J. Powe11. 1991. Environmental monitoring of malathion aerial applications used to eradicate Mediterranean fruit flies in southern California, 1990. Publication EH 91 . 3, California Department of Food and Agriculture, Sacramento, CA.

Simovich, M., R. Brusca, and J. King. 1992. Invertebrate survey 1991-1993 PGT-PGE/Bechtel pipeline expansion project. University of San Diego, Alcala Park, San Diego, California.

Skinner, M., and B. Pavlik. 1994. Inventory of rare and endangered vascular plants of California. 5th edition. January. (Special Publication No. 1.) California Native Plant Society. Sacramento, CA.

Smith, F. 1977. A short review of the status of riparian forests in California. In: Riparian forests in California: their ecology and conservation. Institute of Ecology Publication No. 15, Davis, California. pp. $1-2$.

Spiller, D., 1961. A digest of available information on the insecticide malathion. Adv. Fest Control Res., Vol. IV. 
Springer, P.F. 1977. Reestablishing Aleutian Canada geese. Pages $339-344$ in Temple; S.A., ed. Endangered Birds. Univ. of Wisconsin Press, Madison, WI.

Stebbins, R. C., 1954. Amphibians and reptiles of western North America. McGraw-Hill Book Company, Inc. New York, NY.

1985. A field guide to western reptiles and amphibians. 2nd edition. Houghton Mifflin Company. Boston, MA.

Storer, T. I. 1925. A synopsis of the Amphibia of California. University of California Publications in Zoology 27:1-342.

Taylor, D. W. 1987. Status survey for San Joaquin wooly-threads (Lembertia congdonii). BioSystems Analysis, Inc., Santa Cruz, CA. Prepared for U.S. Fish and Wildlife Service, Office of Endangered Species, Sacramento, CA.

Taylor, D. W., and W. B. Davilla. 1986. Status survey of three plants endemic to the San Joaquin Valley and adjacent areas, California. Biosystems Analysis, Inc., Santa Cruz, CA. Prepared for U.S. Fish and Wildife Service, Office of Endangered Species, Sacramento, CA.

Thompson, K. 1961. Riparian forests of the Sacramento Valley, California. Annals of the Association of American Geographers 51: 294-315.

Tollestrup, K. 1978. The ecology, social structure, and foraging behavior of two closely related species of leopard lizards, Gambelia silus and Gambelia wislizenii. Ph.D. dissertation. University of California, Berkeley, CA.

Tollestrup, K. 1979. The ecology, social structure, and foraging behavior of two closely related species of leopard lizards, Gambelia silus and Gambelia wislizenii. Ph.D. dissertation. University of California, Berkeley, CA.

Turner, B., J. Waithman, and R. Segawa. 1991. Environmental monitoring results of the Mexican fruit fly eradication program, San Diego County, Spring 1990. Publication EH 91-4, California Department of Food and Agriculture, Sacramento, CA.

Twedt, B. 1993. A comparative ecology of Rana aurora Baird and Girard and Rana catesbeiana Shaw at Freshwater Lagoon, Humboldt County, California. Unpubl. MS, Humboldt State Univ. $53 \mathrm{pp}+$ appendix.

Uptain, C., 1990. Natural history and recommended survey protocol for the Tipton kangaroo rat. San Joaquin Valley Endangered Wildi ife Technical Workshop, May 15-16, 1990. San Joaquin Valley Chapter of the Wildlife Society.

USEPA. 1975. Initial scientific and minieconomic review of malathion. Midwest Research Institute. Substitute Chemical Program, EPA-540/1-75-005. Office of Pesticide Programs, U. S. Environmental Protection Agency, Washington, DC.

1986. Memorandum from William L. Burnam, Deputy Chief, Hazard Evaiuation Division, to U.S. Department of Agriculture, Animal and Plant Health Inspection Service. U. S. Environmental Protection Agency, September 4, 1986.

USFWS. 1978. Concept plan for waterfowl wintering habitat preservation, Central Valley, California. U.S. Fish and Wildife Service, Region 1, Portland, OR. $116 \mathrm{pP}$. + appendices.

1980a. Blunt-nosed leopard lizard recovery plan. U.S. Fish and Wildife Service, Portland, OR. $61 \mathrm{pP}$. + Appendices 
1980b. Selected vertebrate endangered species of the sea coast of the United States - Aleutian Canada goose. Biological Service Program No. FWS/OBS-80/01.34. U.S. Fish and Wildlife Service, Washington, DC.

1982. Aleutian Canada goose recovery plan. U.S. Fish and Wildlife Service, Denver, co.

1983. The San Joaquin kit fox recovery plan. U.S. Fish and Wildlife Service, Portland, OR.

1984. Recovery plan for the valley elderberry longhorn beetle. Fish and Wildlife Service, Endangered Species Program; Portland, OR.

1985. Revised blunt-nosed leopard lizard recovery plan. U.S. Fish and Wildlife Service, Portland, OR. $85 \mathrm{pp}$.

1990. Endangered and Threatened Wildlife and Plants; Determination of Endangered or Threatened Status for Five Plants From the Southern San Joaquin Valley. Federal Register 55(139):29361-29370.

1991a. Biological Opinion for use of Malathion to Control Curly Top Virus in Imperial, Los Angeles and Riverside Counties, California (1-6-91F-20)." U.S. Fish and Wildlife Service, Southern California Field Station, Laguna Niguel, CA.

1991b. "Formal Section 7 Consultation on Renewal of a Five-year Pesticide Use Permit to the California Department of Food and Agriculture for Use of Malathion to Control Curly Top Virus, 1-1-91-F-6 (San Joaquin Valley/Coastal Valley Element)." U.S. Fish and Wildlife Service, Sacramento Field office, Sacramento, CA.

1994. Endangered and threatened wildlife and plants; determination of endangered status for the Conservancy fairy shrimp, longhorn fairy shrimp, and vernal pool tadpole shrimp; and threatened status for the vernal pool fairy shrimp. Federal Register 59:48136-48153. (September 19, 1994)

Ware, G.W., N.A. Buck, and B.J. Estesen. 1984. Deposit and drift losses from aerial ultra-low-volume and emulsion sprays in Arizona. J. Econ. Entomol. $77: 298-303$.

Wauchope, R.D. 1978. The pesticide content of surface water draining from agricultural fields--a review. J. Environ. Qual. 7:459-472.

Williams, D. F., 1980. Distribution and population status of the San Joaquin antelope ground squirrel and giant kangaroo rat. Nongame Wildlife Investigation Report E-W-4. California Department of Fish and Game, Sacramento, CA.

1985. A review of the population status of the Tipton kangaroo rat, Dipodomys nitratoides nitratoides. Final report. (Order No. 10181-4861 [ts] -84, SE-0020-4.) U.S. Fish and Wildlife Service Endangered Species Office, Sacramento, CA.

1986. Mammalian species of special concern in California. California Department of Fish and Garne, Sacramento, CA.

1992. Geographic distribution of population status of the giant kangaroo rat. Pages $301-328$ in Williams, D. F., et al. (eds.). Endangered and sensitive species of the San Joaquin Valley, California. California Energy Commission, Sacramento, CA. 
Wright, A.H. and A.A. Wright. 1949. Handbook of frogs and toads of the United States and Canada. Comstock Publishing Company, Inc., Ithaca, NY. xii + $640 \mathrm{pp}$.

Yokomi, R. K., 1979. "Phenological Studies of Circulifer tenellus (Baker) (Homoptera: Cicadellidae) in the San Joaquin Valley of California." Doctoral thesis, University of California, Davis.

Zink1, J.G., W.L. Lockhart, S.A. Kenny, and F.J. Ward. 1991. The effects of cholinesterase-inhibiting insecticides on fish. In: Mineau, P. (ed.), Cholinesterase-inhibiting insecticides--their impact on wildife and environment. Elsevier, Amsterdam.

Zoellick, B. W., T. P. O'Farrell, and T. T. Kato. 1987. Movements and home ranges of San Joaquin kit foxes on the Naval Petroleum Reserves, Kern County, California. (EG\&G 10282-2184, DE88 05188.) EG\&G Energy Measurements, Inc. Goleta, CA. Prepared for U.S. Department of Energy, Naval Petroleum Reserves in California, and Chevron USA, Inc., Nevada Operations Office, Reno, NV.

\section{PERSONAL COMMUNICATIONS}

Ms. Ellen Cypher, San Joaquin Valley Endangered Species Recovery Planning Program, Fresno, CA

Mr. Dan Yparraguirre, Wildlife Biologist. California Department of Fish and Game, Sacramento, CA. June 21, 1993.

Mr. Robert L. Peterson, Senior Entomologist. Curly Top Virus Control, California Department of Food and Agriculture. September 4, 1996. 
Appendix A

The contents of this appendix are based on information in the Joint Environmental Assessment (joint EA) of the Curly-top Virus Control Program, 1997-2001 (BIM \& DOE 1995).

\section{History of the Curly Top Virus Control Program}

With only a 1\% loss from CTV in California, it is estimated that during the period 1974-1976, California suffered annual losses of $\$ 9.75$ million in commercial crops alone. A $\$ 2.68$ million loss in home gardens can be extrapolated from a 1974 value using a 1\% infection rate (Yokomi 1979). Without control where required, beet leafhopper is capable of an infection rate of $10-40 \%$ or more. Infection rates as high as $80 \%$ were observed near Huron, California in 1977.

The "Proposed Action" alternative of the Curly-Top Virus Control Program (CTVCP) seeks to control the beet leafhopper statewide where the infection of susceptible crops and backyard gardens is likely. Control is performed within rangeland habitat on both public and private lands; and along ditch banks, roadsides, and fallow fields in cultivation adjacent to rangeland. The joint EA Appendix "E" comprises, [1] maps of potential CTVCP treatment areas [2] a relative treatment "probability" chart, and, [3] graphs of the probable seasonality of treatments.

In the state of California, there is a total of approximately 2,506,240 acres of potential BLH treatment area. Of the $2,506,240$ acres, approximately 628,480 acres or $25 \%$ is public land. (See joint EA Appendix "A" for detailed descriptions of public land that is potentially treated.)

An average of 85,738 acres per year has been treated during the past 11 years. (See Treatment Chart in joint EA Appendix "E", page xii.) The 11-year average includes applications to roadsides and fallow fields as well as rangeland. Average annual rangeland treatment totals would be less than the yearly average. In any given year, the CTVCP may treat between 5,000-20,000 acres of public land. The acreage will vary from year to year depending on the frequency of Imperial County treatments. The total acreage treated in any given year also depends on rainfall patterns and leafhopper density.

Treatment may occur at any location within the potential treatment areas mapped (See joint EA Appendix "E").

Throughout California, the BLH population builds up at various times of the year, carrying CTV from weed host to cultivated crops and back from crops to annual weeds. Control is a year-round effort. As with most pest insects, control is linked to the life cycle and directed at disrupting its continuity. Aerial treatments are employed to control BLH populations in rangeland habitat and in large cultivated fallow fields. 
Appendix $B$

Species Judged Not Likely to Be Adversely Affected by the Proposed Project

This appendix was developed by the U.S. Fish and Wildlife Service.

a. Birds; Birds of Prey: Hawks, Eagles, Falcons, and California Condor:

The bald eagle, peregrine falcon, and California condor are federally listed as threatened or endangered and may occur within the potential CTVCP treatment areas. No significant impacts to these birds of prey and condors are anticipated due to treatment activities, due to:

1. The large foraging range of individual birds of prey, which are likely to extend beyond treated areas.

2. Minimal impacts to food supplies, other than insects, such as small and medium-sized mammals, birds, reptiles and fish. Bald eagles typically obtain food from water bodies. Water bodies are to be avoided as part of the proposed action. California condors obtain food in the form of carcasses, such as cattle, sheep, deer, and squirrels.

3. Riparian systems and cliff faces used for nesting sites are not treated during CTVCP operations.

b. Birds; Riparian Birds:

Several California state-listed species may occur in the CTVCP project area, including the western yellow-billed cuckoo, elf owl, gilded northern flicker, Gila woodpecker, black-tailed gnatcatcher, Arizona Bell's vireo. These species may be affected by the project, primarily through effects of malathion drift or runoff on their insect prey, and compliance with State regulations administered by the California

Department of Fish and Game is necessary.

c. Birds; Shorebirds; western snowy plover:

1. The proposed action will occur outside of the breeding and wintering range of the western snowy plover.

d. Invertebrates; Fairy Shrimp

Conservancy fairy shrimp:

1. No known populations of the endangered Conservancy fairy shrimp are found within CTVCP potential treatment areas (Eng et al. 1990 and USFWS 1994).

2. The CTVCP avoids natural or man made aquatic situations during control activities (see "Key Features of Proposed Action" page 17, joint EA).

3. Temporary or ephemeral bodies of water are located during the intensive mapping surveys performed three to four weeks prior to aerial applications. No aerial or ground application of malathion will be made within one-half mile of known listed fairy. shrimp habitat.

e. Other Invertebrates:

Due to the potential impacts of CTVCP activities, specific measures have been adopted to minimize impacts (see joint EA pages $21 \& 23$ ). A negligible impact to dune beetle populations is anticipated due to 
specific measures of the "Proposed Action", habitat sensitive vehicle restrictions, and the virtually non-phytotoxic properties of malathion.

\section{f. Plants}

Large flowered-fiddleneck will be avoided during malathion spray applications. As agreed to in a meeting between the Service, the Bureau, and CTVCP executives on August 7,1996 , there will be no groundrig spraying in Corral Hollow west of Interstate 5, an area potentially inhabited by the large-flowered fiddleneck. [The California red-legged frog also inhabits this drainage.]

The closest known populations of palmate bracted bird's beak are located north of Tracy and east of Mendota. These areas will not be sprayed by the CTV control program.

The closest known populations of robust and Monterey spineflowers are more than 3 miles from the program's mapped spray areas in Monterey County. The program has also committed to avoiding known populations of the spineflower during their blooming period (updated proposed action faxed to the Service on October 3, 1996). 
The primary objective in handling a sick or injured specimen is effective treatment and care. The primary objective when encountering a dead specimen is to preserve biological materials " in the best possible state for later analýsis of cause of death; preserving biological materials is also preserving evidence." In conjunction with treatment of sick or injured ${ }^{2}$ animals, the finder has a responsibility to ensure that evidence extrinsic to the specimen is not unnecessarily disturbed. Therefore, upon locating a dead injured or sick endangered or threatened species specimen:

1. Contact a wildlife law enforcement agent immediately. DO NOT disturb the scene or the carcass (if the specimen is dead). It is preferable to contact a Service agent, but if one is not immediately available, a State agent should be contacted. The law enforcement agent will need to make a determination as to whether or not legal action should be taken. Specifically request instructions on handling the sick/injured or dead specimen in order to effectively treat or preserve it. strictly follow all instructions provided by the agent.

2. In cooperation with the wildijfe enforcement agent, contaci either: the National Wildlife Health Research Center (NWHR) in Madison, Wisconsin at (608) 271-4640 for vertebrates other than fish; (b) the National Fisheries Research Center - Leetown in Kearneysville, West Virginia at (304) 725-8461 for fish; or (c) for invertebrates and plants contact the appropriate Fish and Wildlife Service Field or Regional office specified in the biological opinion. You will be provided with specific guidance regarding care preservation and shipment for postmortem evaluations. General Instructions are provided in Attachment 1. Additional detail is available in.Fish and Wildlife Service Resource Publication 161, "Field Guide to Wildlife Diseases." However, SPECIFIC INSTRUCTIONS MAY VARY DEPENDING ON THE CIRCUMSTANCES INVOLVED.

In general, it is important to contain a dead specimen in a plastic bag and chill it as soon after discovery as possible by the use of refrigeration, blue ice packs or wet ice. If delays of more than 24. hours are anticipated in shipping the carcass, it should be frozen immediately.

3. Field observations and data are important for guiding cause of death or sickness investigations. As complete a case history as possible should accompany each report. Information should include location, proximity to manmade structures (roads, powerlines, fences, etc.), information on pesticides used in the vicinity (name, formulation, date when last applied, conditions during and after last application, etc.), presence of any specimens of nonlisted species, and other 
pertinent information such as that identified in Attachment 2. Necropsy findings and evaluation of the case history will determine whether chemical analysis should be performed.

4. Inform the appropriate Fish and Wildlife Service Field or Regional office of the incident as spectfied in the biological opinion.

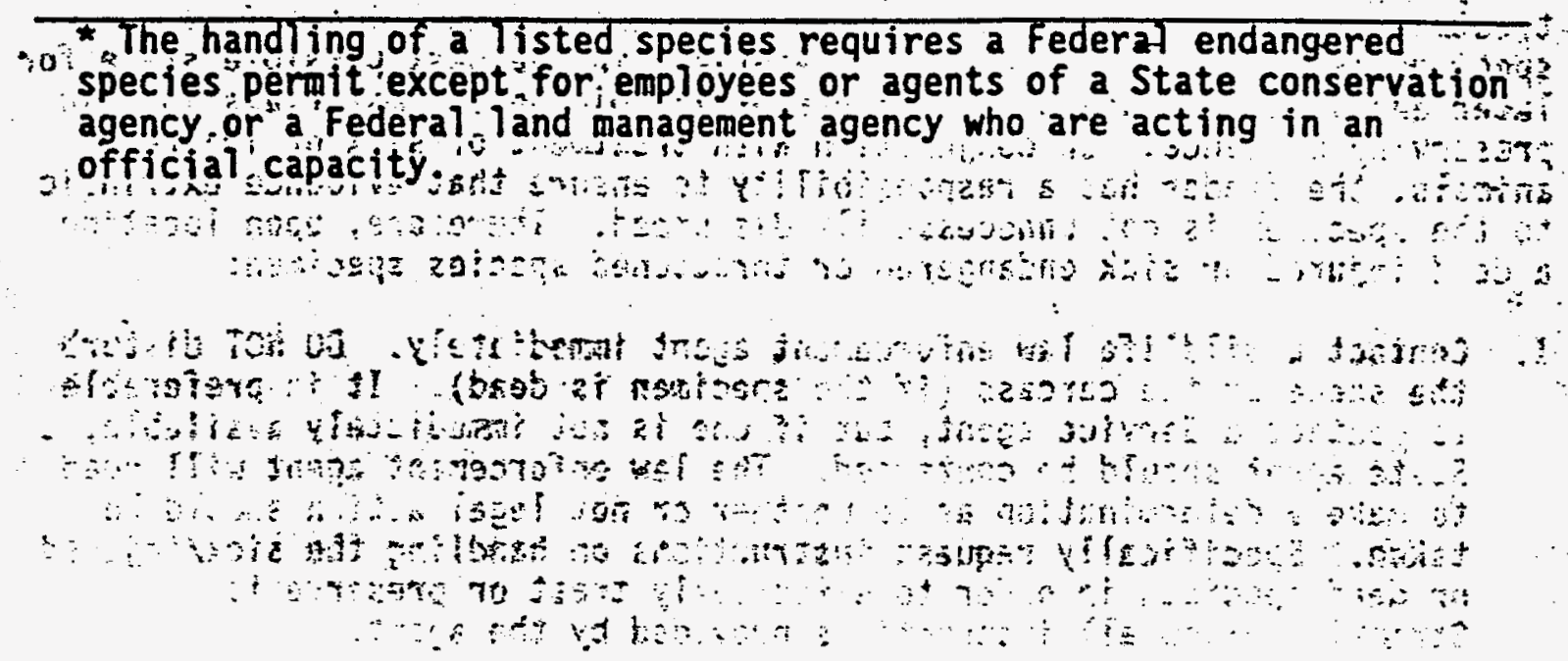

1

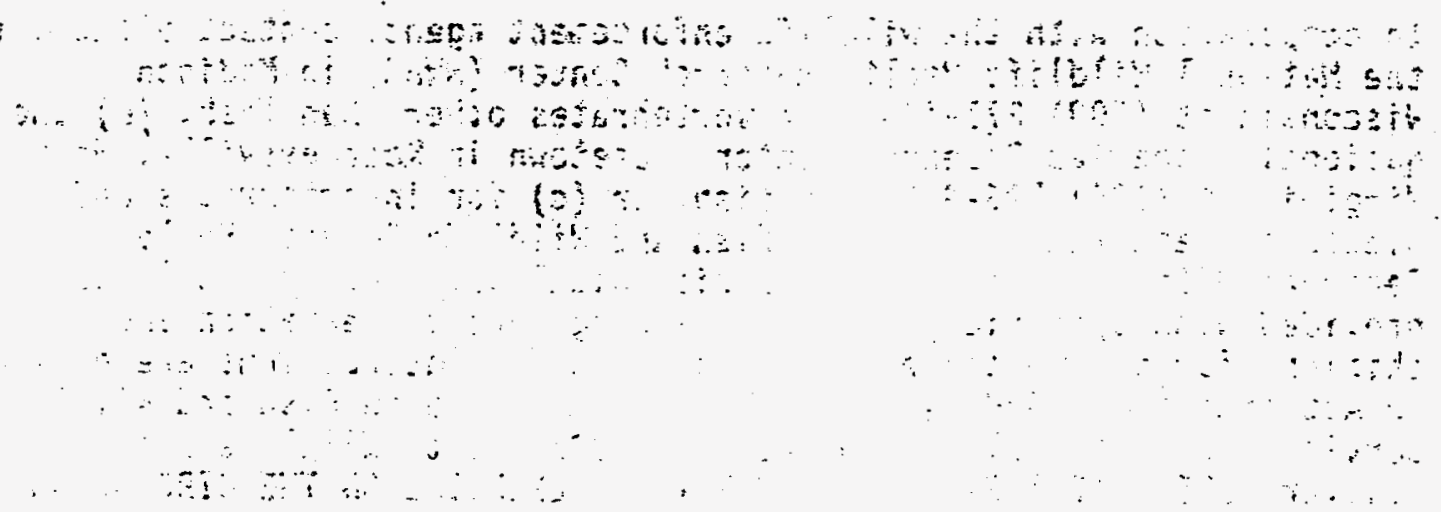


Endangered Species Act Intra-Service Consultation Handbook - November 1994

\section{Attachment 1 \\ SPECIMEN SHIPMENT \\ National Wildlife Health Research Center}

1. Call the Center at (608) $271-4640$ to determine type and number of specimens needed, preservation of specimens during shipment, and when mba they should be shipped. nYur call will be responded to by a nember of the Resource Health Team.

2. Label each specimen, double-bag it, and place it in a styrofoam cooler lined with a plastic bag. Frozen specimens generally do not require ice; they will remain frozen for up to 24 haurs if the volume is large enough (i.e., six frozen mallards in one cooler will, not require ice, but one frozen mallard will) Always use refrigerant with fresh 1 is specimens or intersperse with frozen specimens 3. Blue ice packs are usually the best refrigerant to use. Bock joe or
cubes must be properly baged to prevent leakage. When ice packs are used, intersperse them among specimens and fill in empty space in cooler with newspaper.

4. Close the plastic bag lining the cooler and seal the lid with strapping tape.

5. Tape specimen data sheet and history, contained in an envelope within in a plastic bag, to the top of the cooler.

6. Place the styrofoam cooler in a cardboard box and seal the lid with strapping tape.

7. Address cardboard box to:

National Wildlife Health Research Center

6006 Schroder Road.

Madison, Wisconsin 53711

[Include return address on outside of box.]

8. Write "Diagnostic Specimens (Wildlife)" on outside of cardboard box.

9. Ship on a carrier that can get the package to the Center within 24 hours. Air freight or U.S. Postal Express mail are usually preferred; check prices. Overnight delivery services (DHL, Federal Express, Purolator, or Emery) can also be used but may be significantiy more expensive.

10. Call the Center with an airbill number, carrier used, and estimated time of arrival in Madison. 
Endangered Specles Act Intra-Service Consultation Mandbook - Movember 1994

\section{Attachment 2}

Supplemental Information to be Provided with Carcass Submissions*

\section{Species}

Number Submitted

Date

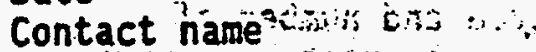

Address and Phone Number

Affiliation

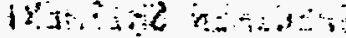

$\because \therefore \quad \begin{aligned} & \text { Location } \\ & \text { County } \\ & \text { State }\end{aligned}$

State

$\therefore \therefore$ Others with kriowledge of this event that could be contacted for further

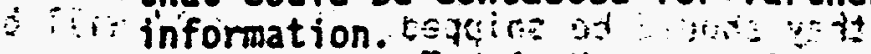

How many sick or dead animals have been found? . Lis9t

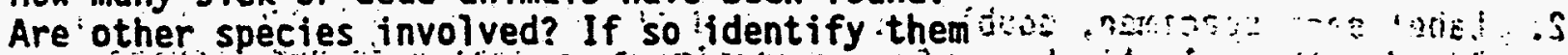

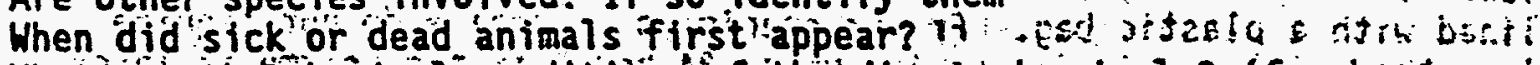
What are the physical conditions of -the' diseased animals? (fresh

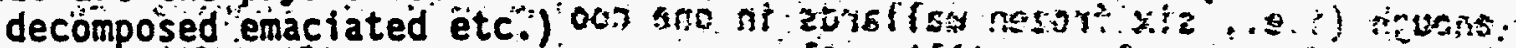
What clinical signs (symptoms) have been observed?

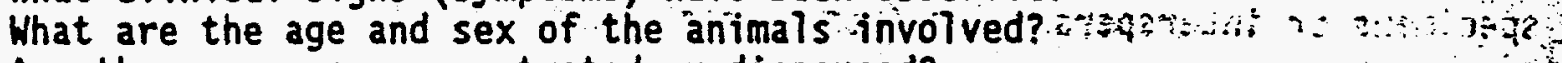
Are the carcasses concentrated or dispersed?

Are the aninals dying quickly or siowiy?

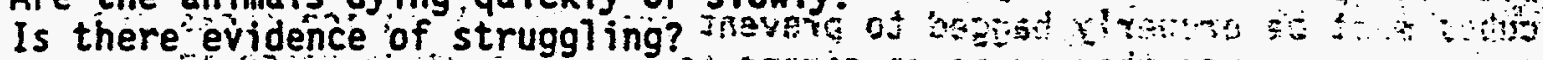
How large an area is involved? and 2 ns What is the general vegetative composition of the area? What are the habitat conditions? What are the major water suppliés? What are the major food supplies? What were the climatic conditions prior to the problem? Have there been any unusual changes on the area recéntly? If so what? is . Are there livestock/poultry or domestic animals on or adjacent to the area? What is the proximity of carcasses to human activities (agriculture mining. etc.) and manmade structures (fences roads power lines train tracks etc.) What pesticides (and formulations) have been used in the vicinity and when and how (aerial ground) were they last applied?

* Provide information to as many of these questions as possible.

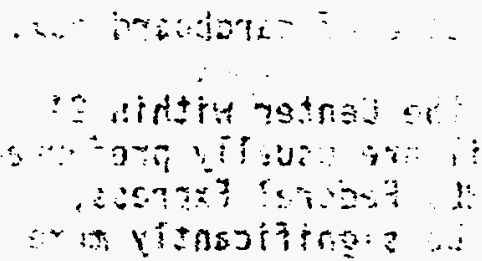

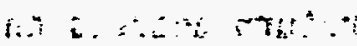




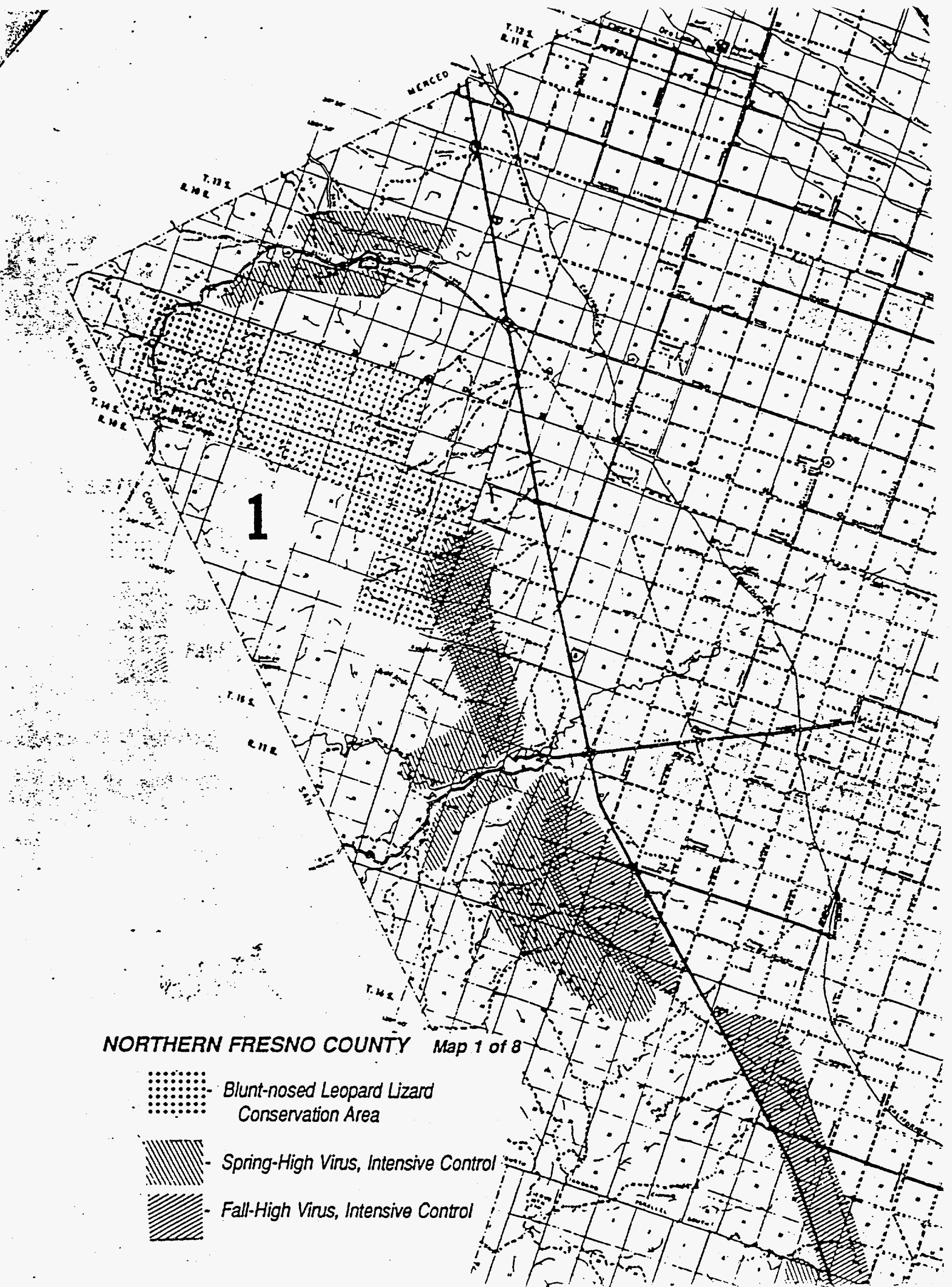


WESTERN FRESNO COUNTY MaP 2 of 8

$:::: \because: \vdots$ B Blunt-nosed Leopard Lizard

$:::::$ : Consenvation Area

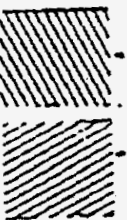

Spring-High Virus, Intensive Controi

Fall-High Virus, Intensive Control

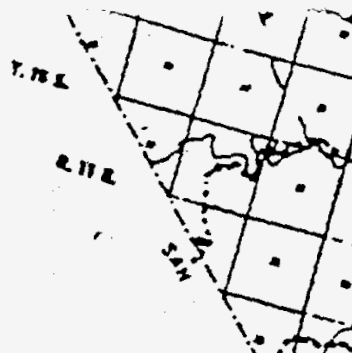

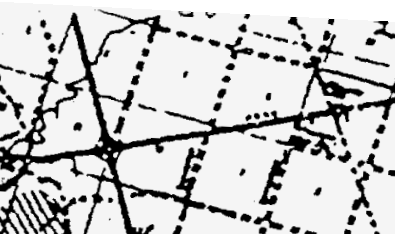

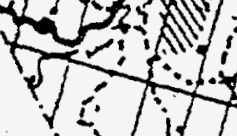

-
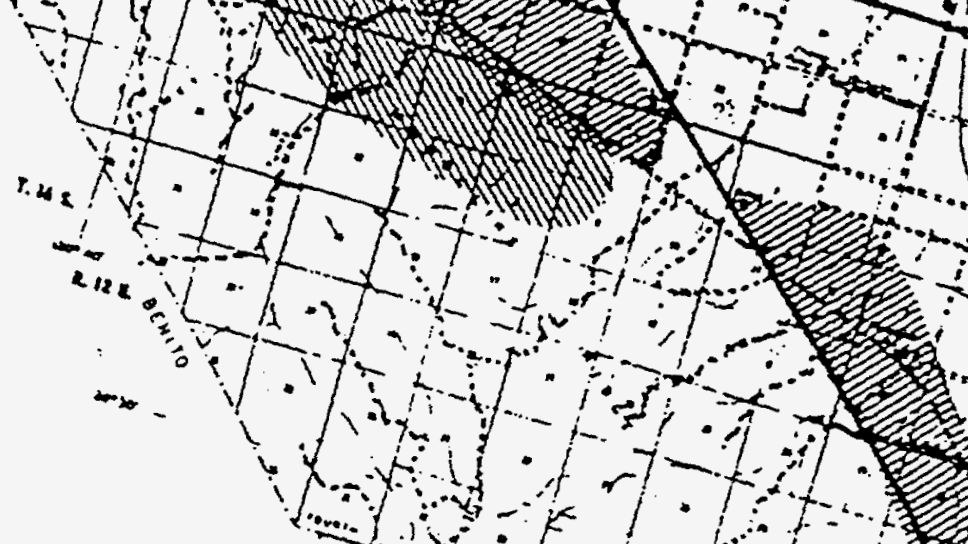

r)

.
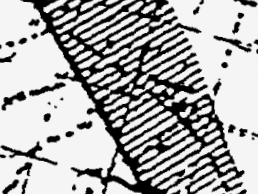


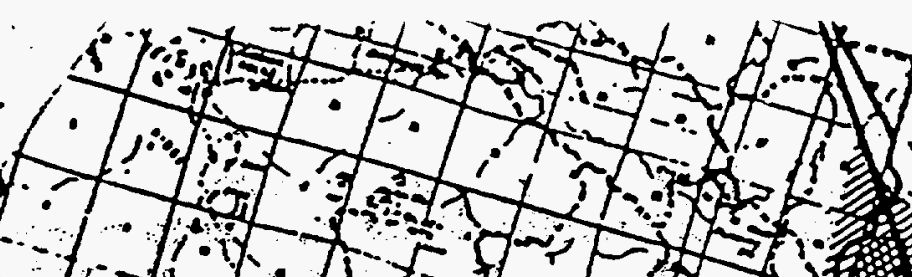




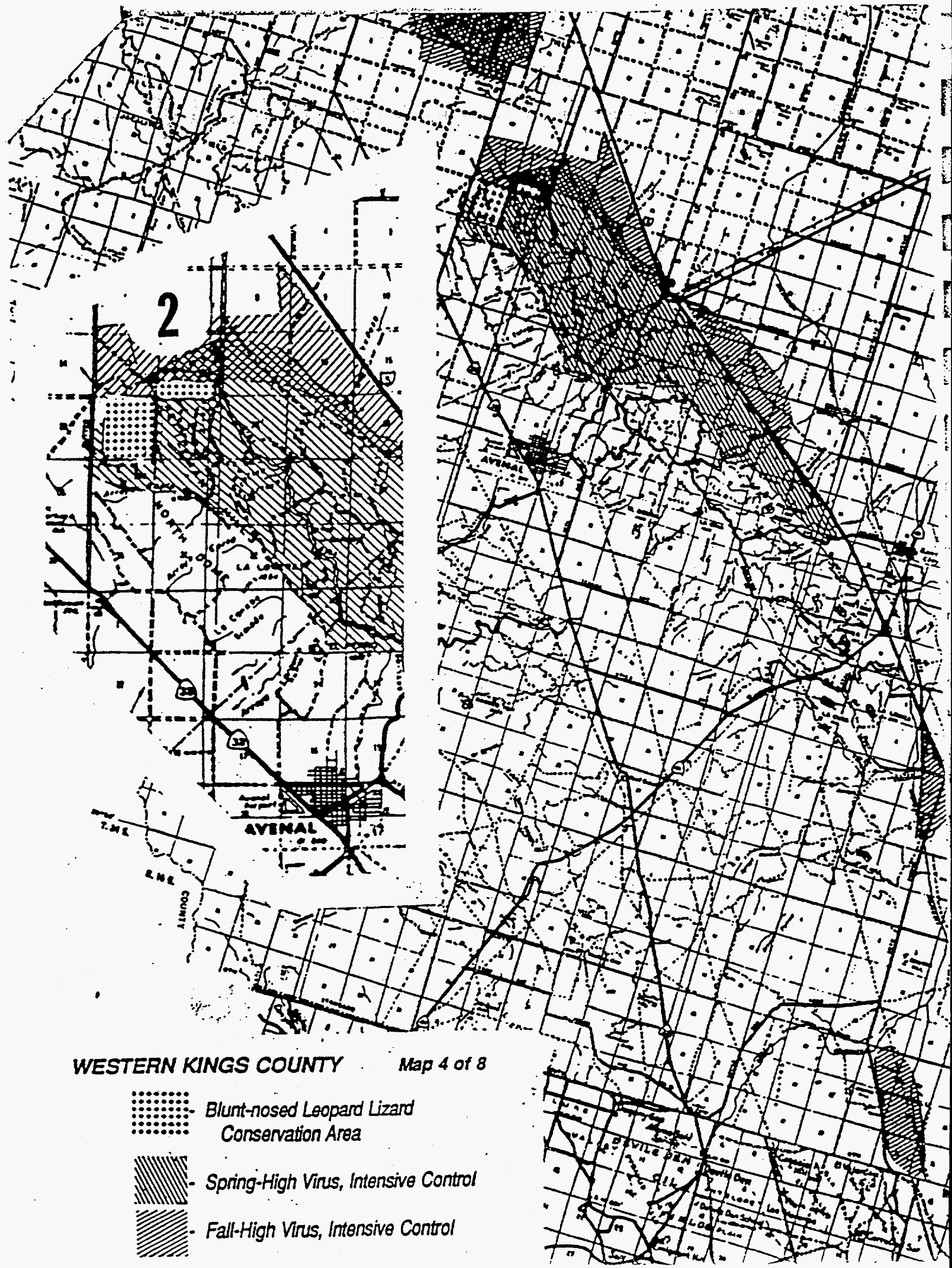




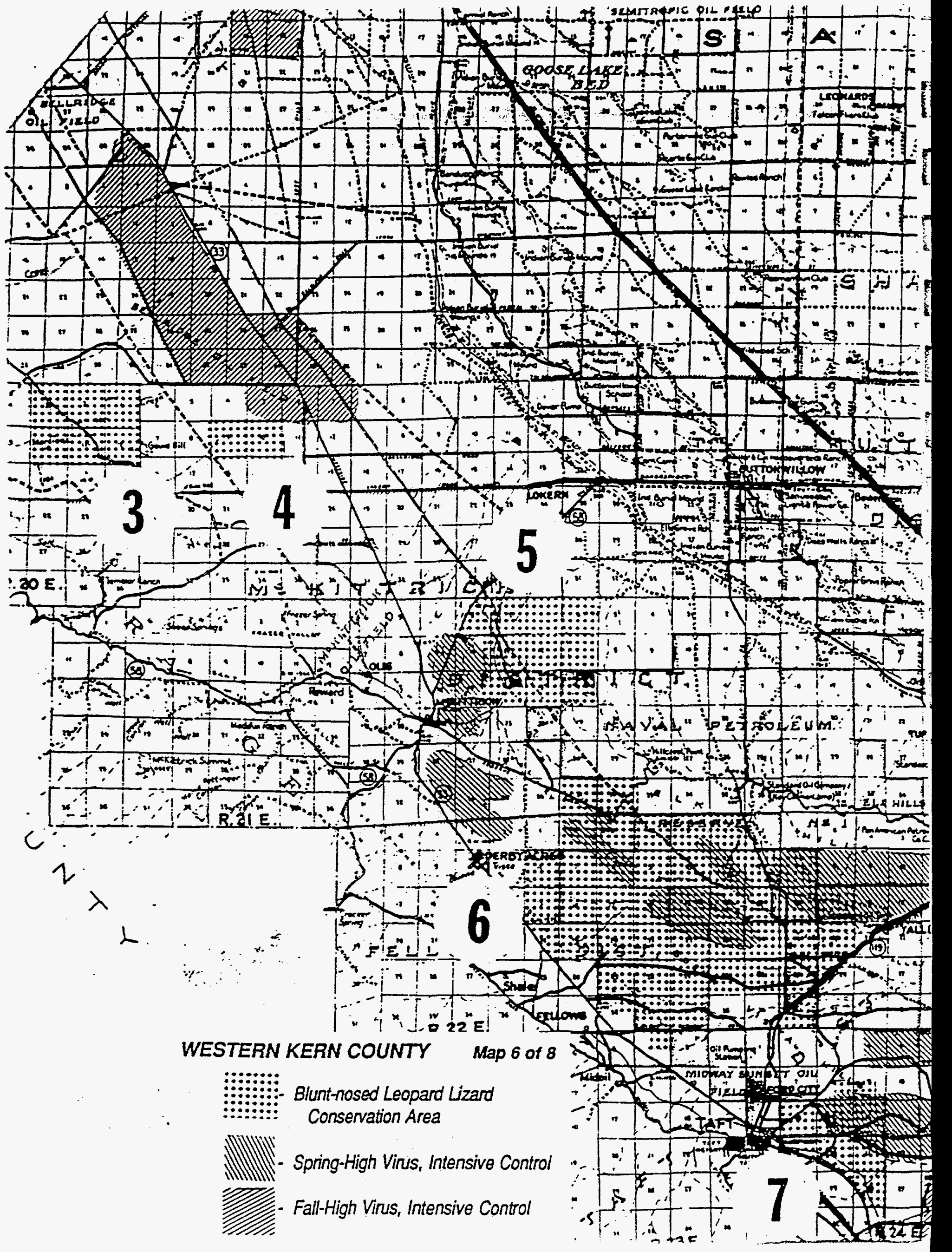


. (n) " -1

(yj)

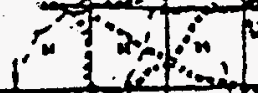

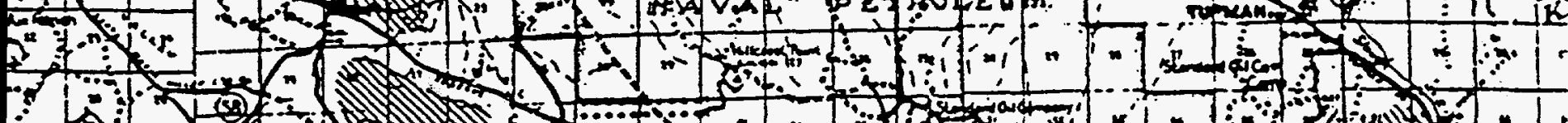
\%

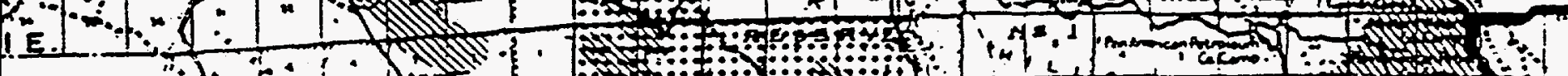
|

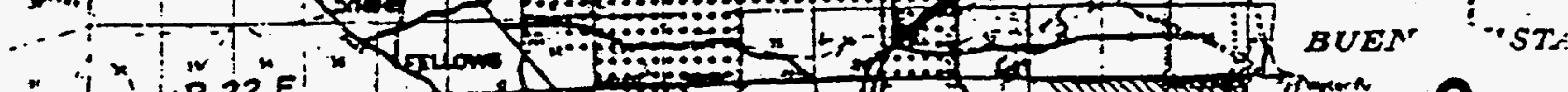
$*$ R. $22^{n} E$

SOUTHWESTERN KERN COUNTY

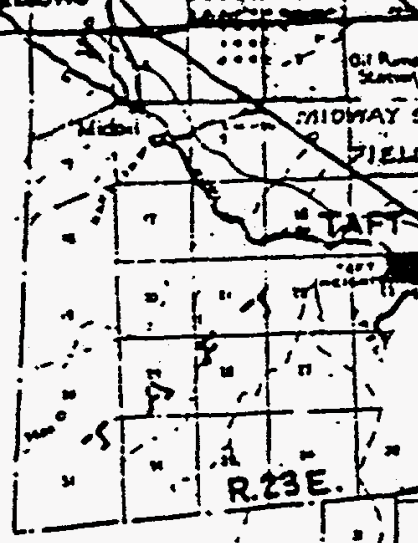

$::::::$ : Blunt-nosed Leopard Lizand

$:::::$ Conservation Area

.) 114 MYII

Spring-High Virus, Intensive Control

У)

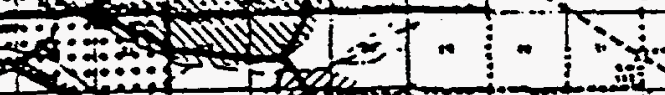

Map 7 of 8
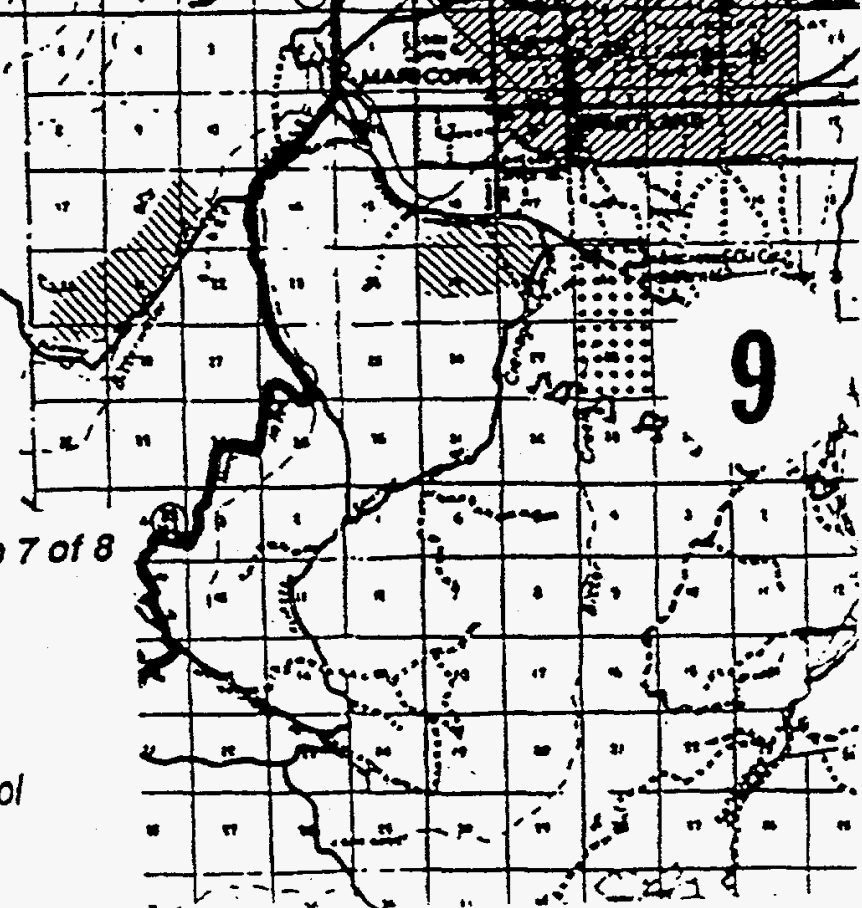


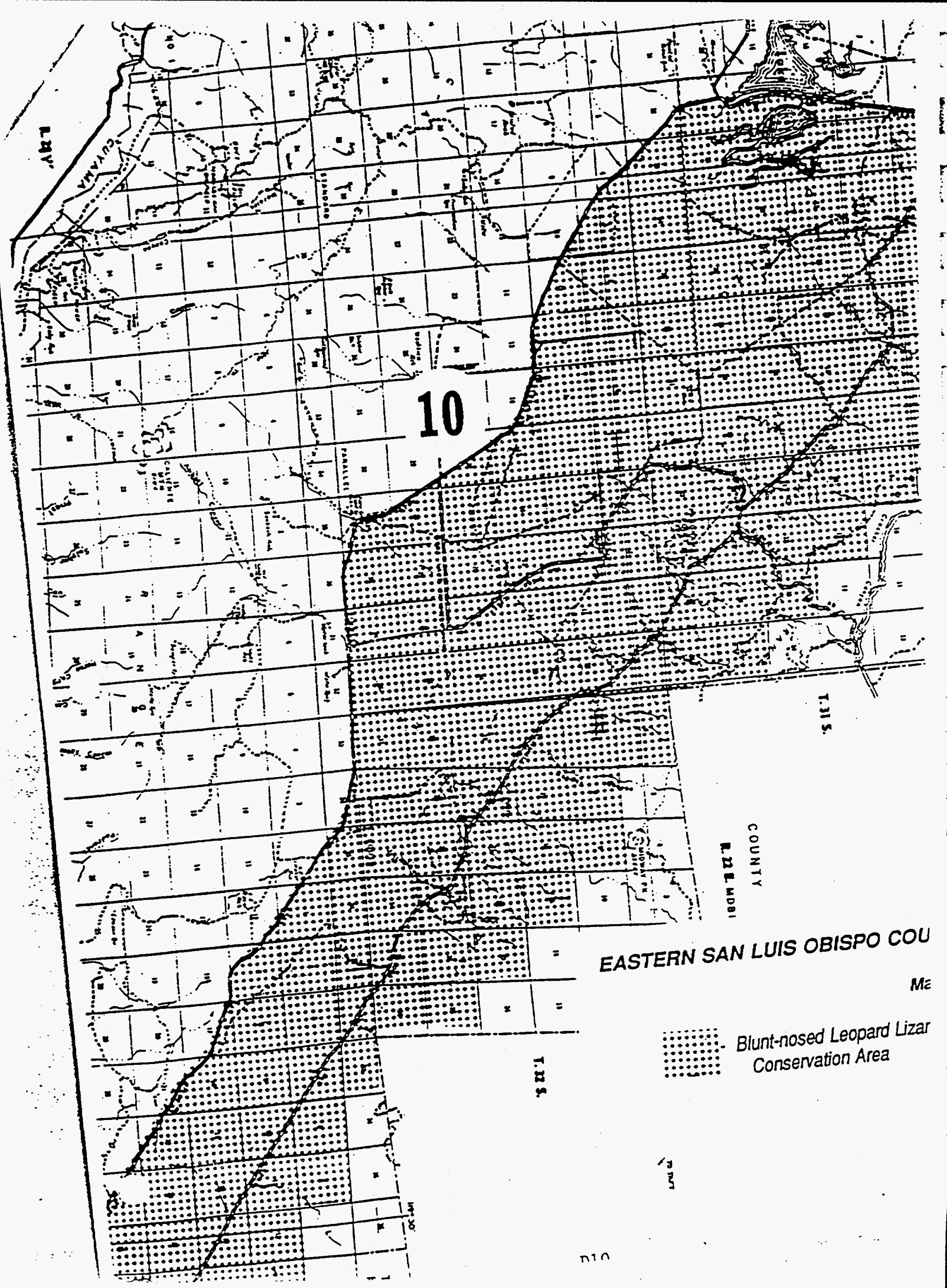




\section{los angeles audubon society}

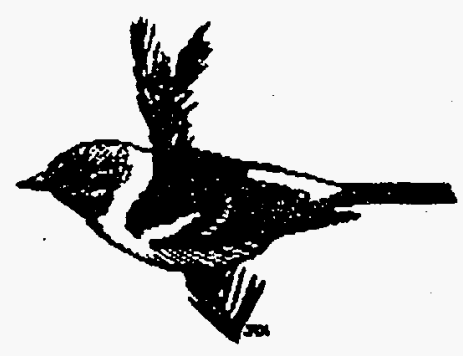

7377 santa monica boulevard • west hollywood, california 90046-6694 • 213 876-0202

January 27,1997

Ed Hastey, State Director

Bureau of Land Management

2135 Butano Drive

Sacramento, California 95825-0451

Re: Malathion Spraying To Control Beet Leafhoppers

Dear Mr. Hastey:

\begin{tabular}{|c|c|c|}
\hline \multicolumn{3}{|c|}{ initis bot. } \\
\hline $7 \sqrt{50}$ & 4 & \\
\hline 2150 & F & \\
\hline ADuir & & \\
\hline$3 \longdiv { 0 0 0 }$ & $M$ & \\
\hline Dos. & 0 & \\
\hline Ei & & \\
\hline mass: & & \\
\hline ILE & & \\
\hline Getum is & & \\
\hline Litrts & & \\
\hline
\end{tabular}

The Los Angeles Audubon Society (LAAS) is a 2,500-member non-profit organization dedicated to the conservation of birds and their natural habitats. Bird survival depends on the continued functioning of complex interactions that characterize an ecosystem. For this reason, LAAS expresses its opposition to renewal of the permit for the State of California Department of Food and Agriculture (CDFA) to spray public lands with the pesticide malathion to control beet leafhoppers. The removal of the lower trophic levels in rangeland food webs through the use of broad spectrum pesticides such as malathion can diminish ecosystem function and cause local collapse of bird populations through trophic effects. A recent report in Audubon magazine (January-February 1597) gives a conservative, well-documented estimate of the number of birds in the United States killed annually by pesticides: 67 million. The State of California should not contribute to this total by spraying pesticides on public lands.

Fortunately, agricuitural pests can be controlled using alternative, less toxic methods. LAAS urges the Bureau of Land Management (BLM) to explore these alternatives, which include biocontrols and pesticides of lower toxicity. The well-known agricultural economist George Ware claims that there is no cbemical treatment effective against leafhoppers (per. com., Laurie Simon, Bio-Integral Resource Center). Agricultural experts instead recommend integrated pest management (IFM) to control lesfhoppers. IPM measures could include the application of insecticidal soap, planting resistant species and covering seedbeds with tow covers. Natural predators are also efficient at controlling leathoppers. For example, green lacewings have been used as biological control agents against a number of species of leafhoppers.

Given that current agricultural science does not seem to support the use of malathion for the control of leafhoppers, we urge the BLM to deny the permit requested by the CDFA If the BLM does continue to allow the use of pesticides on public lands for the control of beet leafhoppers, several options other than malathion exist that would control leafhoppers while minimizing mortality to other insects. Malathion has a high contact toxicity (that is, it kills insects on contact). Amidacloprid, a "biorational" compound, is toxic to insects only through 
Mr. Ed Hastey

January 27, 1997

Page 2

ingestion, sparing parasitoids and camivorous insects, while better targeting pest species (see Agrichemical and Environmental News, June 1994). Another less toxic possibility is dihydroazadirachtin, a natural product from the bark of the neem tree that has been used successfully against leathoppers (se IPM Practitioner, vol. 16, no. 10, October 1994).

Additional information about less toxic methods for control of the bet leafhopper, including integrated pest management and alternative insecticides, can be provided by the Bio-Integral Resource Center, a non-profit organization that provides practical information on least toxic methods for managing pests. They can be reached by telephone at 510-524-2567. The National Pesticide Telecommunications Network, available toll-free at 1-800-858-7378, provides information about alternative insecticides.

LAAS acknowledges that malathion is a relatively mild organophosphate pesticide and has a high LD 50 for birds and mammals. However, we urge the BLM to encourage the CDFA to explore less toxic methods of pest control. Besause our public lands serve to maintain much of California's biodiversity, it is unacceptable to harm the diverse native insect and bird fauna simply to perpetuate unsustainable farming practices for which there are now viable alternatives.

Sincerely,

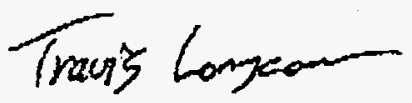

Travis Longcore

First Vice President

cc: Bio-Integral Resource Center 


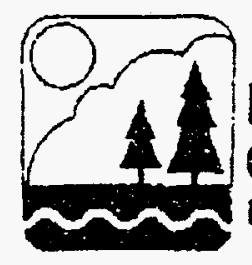

Jan. 20,1997

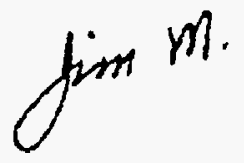

State Director

Buresu of Land Management

2135 Butano Drive

Sacramento, CA 95825

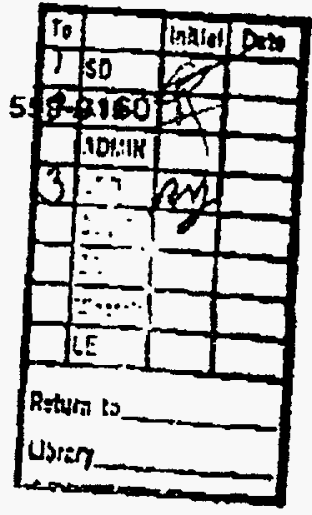

\section{Dear Director,}

It has come to our attention that the Bureau of Land Management and the Department of Energy are considering a request by the State of California, Department of Food and Agriculture for a 5 year permit to treat annual infestations of beet leafnopper insects on public rangelands, in an attenpt to curb the "curly top virus" spread by these insects. Th1s request involves the use of the pesticide malathion.

While we understand the need to control pests that spread viruses to commercial agricultural crops, we are opposed to the use of malathion on public rangelands.

The beet leafhopper, as a vector for "curly top virus", poses an enormous threat to crops, with subsequent losses not only to commercial agricultural enterprises, but also to the general public in the loss of nutritional divers1ty. However, malathion poses an even greater threat to human health and reproductive capacity.

For every insect pest, there is a biologic control/antigote. For example: aphids and ladybugs; mosquicoes and bats. We urge you to consult with all avaliable agriculcural scientists to determine the most effective biological control/antagaonist to the beet leaftopper and to put that control into inmediate effect. What good does it do us to control an agricultural pest if we destroy human life in the process? Solutions other than malathion are available. It is your duty to find and use them.

Sincerely,

Anna Harlowe

Issues Coordinator

sincerely,

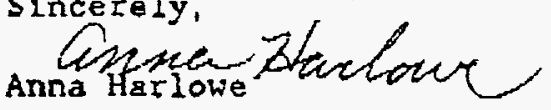

Issues Coordinator 


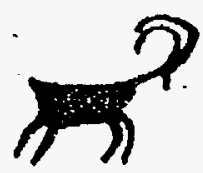

DESERT

SURVIVORS

State Director

Bureau of Land Management 2135 Butano Drive

Sacramento, CA 95825-0451

State Director:

January 2, 1997

I have received a notice about proposed spaying for "curly top virus" on public lands in the San Joaquin Valley and in Riverside and Imperial Counties. According to the news release of December 27, an Environmental Assessment" is available. Please send me copies of both the Environmental Assessment and the "pesticide use permit" that you intend to approve. I would like to comment by January 31, 1997, per your requirements.

Send the above-mentioned documents to me at the address below.

(510) $769-1706$

Sincerely,

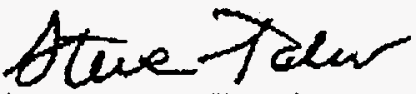

Steve Tabor, President

Desert Survivors

P.O. Box 20991

e-mail: StevTabor@AOL.com

Oakland, CA 94620-0991

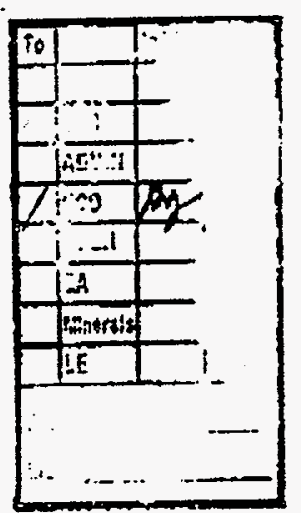

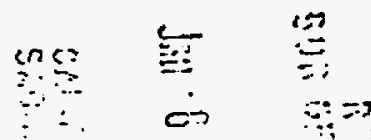




\section{REFERENCES CITED}

Bollen, W. B., 1961. Interactions Between Pesticides and Soil Micro-organisms. Ann. Rev. Microbiol. 15:69-92.

Bolster, Betsy and Kimberly Nicol, 1989. The Status of the Flat-tailed Horned Lizard (Phrynosoma mcallii) in California. State of California, The Resources Agency, Department of Fish and Game, Sacramento, CA.

Bourquin, A. W., 1977. Effects of Malathion on Microorganizms of an Artificial Salt Marsh Environment. J. Environ. Qual. 6(4):373-387.

Buckman, H. O.; Brady, N. C., 1969. The Nature and Properties of Soils. London, England: MacMillian Publishing Co., Collier-MacMillian Limited.

California Department of Fish and Game, 1992 Annual Report on the Status of California's State Listed Threatened and Endangered Plants and Animals.

California Department of Food and Agriculture, April 1994. The Exotic Fruit Fly Eradication Program Using Aerial Application of Malathion and Bait- Final EIR. State Clearinghouse Number 91043018

California Department of Health Services, 1991. Health Risk Assessment of Aerial Application of Malathion-Bait. $458 \mathrm{pp}$.

California Department of Water Resources, 1969. San Joaquin Valley Drainage Monitoring Program; 1969 Summary. Sacramento, CA.

Culley, D. C. and H. G. Applegate, 1967. Insecticide Concentrations in Wildlife at Presidio, Texas. Pest Monitoring Journal: 1 (2) 21-28.

Curley, W. H.; Donohue, J. M., 1986. Risk Analysis of Multiple Pesticide Applications for the Rangeland Management Program. Virginia: V. J. Ciccone and Associates, Inc.

Davillers, J. and Donohue, J.M., 1992. Ecotoxicity of chemicals to amphibians. Handbooks of Ecotoxicological Data (ed. J. Devillers), Vol. 1. Gordon and Breach Science Publishers, Philadelphia.

DOI, U.S. Department of the Interior, 1963. Pesticide Wildlife Studies - A Review of Fish and Wildlife Service Investigations During the Calendar Year. U.S. Department of the Interior, Circular 199. 
Dobroski, C. J., Jr.; Lambert, W. P., 1984. Malathion: A Profile of its Behavior in the Environment. Submitted to U. S. Department of Agriculture, Animal and Plant Health Inspection Service, Plant Protection and Quarantine. Contract 53-6395-1-151.

Eng, Larry L.; Belk, Denton; and Eriksen, Clyde H., 1990. California Anostraca: Distribution, Habitat, and Status. Journal of Crustacean Biology, 10(2): 247-277.

EPA, U.S. Environmental Protection Agency, 1986. Memorandum from William L. Burnam, Deputy Chief, Hazard Evaluation Division, to U. S. Department of Agriculture, Animal and Plant Health Inspection Service; September 4, 1986.

EPA, U. S. Environmental Protection Agency, 1975. Substitute Chemical Program-Initial Scientific and Minieconomic Review of Malathion. Midwest Research Institute. Kansas City, Missouri and Criteria and Evaluation Division OPP, EPA, Washington D. C.

Fischer, P., 1966. Effects of Aircraft Applications of Malathion on Fish and Aquatic Invertebrates. Federal Aid Project No. F-17-R-1, Job No. 8. Parks and Wildlife Department, Austin, TX.

Gains, T. B., 1969. Acute Toxicity of Pesticides. Toxicol. Appl. Pharmacol., 14:515-534.

Garrestson, A. L.; San Clemente, C.L., 1968. Inhibition of Nitrifying Chemolithotropic Bacteria by Several Insecticides. J. Econ. Entomol. 61(1):285-288.

Giles, R. H., Jr., 1970. The Ecology of a Small Forested Watershed Treated with the Insecticide Malathion-S35. Wild. Monogr. No. 24.

Hall, Russell J. and Clark, Donald R, 1982. Responses of the Iguanid Lizard Anolis Carolinensis to Four Organophosphorus Pesticides. Environmental Pollution (Series A) 28 (1982) pp. 45-52.

Hall, R. J. and Kolbe, E., 1980. Bioconcentration of Organophosphorus Pesticides to Hazardous Levels by Amphibians. J. Tox. and Environ. Health 6(4):853-860.

Hansen, D. J.; Keltner J. M. Jr. and Schimmel, S., 1973. Avoidance of Pesticides by Grass Shrimp (Palaesmonetes pugio). Bull Environ Contam Toxicol, 9(3): 129-133, 1973.

Hardy, Alan R. and Andrews, Fred G., 1979. An Inventory of Selected Coleoptera from the Algodones Dunes. Contract number CA-060-CT8-68. Calif. Dept. of Food and Agriculture.

Hill, E. F.; D. A. Eliason; and J. W. Kilpatric, 1971. Effects of Ultra-Low Volume Applications of Malathion in Hale County, Texas, J. Med. Entomol., 8(2):173-179. 
Hopkins, Jean \& Associates, Inc., September 11, 1994. Pleasant Valley Habitat Conservation Plan (administrative review draft). Prepared for: Pleasant Valley HCP Steering Committee. Huddleston, E. W.; Ward, C. R.; Pulley, J. L., 1968. Spring Population Trends of Non-target Insects Following the Fourth Year of the High Plains Boll Weevil Control Program. Entomol. Reports No. 68-2 (Supplemental).

Huddleston, E. W.; Ward, C. R.; Pulley, J. L., 1968. Spring population trends of nontarget insects following the fourth year of the high plains boll weevil control program. Entomological Reports No. 68-2 (Supplemental).

Kato, Thomas T., Barbara R. Rose and Thomas P. O'Farrell, 1987. Diet of the Blunt-nosed Leopard Lizard, Gambelia silus, on Naval Petroleum Reserves No. 1 and No. 2 Kern County, CA. E.G.\&G. Energy Measurements, Goleta, CA.

Kenaga, E. E. and Goring, C. A., 1980. Relationship Between Water, Solubility, Soil Sorption; Octanol-water Partitioning, and Concentration of Chemicals in Biota. Aquatic Tox. ASTM STP 707, 78-115.

Manser, P. D., and F. D. Bennett, 1962. Possible Effects of the Application of Malathion on the Small Moth Borer, Diatraea saccharalis $(F)$, and Its Parasite Lizophaga diatraea (Tns.) in Jamaica, Bull. Entomol. Res. 53:75-82 (1962/1963).

Matsumura, F.; Boush, G. M., 1966. Malathion Degradation by Trichodermaviride and a Pseudomonas Species. Science 153:1278-1280.

Mazer. S.; Hendrickson, B. July, 1993. Demography and Reproductive Biology of San Joaquin Woolly Threads (Lembertia congdonii: Asteraceae). Final report to the State of California Department of Fish and Game, contract \# FG 1460. Department of Biological Sciences University of California, Santa Barbara.

Mazer, S.; Hendrickson, B., Sept. 1993. Demography, Ecology and Reproductive Biology of the California Jewelflower (Caulanthus californicus: Brassicaceae). Final report to the State of California, Department of Fish and Game, contract \# FG 1461. Department of Biological Sciences, University of California, Santa Barbara.

Metcalf, R. L., 1972. DDT Substitutes, Crit. Rev. Environ. Contr., 3(1):25-59, Ref. 110.

Montanucci, Richard R., 1965. Observations on the San Joaquin Leopard Lizard (Crotophytus wislizenii silus Stejnegar). Herpetologica Vol. 21 No. 4. 1965.

Mulla, M. S.; Mian. L. S., 1981. Biological and Environmental Impacts of the Insecticide Malathion and Parathion on Nontarget Biota in Aquatic Ecosystems. Residue Rev. 78:101-135. 
Murray, H.E. and Guthrie, R. K., 1980. Effects of Carbaryl, Diazinon, and Malathion on Native Aquatic Populations of Microorganisms, Bull. Environ. Cont. Tox. 24(4): 535-542, 1980.

NIOSH, National Institute for Occupational Safety and Health, 1987. Registry of Toxic Effects of Chemical Substances. Washington, DC: Government Printing Office.

NLM, National Library of Medicine, 1988. Hazardous Substances Databank. Bethesda, MD: National Institute of Health.

Paris, D.F. and Lewis, D. L., 1974. Rates and Products of Degradation of Malathion by Bacteria and Fungi from Aquatic Systems, presented at the 167th National Meeting of the American Chemical Society, Division of Pesticide Chemistry, Los Angeles, CA.

Pascal, D. C., Neville, M. E., 1976. Chemical and Microbial Degradation of Malaoxon in an Illinois Soil. J. Environ. Qual. 5(4):441-443.

Peterle, Tony J. and Giles, Robert H., January 1964. New Tracer Techniques for Evaluating the Effects of an Insecticide on the Ecology of a Forest Fauna. The Ohio State University Research Foundation, $435 \mathrm{pp}$.

Piemeisel, R. L., Chamberlain, J. C., 1936. Land Improvement Measures in Relationship to a Possible Control of the Beet Leafhopper and Curly Top Virus. U.S. Department of Agriculture, Circular No. 416.

Severin, H. H. P., 1933. Field Observations on the Beet Leafhopper, Eutettix tenella, in California." Hilgardia 7: 281-360.

Snelling, Roy R. and Chris D. George, 1979. The Taxonomy, Distribution and Ecology of California Desert Ants. B.L.M. Contract No. CA-060CT8-000007.

Snow, Carolyn, January 15, 1972. Habitat Management Series for Endangered Species. Technical Note. Bureau of Land Management Technical Note. Report No. 3 Blunt-nosed Leopard Lizard, Crotophytus silus. B.L.M. Portland Service Center. Portland, Oregon.

Spiller, D., 1961. A Digest of Available Information on the Insecticide Malathion, Adv. Pest Control Res., Vol. IV, Interscience Publishers.

Stucky, N.P., 1976. Direct Effects of Wide-area Malathion Application on Fish. Trans. Nebr. Acad. Sci. 3:69-73, 1974.

Tagatz, M. E., Borthwick, P. W., Cook, G. H. and Coppage, D. U., 1974. Studies on Effects of Ground Applications of Malathion on Salt Marsh Environments in Northwestern Florida". Mosquito News, 16 pp. 
Tollestrup, Kristine, 1972. "The Ecology, Social Structure, and Foraging Behavior of Two Closely Related Species of Leopard Lizards, Gambelia silus and Gambelia wislizenii". University of California, Berkeley. Pages 44-47.

Tucker, R. K. and Crabtree, D. G., 1970. Handbook of Toxicity of Pesticides to Wildlife. U. S. Fish and Wildlife Service Resource Publication 84.

Twisselman, Emest C., 1967. A Flora of Kern County, California. Reprinted by the California Native Plant Society with permission from the University of San Francisco from the Wasmann Journal of Biology, Vol. 25, Nos. 1 and 2, 1967.

USDA, U.S. Department of Agriculture (APHIS), 1991. National Boll Weevil Cooperative Control Program: Final Environmental Impact Statement, Washington, DC: U. S. Department of Agriculture.

USDA, U.S. Department of Agriculture, 1985. Gypsy Moth Suppression and Eradication Projects: Final Environmental Impact Statement. Washington, DC: U.S. Department of Agriculture.

U. S. Fish and Wildlife Service, May 1991. Biological Opinion for use of Malathion to Control Curly Top Virus in Imperial, Los Angeles and Riverside Counties, California (1-6-91-F-20). U. S. Fish and Wildlife Service, Southern California Field Station, Laquina Niguel, CA.

U. S. Fish and Wildlife Service, Sept. 1991. "Formal Section 7 Consultation on Renewal of a Fiveyear Pesticide Use Permit to the California Department of Food and Agriculture for Use of Malathion to Control Curly Top Virus, 1-1-91-F-6 (San Joaquin Valley/Coastal Valley Element). U. S. Fish and Wildlife Service, Sacramento Field Office, Sacramento, CA.

U. S. Fish and Wildlife Service, 1993. Proposed Rule to list the Southwestern Willow Flycatcher Endangered with Critical Habitat. Federal Register, Vol. 58, No. 140, page 39502, July 23, 1993.

U. S. Fish and Wildlife Service, July, 1994. Biological Opinion 1-1-93-F-47, Formal Section 7 Consultation Concerning Label Restrictions for Strychnine Use Within 9 Counties of California, July 15, 1994. Sacramento Field Office.

U. S. Fish and Wildlife Service, Sept., 1994. Determination of Endangered Status for the Conservancy Fairy Shrimp, Longhorn Fairy Shrimp, and the Vernal Pool Tadpole Shrimp, and Threatened Status for the Vernal Pool Fairy Shrimp, Final Rule." Federal Register, Vol.59, No. 180 , page 48136, September 19, 1994.

U. S. Fish and Wildlife Service, Department of Interior 1994. Code of Federal Regulations (50 CFR, CH1) Critical habitat-fish and wildlife (17.95) and Critical habitat-plants (17.96), October 1, 1994. 
U. S. Fish and Wildlife Service, July, 1996. Formal Section 7 Consultation on Renewal of a Five-year Pesticide Use Permit to the California Department of Food and Agriculture for Use of Malathion to Control Curly Top Virus" (1-6-96-F-32), U. S. Fish and Wildlife Service, Carlsbad Field Office, Carlsbad, California.

Wall, J. and Marganian, V. M. Jr., 1971. Control of Culicoides melleus with Granular Organophosphorus Pesticides, and the Direct Effects on Other Fauna. Mosquito News, 31(2): 209214.

Wheeler, G. C. and J. Wheeler, 1973. Ants of Deep Canyon. University of California, Riverside. xiii $+126 \mathrm{pp}$.

Wolfe, N.L. et al., 1977. Kinetics of Chemical Degradation of Malathion in Water. Environ. Sci. Technol. 11(1):88-93.

Yokomi, Raymond Kazoo, 1979. Phenological Studies of Circulifer tenellus (Baker) (Homoptera: Cicadellidae) in the San Joaquin Valley of California. Doctoral thesis University of California, Davis. Davis, CA. 


\section{REFERENCES REVIEWED, BUT NOT CITED}

Abrams, Leroy, 1968. Illustrated Flora of the Pacific States. Stanford University Press, Stanford, CA. Vols. I-IV.

American Birds, Eighty-ninth Christmas Bird Count (1988) Vol. 43, No. 4: Carrizo Plains, CA; Martinez Lake, Yuma, AZ; Panoche Valley, CA; Salton Sea (south), CA; San Jocund Lake, CA.

Barbour, Michael G. and Major, Jack, 1977. Terrestrial Vegetation of California. A WileyInterscience publication, John Wiley \& Sons, Inc.

Brode, John M. et al, 1980. Blunt-nosed Leopard Lizard Recovery Plan. U. S. Fish and Wildlife Service Endangered Species Program, Region I. Portland, Oregon.

California Department of Fish and Game, March 1990. 1989 Annual Report on the Status of California's State Listed Threatened and Endangered Plants and Animals.

California Department of Fish and Game, February 1994. Special Plants List: Natural Heritage Division, Natural Diversity Data Base.

California Department of Fish and Game, July 1994. Endangered and Threatened Animals of California. Natural Heritage Division, Natural Diversity Data Base.

California Department of Fish and Game, October 1994. Designated Endangered, Threatened or Rare Plants by County. Region 4.

California Department of Health Services, December 1980. Understanding Malathion and the Mediterranean Fruit Fly Eradication Program.

California Native Plant Society, February 1994. Inventory of Rare and Endangered Vascular Plants of California. Special Publication \#1, Fifth Edition.

Cole, Arthur C. Jr., 1969. Pogonomyrex Harvester Ants: A Study of the Genus in North America. University of Tennessee Press. Knoxville, Tennessee.

Department of Energy, September 1994. Environmental Assessment for Continued Exploration, Development, and Operation-Naval Petroleum Reserve \#2 (Buena Vista Hills) Kern County, California; Draft.

Endemic Species Committees, 1977. Endemic Fishes of the Colorado River System-A Status Report. Colorado River Wildlife Council, 16pp. 
E.G.\&G., Energy Measurements, 1986. Biological Assessment of the Effects of Petroleum Production at Maximum Efficient Rate, Naval Petroleum Reserve No. 1 (Elk Hills), Kern County, California, on the Endangered Blunt-nosed Leopard Lizard (Gambelia silus). E.G.\&G. Energy Measurements, Santa Barbara, CA.

Fletcher, J. L.; Busnel, R. G., eds., 1978. Effects of Noise on Wildlife." New York, NY: Academic Press.

Flock, R. A, R. L. Doult, R. C. Dickson and E. E. Laird, 1962. A Survey of Beet Leathopper Egg Parasites in the Imperial Valley, California. J. Econ. Entomol. 55: 227-281.

Glazer, H. S. R., 1970. The Distribution of Amphibians and Reptiles in Riverside County, CA. Riverside Museum Press, Natural History Series. No. 1. 40pp.

Hartung, W. J. and H. H. P. Severin, 1915. Natural Enemies of the Sugar Beet Leafhopper in California. California State Commission Horticulture Monthly Bulletin 4: 277-279.

Hickman, James C., 1993. The Jepson Manual: Higher Plants of California. University of California Press.

Howitt, Beatrice F. and Howitt, John Thomas, 1964. The Vascular Plants of Monterey County, California. Reprinted from the Wasmann Journal of Biology, Vol. 22, No. 1, Spring 1964.

Hudson, R. H.; Tucker, R. K.; Haegele, M. A., 1984. Handbook of Toxicity of Pesticides to Wildlife. Resources Publication 153. Washington, DC: U.S. Department of the Interior, Fish and Wildlife Service.

Ingles, Lloyd G., 1970. Mammals of the Pacific States. Stanford University Press. Stanford, CA.

Jepson, Willis Linn, 1951. A Manual of the Flowering Plants of California. University of California Press. Berkeley.

Kato, Thomas T., Barbara R. Rose and Thomas P. OFarrell, 1987. Distribution, Abundance, and Habitat Use of the Endangered Blunt-nosed Leopard Lizard on the Naval Petroleum Reserves, Kern County, California. E.G.\&G. Energy Measurements.

Knowiton, G. F. and M. J. Janes, 1933. Lizards as Predators of the Beet Leafhopper. J. Econ. Intimal. Vol. 26 1011-1016.

Lawson, Francis R., Joseph C. Chamberlain and George T. York, 1951. Dissemination of the Beet Leafhopper in California. U. S. Department of Agriculture. Washington D. C. 
Maramorosch, Karl and Kerry F. Harris, 1979. Leafhopper Vectors and Plant Disease Agents. Academic Press. New York.

1981. Plant Diseases and Vectors. Academic Press. New York.

Mayer, F. L., Jr., Ellersieck, M. R., 1986. Manual of Acute Toxicity: Interpretation and Data Base for 410 Chemicals and 66 Species of Fresh-water Animals. 579 pp., Washington, DC: U. S. Department of the Interior, Fish and Wildlife Service. Resource Publication 160.

Mazer, S.; LeBuhn, G.; Meade, D., 1993. Demography and Reproductive Biology of Kern Mallow (Eremalche kernensis: Malvaceae). Final report to the State of California, Department of Fish and Game, contract \# FG 1460. Department of Biological Sciences, University of California, Santa Barbara.

Montanucci, Richard R., 1968. Notes on the Distribution and Ecology of Some Lizards in the San Joaquin Valley, California. Herpetologica 24: 316-320.

. 1969. Remarks upon the Crotophytus-Gambelia Controversy (Sauria Iguanidae). Herpetologica 25: 308-314.

Peterson, Roger Tory, 1990. A Field Guide to Western Birds. Houghton Mifflin Co. Boston.

Piemeisel, R. L., 1932. Weedy Abandoned Lands and the Weed Host of the Beet Leafhopper. U. S. Department of Agriculture, Circular No. 229.

and Lawson F. R., 1937. Types of Vegetation in the San Joaquin Valley of California and their Relationship to the Beet Leafhopper. U.S. Department of Agriculture, Tech. Bulletin No. 557.

Quad Consultants, 1981. Rare and Endangered Plant Inventory: California Aqueduct R.O.W. From Mile Post 155.64 to Mile Post 293.45. California Department of Water Resources. Sacramento, CA.

Rado, Theodore, A. Analysis of Actual and Potential Loss of Flat-tailed Horned Lizard (Phrynosoma mcallii) Habitat. Unpublished. U.S. Department of the Interior. B.L.M. Sacramento, CA.

Roberts, J. E., R. D. Chisholm and L. Koblitsky, 1962. Persistence of Insecticides in Soil and their Effect on Cotton in Georgia. J. Econ. Intimal. 55 (2).

Severin, H. H. P., 1919. The Beet Leafhopper: A Report on Investigations into Occurrences in California. Facts About Sugar 8:130-131. 
- 1922. The Life History of the Beet Leafhopper. A Record from Studies of Eutettix tenella conducted in the San Joaquin Valley, CA." Facts About Sugar 14.9 92-93.

Smith, Kenneth M., 1972. A Textbook of Plant Viruses. Academic Press, New York.

State of California, 1980. At the Crossroads: A Report on the Status of California's Endangered and Rare Fish and Wildlife. Resources Agency, Fish and Game Commission and the Department of Fish and Game, Sacramento, CA.

Stebbins, Robert C., 1966. A Field Guide to Western Reptiles and Amphibians. Houghton Mifflin Co. Boston.

Taylor, Dean Wm. and William B. Davilla, 1986. Status Survey of Three Plants Endemic to the San Joaquin Valley and Adjacent Areas, California, U. S. Fish and Wildlife Service, 2800 Cottage Way, Sacramento, CA.

Turner, Frederick B., James C. Rorabaugh, Eric C. Nelson and Mark C. Jorgensen, 1980. A Survey of the Occurrence and Abundance of the Flat-tailed Horned Lizard (Phrynosoma mcallii) in California. Laboratory of Nuclear Medicine and Radiation Biology. University of California, L. A. 90024. B.L.M. Contract No. YA-512-CT8-58.

USAF, U.S. Air Force, 1984. Air Installation Compatible Use Zone Handbook. Washington, DC: U. S. Department of the Air Force.

U. S. Department of the Interior, Bureau of Land Management, July 1987. Recreation Area Management Plan and Environmental Assessment for the Imperial San Dunes. Department of the Interior, Bureau of Land Management, El Centro Resource Area, CA.

U. S. Department of the Interior, Bureau of Land Management, 1990. Management Strategy for the Flat-tailed Homed Lizard (Phrynosoma mcallii) on Bureau of Land Management Administrated Lands within the California Desert Conservation Area. U. S. Department of the Interior, Bureau of Land Management, Sacramento, CA.

U. S. Department of the Interior, Fish and Wildlife Service, June 14, 1989. U.S. Fish and Wildlife Service Biological Opinion on Selected Pesticides. U.S. Department of Commerce.

U. S. Fish and Wildlife Service, 1985. Blunt-nosed Leopard Lizard Recovery Plan. U. S. Fish and Wildlife Service, Portland, Oregon. 85pp.

U. S. Fish and Wildlife Service, 1993. Determination of Threatened Status for the Giant Garter Snake. Federal Register, Vol. 58, No. 201, pages 54053-54065, October 20, 1993. 
U. S. Fish and Wildlife Service, 1994. Proposed Rule to list the Laguna Mountains Skipper and Quino Checkerspot Butterflies as Endangered. Federal Register, Vol.59, No. 149, pages 39868-39873, August 4, 1994.

U. S. Fish and Wildlife Service, 1995. Endangered and Threatened Wildlife and Plants. 50 CFR $17.11 \& 17.12$, October 31, 1995. 


\section{APPENDIX LISTING}

Page

Appendix A Description of BLM Land Involved.

Al-A8

Appendix B Malathion Labels.

B1-B6

Appendix C Correspondence sited: Hastey (BLM) to Clark (CDFA ) 3/30/93 - Hoover's wooly-star; Pierce (USFWS) to Hastey (BLM) 11/8/93 - Spontaneous Abortion Relating to Kangaroo Rats; USFWS to G. Walker (UCR) 9/6/94 \& 8/23/96 - BLH Parasite Evaluations

Appendix D Summary of Measures (a-l) to Avoid BNLL Impacts; Maps of CTVCP Designated BNLL Conservation Areas; "High Virus-Intensive Control" Areas.

Appendix E Potential Treatment Maps, Chart of Probable Treatment, Acres Sprayed (1979-1995), Ground-rig Frequency and Application.

Appendix F Control Strategies - San Joaquin Valley, Imperial and Eastern Riverside Counties, Western Riverside County and Monterey County

Appendix G Plants and Animals of the San Joaquin Valley, Imperial and Eastern Riverside Counties and Western Riverside County within or Near CTVCP Potential Control Boundaries

Appendix $\mathbf{H}$ Harvester Ant Monitoring.

$\mathrm{H} 1-\mathrm{H} 2$

Appendix I Pesticide Spill Contingency Plan.

Appendix J Summary of Toxicology Data and Toxicology Study Evaluation Work Sheet (reproduction) for Malathion as Evaluated by the Medical Toxicology Branch, Cal EPA

Appendix L Checklist of Species within or Near CTVCP Control Boundaries for which Critical Habitat has been Designated 
DESCRITPIONS OF BLM LAND INVOLVED

COUNTY: Fresno

BLM DISTRICT HEADQUARTERS: Bakersfield

\section{TOWNSHIP RANGE SECTON}

$13 S$

$14 S$

$15 S$

$16 S$

19S

$20 S$

$21 S$

$22 S$
$11 \mathrm{E} \quad 32,33,34$

35

10E $\quad 1$

$2,10,11,12,13$

$11 \mathrm{E}$

$1,12,13$

$3,10,11,14,24$

25

$12 \mathrm{E}$

31

$11 \mathrm{E} \quad 22,23,24$

$12 \mathrm{E}$

$6,7,8$

$17,18,19$

21,22

$12 \mathrm{E} \quad 1,2,12$

5,6

13E $\quad 7,17$

$14 \mathrm{E} \quad 34$

$15 \mathrm{E} \quad 4$

$2,12,24$

$16 \mathrm{E}$

18

14E 2

15E 2,12

$15 \mathrm{E} \quad 22,26,28$

$16 \mathrm{E} 24$

$17 \mathrm{E} \quad 18,28,32,34$

$17 \mathrm{E} \quad 2,4,8,12,14$
FREOUENCY

Unlikely, Infrequent

Infrequent

Unlikely

Frequent

Infrequent

Potential

Infrequent

Unlikely

Infrequent

Annual

Annual

Infrequent

Unlikely

Frequent

Unlikely

Infrequent

Frequent

Infrequent

Frequent

Annual

Frequent

Frequent
PERIOD

OF TREATMENT

Winter/Spring

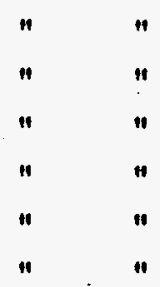

$\begin{array}{ll}n & n \\ n & n \\ n & n\end{array}$

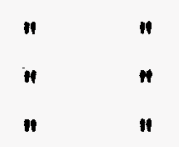

11

11

"I . II

11 11

Fall

Winter or Spring

Winter, Spring or Fall

Winter

Winter or Spring 
DESCRITPIONS OF BLM LAND INVOLVED

COUNTY: Kern

BLM DISTRICT HEADQUARTERS: Bakersfield

\section{TOWNSHIP RANGE SECTON}

$25 S$

$\begin{array}{ll}18 \mathrm{E} & 11,15,22 \\ 19 \mathrm{E} & 33 \\ 20 \mathrm{E} & 33\end{array}$

$26 S$

27S

$28 S$

29S

$30 S$

$31 S$
18E $\quad 28$

30,32

$18 \mathrm{E} \quad 1-4,11-13$

28,33

$19 \mathrm{E}$

$$
29
$$

30

$19 \mathrm{E} \quad 11,14$

$27 \mathrm{E}$

$29 \mathrm{E}$

$10,14,22,24$

$2,28,34$

21E 29,33

22E $\quad 4,30,32$

$21 \mathrm{E} \quad 4,5,7-10,22,25,27$

22E $2,4,6,8,10,18$, $22,26,29,30$

$23 E$

4

22E

$3,4,5,8,9$

2,2012,21,22,

$23,24,25,27$

35

23E

24E
$6,24,32$

14,20

\section{FREQUENCY}

Infrequent

Frequent

Infrequent

Frequent

Frequent

Potential

Annual

Unlikely

Potential

Annual

Potential

Infrequent

Frequent

Unlikely

Annual

"

"

"
Spring

Fall

Spring

PERIOD

OF TREATMENT

Fall

"

1-4 Fall

11-13 Spring

Fall

1

w

"

"

"

"

I1

11

"

Fall

Spring 
DESCRITPIONS OF BLM LAND INVOLVED

COUNTY: Kern Continued

BLM DISTRICT HEADQUARTERS: Bakersfield

\begin{tabular}{|c|c|c|c|c|}
\hline TOWNSHIP & $\underline{\text { RANGE }}$ & SECTON & FREQUENCY & OF TREATMENT \\
\hline $31 S$ & $25 E$ & 6 & Infrequent & Spring \\
\hline $32 \mathrm{~S}$ & $\begin{array}{l}23 \mathrm{E} \\
24 \mathrm{E}\end{array}$ & $\begin{array}{l}4,5,9,10,15 \\
20,24,28,30\end{array}$ & Annual & $"$ \\
\hline $11 N$ & $\begin{array}{l}23 W \\
24 W\end{array}$ & $\begin{array}{l}17-23 \\
25-28 \\
3,10,11,13,14 \\
15,21-28,33,35\end{array}$ & $\begin{array}{l}\text { Infrequent } \\
\text { Unlikely } \\
\text { Infrequent to } \\
\text { Unlikely }\end{array}$ & " \\
\hline $12 N$ & $23 \mathrm{~W}$ & 31,32 & Frequent & Spring/Fall \\
\hline
\end{tabular}

COUNTY: Kings

BLM DISTRICT HEADQUARTERS: Bakersfield

\section{Tor}

TOWNSHIP

$22 S$

$18 \mathrm{E}$

$23 S$

$24 S$

$25 S$

$17 \mathrm{E}$

$18 \mathrm{E}$

$19 \mathrm{E}$

\section{RANGE}

24

$6,8,30$

$18,20,26,28$

2

10,12

29

$18 \mathrm{E} \cdot 11,15,22$

\section{FREOUENCY}

Frequent

Infrequent

Frequent

Infrequent

Frequent

Infrequent
PERIOD

OF TREATMENT

Winter

.

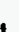

n

Fall

Spring or Fall 
DESCRITPIONS OF BLM LAND INVOLVED

COUNTY: Merced

TOWNSHIP RANGE SECTON

$12 S$

$13 S$

$11 \mathrm{E} \quad 18,19$

$10 \mathrm{E}$

$15,29-32$

COUNTY: San Luis Obispo

\begin{tabular}{|c|c|c|}
\hline TOWNSHIP & RANGE & SECTON \\
\hline $9 \mathrm{~N}$ & $25 \mathrm{~W}$ & 1,2 \\
\hline $10 N$ & $\begin{array}{l}24 W \\
25 W\end{array}$ & $\begin{array}{l}18 \\
8,9,13,14,15 \\
12 \\
28,29,34\end{array}$ \\
\hline $11 N$ & $\begin{array}{l}24 \mathrm{~W} \\
25 \mathrm{~W} \\
26 \mathrm{~W}\end{array}$ & $\begin{array}{l}30,31 \\
7,8,17,20 \\
4,10\end{array}$ \\
\hline $12 \mathrm{~N}$ & $26 \mathrm{~W}$ & 31,32 \\
\hline $29 \mathrm{~S}$ & $19 \mathrm{E}$ & 35 \\
\hline $32 S$ & $22 \mathrm{E}$ & $18,19,22,23$ \\
\hline
\end{tabular}

BLM DISTRICT HEADQUARTERS: Bakersfield

PERIOD

FREQUENCY

Infrequent

OF TREATMENT

Winter or Spring

Unlikely
BLM DISTRICT HEADQUARTERS: Bakersfield

PERIOD

FREOUENCY

OF TREATMENT

Infrequent

Potential

Infrequent

Annual

Potential

Infrequent

Unlikely

Annual
Fall

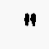

w

II

เ

Fall

COUNTY: Santa Barbara

BLM DISTRICT HEADQUARTERS: Bakersfield

PERIOD

TOWNSHIP RANGE SECTON

FREOUENCY

OF TREATMENT

9N

26W 3

Potential

Fall

$10 \mathrm{~N}$

$25 W$

$28,29,33,34$

Frequent

H 
PESCRITPIONS OF BLM LAND INVOLVED

COUNTY: Ventura

BLM DISTRICT HEADQUARTERS: Bakersfield

TOWNSHIP

RANGE SECTON

FREQUENCY

PERIOD

8N

19W $\quad 16,26,27,34,35$

Potential

OF TREATMENT

*Undetermined

COUNTY: Imperial

San Bernardino - Meridian - Base Line)

TOWNSHIP RANGE SECTON

$8 \mathrm{~S}$

9S

$10 S$

$11 S$

$12 S$

$13 S$

9S

$10 \mathrm{~S}$

11S

$12 S$

$13 S$

$14 S$

$15 S$

$16 S$

$17 S$

$11 S$

12S

$13 S$

$14 S$

$15 S$

$16 S$

$16-1 / 2 S$

$17 \mathrm{~S}$
$9 \mathrm{E}$

1-36

$1-36$

$1-36$

$1-36$

$1-36$

$1-36$

$10 \mathrm{E}$

$1-36$

$1-36$

$1-36$

$1-36$

$1-36$

$1-36$

$1-36$

$1-36$

$1-36$

$11 \mathrm{E}$

$6,7,8,17,18,19,20$, $21,28-32, \mathrm{NW} 1 / 433$

2-8,17-21,26-36

$1-36$

1-36

1-36

$1-36$

$1-6$

$1-36$
BLM DISTRICT HEADQUARTERS: Bakersfield

PERIOD

FREQUENCY

Unlikely

OF TREATMENT

Winter/Spring

Periodic

Unlikely

$"$

$"$

"

$"$

$n$

Periodic

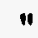

"

n

4

Unlikely

$"$

$n$

n

w

"

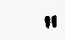

w

n

11

1

w

"I

11

*1

n

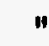

1

ต

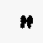

II

ข

* 
DESCRITPIONS OF BLM LAND INVOLVED

COUNTY: Imperial

BLM DISTRICT HEADQUARTERS: Bakersfield

(San Bernardino - Meridian - Base Line)

TOWNSHIP RANGE SECTON

$13 S \quad 12 \mathrm{E}$

$14 S$

$16 S$

$16-1 / 2 S$

$17 \mathrm{~S}$

$14 S$

$13 E$

$5-9,15-22,26-34$

35

$1-9,17-20,30-32$

$6,18,19,29-34$

$2-6$

$1-36$

$7,17-20,29,30,32,33$
FREQUENCY

Periodic

Unlikely

Periodic

n

,
PERIOD

OF TREATMENT

PERIOD

$1,2,3,11,12,13,25$

$16 E$

$19,29,30-33$

$1-36$

1-5,8-12,13-16,

21-28,34-36

$1,2,11-14,23-26,35,36$

$1,2,-11-14,23-25,36$

$1,12,13,24,25,35,36$

$1,10-13$

$17 \mathrm{E}$

$1-36$

1-36

$1-36$

1-36

1-36

1-12

$18 \mathrm{E}$

$1-36$

$1-36$

$1-36$

$1-36$

$1-36$

$1-11$
FREOUENCY

Unlikely

\section{OF TREATMENT}

Winter/Spring

Periodic

"1

II

n

11

11

it

11

"

เ1

*

Unlikely

Periodic

n

n

เ

Unlikely

Periodic

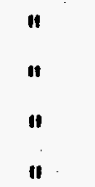

n

"

"

"

"

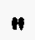

n

"

II

11

II

$n$ 
DESCRITPIONS OF BLM LAND INVOLVED

COUNTY: Imperial

BLM DISTRICT HEADQUARTERS: Bakersfield

(East Side)

\begin{tabular}{|c|c|c|c|c|}
\hline TOWNSHIP & RANGE & SECTON & FREOUENCY & OF TREATMENT \\
\hline 13S & $19 \mathrm{E}$ & $1-36$ & Periodic & Winter/Spring \\
\hline $14 S$ & & $1-36$ & " & " \\
\hline $15 S$ & & $1-36$ & $"$ & $"$ \\
\hline $16 S$ & & $1-36$ & " & $"$ \\
\hline $17 \mathrm{~S}$ & & $1-6$ & $"$ & $"$ \\
\hline $12 S$ & $20 \mathrm{E}$ & $19,20,29-33$ & $"$ & " \\
\hline $13 S$ & & $4-9,16-21,28-33$ & " & " \\
\hline $14 S$ & & $1-36$ & " & " \\
\hline $15 S$ & & $1-36$ & " & " \\
\hline $16 S$ & & $1-36$ & $"$ & $"$ \\
\hline $17 \mathrm{~S}$ & & $1-6$ & Unlikely & " \\
\hline $15 S$ & $21 \mathrm{E}$ & $17-20,29-32$ & " & $"$ \\
\hline $16 S$ & & $1-36$ & " & $"$ \\
\hline
\end{tabular}




\section{MALATHION

\section{Organophosphate Insecticide}

This product is used undiluted in specially designed aircratt or ground equipment capable of applying uttra low volumes for the control of the insects indicated on this label.

ACTIVE INGREDIENTS

BY WEIGHT

Malathion"-

INERT INGREDIENTS

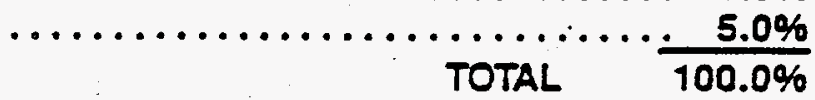

- 0.0-dimethyl phosphorodithioate of diethyl mercaprosuccinate. Contains 9.7 pounds of Malathion per gallon.

KEEP OUT OF REACH OF CHILDREN CAUTION

See Side Panel For Additional Precautionary Statements

NET CONTENTS 5 GALS. (18.92 L) 
Bators uing reed un athections contalnod on thit label tor the proper methode and procadures which muat be tollownd to schibve oftectrve

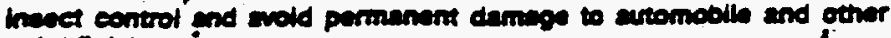
patme Anianes.

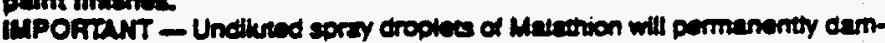

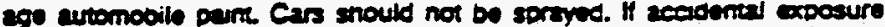

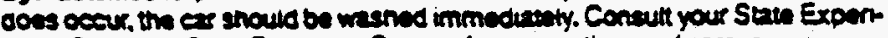

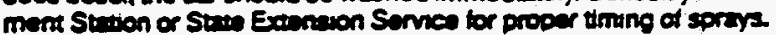

\section{PRECAUTIONARY STATEMENTS HAZARDS TO HUMANS AND DOMESTIC ANIMALS}

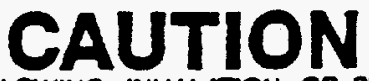

HARMFUL GY SWALLOWING. INHALATION. OR SKIN CONTACT. ANOI broming spray mest Avoid conted with sikn

Poreoral Protwetwi Equipoment:

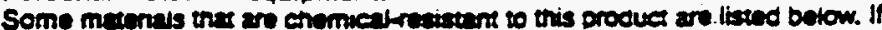
you wert more ootions tollow the instructions for catagory (F) on the EPA chemel reastances extegory sabetion char.

Applientors and other handiers murt wasr: long-swowed shin and long parts cenemicamremstam gloves such as: oamer laminate, butyl ruboer. nt trile ruboer of vion and snoes plus socke.

Follow manutacturer's instructoons tor eleanng and mantaning PPE. If no

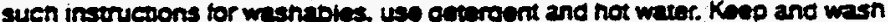
PPE seasurety from other laundry.

Engineering controte etribmomt:

When mandlers use closed svarems snciosed caos, or aircrat in a manner that meens with recurements listed in the Worker Prorection Standard (WPS) tor agncutural Desticices ! 40 CFR 170.240 (d) (Loi)), the nandier PPE requirements may oe requeec or moditied as soectied in the WPS.

\section{USER SAFETY RECOMMENDATIONS}

\section{Users should:}

Wasn nands botore eating, crinking. Chemng gum. using tobaceo or using the toviet.

Remove ctotning irnmediatery if pesticade gets insude. Then wash thor. oughly and out on clean clothing.

Removo PPE immedianty aner handling this procuze. Wasn the outsioe of gloves betore removing. As soon as possible, wesh thoroughty and crange into ejean etothing.

\section{STATEMENT OF PRACTICAL TREATMENT}

If Swallowed: Call a onvesetan of Poison Controt Conter immediatrey. Drink one or two graseses of werer and induce vomiting by touching the bacx of throat wth tinger. Repeat until vomit thuid is cloar. Do not inquce vomiting or give amvining oy mouth wo an unconscious person. It innaved: Remove vicalm to fresn ate. Aooty antifical resouration if indicatoc. If On Skin: West atfected areas with soso and water. If in Eyeas. Fiusn oyes wm prenty of water. Call a pmystetan if imtation persists. Note to Physecien: This oroouct may cause cholinesterase inntotion. Atropine is amucotal. 2PAM may Do effective as an adjunes to atropine.

\section{ENVIRONMENTAL HAZARDS}

This pestictioe is toxic to fist, aquatic imverteorates. and aquatic lite stages of amonibiens. For torrestrial uses. do not apoly directly to wertep. or to arvas - wnere surtace water is presem or to intertical areas betow the mean hign water marx. Do not contaminate water wnen disposing of coupmemt wasnwarers. s.

This proauc is nighiv toxic to bees exposed to diree trextment on blooming croos or waecs. Do not aobly this orocuct or atow it to ant to blooming crops or weeces if bees are visung the area.

\section{DIRECTIONS FOR USE}

It is a viotation of fooord $L a w$ to use this product in a manner inconstsent with its laboting.

Fot any requiroments somertic to your State of Tribe. consult the agency resconsiblo tor pesticiae regutumon.

\section{AGRICULTURAL USE REQUIREMENTS}

Use this orocues onty in aceoroance wrth its labeling and with tho Worker Protectson Stancard. 40 CFA pern 170 . This Stancare contans reoutrements for the orowection of agncultural workers on tarms. lorests. nurseries. and greennouses, and nandiers of agncultural pestuecdes. II comtuns ro quiroments for truning, cecomaminawon, notifieation. and emergency as sustanca if atso contauns spectic instructions and weeptrons pertaining to the stutements on this label about personsl protective souidnemt (PPG). and reatncteonentry imerval. The requirements in this bex onty aobly to uses of this product inat are coversed by tha Wonker Protection Stancare.

1 Do not appty this product in a way that will contact morkers of otner persons. oither difectly of througn drith. Only protected handiers may be in the area during apptication.

Do not emer of allow worter entry into trased arves during the restrineted entry interval (RE) of 12 hours.

PPE required tor earty entry to trated aress that is permitted unow the Worker Prowction Standard and the involves contece with anything thas hes

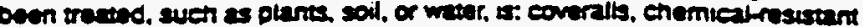
gtoves such as: bemer laminate buryl ruboer, nitrilo rubber of viton and snoss phus soete.

NON-AGRICULTURAL USE REOUIREMENTS The reauremens in this box apoly bo uses of this product that an NOT within the se00e of the Workat Provecton Stancard tor agncultural peaticides (10 CFA Par 170). The WPS apoties when this product is used to produce agncultural plants on terms. torests nursentes of greennouses Keep chitoren and pets out of the teated area until sprays have drioc.

\section{STORAGE AND DISPOSAL}

PROMIBTIONS: Do not comramunate watr. tooc. of leed by storage of disocall Do not stont under conditions when megm adversety attect the contanner of its ability wo funcalon prodorny. STORAGE: Store in sate manner. Store in angina contuner onty. Kees contaner tigntly closec when not in we Reduce stacking hergnt where local conorions can aftec: packenge strengm. Personnet should use cothing and eoupment conststent with g000 pestucce handing. PESTICIOE DiSPOSAL. Wastes resulting trom the use of this product may oe disocesed of on ste of at an approved weste disocesd tacility. CONTANER DISPOSAL. Tnple nnse (or equivalent). Then otfer for recyeting or reconditioning. or punceure and disoose of in a sanitary lancfill. or ov other procecures aoproved ov stale and local authontiles.

\section{GENERAL INFORMATION}

DO NOT USE THIS PRODUCT FOR ANY USES OTHER THAN THOSE SPECIFED ON THIS LABEL

Aonat aoplications are most effecive wnen mace at a boom heugnt of 5 teet and a swaen moth of 50 teet. Do not make applicason wnen winos exceed 5 mon.

Mist blomers and boom spravers utilizing a controlled ar flow to facititate partele size and spray depostion may oe used al a vehicte speed of 4 to 10 mpn.

Mist blomers with a pump capable of produeing up to 40 pai and blower soeeds of 2600 rom are satisiaciorv. Use tiat tan nozzles. 8001 to 8002 . piaced $30^{\circ}$ into al btast or rotary atomizers into the ar olast that oroouce an etficient soray particle with a mass mecium diameter of 40 to 100 microns. Swath woths should not exceed 30 ieet. and applications should not be made when winds excesed $5 \mathrm{mph}$.

Boom soravers wrth a filtered rotary ar comoressor. erther PTO or gas enigine orven or an aur oump caoable of orooueng at least 12 ost are salistaciory. Use air pressure on enemical tanis and an aceurale meterng vatue to assure a calibrated flow of the pesticted. Air should be regulated with revief vaive and gauge for proper alf and liouid mixture Pneumatic-ype soray nozes. as suggested by equidmem manutacturer. snould be used tor spray partictes with mass modium diameter of 3010100 microns. Applications snoule not be made wrien whos exceec 5 mon.

Reoear applications snould be mace as necessary unless otnerwise specifiec.

\section{FOR ULTRA LOW VOUME AEAIAL APPLUCATION WHEAE AUTO} MOBILES, TRALLER, AND PLEASURE BOATS ARE PRESENT:

\section{MPORTANT}

Instructions when MALATHION ULV is to be used in ultra low volume soraying over cttes. lowns and otner areas wnere automodites. trailers and Dieasure boats are present

Aoply with arcratt equioped for uttra low volume application. Generally. soraying should not be attemoted when the mne is at or acove $10 \mathrm{mon}$ or temeeratures are above $82^{\circ} \mathrm{F}$.

Soray drooless of this produc undiluted will permanently damage automobile Daint uniess all of the tollowing conditions are met:

1. Airerat is operated al 150 mon or more.

2. There are no leaks in the urtra low volume soray system.

3. Nozzles are placed on the boom a $45^{\circ}$ angle down and into the wind.

4. Diaonragm enock valves are user on all nozzles to insure postive cut-oft of the soray.

5. Dosage of this product coes not exeand 3.2 fluid ounces per acre ( 40 acres per gallon).

6. The spray system orocuees dropiets of this product in the 50 to 60 mass median dianeter (MMD) micron range. with no more than $10 \%$ of the droplets exceseding 100 mierons. as determined by readings made from microseope sices costed wreh Onofilm.

Do not apply this product through any rype of ingation system. 
DIRECTIONS FOR USE

\begin{tabular}{|c|c|c|c|}
\hline CROP & PESTS CONTROLLED & $\begin{array}{l}\text { FUID } \\
\text { ounces } \\
\text { PER } \\
\text { ACRE } \\
\end{array}$ & $\begin{array}{l}\text { WTERMLL BETWEEN } \\
\text { LAST APPUCATION } \\
\text { ANO HAFVEST }\end{array}$ \\
\hline \multirow[t]{4}{*}{ Altath } & 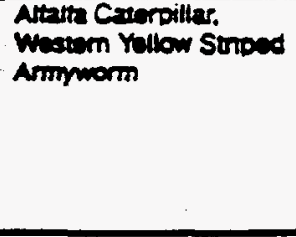 & $8-12$ & 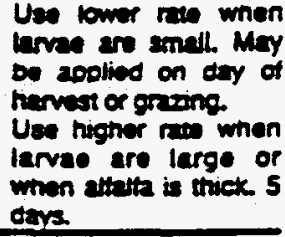 \\
\hline & Altalte Whermi Larvee & 16 & 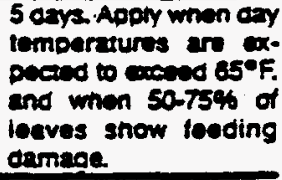 \\
\hline & Best Amrmorm & $8-16$ & 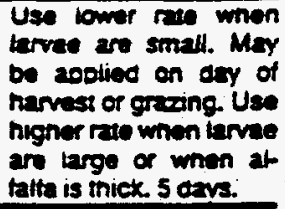 \\
\hline & Grasnodoers & 8 & $\begin{array}{l}\text { May } 08 \text { aooined on dery } \\
\text { of hamest of orazing. }\end{array}$ \\
\hline
\end{tabular}

Beans (uma, Mexiean Bean Bome. B 1 lay

greon. smed. Leathoopers. Green

Navy, rec kilo- Cloverworm daoanese

ner, wax, ory, Beatie Lrgus Bug

blackevel

Sluedernes Blueoern Magoot 10 O cav.

\begin{tabular}{llll}
\hline Chernes Cherry Frutt Fly & $12-16$ & 1 eay. Apoty oy arcerat
\end{tabular} ony. Use higner rate whon toliage is heory of intestanion is severe. Make first aoplicatwon as soon as thies apooar.

Cereal croos Cereal Leat Beath 48 Bariey, Oats, What: 7

(bartiey, corn.

Days of havest or for-

ans. wheat?

age we Com: 5 dars.

Grasses: May be ao

ptived on ory of havest or cramina.

Clover. Pasture Grassnopoers 8 May os apotied on eay

and Range

of harvest of grazing.

Grass Grase.

Grass Hay.

Do nox appty to ctover

Non

agrieultural

Land (wasto-

lands, ronc-

staies. soul bank

lands!

\begin{tabular}{|c|c|c|c|}
\hline Com & Acull Corn Roorworm & 4 & 5 cavs. \\
\hline \multirow[t]{6}{*}{ Corwen } & $\begin{array}{l}\text { Earty Season inseces } \\
\text { Thnos, Fieanoopars. } \\
\text { Leathoooers }\end{array}$ & 48 & oday. \\
\hline & Boll Woont & $8-12$ & $\begin{array}{l}\text { Eary to masarson. } 0 \\
\text { dav. }\end{array}$ \\
\hline & & 16 & Lale season. 0 cay. \\
\hline & Grassnoodors & B & O oav. \\
\hline & Lygus Bugs & $2-12$ & 0 car. \\
\hline & & 16 & $\begin{array}{l}\text { Very neary migrating } \\
\text { poputations } 0 \text { osv. }\end{array}$ \\
\hline 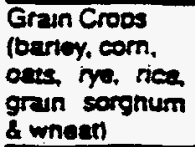 & Grashoppers & 8 & $\begin{array}{l}7 \text { cays Corn: } 5 \text { cays of } \\
\text { hamest or torage uste }\end{array}$ \\
\hline Grain Sorgnum & Sorgnum Miage & $8-12$ & $\begin{array}{l}\text { Apply ounng the otoom } \\
\text { stage. } 7 \text { days of havest } \\
\text { or toreos use. }\end{array}$ \\
\hline Sattiower & $\begin{array}{l}\text { Grenenoppors, Lrgus } \\
\text { Bugs }\end{array}$ & 8 & $\begin{array}{l}3 \text { days of narvestung } \\
\text { seods. }\end{array}$ \\
\hline
\end{tabular}

DIRECTIONS FOR USE

\begin{tabular}{|c|c|c|c|}
\hline CROP & PESTS CONTAOLLED & $\begin{array}{l}\text { FUIO } \\
\text { OUNCES } \\
\text { PEA } \\
\text { ACRE }\end{array}$ & $\begin{array}{l}\text { INTERVAL BETWEEN } \\
\text { LAST APPLUCITION } \\
\text { AND HAFVEST }\end{array}$ \\
\hline Soyoans & 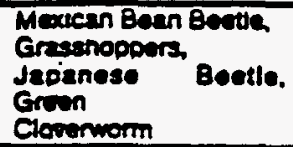 & 8 & $\begin{array}{l}7 \text { ders of havest of tor } \\
\text { gop use }\end{array}$ \\
\hline Suger Bects & $\begin{array}{l}\text { Grasenopoers, Sugar } \\
\text { Beot Roor Magoot } \\
\text { Aduta }\end{array}$ & 8 & $\begin{array}{l}7 \text { arys if tops as to Do } \\
\text { usod } 23 \text { foed. }\end{array}$ \\
\hline $\begin{array}{l}\text { Nonegnoutura } \\
\text { Lanos }\end{array}$ & $\begin{array}{l}\text { Best Leathopper (on } \\
\text { wild nost Dlants) }\end{array}$ & 8 & 0 oxy \\
\hline $\begin{array}{l}\text { Beof Cattio- } \\
\text { Hotd Lous and } \\
\text { Hotding Pons }\end{array}$ & $\begin{array}{l}\text { Adutt Flies \& Mosqur } \\
\text { bes }\end{array}$ & $6-8$ & Oday. \\
\hline
\end{tabular}

OTHER ACRtCULUURAL USES: Althte Clover. Parnure and Range Grass, Grass and Grase Hay. Grain crops. Beans, Aice. Tomatoes and Nonagrieuttural lancs (westotands, soil bank tands): Adult moscuntoes and ties - Apply MALATHION ULV at the rate of 2 to 4 flut ounees for controt of adult mosout wes and at 6 to 8 thuid ounces per acre for control $\alpha$ adutt flies and mosourbes. Repoed appticanons as nocessary. On altute clover, pesture ane range gress grass and gres nay, may oe applied on cay of havest of greang. Do not acory to attatta and ctover in Bloom. Do not use on saed attatta On gram croos. matk no abolication mthin 7 days of havest or torage usa; on com. within 5 days of harvest or torage use: on beans and tomatoes within 1 day of narvest.

FOREST INSECTS: Appty with arteratt equoped tor uttra tow volume applicatuon. Make aoplication when ar is caim and tomporature is below 68.5. Do not allow soray to contact ferns. hickory and mades as infury may resutt. Do not sorav on elms under extreme neat. drougnt and cisease conditions.

\begin{tabular}{|c|c|c|c|}
\hline CROP & PESTS CONTAOLLED & $\begin{array}{l}\text { FUUID } \\
\text { OUNCES } \\
\text { PER } \\
\text { ACRE }\end{array}$ & $\begin{array}{l}S \text { INTEFVAL BETWESN } \\
\text { LAST APPLICATION } \\
\text { AND HARVEST }\end{array}$ \\
\hline $\begin{array}{ll}\text { Douglas } & \text { Fir, } \\
\text { True } & \text { Fir. } \\
\text { Soruce } & \\
\end{array}$ & Spruce Buoworm & 13 & $\begin{array}{l}\text { Apply wnen hignesi } \\
\text { percentage of larvae } \\
\text { are in the fifth instar. }\end{array}$ \\
\hline Hernmiocx & Hemiocx LOODer & 6 & $\begin{array}{l}\text { Aodiy when most lar. } \\
\text { vae are in tae iniro and } \\
\text { tourth instar. }\end{array}$ \\
\hline \multirow[t]{2}{*}{ Pines } & European Pine Sawtly & 10 & $\begin{array}{l}\text { Appry when lavae are } \\
\text { in the first or second in- } \\
\text { star or belore they can } \\
\text { reach '1/2 ince in lenoth. }\end{array}$ \\
\hline & Saraloga Sortileoug & 10 & $\begin{array}{l}\text { Aoply when } 95 \% \text { of the } \\
\text { pooulation nas become } \\
\text { acutt. }\end{array}$ \\
\hline Laren & Laren Caseoearer & 8 & $\begin{array}{l}\text { Apory in soning as soor. } \\
\text { as lavae break hiber- } \\
\text { mation and begin Jeed- } \\
\text { ino on new toliage. }\end{array}$ \\
\hline
\end{tabular}

NOTICE

PLATTE WARRANTS THAT THIS PRODUE CONFORMS TO THE CHEMH CAL DESCRIPTION ON THE LABEL THEREOF AND IS REASONABLY FIT FOA THE PURPOSES STATED ON SUCH LABEL ONLY WHEN USED IN ACCORDANCE WITH THE OIRECTIONS UNOER NORMAL USE CONDITIONS. IT IS IMPOSSIBL TO EUMMINATE ALL RISKS INHEFENTLY ASSO. CIATED WITH THE USE OF THIS PAODUCT. CROP INJURY, INEEFECTIVENESS. OR OTHER UNINTENDED CONSEOUENCES MAY RESULT BECAUSE OF SUCH FACTORS AS WEATHEA CONOITIONS. PRESENCE OF OTHER MATERLALS, OR THE MANNER OF USE OR APPL:CATION ALL OF WHICH ARE BEYOND THE CSNTROL OF PI ATTE IN NO CASE SHALL PLATTE BE LIABLE FOR CONSEQUENTIAL SPECIAL OR INOIREG DAMAGES RESULTING FROM THE USE OR HANOLING OF THIS PAODUCT. ALL SUCH RISKS SHALL BE ASSUMED BY THE SUYER. EXCE?TT AS EXPRESSLY PROVIDED HEREIN. PLATTE MAKES NO WARRANTIES. GUARANTEES. OR REPRESENTATIONS OF ANY KINO. ETTHER EXPRESSED OR IMPLIED. OR BY USAGE OF TRADE. STATUTORY OA OTHERWISE. WITH REGARD TO THE PRODUCT SOLD, INCLUDING. BUT NOT LIMITED TO. MERCHANTABILTT. FITNESS FOR A PARTICULAR PUAPOSE USE OR ELIGIBILTY OF THE PROOUCT FOR ANY PAFTICU. LAR TAADE USAGE.

FORMULATED FOR

PLATTE CHEMICAL CO.

150 SO. MAIN STAEET FAEMONT, NEBRASKA 68025-5697 


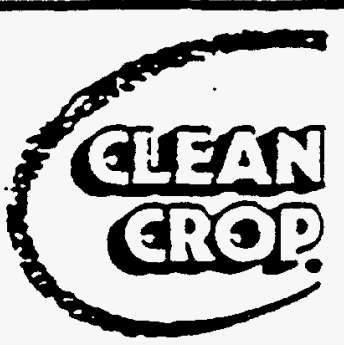

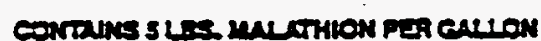

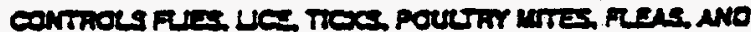

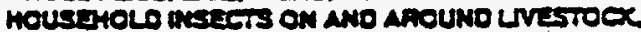

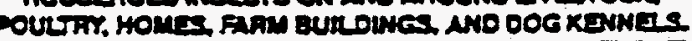

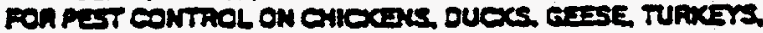

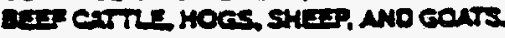

\section{Aetre menustert:}

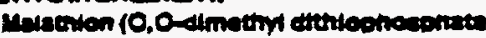

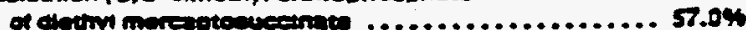

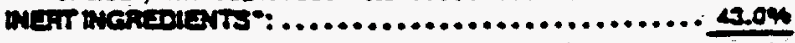

rotel $\frac{100.04}{104}$

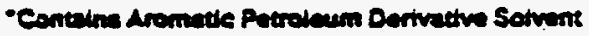

Com

\section{KEEP OUT OF REACH OF CHILDREN CAUTION}

SEE BELOW FOR ADOTIONAL CAUTIONS

EPA REG NO. 5481-10-34704

EPA EST. NO. $279-C 41$

2019

NET CONTENTS 1 GALLON

intes

PRECAUTIONARY STATEMENTS

HAZARDS TO HUMANS AND DOMESTIC ANIMALS

\section{CAUTION}

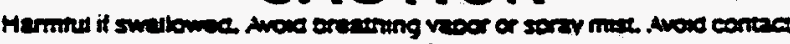

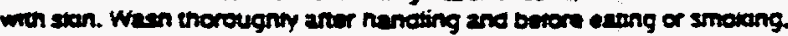

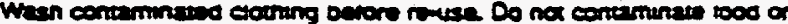

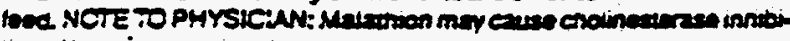
ven Aucowio as ancetel.

\section{STATEMENTS OF PRACTICAL TREATMENT}

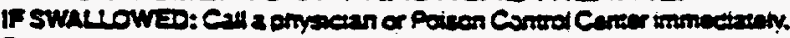

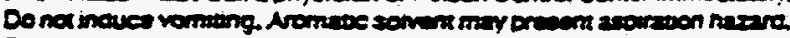
Do not incues vomting of giv anytring oy moutr be an uncensolus or comulaing parson.

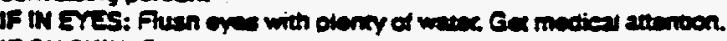

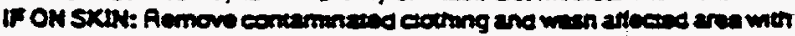

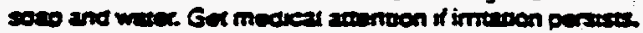

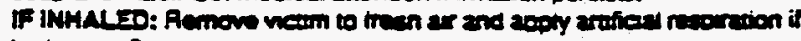

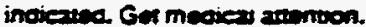

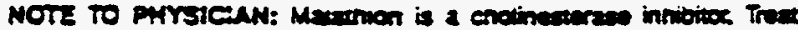

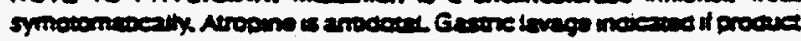
wat smmonec.

\section{ENVIRONMENTAL HAZARDS}

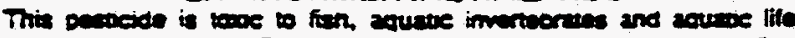

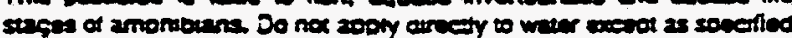

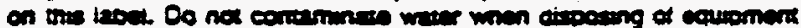
weanmelers

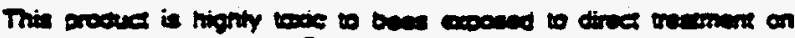

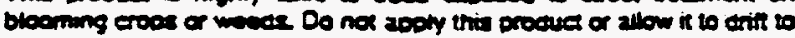

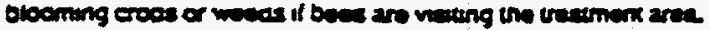

PHYSICAL OR CHEMICAL HAZARDS

Do nou use pouk spill or sorv nous nex or open theme.

\section{DIRECTIONS FOA USE}

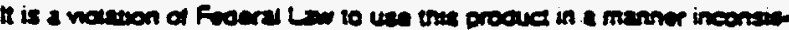

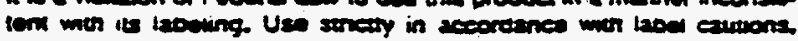

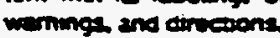

STORAGE AND DISPOSAL

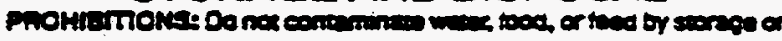
anderent

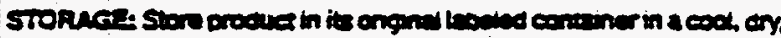

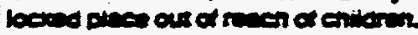

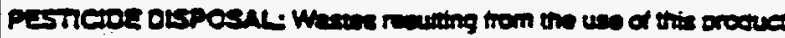

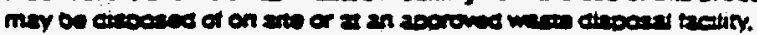

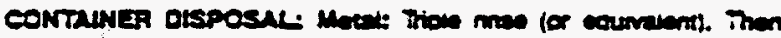

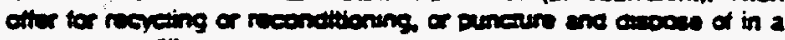

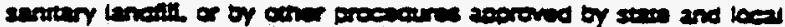
aturerrece.

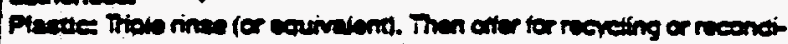

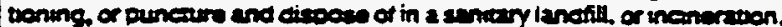

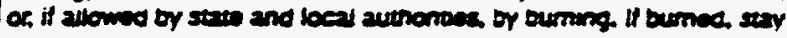
out of smowa.

\section{DIRECTONS}

FYY CONTROL- Mix 1 gavion MALATHiON 57 SPquY to 50 gallons of

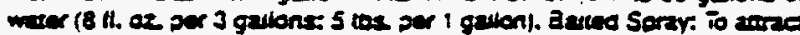

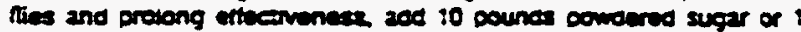

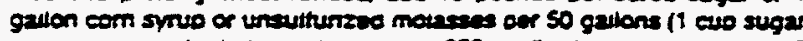

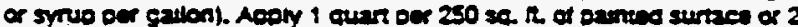

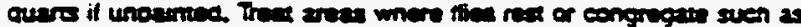

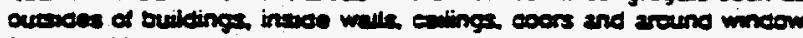

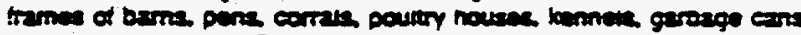

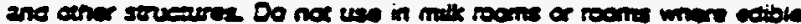
procues aro handiec.

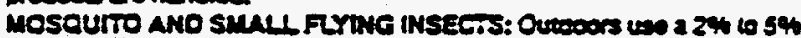

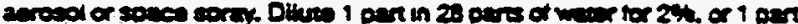

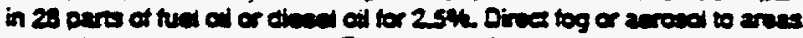

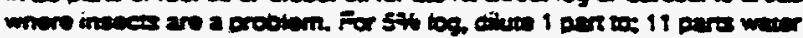
CF is asers tuet ai iorl diesel oul.

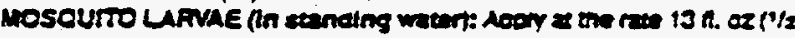

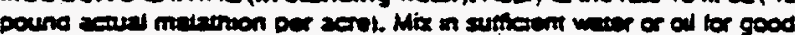

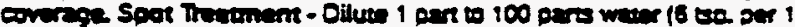

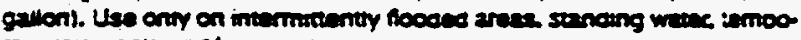
ray ran poos and log ponces.

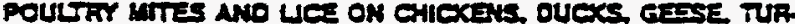
KEYS: Use 1 oz $(2$ vee) per 1 gullon of werer and sorky on bres using 1

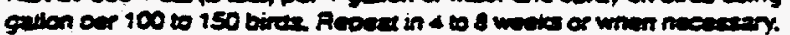

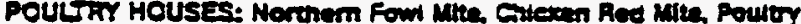

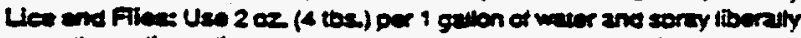

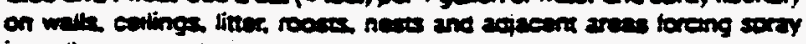
inw at ereces and crunces.

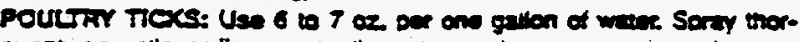

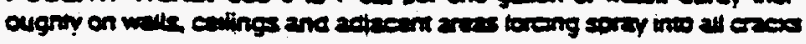
ane crmaer.

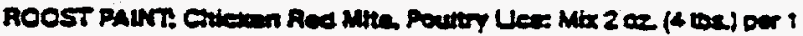

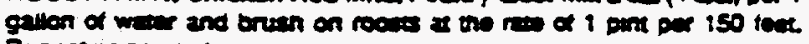
Alooet as nowact

PAEMISE SPRAY FOR FLEAS: Remow at dens of manure Thor-

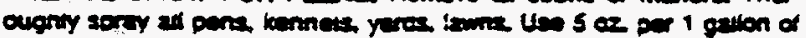
wear oer 1,000 so. it. Do nor soroy coces and ex.

LCS ON BEE CATTL AND SWmE: Use one gatlon oer 100 gallors of

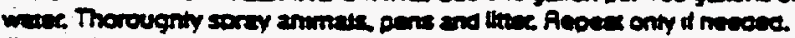

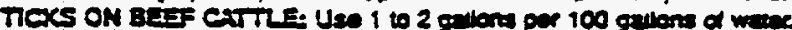

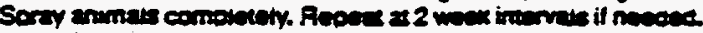

WeE TCXS ANO KEDS ON SMJSP AKO COATS: Use One grilon per 100 gallons (1'ts h. oz oer 1 gavion) and sordy anmus thoroughry.

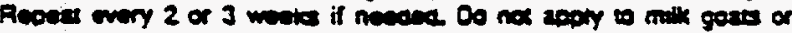
anumate uncer ons momn of age

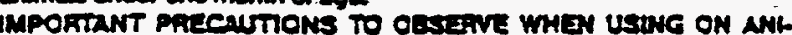

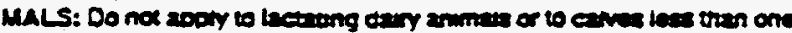

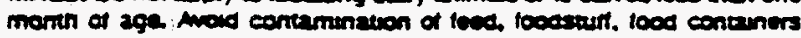

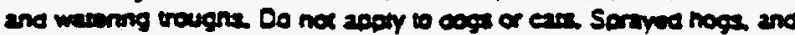

(c) 


\section{MALATHION 57 SPRAY}

EPA REG NO. 5481-10-34704

\section{and}

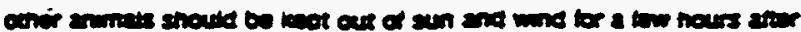
tremente

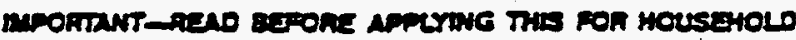

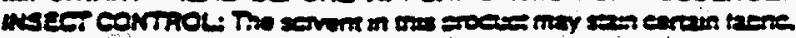

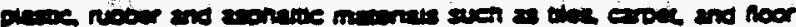

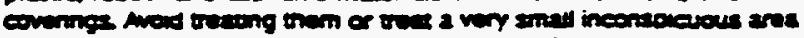

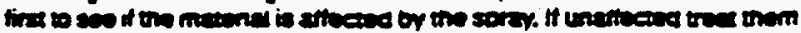

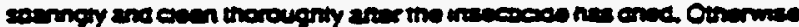
concerac.

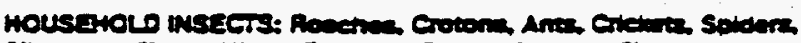

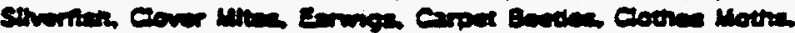

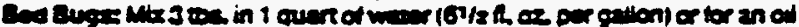

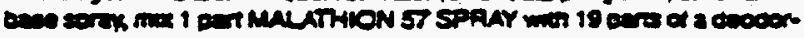

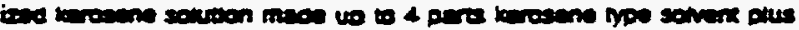

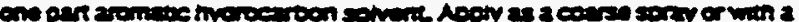

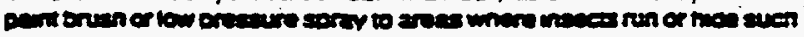

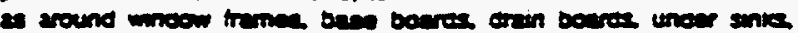

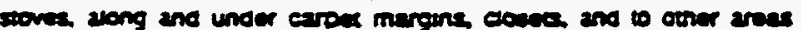

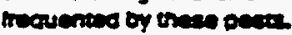

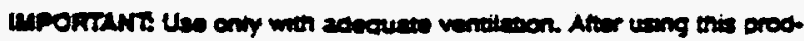

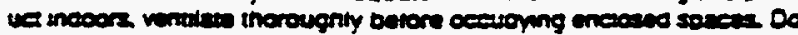

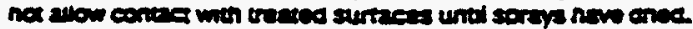

\section{NOTCE}

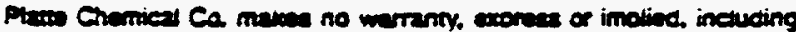
the warmmes of merenantsotity andor fitneas for am armesist oup-

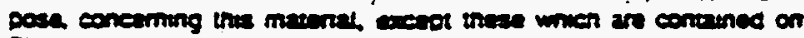
Ptent's laven 
BUREAUU OF LAND MANAGEMTENT

Callformiz Sezte Odere

2800 Coceage Way, Room E.2845

Sacrzmerto, Californiz 95825 -1889

MAR 304000

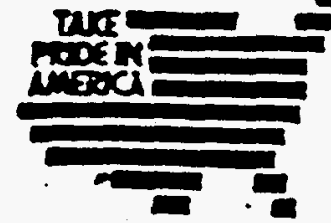

arens vinete

6840

9011

CA-952.10

De: Clark, Program Supervisor

Corrol and Ezciacion

Caijiornia Deparment of Food and Agriculture

1700 ग" Stree:

Sacuraezro, Califoraia 93\%

Desr Mr. Caris

Oi Desenioe: 18, 109I, the Burean of I and Managemeat (BLY) arthorized the Califoria Deparranen of Food and Agriesinure to apoiy aniathion to pubiic lands in Cailiforia for a five-year period to corrol the jest lear bopoer in angeiand and aitivared fallow Ifeics to limit the spread of the ariy top viras to susepptible host agricuitural cops. The Pescicice Uise Permit (91-C4-95-0001) inciuded several scipulations to minimize or aroid impaces to threatened and endangered species based on terms and condicions and discrevionary. conservation recommendarions in biological opirioins from the US. Fish and Wridife

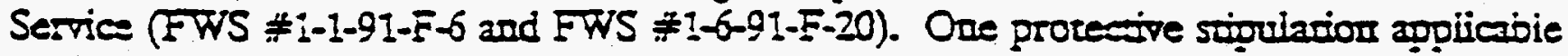
to the Eloovers wooly-sar was based on the following discrevionary conservation

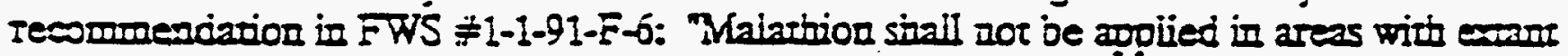
popuiarions of the federally listed ezciangered Califorria jewelflowe-, Bakersie!d ancous San Joacuin woolly-itreaces, Kens mallow, and itreatened Foover's mooiy-san during the Elowering period" (See secion BI of the exciosed copy of Pescicide Lise Perair $91-(4-93-0001)$

Data gathered in the past two years incieare that the Hoover's wooly-sar is Inuci more widespread than originally believed, and that teant populations of this plant ocesr in mant of the poremial curiy top virus trezomezr areas. On the basis of recent discussions berween our Baics:sieid Discrice Office and the Sacramento Fieid Office of the Fist and Wudlife Service we have concuucied that aroiding treament of areas ocespied by the. Foover's wooly-star is no longer a reasonable or resessary conservation measure for this threareaco species. As a consequence, we are modifying the Iirs sentexce of scipuiation B.1(a) of Pescicide Use Permir 91-CA-93-0001 to read as follows: Malaction simall not be applied in areas with exame populacious of the federally listed endangered Califonniz jewelllower, Bakersield ecas, San Joaquin woolly-threads, and Kern mallow during the flowering period" To effee the above change, scioulacion B.1(b) is 
aiso modified as follows: "On an anoual basis, the Deparment shall consult the California Nanural Diversity Database and knowledgeable botaniss prior to initiating the spray program to determine if areas proposed for spraying support known populations of the above listed endangered plants and shall avoid them during the llowering period." (Additions and delecions to the ters are shown by stading and strikeover, respectively).

We bave consuited our Washington Ofics on this matter and are advised that as of the dare of this cortespondence you are no longer reguired to implenent stipulation B.1 of Pescicide Lise Permit 91-CA-93-0001, as it was originally writren with respec to the Foover's woolysinr. Quescions regarding this matrer may be directed to $J i m$ Morrison or Ed Lorezazen in the Caiiforin State Offes at (916) $978 \div 72$.

Sincere:y,

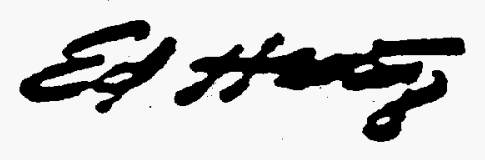

Ed Finsiey

Stare Direceor

\author{
Enciosure

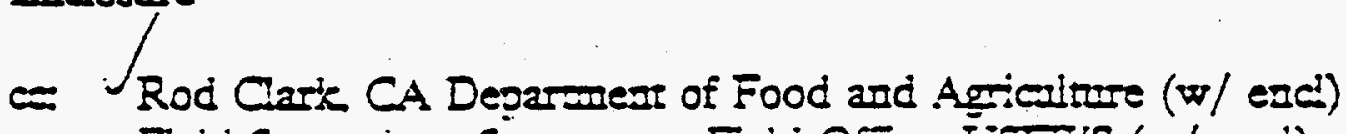

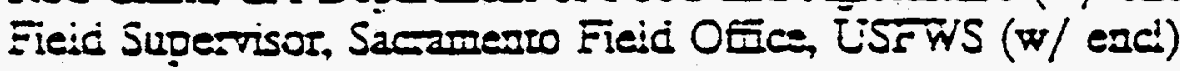 \\ WO-230, IS, RI 204 (w/0 end) \\ DM, Bakersieid ( $\% / 0$ encl) \\ AM, Calieme (w/o end) \\ All Eollister ( $w / 0$ enci)
}




\title{
United States Department of the Interior
}

\author{
FISH AND WILDLTFE SERVICE \\ Eoologial Series \\ Secrumento Freld Office \\ 2800 Counge Way, Room E-1803 \\ Sacramento, Califormia 9585
}

In Repiy Refe- Ta:

$1-1-91-5-6(R)$

Novemiber 8,1993

Mecorandum

To: Ed Hastey, Siace Direcsor, Bureau of Iand Lanagemed 2800 Corzage Way, Saczamento, Calisoraia 95825

Fram: Aceing Fieid Supervisor, Saczamenco Field osfice Saczameaco. Calizorria

Subjee Amendment to Biological Opirion (1-1-9l-F-ó) Concenaing Caanges in ine Iezus and Condizions Relaziag to Kangazoo Rass

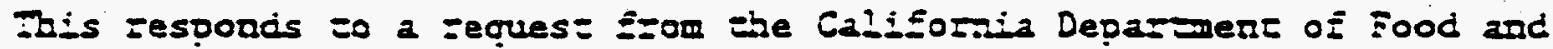

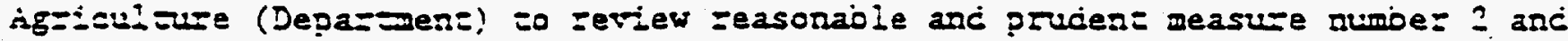
je measures enumezased undez rezI and condi=ion numez 2 as zequized by jie

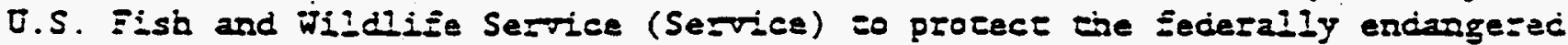
giari kangaroo sas (Dipodomrs ingens) and Iipeon kasgaroo zat (Dipodours

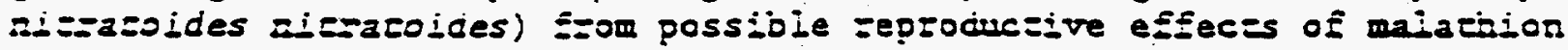
Iesulling from be Deparement's curly sop firus control program. Ihe Depa-mert concends jia the Service misincerpreced a scudy wich showed possible sponcaneous abortion of embros flom ingestion of the pesticice. Foliowizg meetizgs wi jie Bureau of lanc Management (Bureau), ive Deparyeat, anc je Sezice on Ianuafy 27. 1093, and kazis 16, 1903, ale

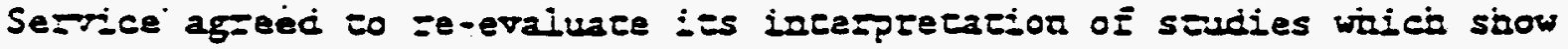

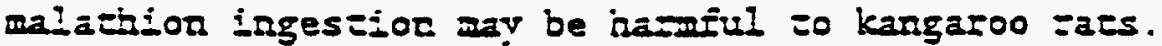

jewel Bennes: Exom je Concaminanes Branci of my scaff geviewed the existing

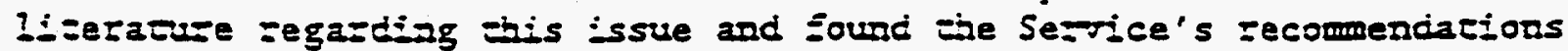
regarding ihe spray program to procect ine ieangazoo lacs was 500 conservative

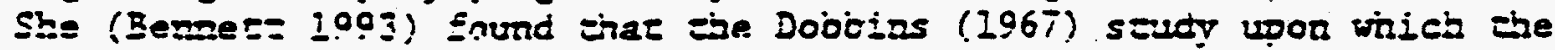

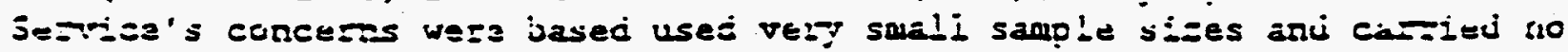

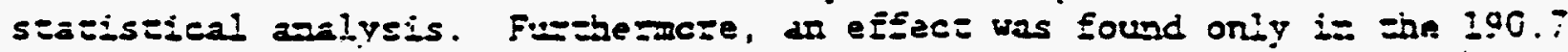

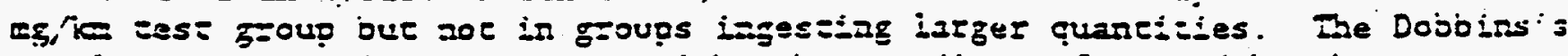

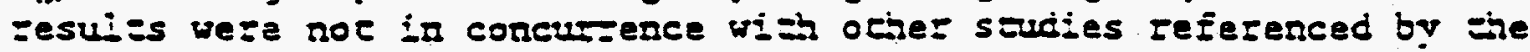
Deparment. Bencer (1993) concluded: "Sole use of the malabion coxicif? daca generaced by je Dobbins's (1967) seudy to calculace a lisik assessment Đor kangaroo lass is not advisable. Other daca generated in a more acceptaile siudy did not indicace malathion caused geproductive eiffecss in lars, and limiled compzzacive soxicigy daea incicales kangaroo raes aze nor more sensilive chac laborajofy raes to anocier of compound (melhy! parachion)."

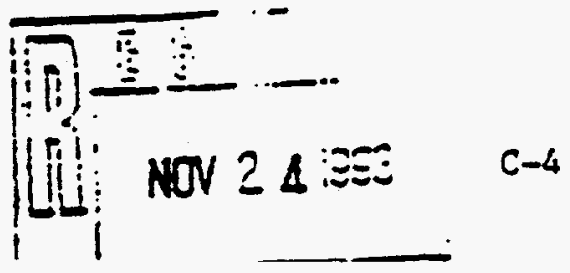


Therefore, based on the foregoing re-evaluacion of the effeces if malachrow or kangazoo Iass, the Service amends ies biological opinion as jefezencod above as follows:

1. Ressonable and prudent messure number 2 is feworded as follows: Incicencal saike of giane and Iipeon kangaroo zaes shall be minimized.

2. Tenm and condision number 2 is modified. Measures $a, b$, and $d$ are zemovec. In lijeir place, mezsure $2(c)$ becomes measure $2(a)$.

This concludes reinifiation of formen consel eation. Reinisiation will again be zeourized if ebe amours of extent of incidental eake is exceeded, if new

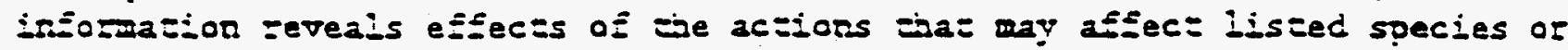

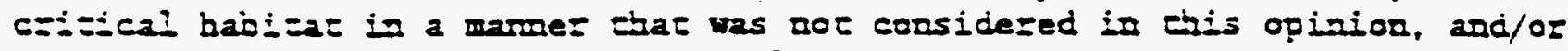
if a new species is listed or czijical babilat is desigareed that way be

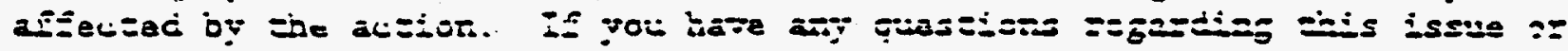

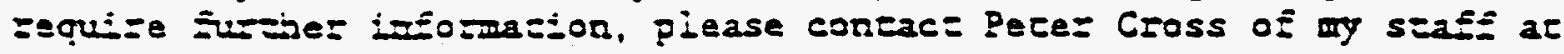
(90) $\$ 78-4860$.

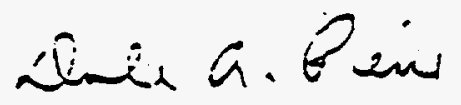

\section{Dale Piezce}

$c=$ : Assistane Regional Di=ecsor, Porsiand, Oregon (ARD-ES)

ChieE, Division of Encangered Species and Habilat Consezvasion, تasizing=on, D.C.

Rodney A. Clazk, Depargene of Food and Ag=icul wre, Constol and Ezadication, 2895 Nord ingikin, Suize A, Ezespo, CA 93727 


\section{ITSH AND WID JWE SERVICE Eavlogionl Serices \\ Secrarento Field Orrice \\ 2800 Cuttage Way, Rowen E-1803 \\ Srormento, Cilifornin 95825}

United States Department of the Interior

In Reply Refer To:

1-1-94-IA-1609

Saprembar 6, 1994

Greg WaIker

Depazcment of Entomology

University of Califorain

Rivesside, a 92521

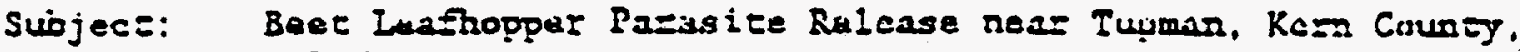
Califoraia

Dent $1=$ Waiker.

This zesponds to your lacter dured August 3, 1994, requesting concurzence wi th the decezminnliun that the proposed action of raleasing the parasiis Aprelinoicien turanica for biological control of the beer leafhopper in Calfformin will not adversely affect faderally listed threacened und endangered species. We have sevicwed the materlal crawumited with your corraspondance and concrs with your detemiantion. This ducarminacion is based on currene sciencific konwledge that the dphelisoicies curaries is is pararite only of leafropper agg3, and is specific for tine beec lazfbopper, Circulifer cenellus. Tharefore, unless naw information reveals tefocis of the proposed action that may affect listed speclus in a manor noc considared, or a new species is designated that way be affected by the proposcd sc:ion. no furcier action pursuant to bo Endangezed Specias Act of 1973. as amended, is necessary.

Please conesce Jociy Broun of wy yenfE ac (316) 978-4866, extensinn jui, jf you have ang questions segarding this response. Itacik you for your concern for endangerad species.

Sincerely,

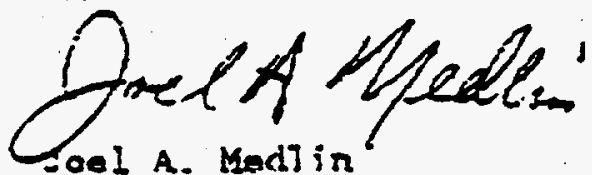

Field Supervisor

ce: ARD-aS, Portlund, OR

Dr. Darfel Williams, 3JVESRPp, Fresno, CA

HI. Brias Cypher, FCSE/EM, Tupuan 


\title{
United States Department of the Interior
}

\author{
FLSE AND WIT DLIFE SERVICE \\ Eoloigal Service \\ Secrangeto Field Ontra \\ 3310 E1 Caraia Averee, Suite 230 \\ Sacromento, Catiforrita 95821-0340
}

marerester ro

$1-1-96-I-2496$

Augus= 23. 1996

\begin{abstract}
Mroaradum
To:

Seate Difectar, Burazu of Land Mrageware, Calfforgla Seate ofe1ca, Sucrumaneo, Califarmia
\end{abstract}

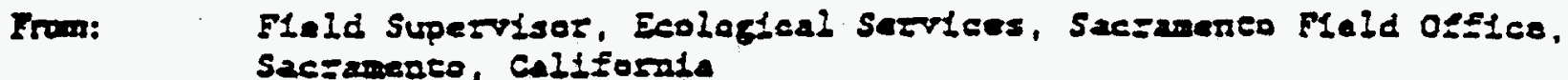

Subje Fleld Raierse of Sever specles of Cheleidold Iarasieic Wespe for Biological Contzol of leat Lathopper Hot Likely so Advezsely Afface Ibreatened or Erdengarad Specias

\begin{abstract}
We have been concacesd by Dr. Greg Wajker. Saculyy of the Depargment of Eneomoiogy is the linivessigy of Califormin, Bivesside, Fegurding proposed fi-ld relenses of several non-native species of wasps that parasilize bbe eggs of the beet lanfhopoes (CL-eulifer eneilus) -.a son-native pest of numerous crops and vecsor of cerriy cop. Fizus. Mese relenses might eaik place in $a$ variety of locacions where beet lezfroppar populacians butld up in cercinl

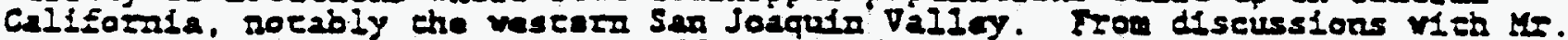
Ed Lorentzen of your offics and offielals of the Callformin Depatzent of Food and Ag=icul gure's Cus'y nop Vifus Conczol PFogrem (CtVCP), it is our underseardizs elare Dr. Ralker's proposed release progran is part of a

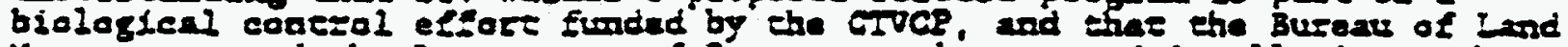
Hanagement and the Deparment of Gnezsy arz lntarnsted in allowing such

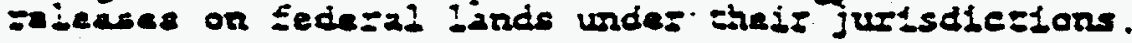

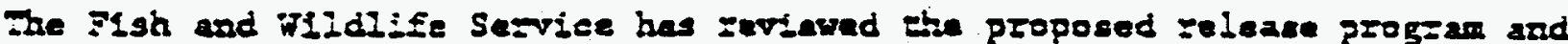
finds thre the Elald zalease of Aragrus acsmus, three posstbiy undescribed specles of conatocerus, an unde exmined spoctes of poljrem (ell in whe family

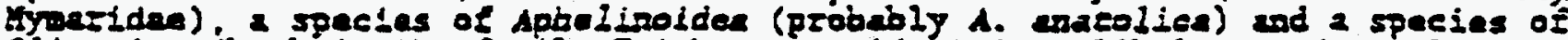

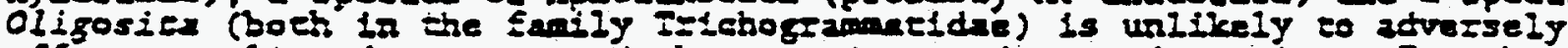
affect any liscad or proposed threntaned or ancingered speeies. For the undesczibed and underermined wop spuefes, this deserminaet on shall apoly only

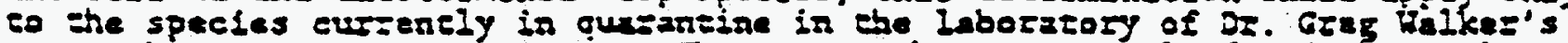
research group at UC Rivers1de. The Service bas previously found ghat relence

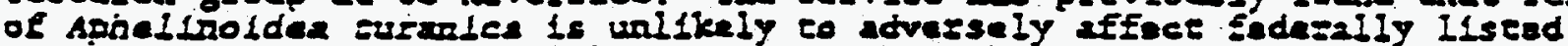
spectes (Seprember 6, 1994 lecear eo DI. Greg Halket. flie 1-1-94-2A-1609).

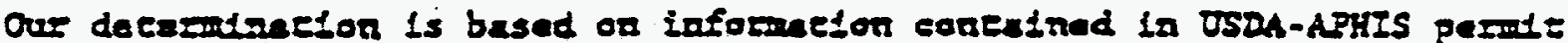

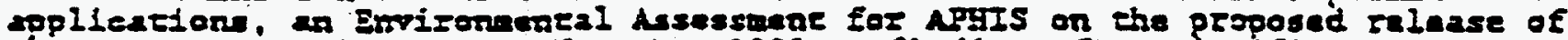

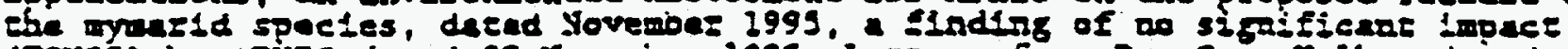

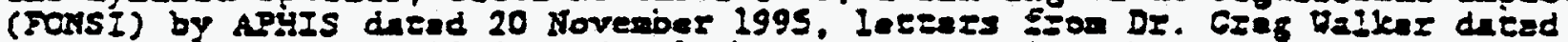

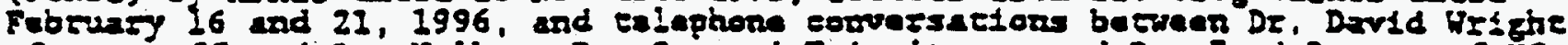
of ny reafe and DF. Halkar, Dr. Sergunt Irlapiesyn. and Dr. Inad bayoun of UC

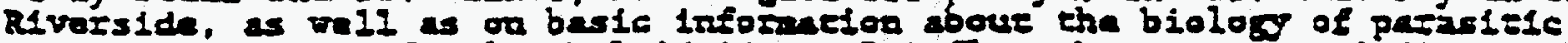

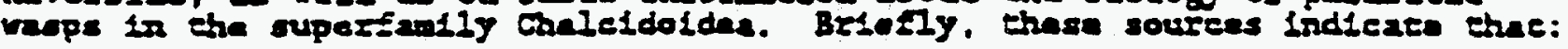

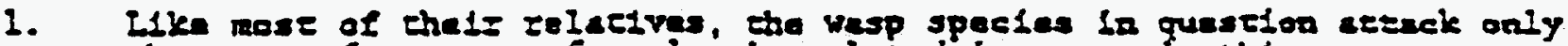
the egzs of ora or a fow clocely ralaend inseces, in this case, leafhoppars. Leafhoppers feed on planes, and lay ebeir eggs lrside plave efssues. 
2. All of the wasps to be released wero collected in southrestern Asla, and are unilkely to be able to feed wdaly on natbo Callformla leathoppers or othar lnseces.

3. The waps rely on searching behaflor that 1a parely Lnstincefve co EInd

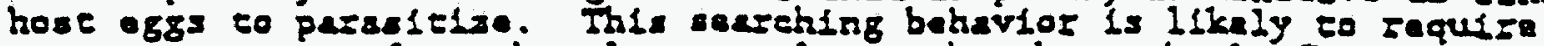
one or wore cues from the plune or planes that bont the lanelopper. passtbly Includirg charactaristics of the plancs' curerute, small or easte. AIl of the waspe to be raleased were collectad fron planes nos nacive to Calisernia, Ineluding sugar benes and dussian ebisela. Thay are lexs likely to soareh, or to seaseh sucesssfully, for proy on dative planea.

Theza are no fedezxily lisead or proposed lexhopper species in Callforata. and the relatively natzow host gange and spocialized seerehisg bobrvior of

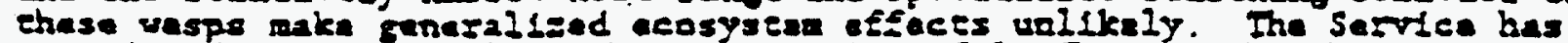

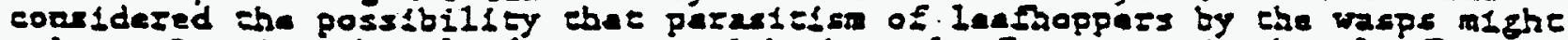

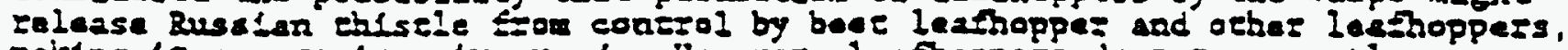
making 15 2 moze 1rvastve wasd. However, lesthoppers do not curzenely seem to control ausstan thistle, zacher, Russtan thiste (Salsola tragre) is deperdame on soil disturbance. Ocher plants, both native and non-native, out-compete and replace it in the absence of conetnuing discuriance. The ClJCP blological

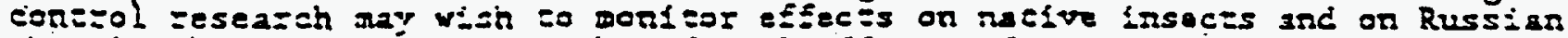

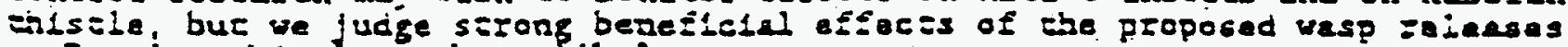
on aussien thisele to be unitkely.

Therefork, unless new informetion ravenls thet the proposed acton may affect Ilstad specias in a maner not considered, or a naw spectes is deslgnarad jas may be ajecsed by the proposed bioiogiegl conesol progran, no furjher action pussuane to the Endangegad Speclas Ac of 1973 , as amended; is necassary.

If you have any gueselons about thls memorandum, please concact David WIight: es $(916) 979-2739$ ex $=$. 440 .

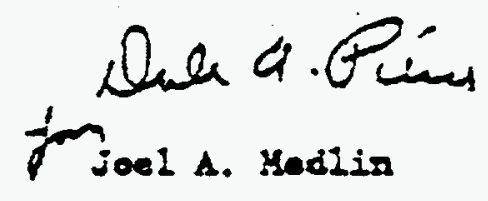

ce: AES, Porsland, OR

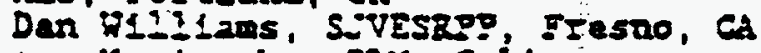

Amy Kufizaubo. BLY, Coliente

Sam FIESon, Bix, Holl1:Ear 


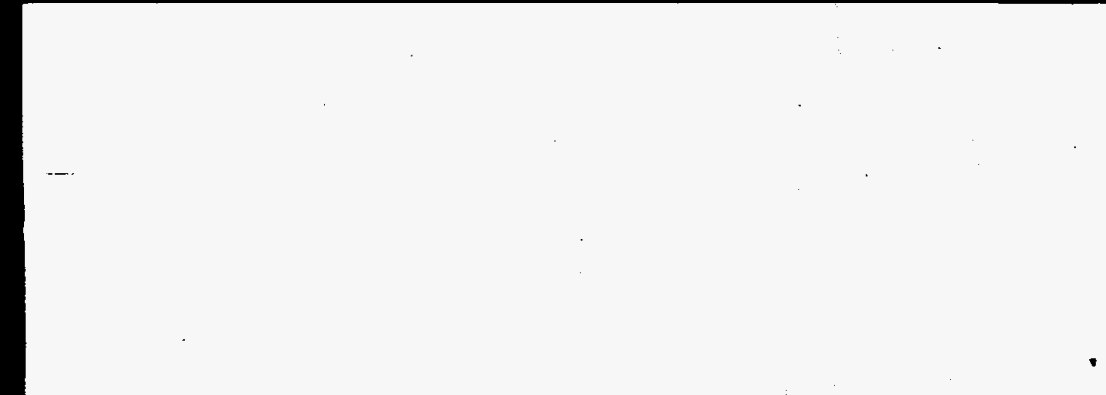




\begin{tabular}{|c|c|c|}
\hline $\begin{array}{l}\text { Non-Habitat } \\
(\mathrm{BNLL}) \\
(\mathrm{s}) \\
\mathrm{s}\end{array}$ & $\begin{array}{l}\text { Presumed BNLL Habitat (habitat } \\
\text { outside desiginated BNLL } \\
\text { conservations areas) }\end{array}$ & $\begin{array}{l}\text { Desiginated BNLL } \\
\text { Conservation Areas } \\
\text { (based on best available } \\
\text { knowledge and } \\
\text { preliminary recovery } \\
\text { planning) } 154,060 \text { ac. }\end{array}$ \\
\hline \multirow{3}{*}{$\begin{array}{l}\text { Any } \\
\text { treatment } \\
\text { necessary, } \\
\text { under } \\
\text { standard } \\
\text { measures (a, } \\
b, c) \\
\text { included in } \\
\text { proposed } \\
\text { action }\end{array}$} & $\begin{array}{l}\text { Standard measures to reduce } \\
\text { impacts } a, b, c\end{array}$ & $\begin{array}{l}\text { No treatments in Areas } \\
1,2,3,4,8,9,10 . \\
\text { Treaments in Areas } 5,6 \text {, } \\
7 \text { under the following } \\
\text { conditions: }\end{array}$ \\
\hline & $\begin{array}{l}1 \text { treatment per year, at up to } \\
100 \text { s coverage, based on pre- } \\
\text { treatment surveys. }\end{array}$ & $\begin{array}{l}\text { Large BLH populations } \\
\text { (15/10 sweep average): } \\
\text { treatment/yr; at up to } \\
50 \% \text { coverage/every other } \\
\text { swath, spot applications } \\
\text { not exceeding } 20 \text { acres. }\end{array}$ \\
\hline & $\begin{array}{l}\text { Designated High Virus-Intensive } \\
\text { Control areas: } 1 \text { or } 2 \text { (spring } \\
\text { and fall) treatments per year, at } \\
\text { up to } 1008 \text { coverage. }\end{array}$ & $\begin{array}{l}\text { Designated High Virus- } \\
\text { Intensive Control areas: } \\
1 \text { (spring and or fall) } \\
\text { treatment per year, up } \\
\text { to } 50 \text { s coverage/every } \\
\text { other swath, spot } \\
\text { applications not } \\
\text { exceeding } 20 \text { acres. }\end{array}$ \\
\hline \multirow[t]{2}{*}{$\begin{array}{l}\text { Range } \\
\text { Management } \\
\text { to reduce } \\
\text { russian } \\
\text { thistle and } \\
\text { other host } \\
\text { plants } \\
\text { (Third } \\
\text { Priority) }\end{array}$} & $\begin{array}{l}\text { Range Management to reduce } \\
\text { russian thistle and other host } \\
\text { plants (Second Priority) }\end{array}$ & $\begin{array}{l}\text { Range Management to } \\
\text { reduce russian thistle } \\
\text { and other host plants } \\
\text { (First Priority). }\end{array}$ \\
\hline & & $\begin{array}{l}\text { Experimental Parasite } \\
\text { Program; target Areas 2, } \\
5,6,7 \text { outside High } \\
\text { Virus-Intensive Control } \\
\text { areas for release. }\end{array}$ \\
\hline
\end{tabular}




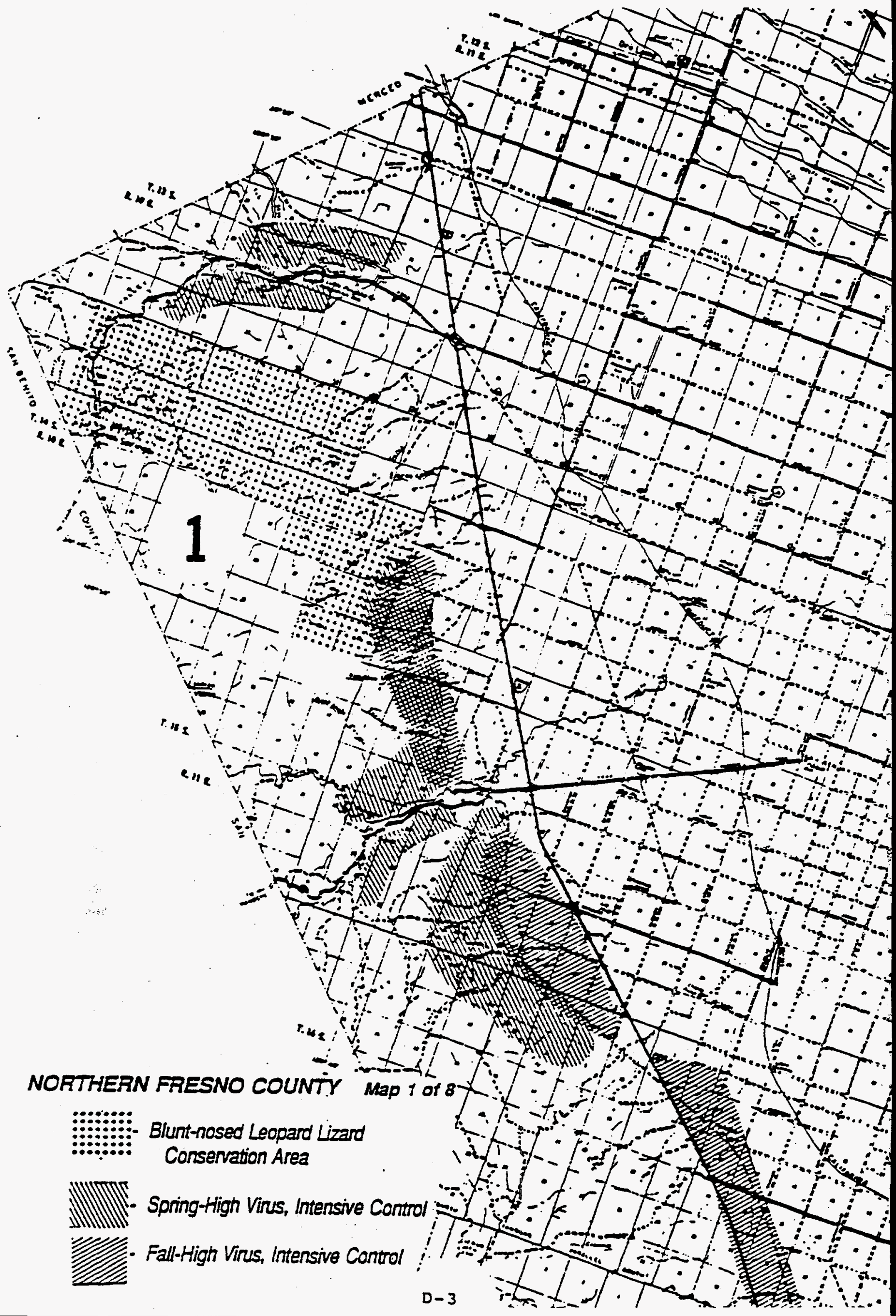




\section{WESTERN FRESNO COUNTY MAD 2 of 8}

::::::: Blumt-nosed Lecpard Lizard

$:::::$ : Conservation Area

Spring-Hign Vinus, Intensive Control

Fall-riign Vinus, Intensive Control
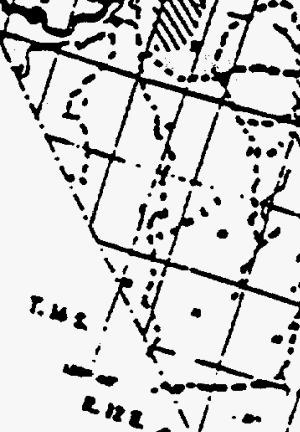

(-3)

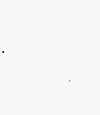




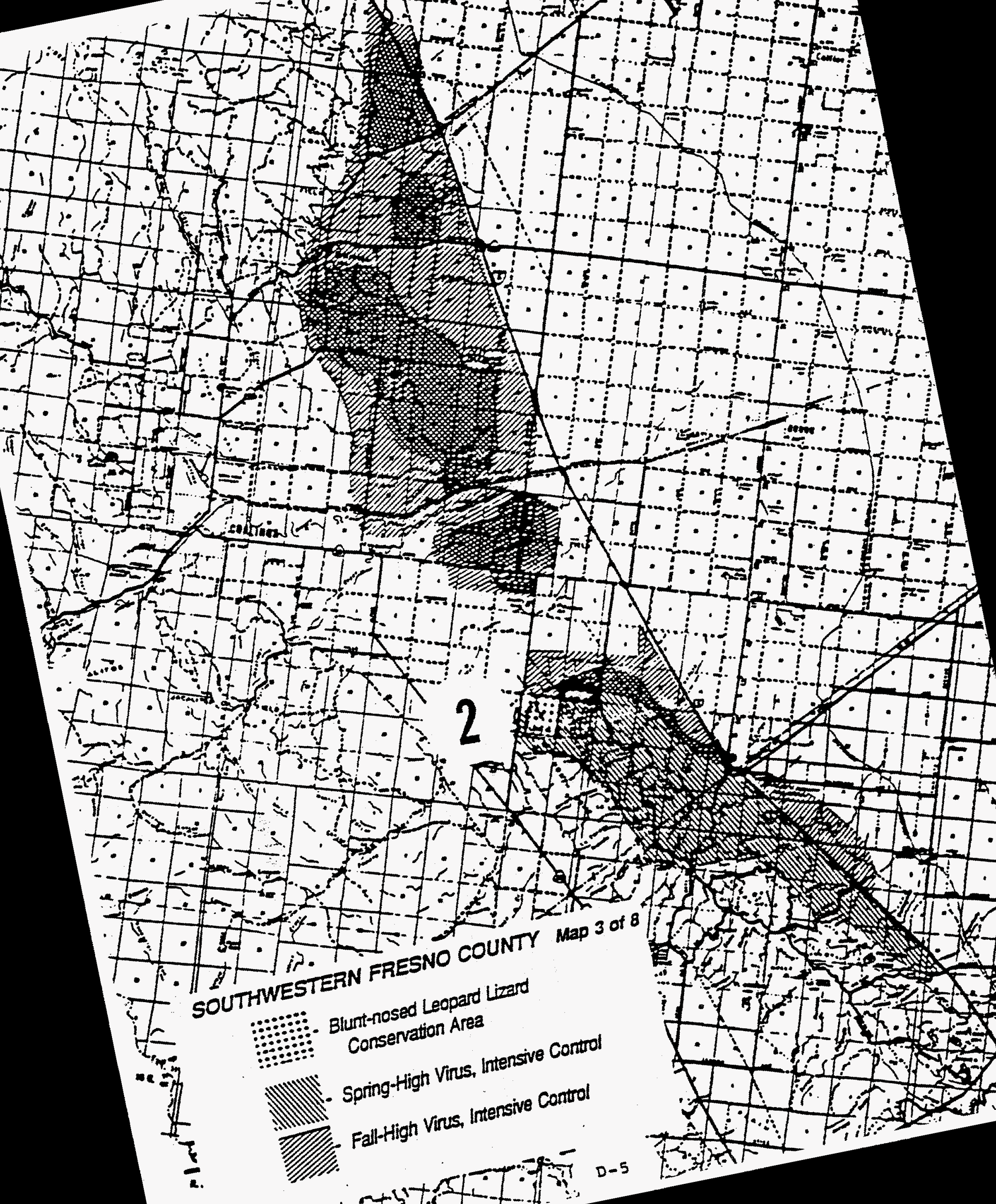




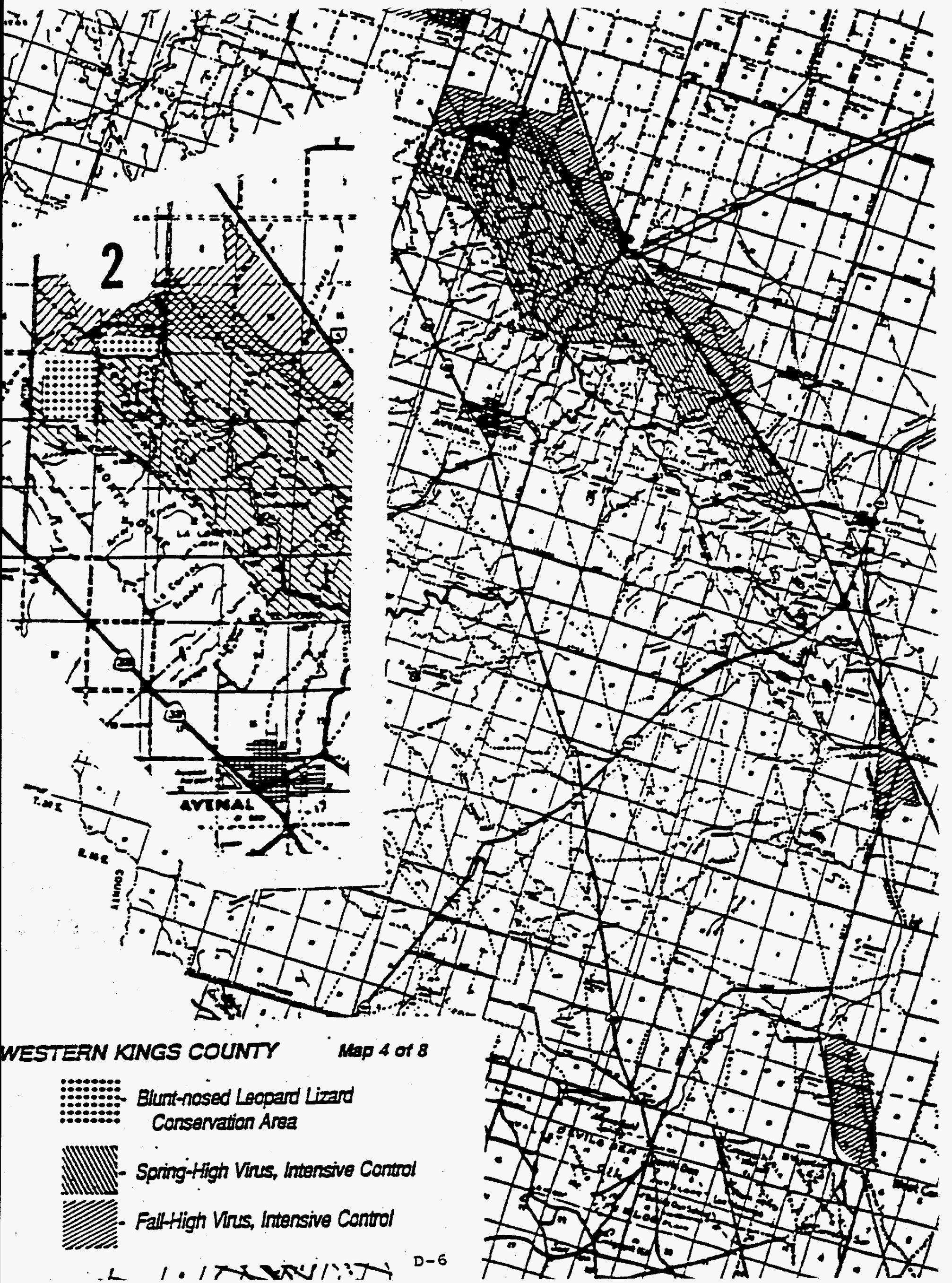




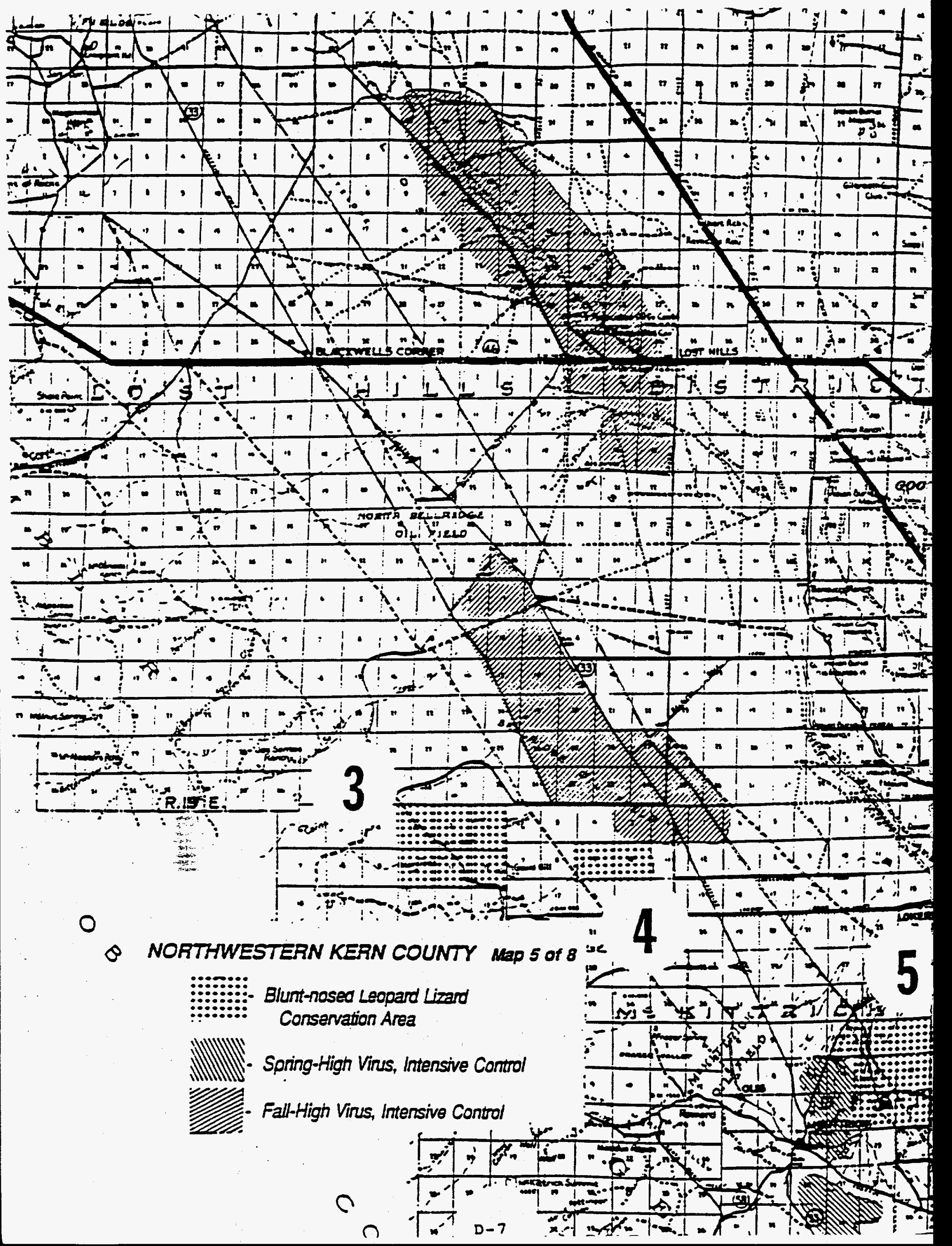




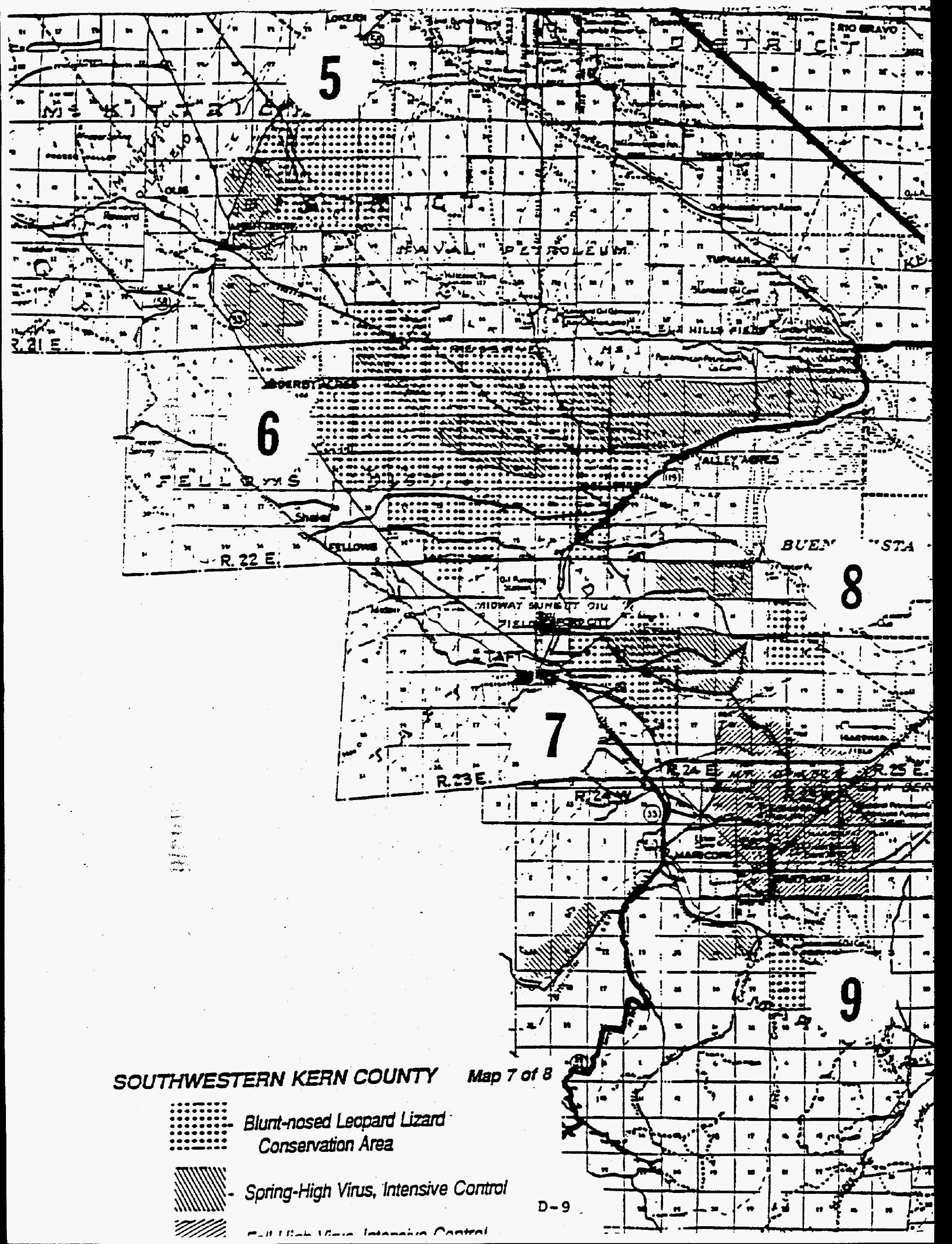



is

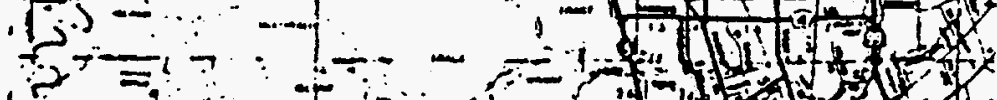

$15-4070$ a

$\therefore$ -

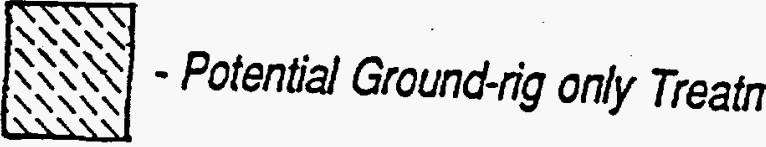

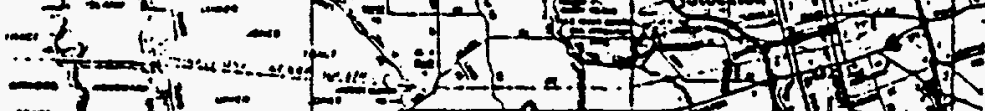

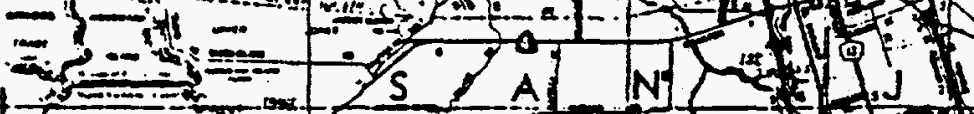

$1=3$

-7 -

(Western San Joaquin and Stanistaus County)

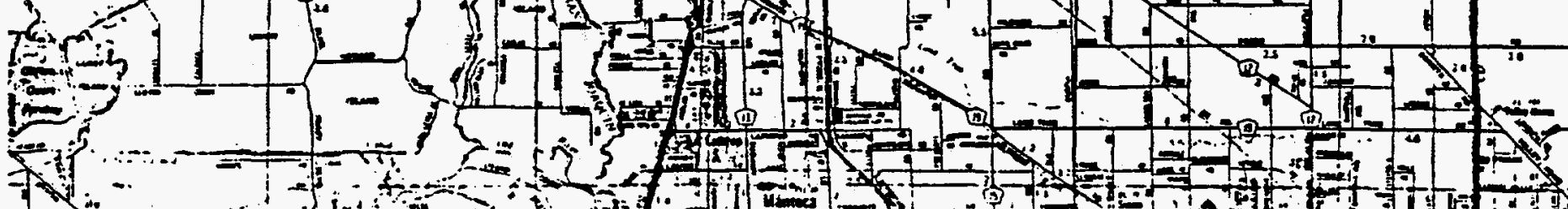

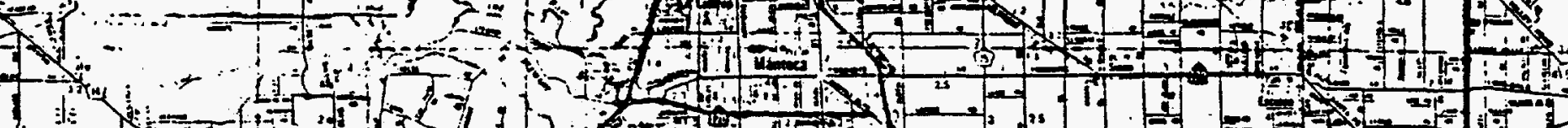

1.

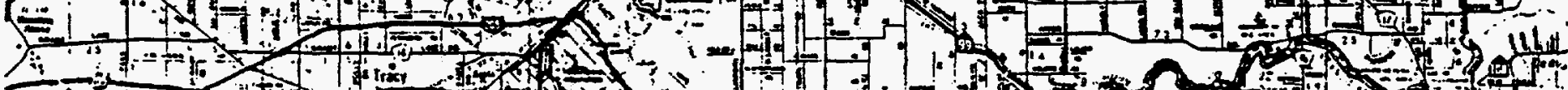

in

\%
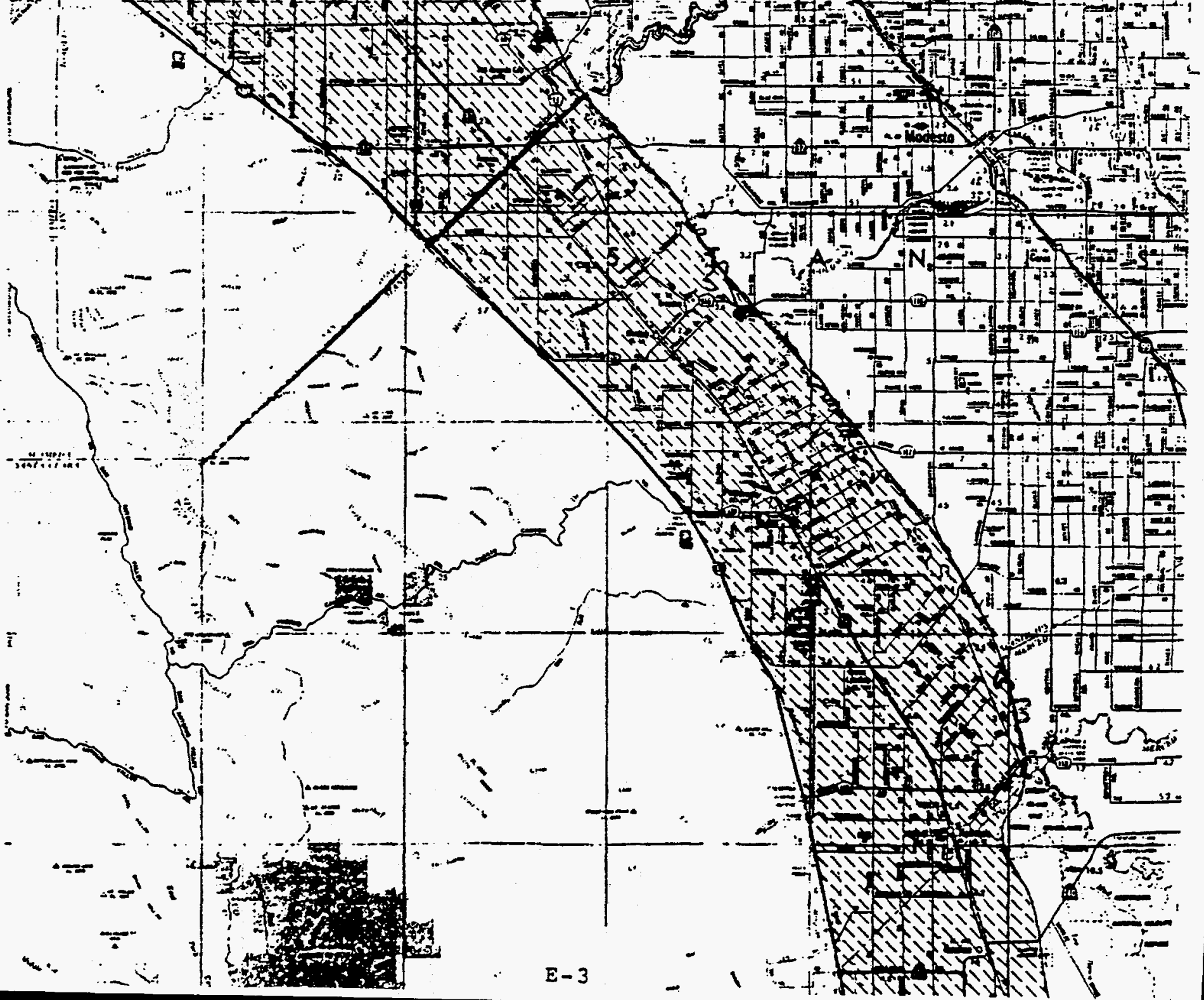


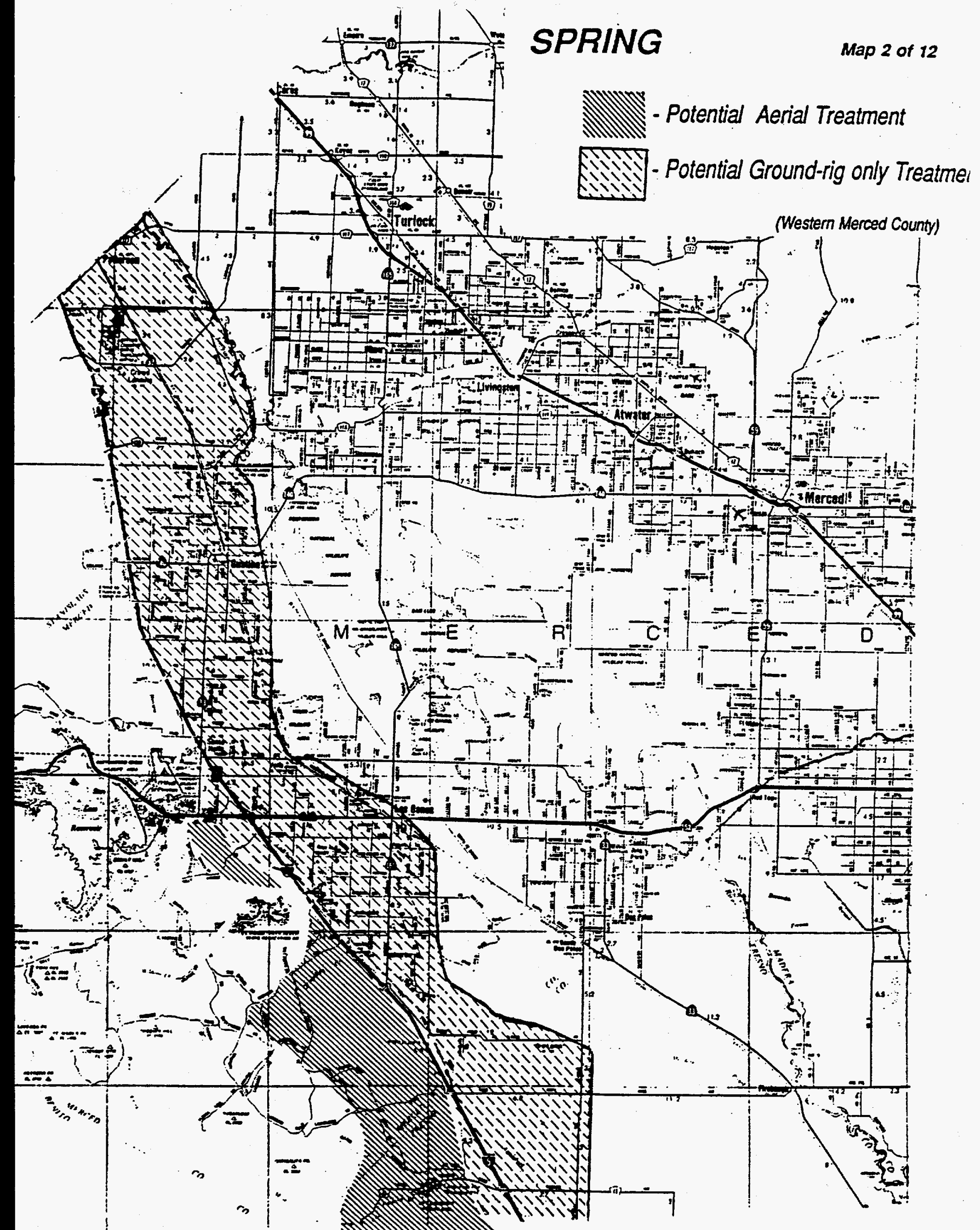




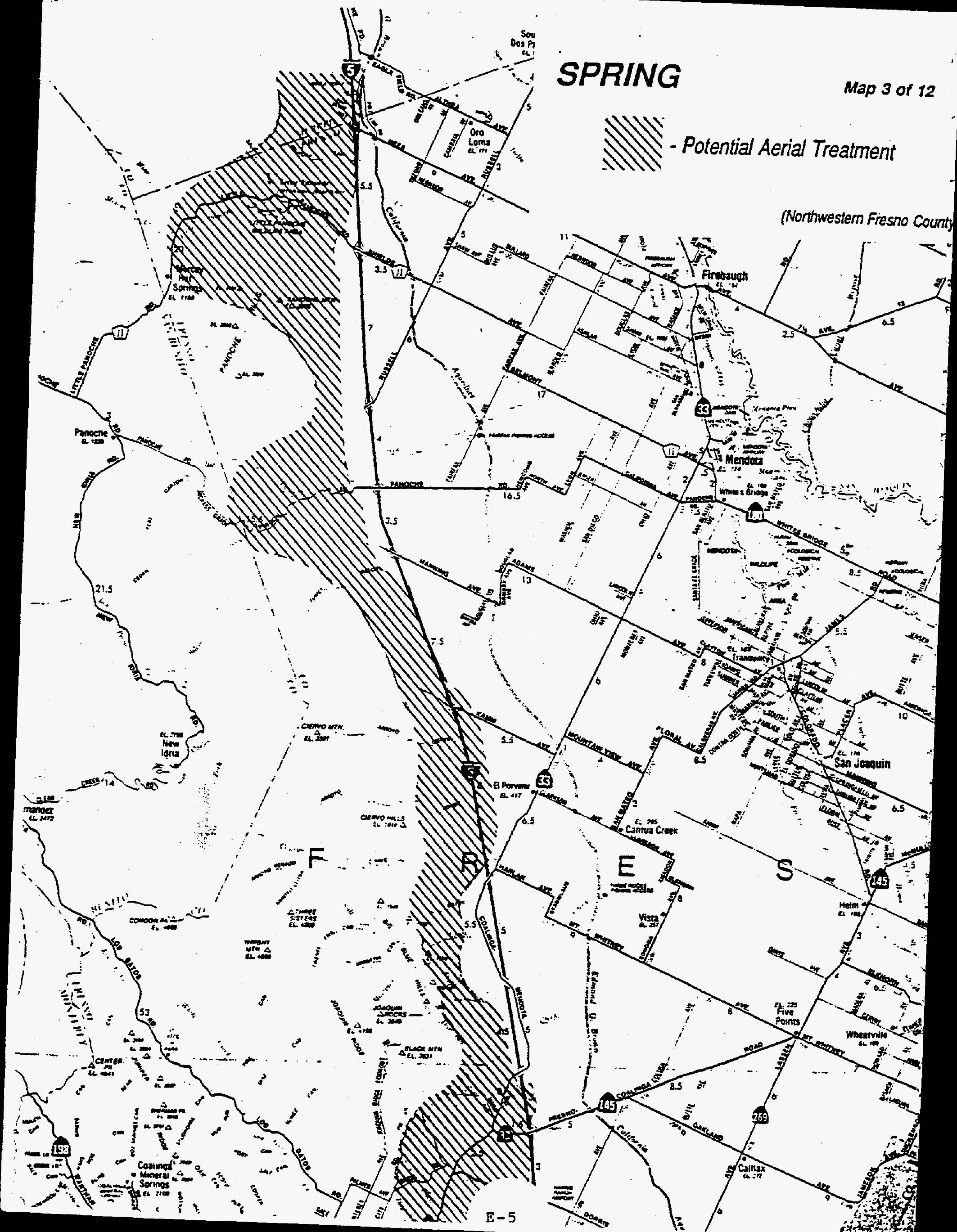




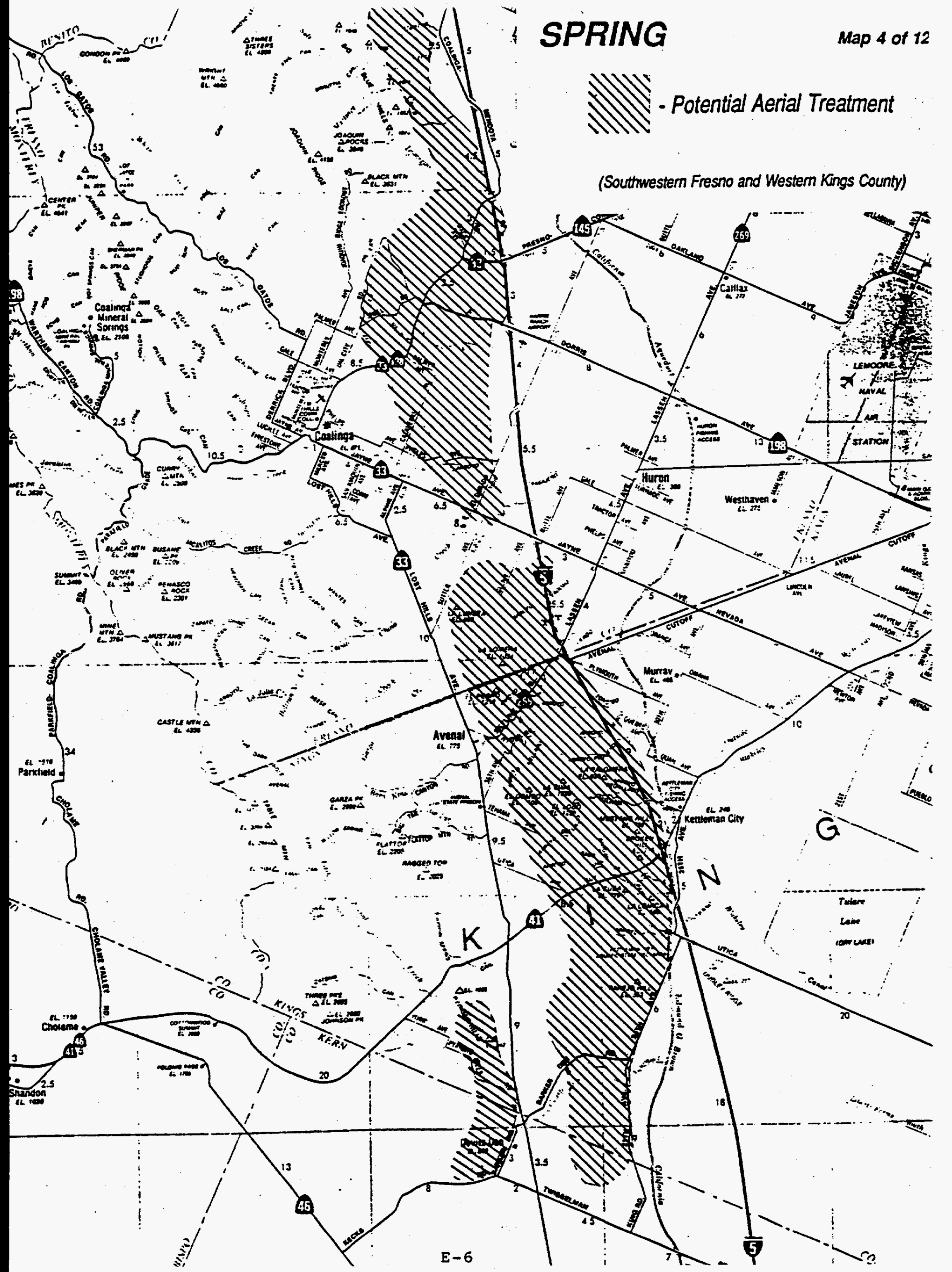




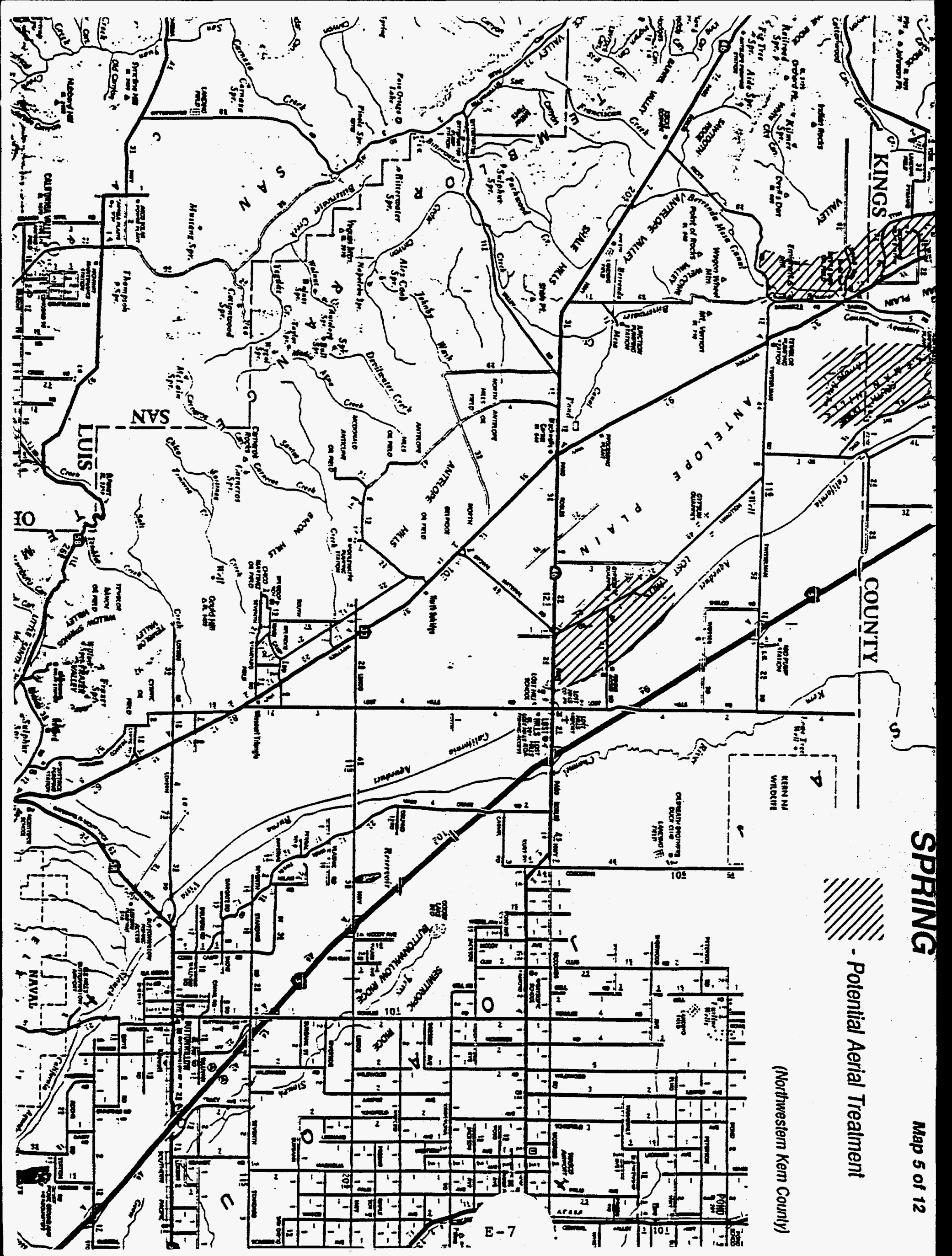




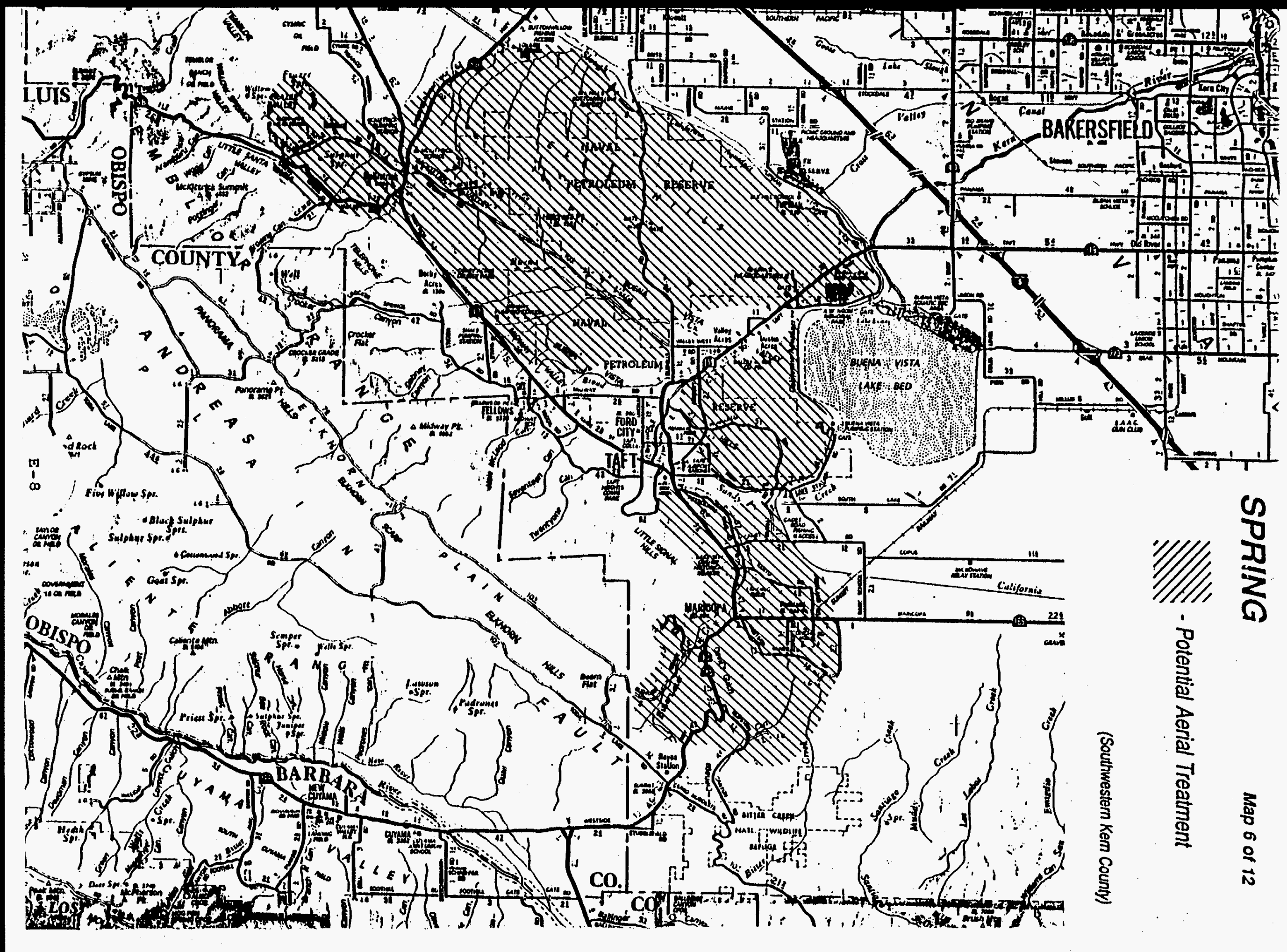




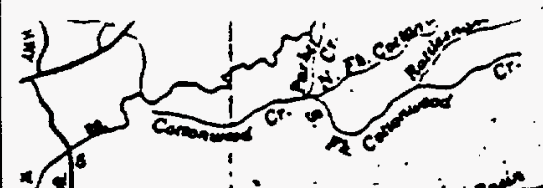

1)

to

(n)

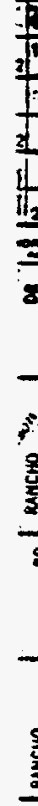

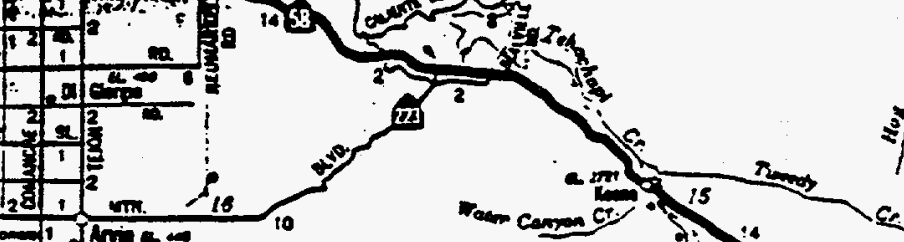

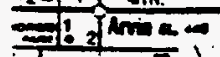

12

(2)

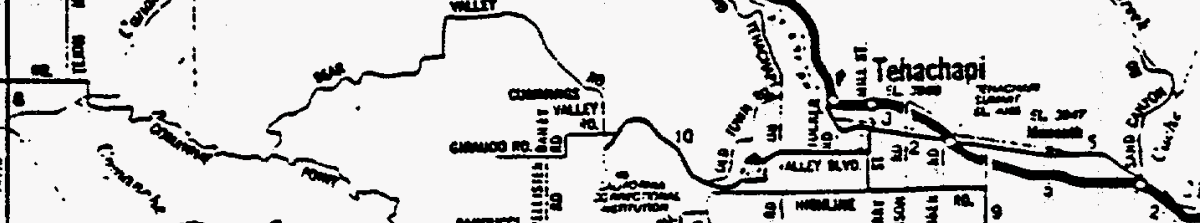

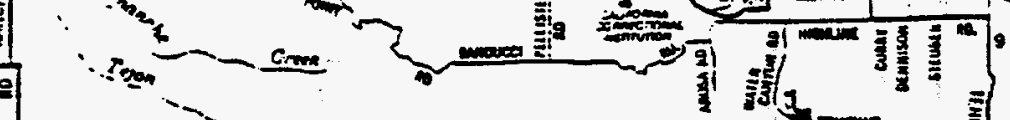

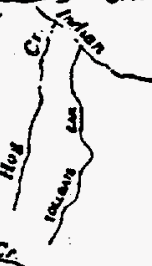

(Southeastem Kem County;

$\int_{13}^{n-2 x}$

$=$

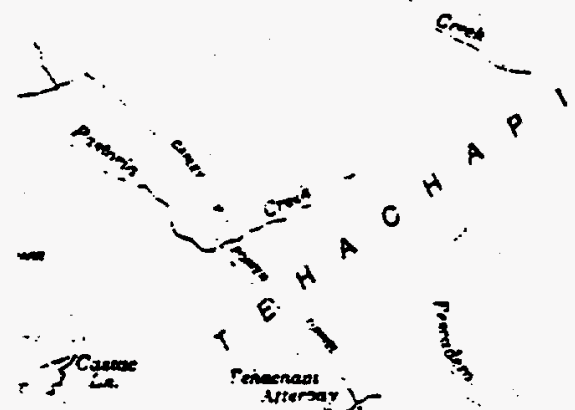

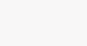

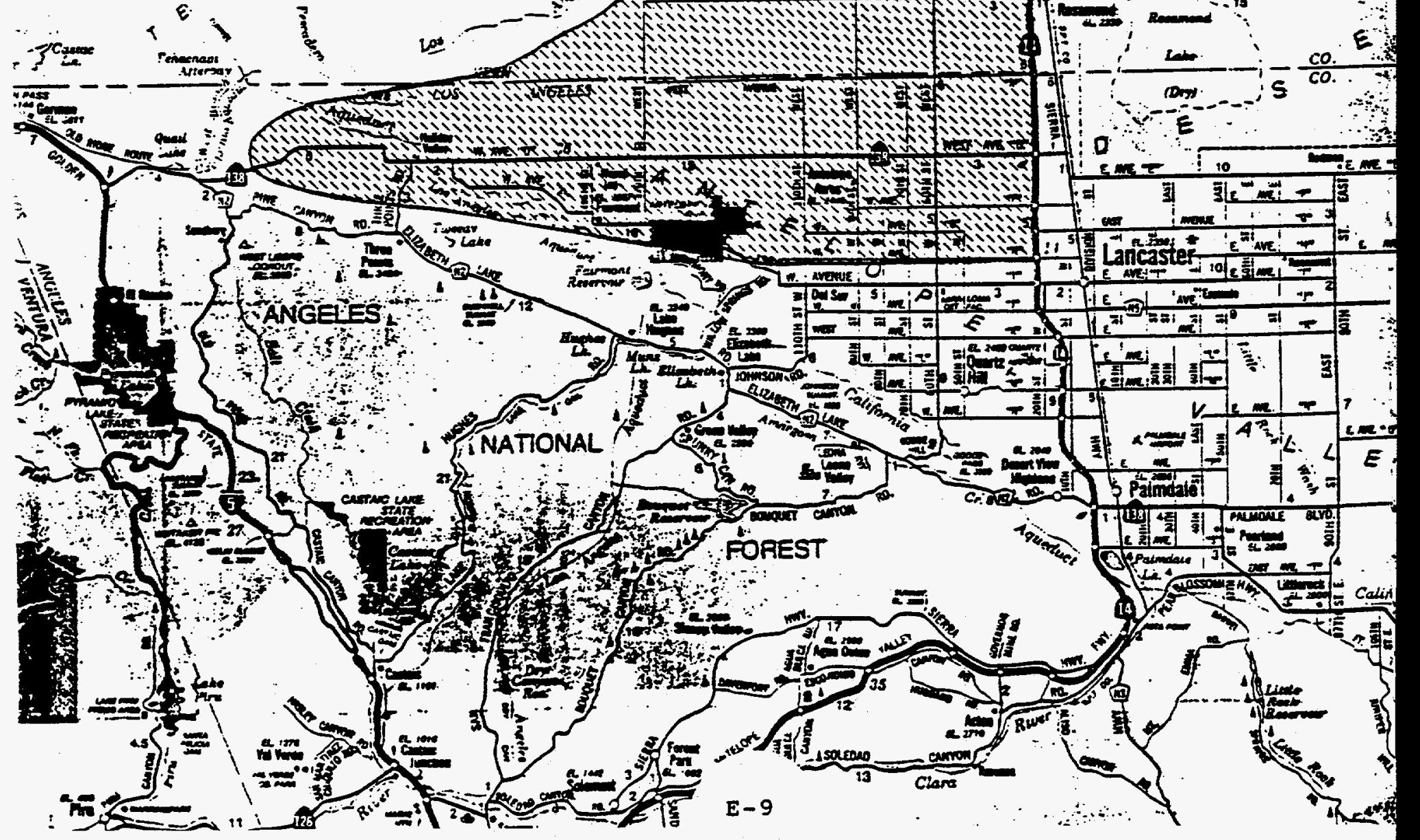




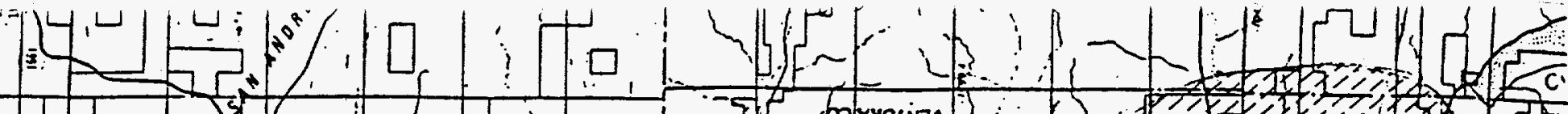

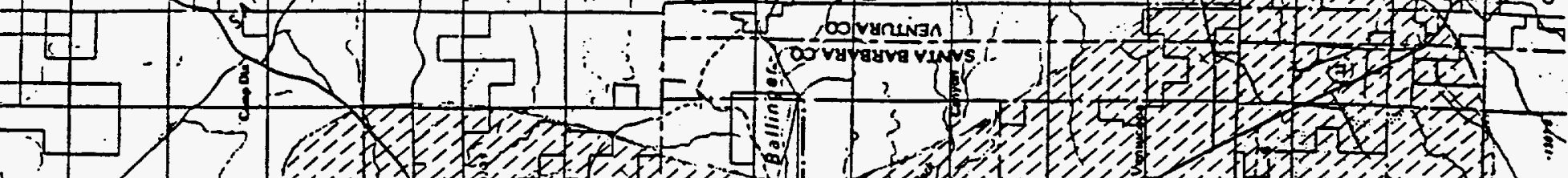
1

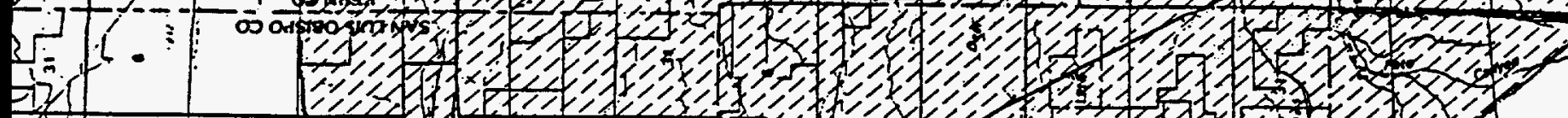

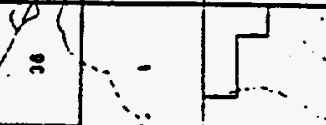

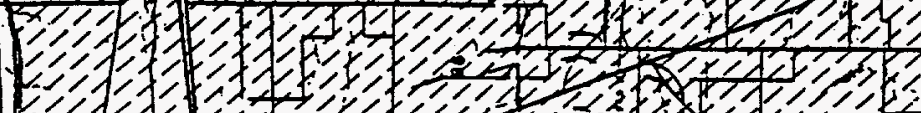

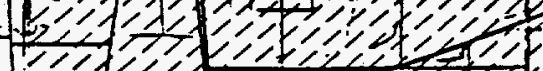

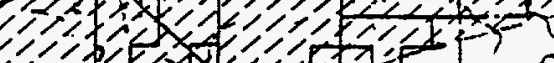

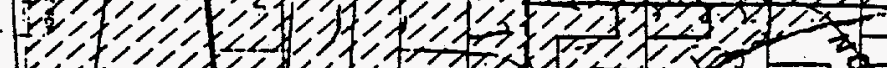

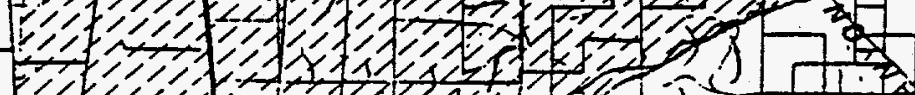

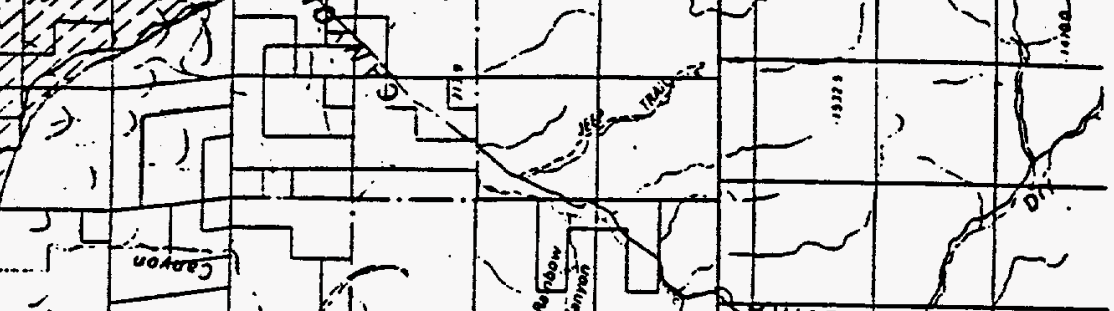

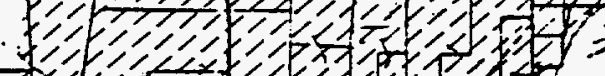

8

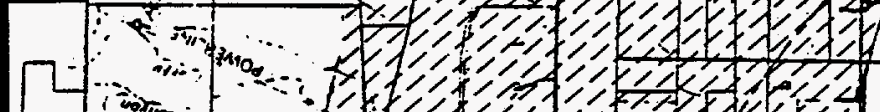

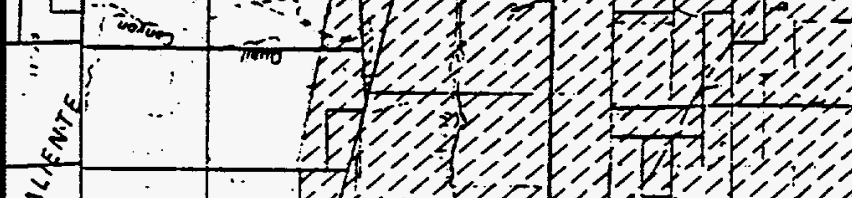

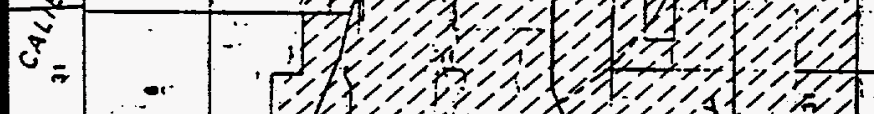

(1)

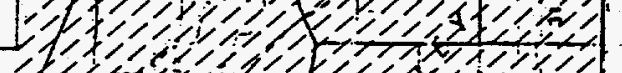

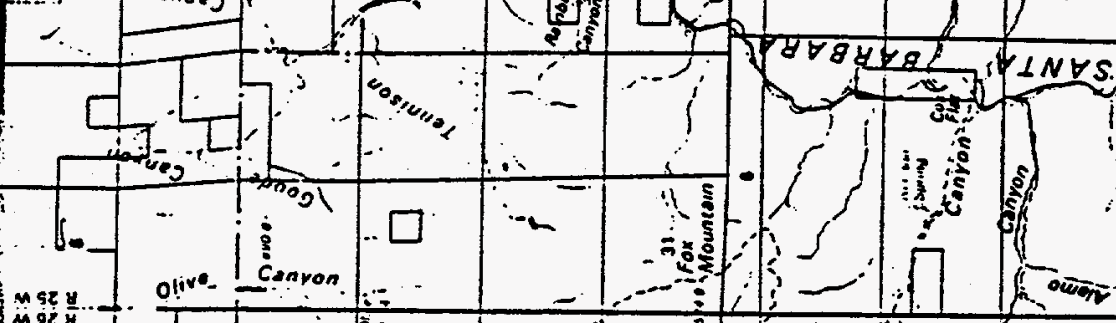

का

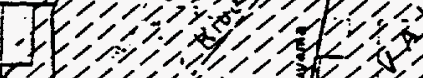

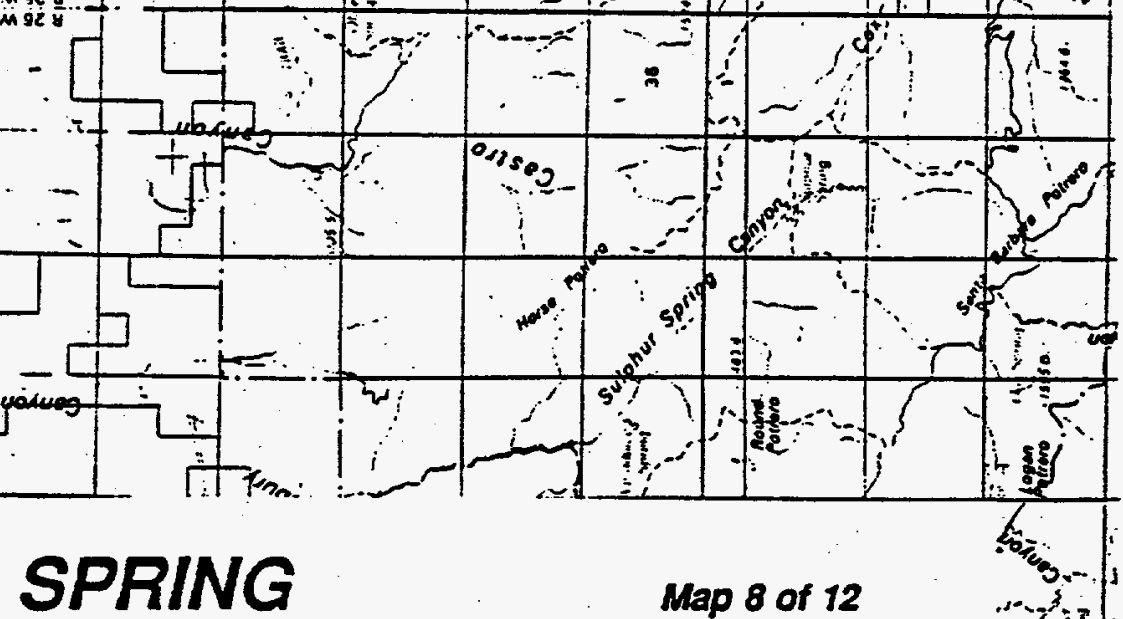

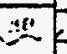

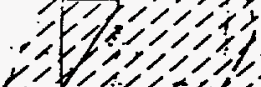

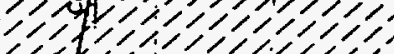

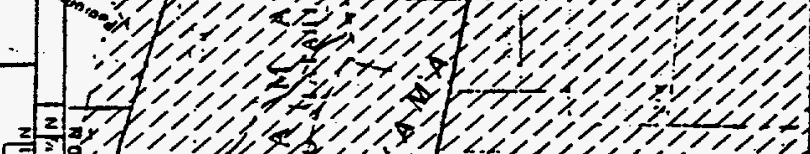

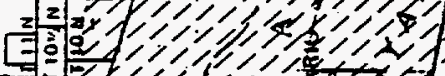

SPRING

Map 8 of 12

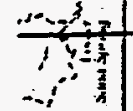

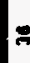

$\int \frac{0}{0}$

.

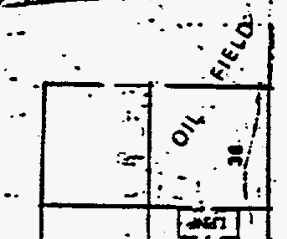

$E \geq \geq \geq \geq$

Potential Ground-rig only Treatment

(Corner of San Luis Obispo, Kern, Santa Barbara, Ventura County)

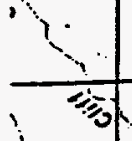

,

8

3\%

sis

都
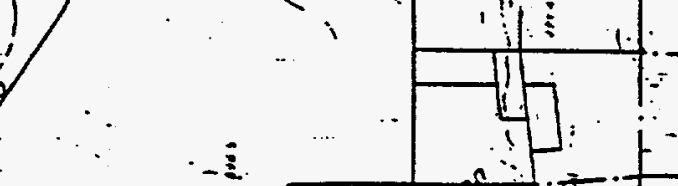

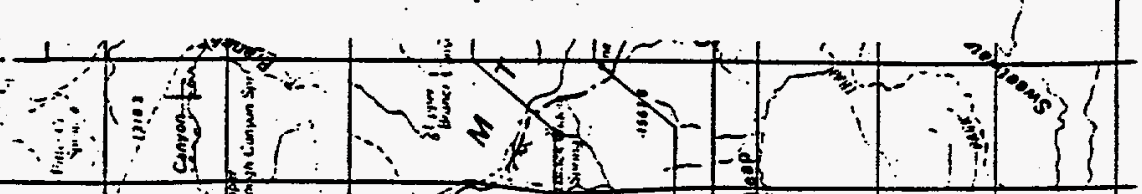

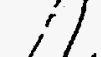

i.

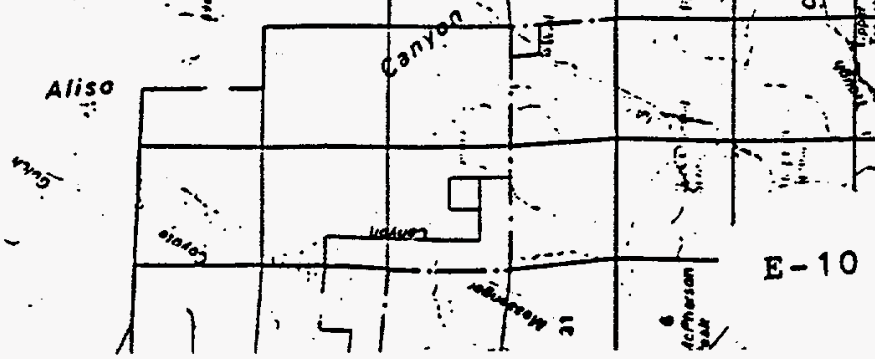

t 
i

$=1,1$

$T_{\text {TIONAL }}$

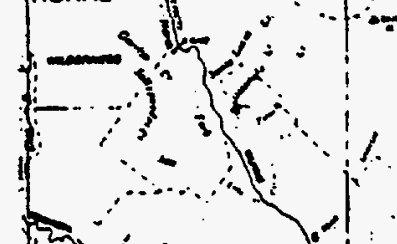

1.1

(Monterey County)
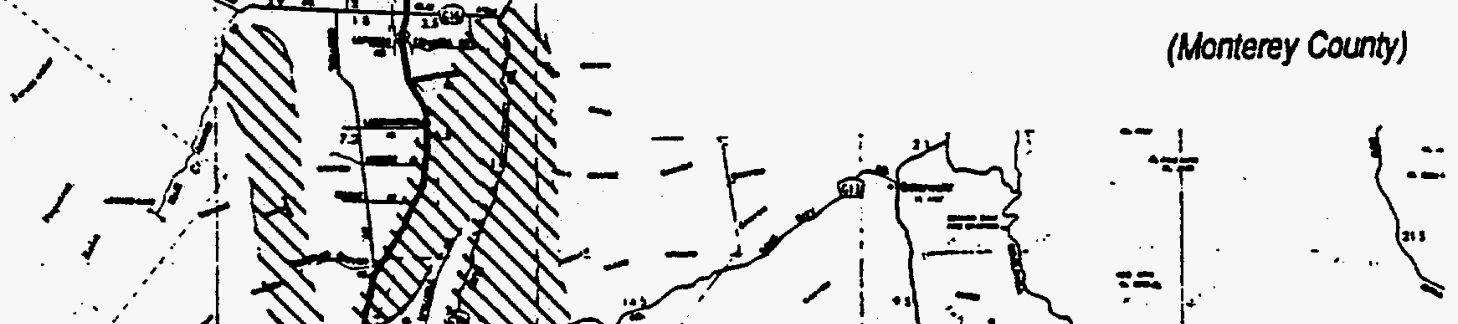

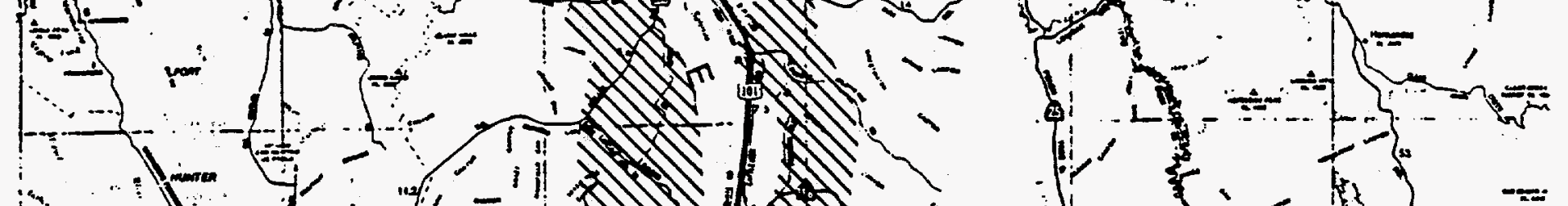

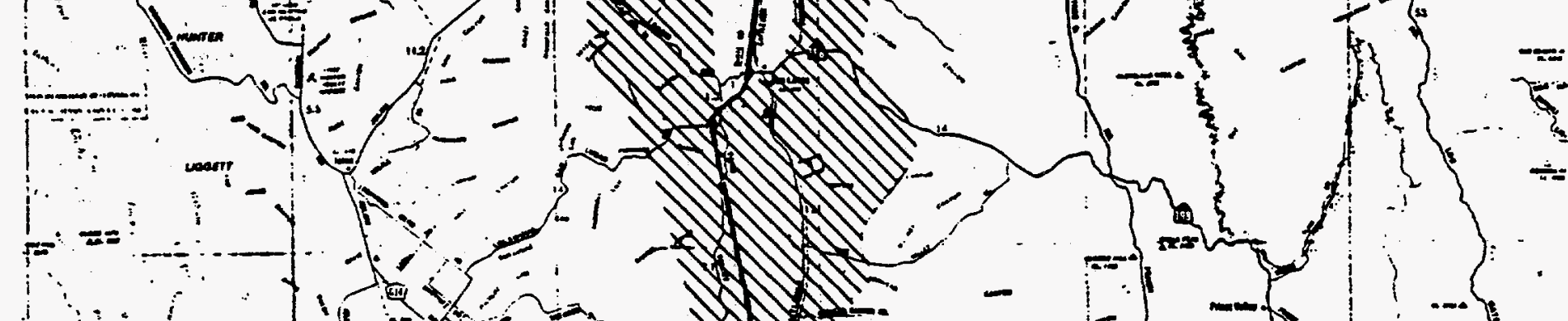

$+1$

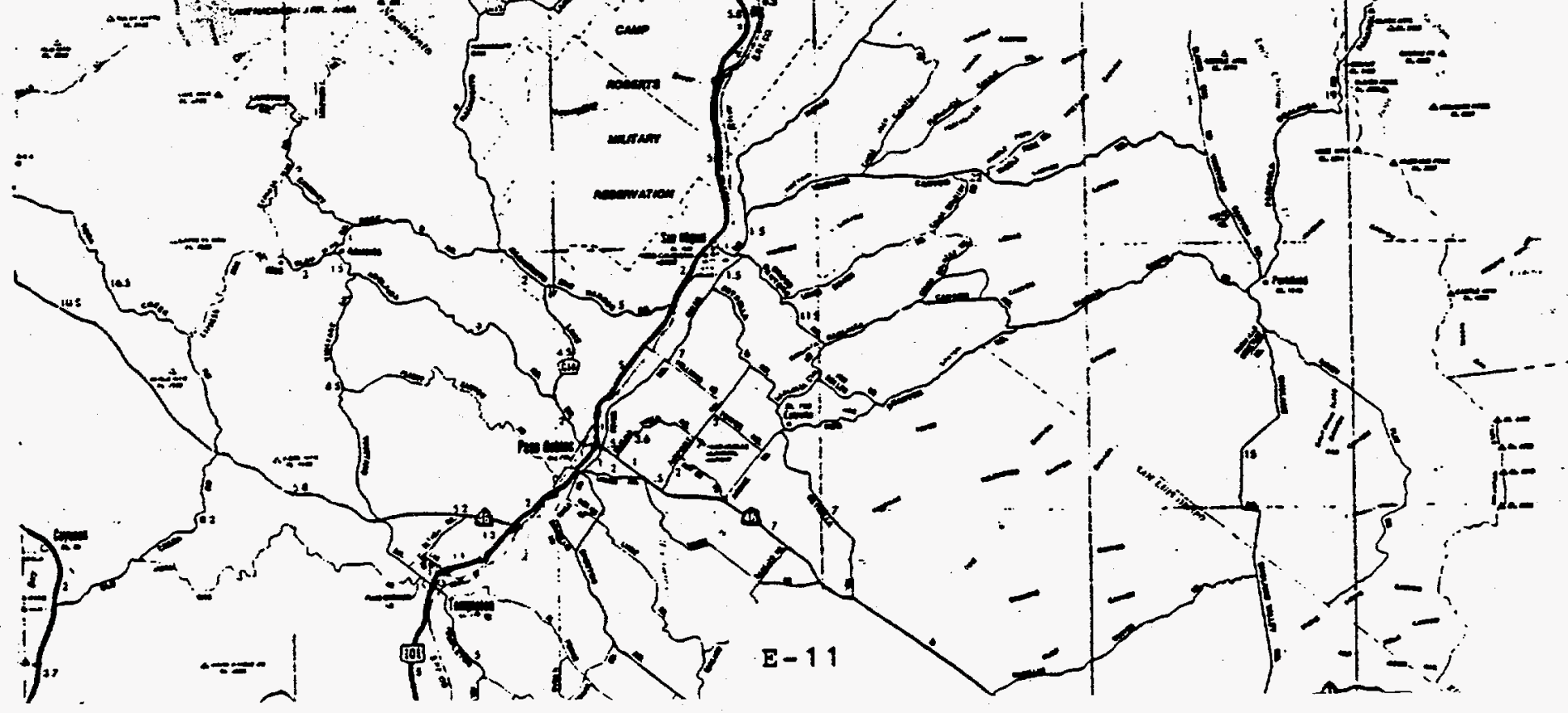


Sonve

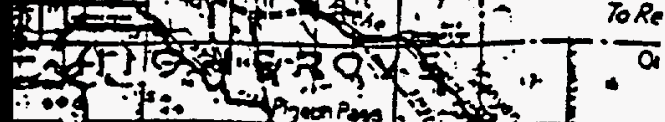

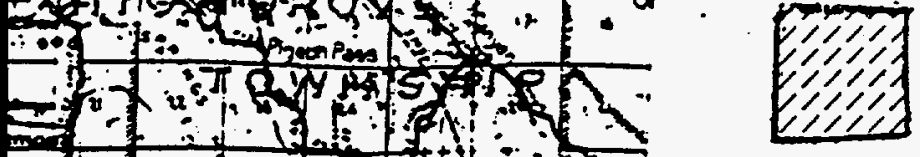
Potential Ground-rig only Treatment

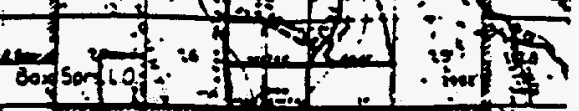

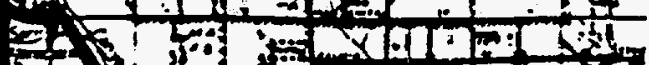
(Westem Riverside County)

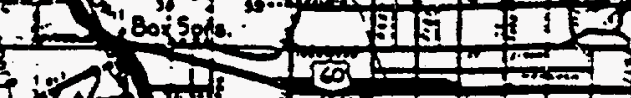
Sis

(1)

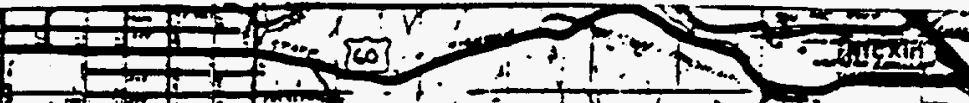
TH anm tilt $10=2 ; 0$.

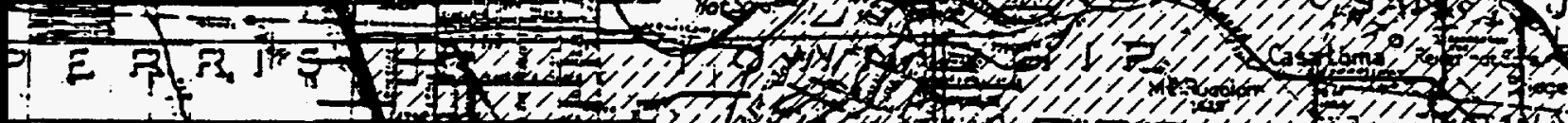

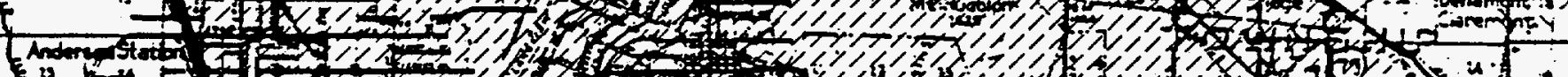

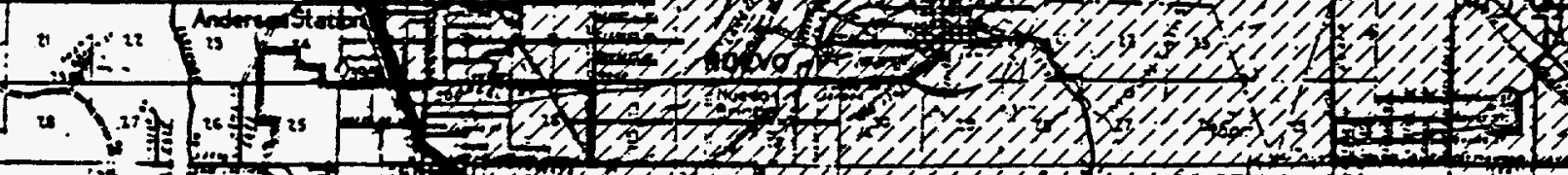

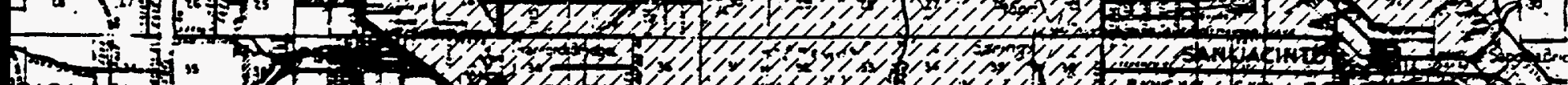

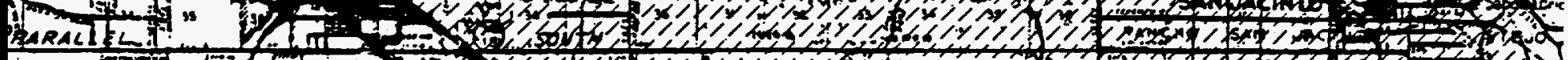

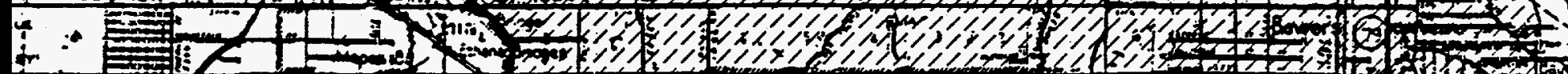

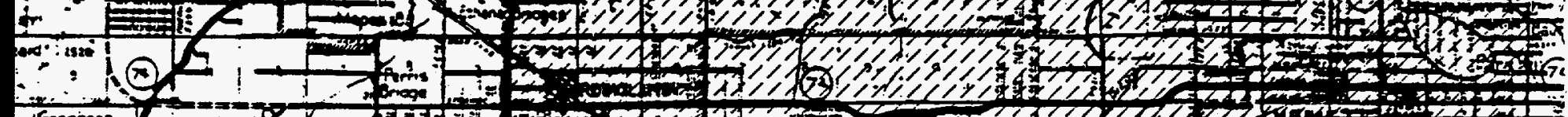

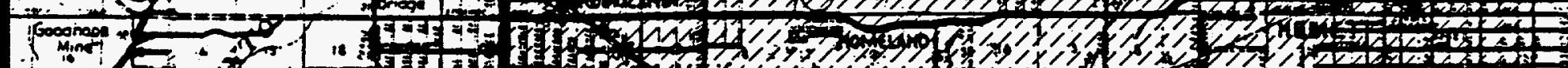
$\therefore$ (1)

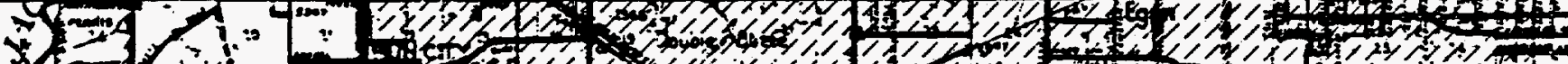

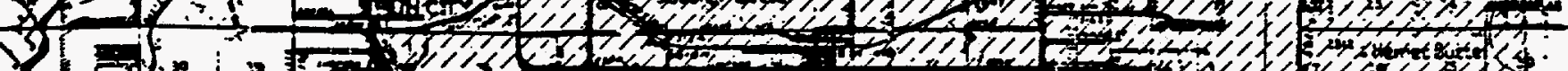

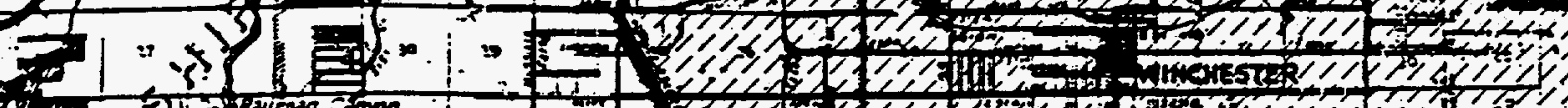

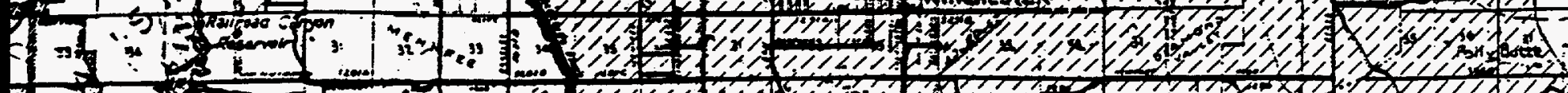
(c) 5 . in:

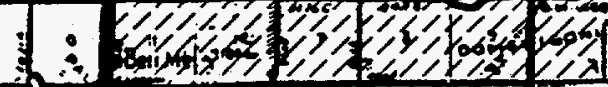

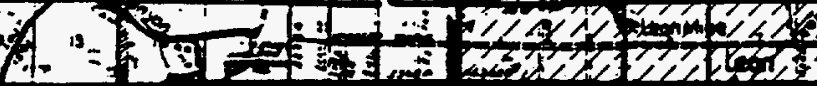




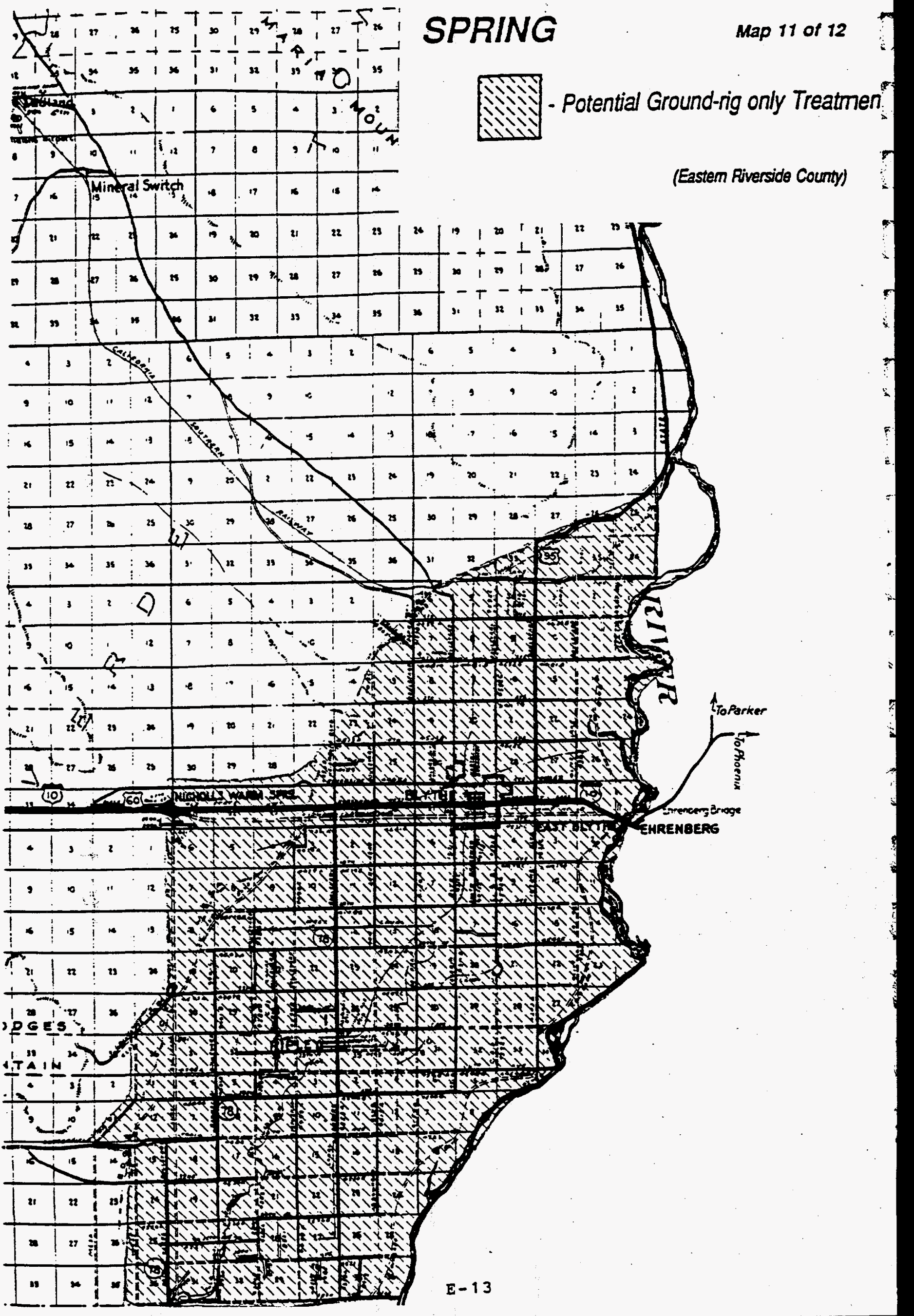




\section{SPRING}

Map 12 of 12

- Potential Aerial Treatment $\rightarrow$ in

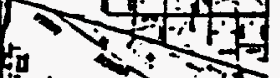

in

ting

Treatment

is

$\underbrace{1}_{-\infty}$

$\therefore$ ín

$1=4$

$\rightarrow=$

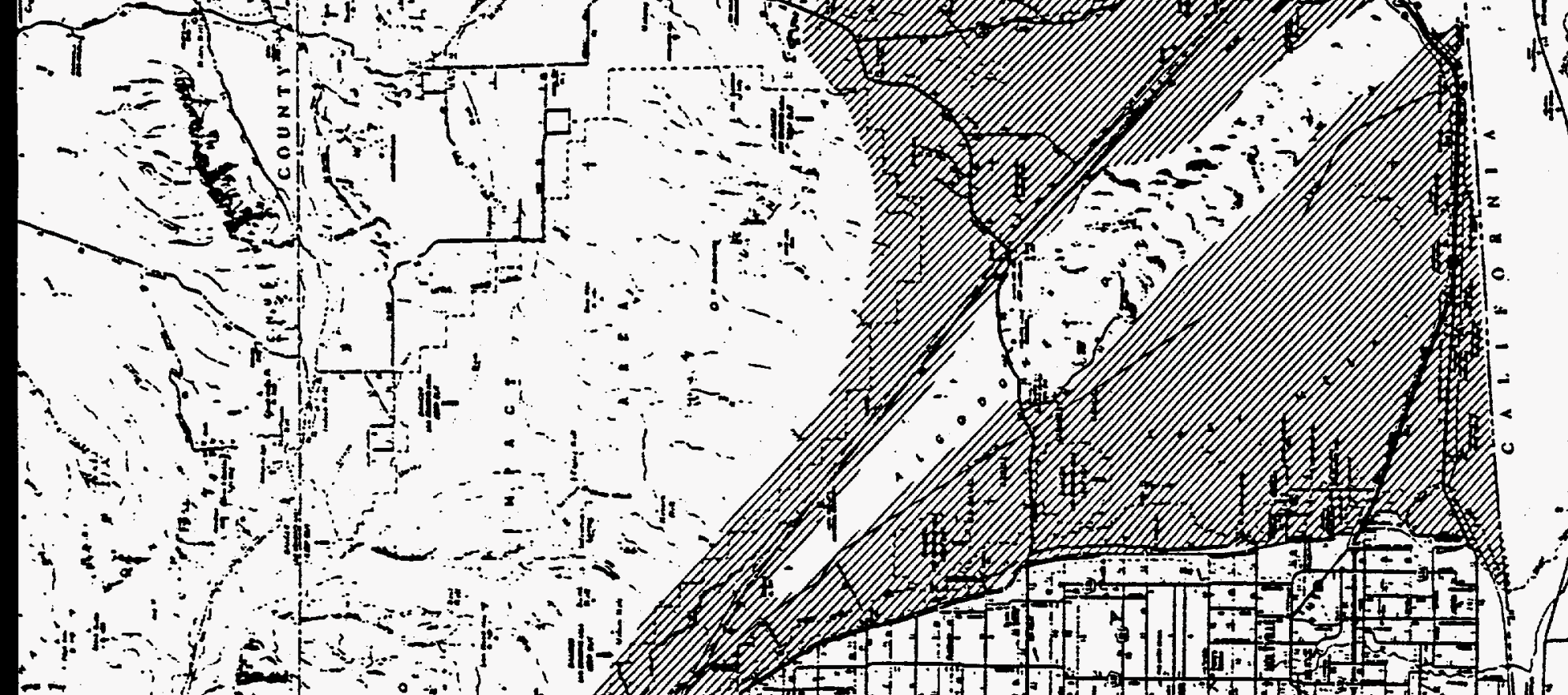

$+2$

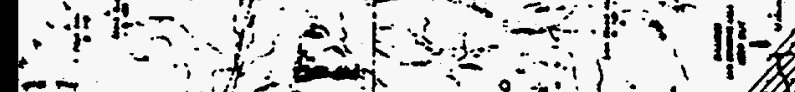

(Imperial County)

政

Dratyloty (3) III

$1+y$.

150

(1)

a

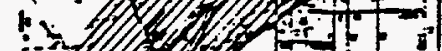

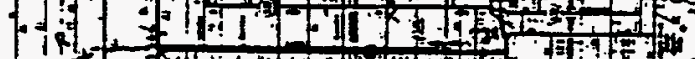

.

1)

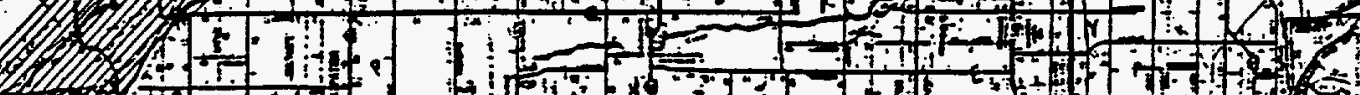

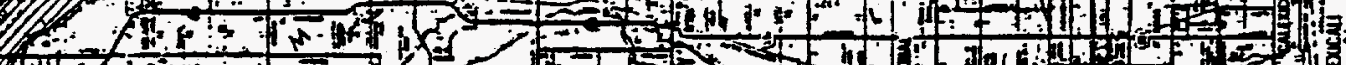

$-1$ 作 $1+2$

Hax 9 .

-

(1) $y$.

-in $-2,-20$

-

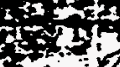




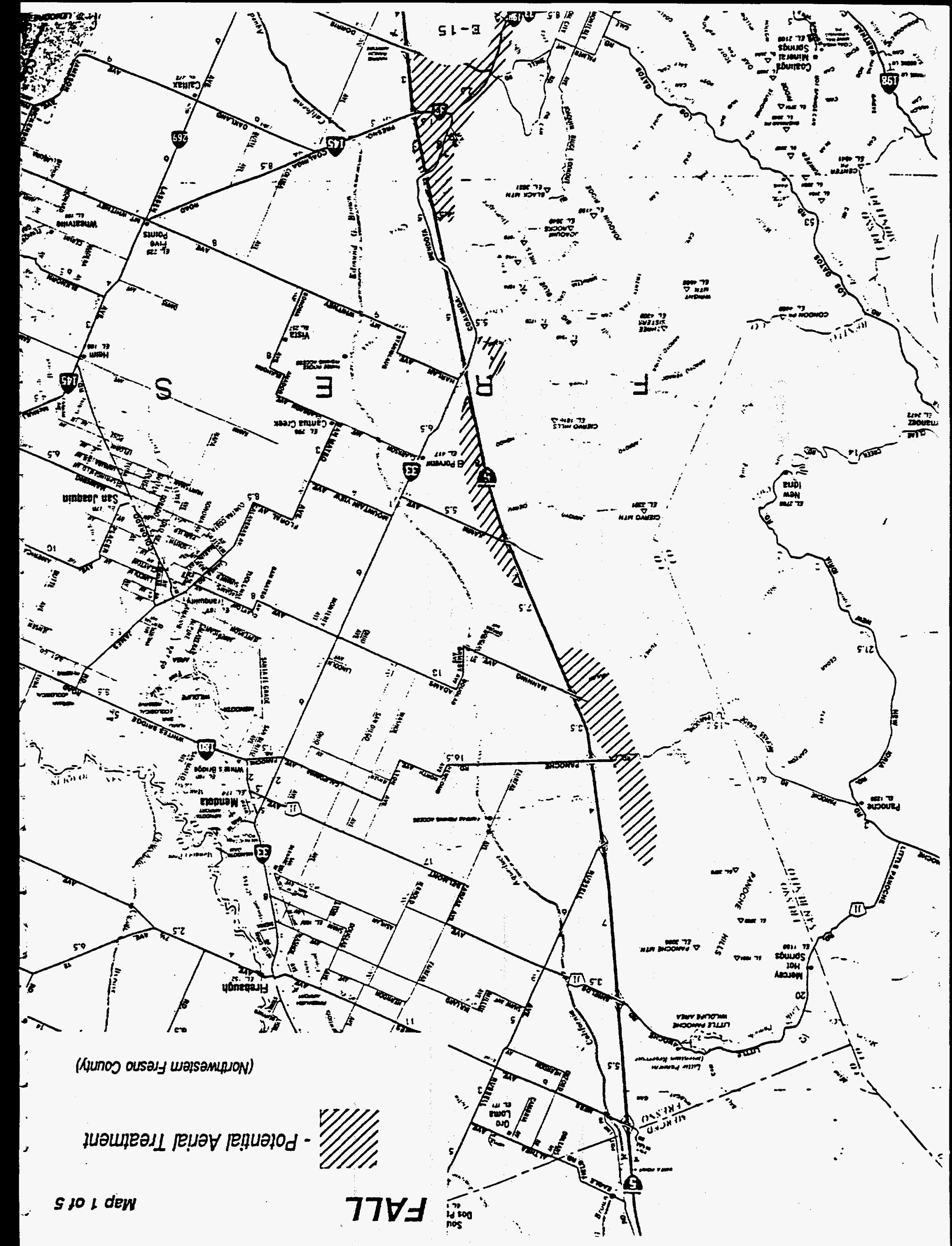




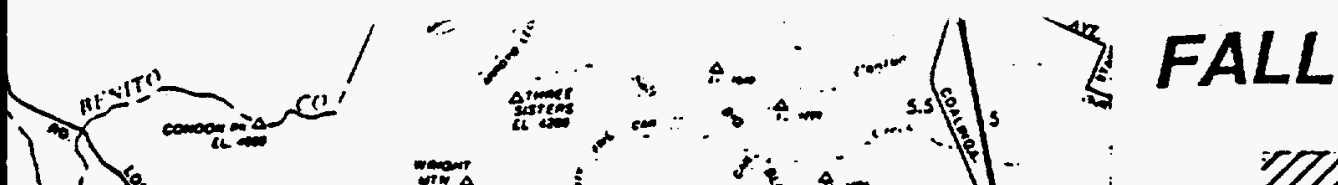

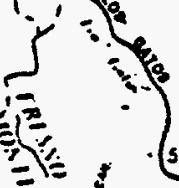

in

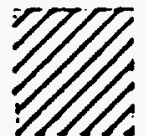

Potential Aerial Treatment

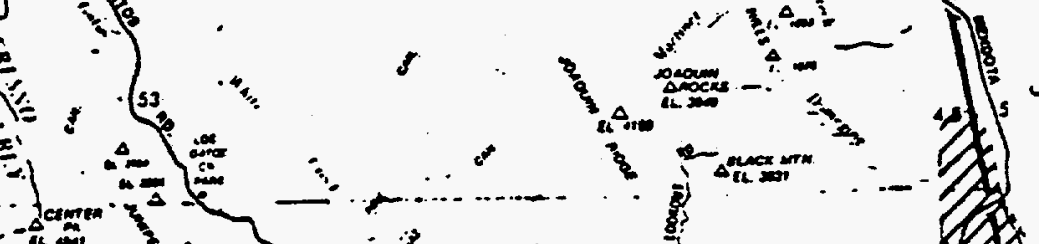

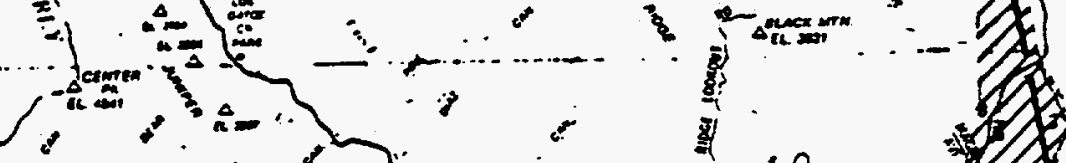

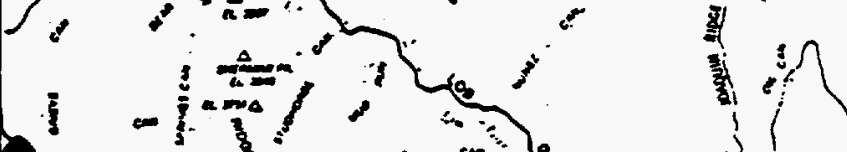
$198,-10+\infty$ 198 (1)

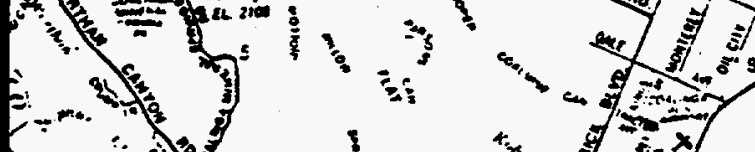
, 1 un

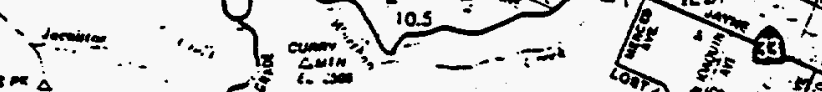
arsmis

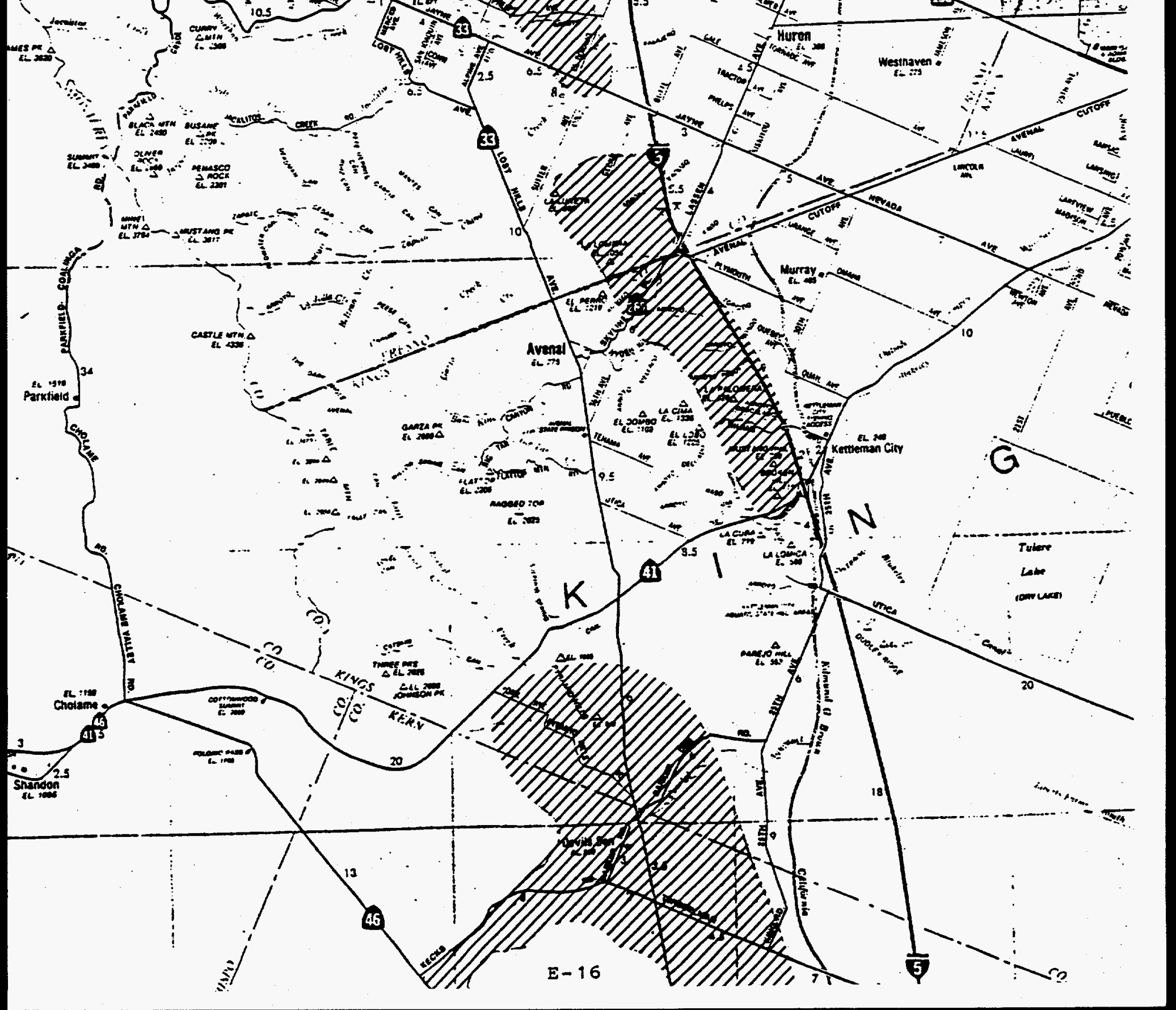




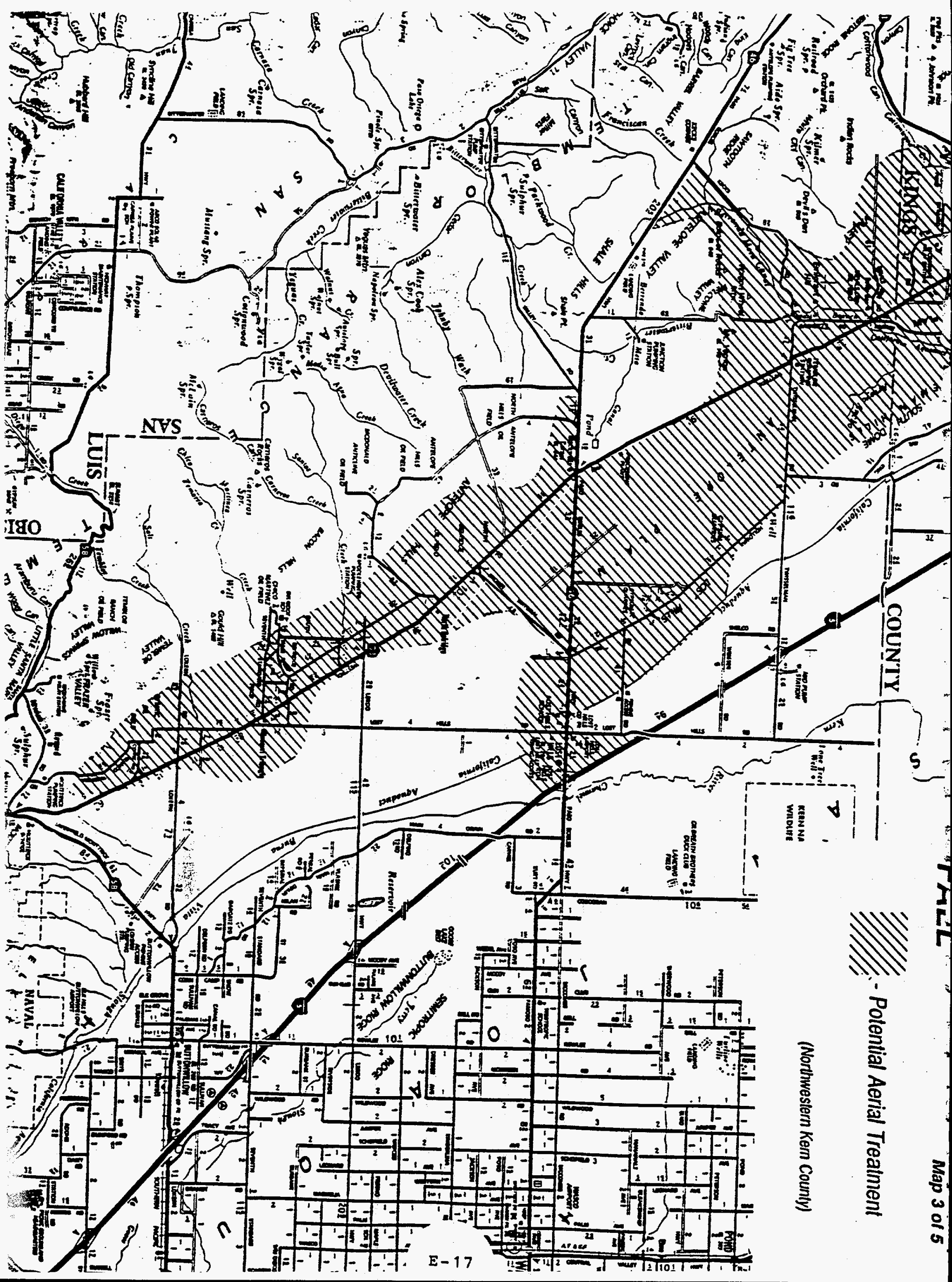


FALL 年

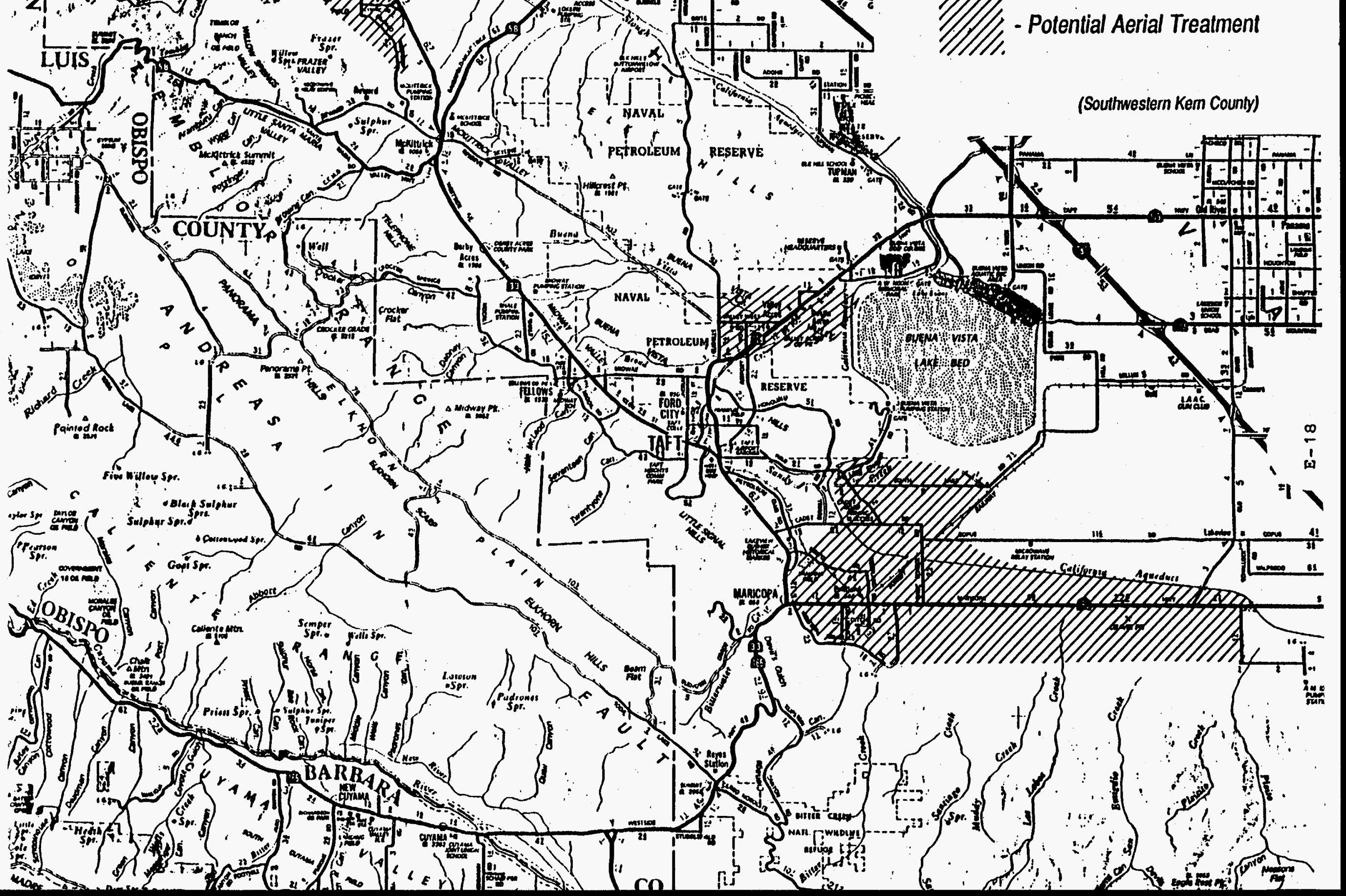




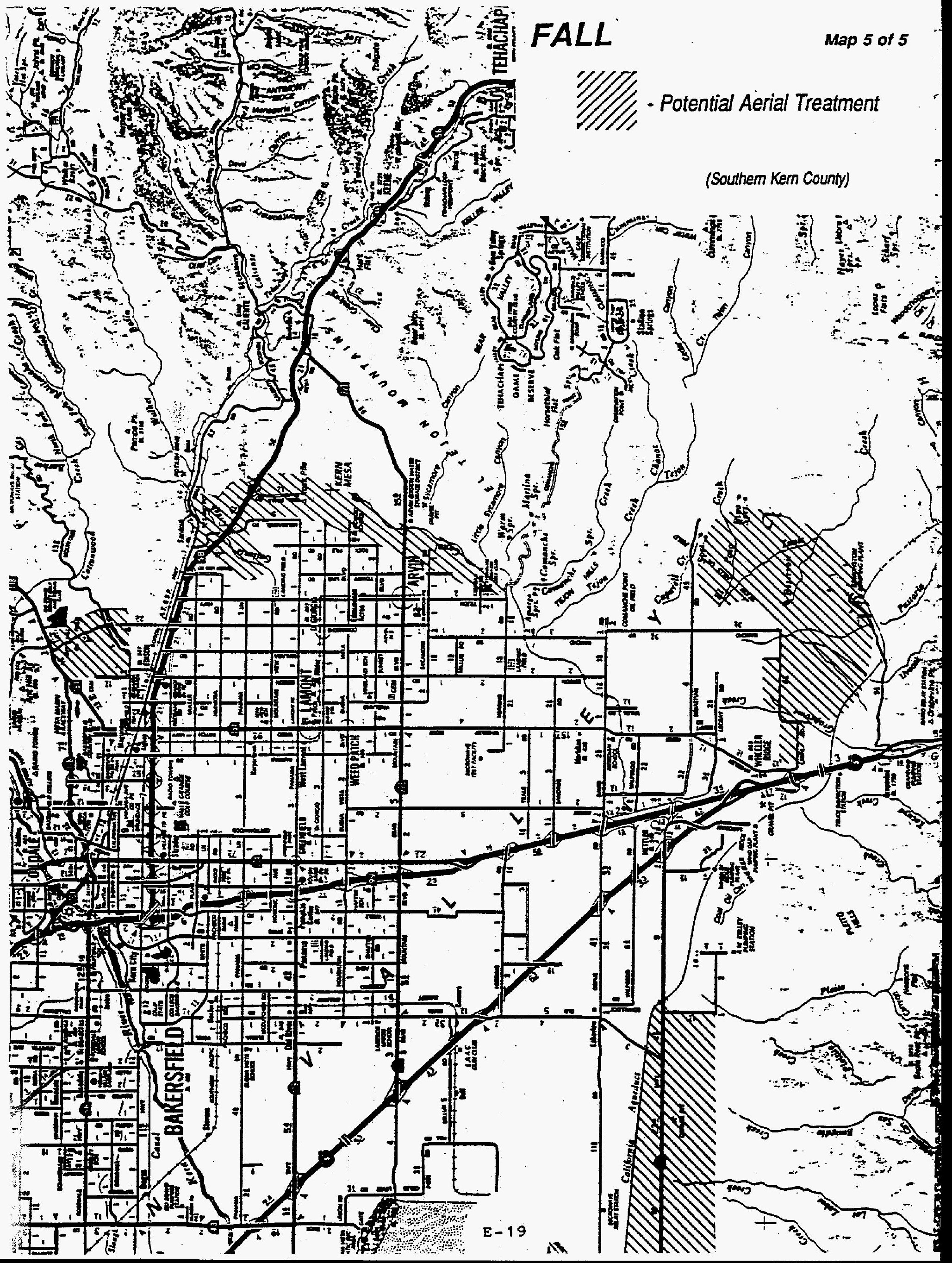




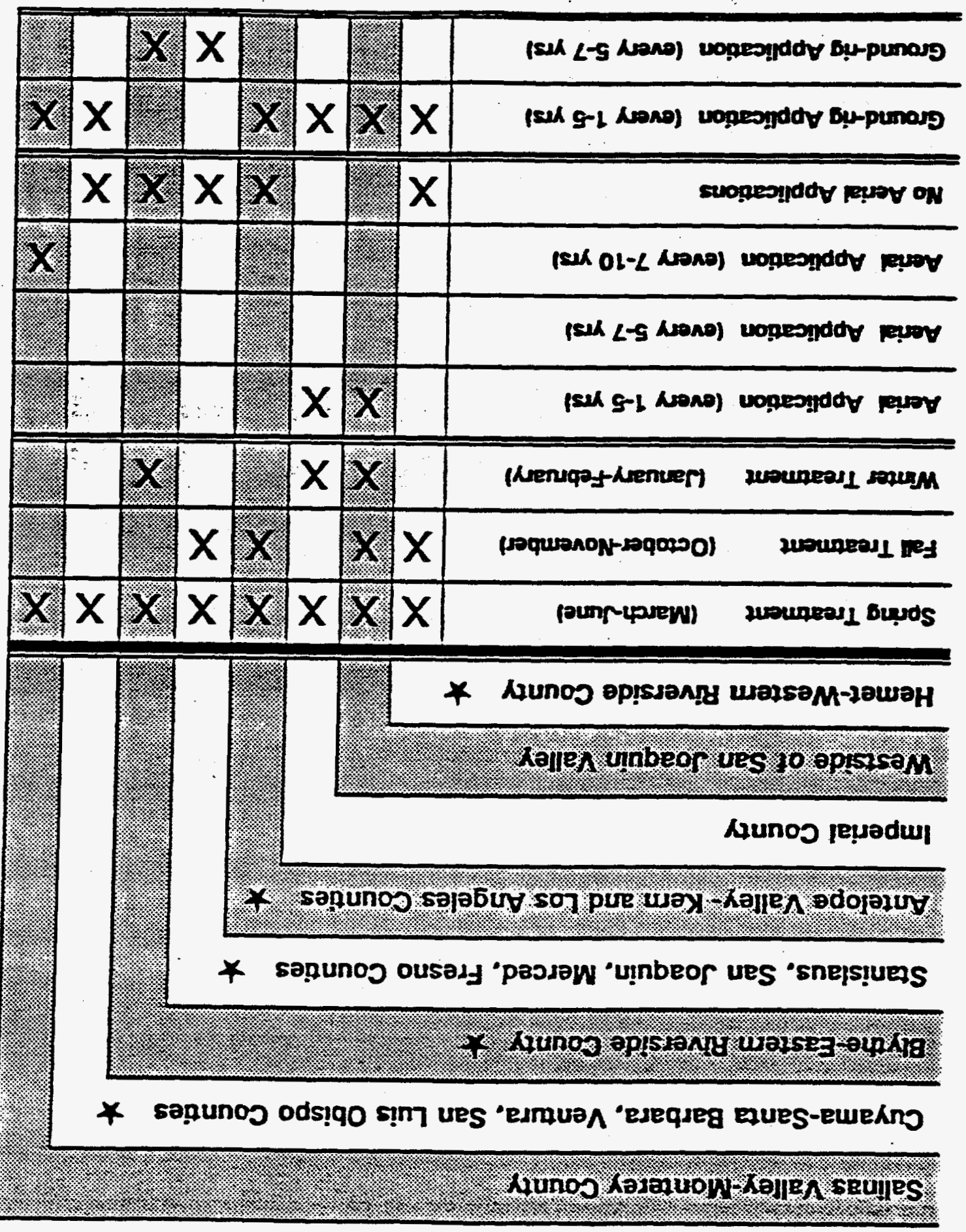

sease zuauneas 1/uo 6!s-punos6 Y

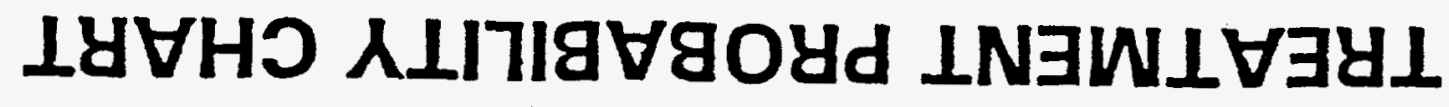


CURLY TOP VIRUS CONTROL PROGRAM

Acres Sprayed Breakdown

Run Date: $\quad$ 10/29/96

CALENDAR YEAR - ACres Sprayed

SAN JOAQUIN \& INTERCOASTAL VALLEYS

SOUTHERN CALIFORNIA

Riverside/Imperial Co

\begin{tabular}{|c|c|c|c|c|c|c|c|c|c|c|c|}
\hline YEAR & \multicolumn{2}{|c|}{ WINTER } & SPR & SPRING & \multicolumn{2}{|c|}{ FALL. } & Air & Ground & \multicolumn{2}{|c|}{ YEARLY TOTALS } & $\begin{array}{l}\text { TOTAL ACRES } \\
\text { SPRAYED }\end{array}$ \\
\hline $\begin{array}{c}1979 \\
1980 \\
1981 \\
1982 \\
1983 \\
1984 \\
1985 \\
1986 \\
1987 \\
1988 \\
1989 \\
1990 \\
1991 \\
1992 \\
1993 \\
1994 \\
1995 \\
1996\end{array}$ & $\begin{array}{r}6,809 \\
6,401 \\
0 \\
9,112 \\
9,418 \\
6,258 \\
3,340 \\
16,126 \\
7,450 \\
9,308 \\
19,124 \\
3,269 \\
4,674 \\
6,760 \\
10,800 \\
3,951 \\
5,724 \\
7,872\end{array}$ & $\begin{array}{l}0 \\
0 \\
0 \\
0 \\
0 \\
0 \\
0 \\
0 \\
0 \\
0 \\
0 \\
0 \\
0 \\
0 \\
0 \\
0 \\
0 \\
0\end{array}$ & $\begin{array}{r}36,860 \\
18,695 \\
25,882 \\
33,386 \\
16,947 \\
9,891 \\
9,495 \\
45,420 \\
33,750 \\
34,173 \\
55,781 \\
42,257 \\
45,639 \\
41,909 \\
34,740 \\
36,658 \\
45,569 \\
47,203\end{array}$ & $\begin{array}{r}3,405 \\
2,100 \\
6,000 \\
1,094 \\
240 \\
415 \\
1,183 \\
8,184 \\
3,060 \\
4,440 \\
2,200 \\
1,570 \\
640 \\
820 \\
5,273 \\
6,240 \\
4,992 \\
7,080\end{array}$ & $\begin{array}{r}20,112 \\
34,031 \\
33,489 \\
50,393 \\
26,049 \\
5,238 \\
21,580 \\
31,624 \\
32,217 \\
73,060 \\
19,132 \\
33,768 \\
53,680 \\
21,040 \\
21,245 \\
39,705 \\
43,326 \\
14,425\end{array}$ & $\begin{array}{r}5,514 \\
3,215 \\
1,976 \\
4,576 \\
2,550 \\
1,684 \\
0 \\
1,040 \\
1,022 \\
1,620 \\
400 \\
280 \\
170 \\
0 \\
2,400 \\
864 \\
1,600 \\
480\end{array}$ & $\begin{array}{r}0 \\
8,714 \\
0 \\
0 \\
27,365 \\
0 \\
14,434 \\
19,260 \\
0 \\
14,893 \\
0 \\
0 \\
7,143 \\
0 \\
0 \\
0 \\
0 \\
0\end{array}$ & $\begin{array}{r}0 \\
656 \\
0 \\
0 \\
1,350 \\
0 \\
12,361 \\
7,225 \\
2,559 \\
9,640 \\
2,950 \\
1,200 \\
2,520 \\
1,440 \\
4,960 \\
3,280 \\
3,776 \\
0\end{array}$ & $\begin{array}{r}63,781 \\
67,841 \\
59,371 \\
92,891 \\
79,779 \\
21,387 \\
48,849 \\
112,430 \\
73,417 \\
131,434 \\
94,037 \\
79,294 \\
111,136 \\
69,709 \\
66,785 \\
80,314 \\
94,619 \\
69,500\end{array}$ & $\begin{array}{r}8,919 \\
5,971 \\
7,976 \\
5,670 \\
4,140 \\
2,099 \\
13,544 \\
16,449 \\
6,641 \\
15,700 \\
5,550 \\
3,050 \\
3,330 \\
2,260 \\
12,633 \\
10,384 \\
10,368 \\
7,560\end{array}$ & $\begin{array}{c}72,700 \\
73,812 \\
67,347 \\
98,561 \\
83,919 \\
23,486 \\
62,393 \\
128,879 \\
80,058 \\
147,134 \\
99,587 \\
82,344 \\
114,466 \\
71,969 \\
79,418 \\
90,698 \\
104,987 \\
77,060\end{array}$ \\
\hline $\begin{array}{l}\text { TOTALS = } \\
\text { AVERAGE }\end{array}$ & $\begin{array}{r}128,524 \\
7,578\end{array}$ & $\begin{array}{l}0 \\
0\end{array}$ & $\begin{array}{r}567,052 \\
34,125\end{array}$ & $\begin{array}{r}51,856 \\
3,274\end{array}$ & $\begin{array}{r}559,689 \\
31,895\end{array}$ & $\begin{array}{r}28,911 \\
1,633\end{array}$ & $\begin{array}{r}91,809 \\
5,101\end{array}$ & $\begin{array}{r}53,917 \\
2,995\end{array}$ & $\begin{array}{r}1,347,074 \\
78,699\end{array}$ & $\begin{array}{r}134,684 \\
7,902\end{array}$ & $\begin{array}{c}1,481,758 \\
86,601\end{array}$ \\
\hline
\end{tabular}

\begin{tabular}{|l|c|c||c|}
\hline YEARS & $\begin{array}{l}\text { AC TREATED ON BLM } \\
\text { ADMINISTERED LANDS }\end{array}$ & $\begin{array}{l}\text { AC TREATED ON DOE } \\
\text { ADMINISTERED LANDS }\end{array}$ & \multicolumn{1}{c||}{ YEARLY TOTALS } \\
\hline 1991 & 3,960 & 5,830 & 9,790 \\
1992 & 3,230 & 11,940 & 15,170 \\
1993 & 2,755 & 11,775 & 14,530 \\
1994 & 12,295 & 14,295 \\
1995 & 8,000 & 8,535 & 11,847 \\
\hline \hline Total & 3,312 & 50,375 & 65,632 \\
Average & 15,257 & 10,075 & 13,126
\end{tabular}


FREQUENCY OF GROUND-RIO ONLY TREATMENTS IN GALLONS MALATHION ULV Within Ground-rig Only Treatment Areas

\begin{tabular}{|c|c|c|c|c|c|c|c|c|}
\hline \multirow{2}{*}{$\frac{\text { YEAR }}{1995}$} & \multicolumn{2}{|c|}{$\begin{array}{l}\text { Rlverglde Co } \\
\text { Month/Galione }\end{array}$} & \multirow{2}{*}{$\begin{array}{l}\text { Antelope valley } \\
\text { Month/Gallong }\end{array}$} & \multirow{2}{*}{$\begin{array}{l}\text { Cuyama valley } \\
\text { Month/Gallong }\end{array}$} & \multirow{2}{*}{$\begin{array}{l}\text { San Joaquin Co } \\
\text { Month/Gallong }\end{array}$} & \multirow{2}{*}{$\begin{array}{l}\text { Stanlsiaus Co } \\
\text { Month/Gallons }\end{array}$} & \multicolumn{2}{|c|}{$\begin{array}{l}\text { Merced Co } \\
\text { Month/Galions }\end{array}$} \\
\hline & June & 14 & & & & & April & 5 \\
\hline 1994 & & 0 & 0 & April & 0 & 0 & $\begin{array}{l}\text { June } \\
\text { Nov. }\end{array}$ & $\begin{array}{l}15 \\
9.6 \\
\end{array}$ \\
\hline 1993 & & 0 & 0 & 0 & 0 & 0 & $\begin{array}{l}\text { June } \\
\text { Oct. }\end{array}$ & $\begin{array}{l}5 \\
15 \\
\end{array}$ \\
\hline 1992 & & 0 & 0 & 0 & 0 & 0 & & 0 \\
\hline 1991 & & 0 & 0 & 0 & 0 & 0 & & 0 \\
\hline 1990 & $\begin{array}{l}\text { May } \\
\text { Nov. }\end{array}$ & $\begin{array}{l}16 \\
30\end{array}$ & 0 & 0 & 0 & 0 & & 0 \\
\hline 1989 & $\begin{array}{l}\text { May } \\
\text { Nov. }\end{array}$ & $\begin{array}{l}17 \\
70 \\
\end{array}$ & 0 & 0 & 0 & 0 & & 0 \\
\hline 1988 & & 0 & May & 0 & 0 & 0 & & 0 \\
\hline 1987 & $\begin{array}{l}\text { April } \\
\text { May }\end{array}$ & $\begin{array}{l}86.5 \\
23 \\
\end{array}$ & 0 & 0 & 0 & 0 & & 0 \\
\hline 1986 & & 0 & 63.25 & 0 & 0 & 0 & & 0 \\
\hline 1985 & & 0 & 0 & 0 & 0 & 0 & May & 9 \\
\hline
\end{tabular}

NOTE: Data taken from CTVCP "Pesticide Use Reports" 



\section{CONTROL STRATEGIES}

\section{San Joaquin Valley}

1. Fall

In the fall, usually October, the summer-fall generation of BLH produces an overwintering generation which is concentrated on Russian thistle (Salsola spp.). BLH's remain on thistle until drying or frost forces dispersal into the hills where more favorable overwintering hosts will germinate with the first winter rains. At this stage, large numbers of BLH's are usually concentrated on one host making control to reduce the reproductive overwintering population economically feasible. Timing of the control work is highly critical because malathion quickly degrades in the environment (EPA, 1975). Since malathion is a contact insecticide, it has no effect on BLH eggs deposited in the plant tissue, thus the application must occur after nymphs emerge, but prior to adult migration.

Once the thistle is mapped, CTVCP personnel conduct extensive sampling to selectively delimit the total acreage to be treated to those areas harboring extensive BLH populations. Sweep nets are used to sample and count the number of BLH's per sweep and assess the extent of the parasite and predator populations. Some of the parasites and predators are Anagrus giraulti, Polynema eutettigis, Geocoris pallens, Chrysopa californica, Neides muticus, and Reduvicolis kalmi. Determination of the overall development (nymph to adult ratio) of a given BLH population is made at this time. Those areas within the mapped thistle acreage with the highest BLH count and lowest predator populations will be given highest priority for treatment.

In late October or November, Russian thistle usually becomes unfavorable for BLH and female BLH instinctively begin migrating to the foothills on the west side of the Central Valley. The BLH is a desert insect and will seek out warm slopes with a southern exposure and suitable winter annual host plants in which to deposit eggs.

\section{Winter}

Winter concentrations of BLH are almost all mated females. Their habit of concentrating lends itself again to economical control where a precisely timed control program can prevent egg deposition and reduce the potential spring generation. The winter control program generally takes place during the months of January or February in the canyons near Coalinga and the Kettleman Hills of western Fresno and Kings Counties should concentrations develop. Similar events occur in the Kern County control area; however, historically, the CTVCP has limited winter control to the Fresno, Kings County area due to limited time frame and the possibility of insect mortality if vegetation dries early further south. 
The winter control work is usually limited to a small area of 9,000-12,000 acres because of limited concentrations of BLH and weather conditions. Only portions of south slopes with BLH populations are treated, leaving the north sides and areas unsuitable for BLH reproduction free of pesticide. Once it is apparent widespread egg deposition is occurring, control operations are discontinued as they will not be effective.

\section{Spring}

As weather warms in the spring, usually by March, the eggs deposited by overwintering female BLH begin hatching. This spring generation is still concentrated on slopes with a southern exposure in areas that were not treated in the winter. Nymphs of this generation will flourish, mature, and migrate when winter hosts dry, carrying CTV to susceptible crops.

Timing of the spring control program involves several critical considerations; (1) the progression of nymphal emergence, (2) the number of mature adults, (3) condition of host plants and (4) the proximity to susceptible crops. At this time, there is no way to predict when or where populations will develop. Treatment of the spring population can begin as early as the first part of March or as late as mid-May.

Control is only effective once all nymphis have emerged, but prior to adult migration caused by drying of host vegetation. In warm weather, the effective treatment period can be reduced substantially. Due to rapid insect development and host plant drying, constant monitoring of BLH populations by CTVCP staff is critical to timing of treatment operations.

\section{Imperial Valley}

The Imperial Valley control strategy is usually a winter/spring control program and is dependent on random rainfall patterns. Survey for BLH normally occurs periodically throughout the desert of Riverside and Imperial Counties. Intensive follow-up surveys are made during wet periods which could germinate host plants. The major hosts in the Imperial desert are Plantago spp., Oligomeris linifolia, sand verbena (Abronia villosa), Dune primrose (Oenothera deltoides), Russian thistle (Salsola kali), chinch weed (Pectis papposia) and Mustards, Brassica spp.

In the desert, BLH will usually settle only on the first available host and will not be found on the same host from year to year. Population build-up and the subsequent need for control is entirely dependent on the location and abundance of host plants. BLH may also only be in certain areas where adult females settled early in the season and not be found throughout the entire range of the host plants. For example, in the winter of 1983, BLH were found west of the Salton Sea, and on a strip one-half mile wide, extending from Glamis to Olgilby. Control work usually occurs in March, but could be required as early as December or as late as April. The time of control depends on the time of year host plants germinate, the BLH population size, and the virus content of both the plants and the insect vector. 


\section{Salinas Valley (Monterey County)}

In the Salinas Valley, control efforts take place in the spring. BLH populations develop with some regularity in portions of rangeland vegetation and along roadsides from King City, south to San Ardo. BLH populations have the potential to spread CTV to many susceptible crops growing along the Salinas River. In the history of the CTVCP only one aerial treatment, in 1977, was performed in the Salinas Valley.

Western Riverside County (Hemet); Eastern Riverside County (Blythe); Eastern Kern and Northeastern Los Angeles Counties (Palmdale-Lancaster); Northwestern Ventura, Northeastern Santa Barbara and southeastern San Luis Obispo Counties (Cuyama Valley); Portions of Western Stanislaus, San Joaquin, Merced, and Fresno Counties.

When treatments are necessary in these five separate control areas, only ground-rigs will be used to control BLH populations. Small cultivated fallow fields, roadsides and ditch banks are treated adjacent to cultivation. No rangeland will be treated in these regions. For further information on designated "ground-rig only" areas, see Appendix "E", p. E-20, for "Treatment Probability Chart" and "p. E-22,"Ground-rig Frequency Chart". 



\title{
APPENDIX "G"
}

\author{
PLANTS AND ANIMALS OF THE SAN JOAQUIN VALLEY \\ WITHIN OR NEAR CTVCP POTENTIAL TREATMENT BOUNDARIES
}

Key to Species of Concern:

$\begin{array}{lll}\text { FE Federally listed endangered } & \text { FT } & \text { Federal threatened } \\ \text { FC Federal candidate } & \text { ST } & \text { State threatened } \\ \text { SE State endangered } & \text { SC } & \text { State candidate } \\ \text { CNPS CA Native Plant Society } & \text { SSC } & \text { CA State species of listed sensitive } \\ \quad \text { listed sensitive } & & \text { concern }\end{array}$

\section{A. PLANTS}

The Following is a List of Plant Species of Special Concern:

Forked Fiddleneck (Amsinckia vernicosa var. furcata)

Large-flowered Fiddlencek (Amsinckia grandiflora)

Paimate Bracted Birds Beak (Cordylanthus palmatus)

Heartscale (Atriplex cordulata)

Lesser Satltbush (Atriplex mimuscula)

Bakersfield-Saltbush (Atriplex tularensis)

Lost Hills Saltbush (Atriplex vallicola)

Brittlescale (Atriplex depressa)

Dwarf Golden Star (Bloomeria humilis)

California Jewelflower (Caulanthus californicus)

Slough Thistle (Cirsium crassicaule)

Hispid Bird's-beak (Cordylanthus mollis var. hispidus)

Kern Mallow (Eremalche kernensis)

Hoover's woolly-star (Eriastrum hooveri)

Temblor Buckwheat (Eriogonum temblorense)

Cottony Buckwheat (Eriogomum gossypimum)

Diamond-petaled California Poppy (Eschscholtzia rhombipetala)

Comanche Point Layia (Layia leucopappa)

San Joaquin woolly-threads (Lembertia congdonii)

Bakersfield Prickly Pear (Opuntia basilaris var. treleasei)

Monterey Spineflower (Chorizanthe pungens var. pungens)

Robust Spineflower (Chorizanthe robusta var. robusta)
FC,CNPS

FE,SE

FE,SE

FC,CNPS

FC, CNPS

FC,SE,CNPS

FC,CNPS

FC,CNPS

FC,CNPS

FE,SE,CNPS

FC,CNPS

FC, CNPS

FE,SC,CNPS

FT

FC,CNPS

CNPS

FC,CNPS

FC,CNPS

FE, CNPS

FE, SE,CNPS

FT

FE 


\section{B. ANIMALS}

The principal wildlife within or near potential CTVCP control boundaries are listed below. An asterisk $\left(^{*}\right)$ designates a species of special interest.

\section{MAMMALS}

Order: Marsupialia

Common Opossum (Didelphis marsupialis)

Order: Insectivora

Trowbridge Shrew (Sorex towbridgei)

* Buena Vista Lake Shrew (Sorex ornatus relictus)

Order: Chiroptera

* Pacific western big-eared bat (Plecotus townsendii)

FC,SSC

* Greater Mastiff bat (Eumops perotis californicus)

California Myotis (Myotis californicus)

Yuma Myotis (Myotis yumanensis)

Hoary bat (Lasiurus cinereus)

Western Pipistrelle (Pipistrellus hesperus)

Pallid bat (Antrozous pallidus)

Order: Lagomorpha

Black-tail Hare (Lepus californicus)

Desert Cottontail (Sylvilagus auduboni)

Order: Rodentia

* San Joaquin Antelope Ground Squirrel (Ammospermophilus nelsoni) FC,ST

Beechey Ground Squirrel (Spermophilus beecheyi)

Botta Pocket Gopher (Thomomys bottae)

Little Pocket Mouse (Perognathus longimembris)

* San Joaquin Pocket Mouse (Perognathus inornatus)

* Giant Kangaroo Rat (Dipodomys ingens)

Heermann Kangaroo Rat (Dipodomys heermanni)

San Joaquin Kangaroo Rat (Dipodomys sulraloides)

FC,SSC

FE,SE 
* Short-nosed Kangaroo Rat (Dipodomys nitratoides brevinasus)

FC,SSC

* Tipton Kangaroo Rat (Dipodomys nitratoides nitratoides)

FE,SE

* Fresno Kangaroo Rat (Dipodomys nitratoides exilis)

FE,SE

Western Harvest Mouse (Reithrodontomys megalotis)

Deer Mouse (Peromyscus maniculatus)

Southern Grasshopper Mouse (Onychomys torridus)

Dusky-footed Wood Rat (Neotoma fuscipes)

California Meadow Vole (Microtus californicus)

Order: Carnivora

Coyote (Canis latrans)

* San Joaquin Kit Fox (Vulpes macrotis mutica)

FE,ST

Red Fox (Vulpes fulva)

Long-tailed Weasel (Mustela frenata)

Badger (Toxidea toxus)

Striped Skunk (Mephitis mephitis)

Spotted Skunk (Spilogale putorius)

Ringtail (Bassariscus astutus)

Raccoon (Procyon lotor)

Bob Cat (Lymx rufus)

Mountain Lion (Felis concolor)

Order: Artiodaclyla

Wild Boar (Sus scrofa)

Mule Deer (Odocoileus hemionus)

Prong-horned Antelope (Antilocapra americana)

Tule Elk (Cervus nannodes)

\section{REPTILES}

* Northwestern Pond Turtle (Clemmys marmorata)

FC,SSC

* Southwestern pond turtle (Clemmys marmorata pallida)

FC,SSC

* Blunt-nosed Leopard Lizard (Gambelia silus)

FE,SE

Western Fence Lizard (Sceloporus occidentalis)

Side-Blotched Lizard (Uta stansburiana)

* California Horned Lizard (Phrynosoma coronatum frontale)

Gilberts Skink (Eumeces gilberti)

Western Skink (Eumeces skiltoniamus)

Western Whiptail (Cnemidophorus tigris)

Southern Alligator Lizard (Gerrhonotus multicarinatus) 
California Legless Lizard (Anniella pulchra)

Ringneck Snake (Diadophis punctatus)

Sharp-tailed Snake (Contia teruis)

Striped Racer (Masticophis lateralis)

Coachwhip (Mastcophis flagellum)

Racer (Coluber constrictor)

Gopher Snake (Pituophis melanoleucus)

Glossy Snake (Arizona elegans)

Common King Snake (Lampropeltis getulus)

Long-nosed Snake (Rhinocheilus lecontei)

Common Garter Snake (Thamnophis sirtalis)

Night Snake (Hypsiglena torquata)

Western Black Headed Snake (Tantilla planiceps)

Western Rattlesnake (Crotalus viridis)

* Giant Garter Snake (Thamnophis gigas)

FT,ST

\section{AMPHIBIANS}

* Western Spadefoot Toad (Scaphiopus hammondi)

FC,SSC

* California Tiger Salamander (Ambystoma californiense)

FC,SC

* Foothill Yellow-legged Frog (Rana muscosa)

FC

* California Red-legged Frog (Rana aurora draytonii)

FT

\section{BIRDS}

Large numbers of birds are normally present including migratory waterfowl passing over the area and large numbers of passerine birds stopping at various times of the year. Listed below are some of the more commonly encountered birds and birds of special interest which may be found within or near potential treatment boundaries.

California condor (Gymnogyps californiamus)

FE,SE

Turkey Vulture (Cathartes aura)

* Aleutian Canada Goose (Branta canadensis leucopaveia)

FT

Northern Harrier (Circus cyaneus)

Sharp-shinned Hawk (Accipiter striatus)

* Swainson's Hawk (Buteo swainsoni)

ST

* . Cooper's Hawk (Accipiter cooperii)

SSC

Red-tailed Hawk (Buteo jamaicensis)

* Ferruginous Hawk (Buteo regalis)

FC,SSC

* Golden Eagle (Aquila chrysaetos)

SSC

American Kestrel (Falco sparverius)

* Prairie Falcon (Falco mexicanus)

SSC

California Quail (Callipepla californica) 
Killdeer (Charadrius vociferus)

* White-faced ibis (Plegadis chihi)

* Western snowy plover (Charadrius alexandrimus nivosus)

FC

* Mountain Plover (Charadrius montamus)

* Long-billed Curlew (Numenius americamus)

FC

Mourning Dove (Zenaida macroura)

Greater Roadrunner (Geococcyx californianus)

Great Horned Owl (Bubo virginiamus)

* Burrowing Owl (Athene cunicularia)

SSC

Barn Owl (Tyto alba)

Anna's Hummingbird (Calypte anna)

Northern Flicker (Colaptes auratus)

Lewis' Woodpecker (Melanerpes lewis)

Acorn Woodpecker (Melanerpes formicivorus)

Nuttall's Woodpecker (Picoides nuttallii)

Red-breasted Sapsucker (Sphyrapicus ruber)

Hairy Woodpecker (Picoides villosus)

Western Kingbird (Tyrannus verticalis)

Black Phoebe (Sayornis nigricans)

Say's Phoebe (Sayornis saya)

Horned Lark (Eremophila alpestris)

Cliff Swallow (Hirundo pyrrhonota)

Barn Swallow (Hirundo rustica)

American Crow (Corvus brachyrhynchos)

Common Raven (Corvus covax)

* Western Yellow-billed Cuckoo (Coccyzus americanus occidentalis) SE

Yellow-billed Magpie (Pica nuttalli)

Plain Titmouse (Parus inornatus)

Bushtit (Psaltriparus minimus)

Rock Wren (Salpinctes obsoletus)

Bewicks Wren (Thryomanes bewickii)

Ruby-crowned Kinglet (Regulus calendula)

Western Bluebird (Sialia mexicana)

Mountain Bluebird (Sialia currucoides)

American Robin (Turdus migratorius)

* LeConte's Thrasher (Toxostoma lecontei)

SSC

California Thrasher (Toxostoma redivivum)

Wrentit (Chamaea fasciata)

Phainopepla (Phainopepla nitens)

* Loggerheaded Shrike (Lanis ludovicianus)

FC

European Starling (Sturnus vulgaris)

California (Brown) Towhee (Pipilo crissalis) 
Grasshopper Sparrow (Ammodramus savannarum)

Vesper Sparrow (Pooecetes gramineus)

Lark Sparrow (Chondestes grammacus)

Sage Sparrow (Amphispiza belli)

Savannah Sparrow (Passerculus sandwichensis)

Golden-crowned Sparrow (Zonotrichia atricapilla)

White-crowned Sparrow (Zonotrichia leucophrys)

Dark-eyed (Oregon) Junco (Junco hyemalis organus)

* Tricolored Blackbird (Agelaius tricolor)

Red-winged Blackbird (Agelaius phoeniceus)

* California Horned Lark (Ereophila alpestris actia)

FC

Western Meadowlark (Sturnella neglecta)

Brewer's Blackbird (Euphagus cyanocephalus)

House Finch (Carpodacus mexicamus)

House Sparrow (Passer domesticus)

American Goldfinch (Carduelis tristis)

Lazuli Bunting (Passerina amoena)

\section{INSECTS}

* Ciervo Aegialian Scarab Beetle (Aegialia concinna) FC

* San Joaquin Sooty Wing Skipper (Pholisora libya) FC

* Morrison's Blister Beetle (Lytta morrisoni) FC

* Molestan Blister Beetle (Lytta molesta) $\quad$ FC

* Moestan Blister Beetle (Lytta moesta) FC

* Hopping's Blister Beetle (Lytta hoppingi) FC

* Valley Elderberry Longhorn Beetle (Desmocerus californicus dimorphus) FT

\section{CRUSTACEANS}

* Conservancy Fairy Shrimp (Branchinecta conservatio) FE

* Longhom Fairy Shrimp (Branchinecta longiantenna) FE

* Vernal Pool Tadpole Shrimp (Lepidurus packardi) . FE

* Vernal Pool Fairy Shrimp (Branchinecta lynchi) FT

\section{MOLLUSK}

* Stripped-skinned Snail (Helminthogllypta callistoderma) FC 
$\underline{\text { FISH }}$

There are several lakes and canals near or within the CTVCP potential treatment area in the San Joaquin Valley. They include the San Luis Reservoir, ONeill Forebay, Los Banos Creek Reservoir, California Aqueduct, Little Panoche Detention Reservoir and Buena Vista Lake. There are no threatened or endangered species within these waters which contain common game and non-game fish of the San Joaquin Valley. Great care and effort is taken to ensure that water is not contaminated by runoff, drift or by direct application. (See "Key Points of Proposed Action".) 
FISH SPECIES FOUND IN VARIOUS LOCATIONS WITHIN THE CTVCP POTENTIAL TREATMENT AREAS ON THE WEST SIDE OF THE SAN JOAQUIN VALIEY:

\begin{abstract}
A - Delta-Mendota Canal
C - San Luis Reservoir

E - Buena Vista Lake
\end{abstract}

B - California Aqueduct
D - O'Neill Forebay
F - Los Banos Detention Reservoir

White Catfish (Ictalurus catus)

Channel Catfish (Ictalurus punctatus)

Striped Bass (Morone saxatilis)

Largemouth Bass (Micropterus salmoides)

Smallmouth Bass (Micropterus dolomieui)

Warmouth Bass (Lepomis [Chaenobryhus] gulosus)

Bluegill (Lepomis macrochirus)

Green Sunfish (Lepomis cyanellus)

Black Crappie (Pomoxis nigromaculatus)

White Crappie (Pomoxis annularis)

Common Carp (Cyprinus carpio)

Goldfish (Carassius auratus)

Sacramento Squawfish (Ptchocheilus grandis)

Splittail (Pogonichthys macrolepidotus)

Sacramento Perch (Archoplites interruptus)

Log Perch (Percina caprodes)

Tule Perch (Hysterocarpus traskii)

King Salmon (Oncorhynchus tshawytscha)

Rainbow Trout (Salmo gairdneri)

Sacramento Balckfish (Orthodon microlepidotus)

Hitch (Lavinia exilicauda)

Golden Shiner (Notemigonus crysoleucas)

Threadfin Shad (Dorosoma petenense)

American Shad (Alosa sapidissima)

Pond Smelt (Hypomesus olidus)

Sacramento Smelt (Spirinchus thaleichthys)

Brown Bullhead (Ictalurus nebulosus)

Mississippi Silverside (Menidia audens)

Green Sturgon (Acipenser medirostris)

White Sturgon (Acipenser transmontanus)

Sacramento Western Sucker (Catostomus occidentalis)

Redear Sunfish (Lepomis microlophus)

Starry Flounder (Platichthys stellatus)

Mosquito Fish (Gambusia affinis)

Prickly Sculpin (Cottus asper)

Riffle Sculpin (Cottus gulosus)

Oriental Goby (Acanthgobius flavimanus)

\begin{tabular}{|c|c|c|c|c|c|}
\hline $\mathbf{A}$ & B & C & D & $\mathbf{E}$ & $\mathbf{F}$ \\
\hline $\mathrm{X}$ & $\mathrm{X}$ & $\mathrm{X}$ & $X$ & $\mathrm{x}$ & $x$ \\
\hline $\mathrm{X}$ & $x$ & $\mathrm{X}$ & $\mathrm{X}$ & $\mathrm{x}$ & $x$ \\
\hline $\mathrm{X}$ & X & $X$ & $\mathrm{X}$ & $\mathrm{X}$ & \\
\hline $\mathrm{X}$ & $\begin{array}{l}X \\
X\end{array}$ & $\mathrm{X}$ & $\mathrm{X}$ & $\mathrm{X}$ & $\mathrm{X}$ \\
\hline $\mathrm{x}$ & & & & & \\
\hline$X$ & $\mathrm{X}$ & & $\mathrm{X}$ & $\mathrm{X}$ & $X$ \\
\hline $\mathrm{X}$ & $\mathrm{X}$ & $\mathrm{X}$ & $\mathrm{X}$ & & $x$ \\
\hline $\mathrm{X}$ & $\mathrm{X}$ & $\mathrm{X}$ & $X$ & & \\
\hline & & & $\mathrm{X}$ & $\mathrm{x}$ & $\mathrm{X}$ \\
\hline $\mathrm{X}$ & $\mathrm{X}$ & & $\mathrm{X}$ & $\mathrm{X}$ & \\
\hline$X$ & $\mathrm{X}$ & & & & $\mathrm{X}$ \\
\hline $\mathrm{X}$ & & & & & \\
\hline $\mathrm{X}$ & $X$ & $\mathrm{X}$ & $X$ & & \\
\hline & $x$ & $X$ & & & \\
\hline $\mathrm{X}$ & $X$ & & $\mathrm{X}$ & & $\mathrm{X}$ \\
\hline & & $\mathrm{X}$ & $\mathrm{X}$ & & \\
\hline & $X$ & $\mathrm{X}$ & $\mathrm{X}$ & $x$ & $\mathrm{X}$ \\
\hline $\mathrm{X}$ & $\mathrm{X}$ & $\mathrm{X}$ & $\mathrm{X}$ & & $\mathrm{X}$ \\
\hline & $x$ & & $x$ & & \\
\hline $\mathrm{X}$ & $\mathrm{X}$ & $\mathrm{X}$ & $\mathrm{X}$ & $\mathrm{X}$ & $X$ \\
\hline $\mathrm{X}$ & $\mathrm{X}$ & & $\mathrm{X}$ & & $X$ \\
\hline $\mathrm{x}$ & & & & & \\
\hline $\mathrm{X}$ & & & & & \\
\hline$X$ & $\mathrm{X}$ & $x$ & & $\begin{array}{l}X \\
X\end{array}$ & $\mathrm{X}$ \\
\hline & & & $\mathrm{X}$ & $x$ & \\
\hline $\mathrm{X}$ & $X$ & $\mathrm{X}$ & $\mathrm{X}$ & & $\mathrm{X}$ \\
\hline & & & & $\mathrm{X}$ & $x$ \\
\hline$X$ & & & $\mathrm{X}$ & & \\
\hline $\mathrm{X}$ & $\begin{array}{l}\mathrm{X} \\
\mathrm{X}\end{array}$ & & & & \\
\hline & & $\Omega$ & $\mathrm{x}$ & & \\
\hline
\end{tabular}




\section{PLANTS AND ANIMALS OF IMPERIAL AND EASTERN RIVERSIDE COUNTIES WITHIN OR NEAR THE POTENTIAL TREATMENT BOUNDARIES}

Key to Species of Concern:

$\begin{array}{llll}\text { FE } & \text { Federally listed endangered } & \text { FT } & \text { Federal threatened } \\ \text { FC } & \text { Federal candidate } & \text { ST } & \text { State threatened } \\ \text { SC } & \text { State Candidate } & \text { SE } & \text { State endangered } \\ \text { CNPS } & \text { CA Native Plant Society } & \text { SSC } & \text { CA State species of listed sensitive } \\ & \text { listed sensitive } & & \text { concern }\end{array}$

\section{A. PLANTS}

The dune area of the Imperial Valley are populated by plant species that adapt by holding sand into hillocks. Following is a list of plants found in the Dune habitat or plants which may occur within potential treatment areas.

* Algodones Dunes Sunflower (Helianthus niverus ssp. tephrodes) FC Blazing-Star (Mentzelia spp.) Borrego milkvetch (Astragalus magdalenae var. peirsonii) CNPS

* California barrel cactus (Ferocactus acanthodes ssp. acanthodes) FC

* Coulter Lyrepod (Lyrocarpa coulteri var. palmeri) Creosote bush (Larrea tridentata)

* Desert Christmas tree (Pholisma arenarium)

CNPS Desert buckwheat (Eriogomum deserticola)

FC

Dicoria (Dicoria canescens)

Dune primrose (Oenothera deltoides)

* Flat-seeded spurge (Chamaesyce platysperma)

FC, CNPS

* Foxtail cactus (Escobaria vivipara var. alversonii) FC,CNPS

* Giant Spanish needle (Palafoxia linearis var. gigantea) FC,CNPS Grama grass (Bouteloua spp.) Ironwood (Olneya-tesota)

* Las Animas colubrina (Colubrina californica) Locoweed (Astragalus magadalenae var. peirsonii) Mormon tea (Ephedra californica)

* Munz's cholla (Opuntia munzii)

* Needles knotweed (Polygonum fusiforme) Palo verde (Cercidium floridum)

* Peirson's milk-vetch (Atragalus magdalenae var. peirsonii)

FC,CNPS

FC,CNPS FC FC,SE,CNPS 
Plaited leaf (Coldenia plicata)

Popcorn weed (Chaenactis fremontii)

* Ribbed cryptantha (Cryptantha costata) CNPS

* Sand food (Ammobroma sonorae)

FC,CNPS

Sand-verbena (Abronia villosa)

* Silver-leafed dune sunflower (Helianthus niveus tephrodes) FC,SE,CNPS

Smoke tree (Dalea spinosa)

* Wiggins Croton, (Croton wigginsii)

FC,SC,CNPS

\section{B. ANIMALS}

The principal wildlife in the area under the proposed CTVCP are listed below. An asterisk $\left(^{*}\right)$ designates a species of special interest.

\section{MAMMALS}

Order: Insectivora

Grey Shrew (Notiosorex crawfordi)

Order: Chiroptera

* California leaf-nosed Bat (Macrotus californicus) FC,SSC Hognose Bat (Choeronycteris mexicana)

California Myotis (Myotis californicus)

Western Yellow Bat (Lasiurus ega)

Big Brown Bat (Eptesicus fuscus)

* Spotted Bat (Euderma maculata)

FC,SSC

* Pallid Bat (Antrozous pallidus)

Brazilian free-tailed Bat (Tadarida brasiliensis)

SSC

* Pocketed free-tailed Bat (Tadarida femorosacca)

SSC

* Big-free-tailed Bat (Tadarida molossa)

* Western mastiff Bat (Eumops perotis)

SSC

* Long-legged Myotis (Myotis volans)

FC

* Mexican long-tongued Bat (Choenycteris mexicana)

FC

* Occult Little Brown Bat (Myotis lucifugus occultus)

FC

* Pale Townsend's Big-eared Bat (Plecotus townsendii pallenscens)

FC

* Southwestern cave myotis (Myotis velifer brevis)

* Yuma Myotis (Myotis yrmanesis)

FC

FC 
Order: Lagomorpha

Black-tailed Hare (Lepus californicus)

Audubon Cottontail (Sylvilagus audubonii)

Order: Rodentia

Antelope Ground Squirrel (Ammospermophilus leucurus)

Round-tailed Ground Squirrel (Citellus tereticaudus)

Botta Pocket Gopher (Thomomys bottae)

Bailey Pocket Mouse (Perognathus baileyi)

* Phallid San Diego Pocket Mouse (Perognathus fallax pallidus) FC

Spiny Pocket Mouse (Perognathus spinatus)

Long-tailed Pocket Mouse (Perognathus formosus)

Desert Pocket Mouse (Perognathus penicillatus)

Merriam's Kangaroo Rat (Dipodomys merriami)

Desert Kangaroo Rat (Dipodomys deserti)

Western Harvest Mouse (Reithrodontomys megalotis)

Canyon Mouse (Peromyscus crinitus)

Cactus Mouse (Peromyscus eremicus)

* Southern Grasshopper Mouse (Onychomys torridus)

FC

White-throated Wood Rat (Neotoma albigula)

Desert Wood Rat (Neotoma lepida)

Muskrat (Ondatra zibethica)

* Yuma Hispid Cotton Rat (Sigmodon hispidus eremicus)

FC,SSC

* Colorado River Cotton Rat (Sigmodon arizonae)

Order: Carnivora

Kit Fox (Vulpes macrotis)

Grey Fox (Urocyon cinereoargenteus)

Coyote (Canisa altrans)

Raccoon (Procyon lotor)

Badger (Taxidea taxus)

Spotted Skunk (Spilogale putorius)

Bobcat (Lynx rufus)

* Yuma Puma (Felis concolor browni)

Order: Artiodatlyla

Mule Deer (Odocoileus hemionus) 


\section{REPTILES AND AMPHIBIANS}

Couch's Spadefoot (Scaphiopus couchi)

Woodhouse's Toad (Bufo woodhousei)

Great Plains Toad (Bufo cognatus)

* Colorado River Toad (Bufo alcvarius)

SSC

Red-Spotted Toad (Bufo punctatus)

Leopard Frog (Rana pipiens pipiens)

Bullfrog (Rana catesbiana)

* Desert Tortoise (Gopherus aqassizi)

FE,SE

Sonora Mud Turtle (Kinosternon sonoriense)

* Southwestern Pond Turtle (Clemmys marmorata pallida) FC

Texas Softshell (Trionyx spiniferus emoryi)

Desert Banded Gecko (Coleonyx variegatus variegatus)

* Barefoot Gecko (Coleonyx switaki)

Leaf-toed Gecko (Phyllodactylus xanti nocticolus)

* Western Chuckwalla (Sauromalus obesus obesus)

Desert Iguana (Dipsosaurus dorsalis dorsalis)

Zebra-tailed Lizard (Callisaurus draconoides)

* Colorado Desert Fringe-toed Lizard (Uma notata notata)

FC,SSC

Long-nosed Leopard Lizard (Gambelia wislizenii)

Collard Lizard (Crotaphytus bicinctores)

Yellow-backed Spiny Lizard (Sceloporus magister)

Western Brush-Lizard (Uroscaurus graciosus)

Desert Side-Blocked Lizard (Uta stansburiana stejnegeri)

Tree Lizard (Urosaurus ornatus)

Desert Horned Lizard (Phrynosoma platyrhinos)

* Flat-tailed Horned Lizard (Phyrnosoma mcallii)

Mojave Fringe-toed Lizard (Uma scoparia)

Great Basin Whiptail (Cnemidophorus tigris tigris)

Western Blind Snake (Leptotyphlops humilis)

Western Leaf-nosed Snake (Phyllorhynchus decurtatus pekinsi)

Coachwhip (Masticophi flagellum)

Desert Patch-nosed Snake (Salvadora hexalepis hexalepis)

Sonora Gopher Snake (Pituophis melanoleucus affinis)

Desert Glossy Snake (Arizona elegans eburnata)

Yuma King Snake (Lampropeltis getulus yumensis)

Western Long Nosed Snake (Rhinocheilus lecontei lecontei)

Checkered Garter Snake (Thamnophis marciamus)

Western Ground Snake (Sonora semianmulata)

Mojave Western Shovel-nosed Snake (Chionactis occipitalis occipitalis)

Desert Night Snake (Hypsiglena torquata)

Sonora Lyre Snake (Trimophodon lambda lambda)

Western Diamondback Rattlesnake (Crotalus atrox) 
* Northern Red Diamond Rattlesnake (Crotalus ruber ruber)

Colorado Desert Sidewinder (Crotalus cerastes laterorepens)

Southwestern Speckled Rattlesnake (Crotalus mitchelli pyrrhis)

Red Racer (Masticophis flagellum piceus)

BIRDS (Includes Endemic and Migratory Species) * Species of special interest.

Pie-billed Grebe (Podilymbus podiceps)

Eared Grebe (Podiceps nigricollis)

Western Grebe (Aechmophorus occidentalis)

American White Pelican (Pelecanus erythorhynchos)

Double-crested Cormorant (Phalacrocorax auritus)

SSC

Great Blue Heron (Ardea herodias)

Great Egret (Casmerodius albus)

Snowy Egret (Egretta thula)

* Reddish Egret (Egretta rufescens)

FC

Cattle Egret (Bubulcus ibis)

Green-backed Heron (Butorides striatus)

Black-crowned Night Heron (Nycticorax nycticorax)

Canada Goose (Branta canadensis)

Green-winged Teal (Anas crecca)

* White-faced Ibis (Plegadis chihi)

FC,SSC

Snow Goose (Chen caerulescens)

Ross' Goose (Chen rossii)

Mallard (Anas platynochos)

Northern Pintail (Anas acuta)

American Wigeon (Anas americana)

Ruddy Duck (Oxyura jamaicensis)

* Fluvous Whistling Duck (Dendrocygna bicolor) FC

Ring-necked Duck (Aythya collaris)

* Osprey (Pandion haliaetus)

SSC

Northern Shoveler (Anas clypeata)

Bufflehead (Bucephala albeola)

Lesser Scaup (Aythya affinis)

Common Merganser (Mergus merganser)

* Turkey Vulture (Cathartes aura)

SSC

- Golden Eagle (Aquila chrysaetos)

SSC

* Cooper's Hawk (Accipiter cooperii)

SSC

* Harris Hawk (Parabuteo unicintus) SSC

Red-tailed Hawk (Buteo jamaicensis)

* Ferruginous Hawk (Buteo regalis)

FC

American Kestrel (Falco sparverius)

Gambel's Quail (Callipepla gambelii) 
* Yuma Clapper Rail (Rallus longirostris yumanensis) FE,ST

* California Black Rail (Laterallus jamaicensis coturniculus) ST,FC American Coot (Fulica americana) Black-bellied Plover (Pluvialis squatarola)

* Mountian Plover (Charadrius mountamus)

FC,SSC

Killdeer (Charadrius vociferus)

Black-necked Stilt (Himantopus mexicamus)

American Avocet (Recurvirostra americana)

* Long-billed Curlew (Numenius americamus)

FC,SSC

Western Sandpiper (Calidris mauri)

Least Sandpiper (Calidris minutilla)

Long-billed Dowitcher (Limnodromus scolopaceus)

Ring-billed Gull (Larus delawarensis)

* Black Tern (Chilodonias niger)

FC

* Van Rossem's gullbilled Tern (Sterna nilotica vanrossemi)

FC

Herring Gull (Larus argentatus)

Greater Roadrunner (Geococcyx californianus)

* Western Yellow Billed Cuckoo (Coccyzus americanus occidentalis) SE

Rock Dove (Columba livia)

Mourning Dove (Zenaida macroura)

* Elfowl (Micrathone whitneyi)

Western Screech Owl (Octus kennicottii)

Great Horned Owl (Bubo virginianus)

* Western Burrowing Owl (Athene cunicularia hypogaeae) FC

Anna's Hummingbird (Calypte anna)

Costa's Hummingbird (Calypte costae)

Belted Kingfisher (Ceryle alcyon)

* Gilded Northern Flicker (Colaptes auratus chrysoides) SE

* Gila Woodpecker (Melanerpes uropygialis)

SE

Black Phobe (Sayornis nigricans)

Say's Phobe (Sayornis saya)

* Vermilion Flycatcher (Pyrocephalus rubinus)

SSC

Horned Lark (Eremophila alpestris)

Tree Swallow (Tachycineta bicolor)

Common Raven (Corvus corax)

Veridin (Auriparus flaviceps)

Ruby-crowned kinglet (Regulus calendula)

* Black-tailed Gnatcatcher (Poliotila melamura)

FC

Blue-gray Gnatcatcher (Polioptila caerulea)

* Coastal Cactus Wren (Campylorhynchus brunneicapillus couesi) FC

Marsh Wren (Cistothorus palustris)

Crissal Thrasher (Toxostoma dorsale)

* Northern Cardinal (Cardinalis cardinalis)

Mountain'Bluebird (Sialia currucoides) 
American Robin (Turdus migratorius)

* Western Least Bittern (Ixobrychts exilis hesperis)

FC

Northern Mockinbird (Mimus polyglottos)

American (Water) Pipit (Anthus rubescens)

Phairopepla (Phainopepla nitens)

Loggerhead Shrike (Lanius ludovicianus)

European Starling (Sturnus vulgaris)

* Arizona Bell's Vireo (Vireo bellii arizonae)

SE

* Least Bell's Vireo (Vireo bellii pusillus)

FE,SE

Orange-crowned Warbler (Vermivora celata)

Yellow-rumped Warbler (Dendroica coronata)

Albert's Towhee (Pipilo aberti)

Lark Sparrow (Chondestes grammacus)

Sage Sparrow (Amphispiza belli)

* Belding's Savannah Sparrow (Passerculus sandwichensis beldingi)

FC

* Large-billed Savannah Sparrow (Passerculus sandwichnesis rostratus)

FC

White-crowned Sparrow (Zonotrichia leucophrys)

Dark-eyed (Oregon) Junco (Junco hyemalis orgamus)

Red-winged Blackbird (Agelaius phoeniceus)

Brewer's Blackbird (Euphagus cyanocephalus)

Western Meadowlark (Sturnella neglecta)

* California Horned Lark (Eremophila alpestris actia)

FC

Great-tailed Grackle (Quiscalus mexicanus)

Brown-headed Cowbird (Molothrus ater)

House Finch (Carpodacus mexicanus)

House Sparrow (Passer domesticus)

Plain Titmouse (Parus inornatus)

* Summer Tanager (Piranga rubra)

SSC

* Sonoran Yellow Warbler (Dendroica petechia sonorana) SSC

* Brown-crested Flycatcher (Myiarchus tyrannulus) SSC

* Southwestern Willow Flycatcher (Empidomax traillii extimus) FC

\section{FISH}

a. Present in the Salton Sea

Game Fish:

Orange Mouth Corvina (Cynoscion xanthulus)

Sargo (Anisotremus davidsoni)

Bairdiella/Croaker (Bairdiella icistia)

Mozambique Mouthbrooder (Tilapia mossambica)

Red belly Tilapia (Tilapia zillii) 
Non-game Fish:

* Desert pupfish (Cyprinodon macularius)

FE,SE

Longjaw Mudsucker (Gillichthys mirabilis)

Mosquito Fish (Gambusia affinis affinis)

Threadfin Shad (Dorosoma petenense)

Sailfin Molly (Poecilia latapinna)

Common Carp (Cyprinus carpio)

b. Present in the Colorado River Drainage of California

White Sturgeon (Acipenser transmontanus)

Threadfin Shad (Dorosoma petenense)

Rainbow Trout (Salmo gairdneri)

Common Carp (Cyprinus carpio)

Plains Red Shiner (Notropi lutrensis)

Golden Shiner (Notemigonus crysoleucas)

* Bonytail Chub (Gila elegans)

* Colorado Squaw Fish (Ptychocheilus lucius)

FE,SE

FE,SE

* Humpback (Razorback) Sucker (Xyrauchen texanus)

FE,SE

Channel Catfish (Ictalurus punctatus)

Black Bullhead (Ictalurus melas)

Yellow Bullhead (Ictalurus natalis)

Brown Bullhead (Ictalurus nebulosus)

Mosquito Fish (Gambusia affinis)

Shortfin Molly (Poecilia mexicana)

Striped Bass (Morone saxatilis)

Largemouth Bass (Micropterus salmoides)

Smallmouth Bass (Micropterus dolomieui)

Green Sunfish (Lepomis cyanellus)

Bluegill (Lepomis macrochirus)

Redear Sunfish (Lepomis microlophus)

Warmouth Bass (Lepomis [Chaenobryttus] gulosus)

White Crappie (Pomoxis annularis)

Black Crappie (Pomoxis nigromaculatus)

Yellow Perch (Perca flavescens)

Mozambique Mouthbrooder (Talapia mossambica)

Red Belly Tilapia (Talapia zillii)

Striped Mullet (Mugil cephalus)

Machete (Elops affinis) 


\section{INSECTS}

* Andrew's Dune Scarab Beetle (Pseudocotalpa andrewsi) FC

* Brown-tassel Trigonoscuta Weevil (Trigonoscuta brunnotasselata) FC

* Cheeseweed Moth Lacewing (Oliarces clara) FC

* MacNeil Sooty Wing Skipper (Hesperopsis gracielaea) FC

* Wandering Skipper (Panoquina errans) FC

\section{PLANTS AND ANIMALS OF WESTERN RIVERSIDE COUNTY (HEMET) WITHIN OR NEAR CTVCP POTENTIAL TREATMENT BOUNDARIES}

Key to Species of Concern:

FE Federally listed endangered

FPE Federal proposed endangered

FC Federal candidate

SE State endangered

CNPS CA Native Plant Society

listed sensitive
FT Federal threatened

FPT Federal proposed threatened

ST State threatened

SSC CA State species of concern

\section{A. PLANTS}

The following is a list of plant species of special concern which may be in the potential CTVCP treatment area:

San Jacinto Saltbush (Atriplex coronata var. notatior)

FPE

Spreading Navarretia (Navarretia fossalis)

FPT

Thread-leaved Brodiaea (Brobiaea filiforia)

FPT

Pason's Jewelflower (Caulanthus simulans)

FC

Slender-horned Spine Flower (Dodecahema leptoceras)

FE,SE

California Orcutt Grass (Orcuttia californica)

FE, SE

Munz's Onion (Allium munzii)

Many-stemmed dudleya (Dudleya multicaulis)

ST,FC,CNPS

FC, CNPS

Palmer's grapplinghook (Harpagonella palmeri)

CNPS

Engelmann Oak (Quercus engelmannii)

CNPS

Little mouse-tail (Myosurus minmus)

FC,CNPS 


\section{B. ANIMALS}

The principal wildlife within or near CTVCP potential treatment boundaries are listed below. An asterisk (*) designates a species of special interest.

\section{MAMMALS}

Order: Marsupialia

Common Opossum (Didelphis marsupialia)

Order: Insectivora

Omate Shrew (Sorex ornatas)

Order: Chiroptera

California Myotis (Myotis californicus)

Yuma Myotis (Myotis yumanensis)

* Leaf Nosed Bat (Macrotus californicus)

Hoary Bat (Lasiurus cinereus)

Western Pipistrelle (Pipistrellus hosperus)

* Pallid Bat (Antrozous pallidus)

Big Brown Bat (Eptesicus fuscus)

* Spotted Bat (Eudena maculata)

Western Big-eared Bat (Plecotus tousendi)

* Big Freetailed Bat (Tadarida molossa)

Order: Lagomorpha

Black-tail Hare (Lepus californicus)
Desert Cottontail (Sylvilagus auduboni)
Brush Rabbit (Sylvilagus bachmani)

Order: Rodentia

Beechey Ground Squirrel (Spermophilus beecheyi)

Western Gray Squirrel (Sciurs griseus)

Botta Pocket Gopher (Thomomys bottae)

Little pocket Mouse (Perognathus longimembris)

* Stephen's Kangaroo Rat (Dipodomys agilis)

Merriam Kangaroo Rat (Dipodomys merriam)

Pacific Kangaroo Rat (Dipodomys agilis) 
Deer Mouse (Peromyscus maniculatus)

* Southern Grasshopper Mouse (Onychomys torridus ramona) FC Dusky-footed Wood Rat (Neotoma fuscipes)

California Meadow Mouse (Microtus californicus)

Cactus Mouse (Peromyscus eremicus)

Canyon Mouse (Peromyscus crinitus)

Bush Mouse (Peromyscus boylei)

Pinon Mouse (Peromyscus truei)

Order: Carnivora

Coyote (Canis latrans)

Kit Fox (Vulpes macrotis)

Grey Fox (Urocyon cinereoargenteus)

Raccoon (Procyon lotor)

Ringtail (Bassariscus astutus)

Spotted Skunk (Spilogale putorius)

Striped Skunk (Mephitis mephitis)

* American Badger (Toxidea toxus)

Long-tailed Weasel (Mustela frenata)

Bob Cat (Lynx rufus)

Mountain Lion (Felis concolor)

Order: Artiodaclyla

Wild Boar (Sus scrofa)

Mule Deer (Odocoileus hemiomus)

\section{REPTILES AND AMPHIBIANS}

California Glossy Snake (Arizona elegans occidentalis)

Western Yellow-bellied Racer (Coluber constrictor mormon)

Red Diamond Rattlesnake (Crotalus ruber ruber)

Southern Pacific Rattlesnake (Crotalus viridis helleri)

San Diego Ringneck Snake (Diadophis punctatus similis)

San Diego Night Snake (Hypsiglena torquata klouberi)

California King Snake (Lampropeltis getulus californiae)

Coastal Rosy Boa (Lichamura trivirgata)

California Striped Racer (Masticophis lateralis lateralis)

Red Racer (Masticophis flagellum piceus)

San Diego Gopher Snake (Pituophis melanoleucus annectens)

Western Long-nosed Snake (Rhinocheilus lecontel lecontel)

Coast Patch-nosed Snake (Salvadora hexalepis virgultea) 
California Black-head Snake (Tantilla planiceps eiseni)

Striped Garter Snake (Thamnophis couchi hammondi)

California Red-sided Garter Snake (Thamnophis sirtalis internalis)

California Lyre Snake (Trimorphodon vandenburghi)

Garden Slender Salamander (Batrachoseps pacificus major)

California Toad (Bufo boreas halophilus)

California Tree Frog (Hyla californiae)

Pacific Tree Frog (Hyla regilla)

California Red Leg Frog (Rana aurora draytoni)

FC,SSC

Bullfrog (Rana catesbeiana)

Western Spadefoot (Scaphiopus hammondi)

Southwestern Pond Turtle (Clemmys marmorata pallida)

Silvery Legless Lizard (Anniella pluchra pluchra)

Orange throated Whiptail (Cnemidophorus hyperythrus beldingi)

Coastal Whiptail (Cnemidophorus tigris multiscutalus)

San Diego Banded Gecko (Coleonyx variegates abbotti)

Desert Banded Gecko (Coleonyx variegates variegates)

Long Nosed Leopard Lizard (Crotaphytus wislizenii wislizenii)

Western Red-tailed Skink (Eumeces gilberti rubricaudatus)

Western Skink (Eumeces skiltonianus skiltonianus)

San Diego Alligator Lizard (Gerrhonotus multicarinatus webbi)

* San Diego Horned Lizard (Phrynosoma coronatum blainvillei)

Great Basin Fence Lizard (Sceloporus magister uriformis)

Granite Spiny Lizard (Sceloporus orcutti orcutti)

California Side-blotched Lizard (Uta sansbunana hesperis)

BIRDS (Includes Endemic and Migratory Species)

* Common Loon (Gavia immer)

SSC

Pied-billed Grebe (Podilymbus podiceps)

Horned Grebe (Podiceps auritus)

Eared Grebe (Podiceps nigricollis)

Western Grebe (Aechmophorus occidentalis)

Double-crested Cormorant (Phalacrocorax auritus)

SSC

Great Blue Heron (Ardea herodias)

Great Egret (Casmerodius albus)

Snowy Egret (Egretta thula)

Cattle Egret (Bubulcus ibis)

Green-backed Heron (Butorides striatus)

Black-crowned Night-Heron (Nycticorax nycticorax)

Canda Goose (Branta candensis)

Green-winged Teal (Anas crecca)

Mallard (Anas platynochos)

Northern Pintail (Anas acuta) 
Cinnamon Teal (Anas cyanoptera)

Northern Shoveler (Anas clypeata)

American Wigeon (Anas americana)

Ring-necked Duck (Aythya collaris)

Ruddy Duck (Oxyura jamaicensis)

Turkey Vulture (Cathartes aura)

* Osprey (Pandion haliaetus)

SSC

Black-shouldered Kite (Elanus caeruleus)

* Northern Harrier (Circus cyaneus)

SSC

* Swainson's Hawk (Buteo swainsoni)

ST

Sharp-shinned Hawk (Accipiter striatus)

SSC

* Cooper's Hawk (Accipiter cooperii)

SSC

Red-shouldered Haw (Buteo lineatus)

Red-tailed Hawk (Buteo jamaicensis)

* Ferruginous Hawk (Buteo regalis)

SSC

* Golden Eagle (Aquila chrysaetos)

* Bald Eagle (Haliaeetus levcocephalus)

FC,SSC

FT,SE

* Peregrine Falcon (Falco peregrins)

FE,SE

American Kestrel (Falco sparverius)

California Quail (Callipepla californica)

Mountain Quail (Oreortyx pictus)

American Coot (Fulica americana)

Killdeer (Charadrius vocilferus)

Black-necked Stilt (Himantopus mexicanus)

American Avocet (Recurvirostra americana)

Greater Yellowlegs (Tringa meknoleaca)

* Long-billed Curlew (Numenius americamus)

Least Sandpiper (Calidris minutilla)

FC,SSC

Long-billed Dowitcher (Limndromus scolopaceus)

Bonaparte's Gull (Larus philadelphia)

Ring-billed Gull (Larus delawarensis)

Herring Gull (Larus argentatus)

Rock Dove (Columba livia)

Mourning Dove (Zenaida macroura)

* Western Yellow-billed Cuckoo (Coccyzus americanus)

SE

Greater Roadrunner (Geococcyx californiamus)

Common Barn Owl (Tyto alba)

* Long-eared Owl (Asio otus)

SSC

Great Horned Owl (Bubo virginianus)

* Burrowing Owl (Anthene cuniculaia)

SSC

Anna's Hummingbird (Calypte anna)

Costa's Hummingbird (Calypte costae)

Belted Kingfisher (Ceryle aleyon)

Acorn Woodpecker (Melanerpes formicivorus) 
Nuttall's Woodpecker (Picoides nuttallii)

* Willow Flycatcher (Empidoncx traillii)

N. (Red-sh) Flicker (Colaptes auratus)

Black Phoebe (Sayornis nigricans)

Horned Lark (Eremophila alpestris)

Scrub Jay (Aphelocoma coerulescens)

American Crow (Corvus brachyrhynchos)

Common Raven (Corvuis corox)

Bushtit (Psaltriparus minimus)

* Coastal Cactus Wren (Campylorhynchus brunneicapillus)

SSC

Canyon Wren (Catherpes mexicanus)

Bewick's Wren (Thryomanes bewickii)

Ruby-crowned Kinglet (Regulus calendula)

* Black-tailed Gnatcatcher (Polioptila melanura)

FC

* Coastal California Gnat Catcher (Polioptia californica californica) FT

Western Bluebird (Sialia mexicana)

Mountain Bluebird (Sialia currucoides)

Northern Mockingbird (Mimus polyglottos)

California Thrasher (Toxostoma redivivum)

American (Water) Pipit (Anthus rubescens)

Cedar Waxwing (Bombycilla cedrorum)

Loggerhead Shrike (Lanius ludovicianus)

European Starling (Sturmus vulgaris)

* Least Bell's Vireo (Vireo bellii pusillus)

Yellow-rumped Warbler (Dendroica coronata)

* Yellow Warbler (Dendroica petechia)

FE,SE

Yellow-breasted Chat (Icteria virens)

Rufos-sided Towhee (Pipilo erythrophthalmus)

Vesper Sparrow (Pooecetes gramineus)

Lark Sparrow (Chondestes grammacus)

Sage Sparrow (Amphispiza belli)

Savannah Sparrow (Passerculus sandwichensis)

Song Sparrow (Melospiza melodia)

Lincoln's Sparrow (Melospiza lincolnii)

White-crowned Sparrow (Zonotrichia leucophrys)

Dark-eyed (Oregon) Junco (Junco hyemalis orgamus)

Red-winged Blackbird (Agelaius phoeniceus)

* Tricolored Blackbird (Agelaius tricolor)

Western Meadowlark (Sturnella neglecta)

Brewer's Blackbird (Euphagus cyanocephalus)

Brown-headed Cowbird (Molothrus ater)

House Finch (Carpodacus mexicamus)

American Gold-finch (Carduelis tristis)

House Sparrow (Passer domesticus) 


\section{$\underline{\text { FISH }}$}

There are few bodies of water supporting fish life within the CTVCP potential treatment area near Hemet. They are Anglers' Lake, Little Lake, and Reflection Lake.

There are no threatened or endangered fish known from these small recreational lakes. Great care and effort is taken to ensure that water is not contaminated by runoff, drift or by direct application onto non-target areas. (See "Key Features of Proposed Action".)

\section{INVERTEBRATES}

* Quino Checkerspot Butterfly (Euphydrya editha quino)

FPE

* Riverside Fairy Shrimp (Streptocephalos wootoni)

FE

* Vernal Pool Fairy Shrimp (Branchinecta lynchi)

FT 


\section{Harvester Ant Monitoring}

Harvester ants will be monitored in conjunction with aerial application of malathion in Imperial County. Monitoring will include a pre-treatment monitoring followed by two post-treatment monitorings.

Within each contiguous area to be treated, select a minimum of five (5) active harvester ant colonies. In years when multiple discontinuous areas are treated, a maximum of three treatment areas or 15 sites will be selected within areas to be treated.

As a control, select five (5) total ant colonies in habitats similar to colonies within treated areas. Harvester ant colonies should be active and well removed from treatment areas.

A maximum of 20 sites will be monitored in a given treatment year ( 15 sites within treatment areas and five (5) control sites). Flag, number and map each colony.

\section{Pre-spray Monitoring:}

A pre-treatment monitoring of all selected sites will be performed within 72 hours prior to treatment. During peak ant activity period at each colony, establish a reference point on the foraging trail and count the number of ants passing that point in one direction during a five (5) minute period. Record number of ants per minute. Record date, time, temperature, general weather conditions and general size (small, medium, large) of the colony.

\section{Post-spray Monitoring:}

Within 72 hours after treatment, monitor from established pre-spray reference point, unless foraging trail has changed. Conduct counts as in pre-spray monitoring. Record number of ants per minute, date time, temperature, general weather conditions and number of hours since treatment. When monitoring control colonies, write "control" in place of treatment date. Note any evidence of dead ants either on the ground or being carried by foragers. Note what plants are foraged such as Olegomeris, filaree, Plantago, etc.

A second post-treatment monitoring will be performed 30-60 days after treatment. Conduct counts as in post-spray monitoring.

When conducting pre and post-spray counts, take special precautions to avoid disturbing foraging trails or mounds. Do not drive or walk on trails. After final observations are made, all flags will be removed. 


\section{APPENDIX "I"}

\section{CTVCP Contingency Plans for Malathion Spills}

\section{Objectives}

A. To minimize the risk of further malathion exposure to people, animals, and the environment.

B. To provide a list for notifying federal, state, and local government officials of the size and details of the spills.

C. To provide clean up of small spills (50 gallons or less) and proper disposal of residual materials.

\section{Emergency Procedures}

Use common sense in determining the appropriate action in the event of an accidental crash of a spray rig, tanker, or aircraft.

Designate one person to notify authorities.

A. If a malathion spill involves personal injury, call an ambulance. The health and well being of persons in and around the area is the most immediate concern. If someone was exposed to pesticides remove them to a safe location. Remove clothing and wash contaminated skin with soap and water. Do not move a seriously injured person unless it is absolutely essential due to risk of further injury. Do not leave injured or incapacitated persons until proper medical assistance arrives. A malathion label and/or safety data sheet should accompany exposed people to the hospital.

B. If a fire hazard exists, call the fire department and notify them of the presence of malathion. Eliminate all sources of ignition (electric motors, gasoline engines or smoking) to prevent the threat of fire or explosion.

C. If the spill occurs on the highway, contact the California Highway Patrol through (911).

D. If the spill occurs off-road, call local police or county sheriff.

E. If a tank has a puncture, stop the leak and contain the spill.

F. Containing the spill. 


\section{Minor Spills, 50 Gallons or Less}

1. Wear rubber boots, coveralls, rubber gloves and eye protection.

2. Confine the leak or spill to the smallest area possible by using natural terrain, soil or absorbent material.

3. Shovel contaminated material into a leak proof container.

4. Do not hose down area.

5. Work carefully and safely; do not hurry.

6. Dispose of contaminated material the same manner as with excess pesticides or hazardous wastes.

\section{For Major Spills ( 50 Gallons or More)}

1. Follow steps listed under minor spills.

2. If the spill is too big, or uncertainty exists as to the appropriate action notify, the Chemical Transportation Emergency Center at 1-800-424-9300.

3. If the spill occurs on the highway, call the California Highway Patrol through (911).

4. If the spill occurs off-road, call local police or county sheriff.

\section{Notification List}

Depending of circumstances, it may be necessary to notify and seek assistance from various agencies.

II.

A. Integrated Pest Control Branch in Sacramento and Fresno.

B. California Highway Patrol, if accident is on the highway. Local police or county sheriff, if the accident is not on the highway.

C. County Agricultural Commissioner's office.

D. State Warning Center 1-800-852-7550. 
E. State Department of Water Resources and the California Department of Fish and Game, if the spill threatens or contaminates water.

F. Department of Energy at the DOE headquarters office, if the spill occurs on Naval Petroleum Reserve \#1 or \#2.

G. The Bureau of Land Management, local resource office, if the spill occurs on BLM administered lands.

H. The Federal Aviation Administration, if the malathion spill involves an aircraft crash.

I. Local county environmental health office.

\section{Safety and Cleanup Materials}

The following is a checklist of safety and cleanup materials that should accompany mixingloading vehicles during CTVCP treatment activities.
A. Safety

1. First aid kit

2. Fire extinguisher-516, type A-B-C

3. Goggles

B. Clean Up

1. One shovel

2. Large heavy-duty plastic bags

3. Rubber boots

4. Disposable coveralls

5. Water

6. Rubber gloves

7. Broom and dust pan

8. Liquid detergent

9. Several bags of "kitty litter" or other absorbent materials.

\section{Decontamination}

Surfaces such as paved highways, should be decontaminated. Malathion can be decontaminated by pouring chlorine bleach into the absorptive material (kitty litter) holding the malathion. Material should be shoveled into a leak-proof metal drum for final disposal. All tools and equipment must be decontaminated with chlorine bleach. 


\section{Disposal}

All materials that have been contaminated by spillage, or exposed to large volumes of pesticides including cloth, soil and wood cannot be decontaminated and must be disposed of in the same manner as with excess pesticides. Contaminated absorbent material and materials that cannot be decontaminated will be stored in a leak-proof container and disposed in a Class I dump. 
CALIFORNIA DEPARTMENT OF FOOO AND AGRICULTURE

SUMMARY OF TOXICOLOGICAL DATA

MEDICAL TOXICOLOGY BRANCH

SUMMARY OF TOXICOLOGY DATA

MALATHION

Chemical Code \#: 000367 ; Tolerance $\$ 111$ S8 $950-343$

Juiy 30,1986

Revised 2/23/87; 5/3/88; 10/2/89; $12 / 22 / 89 ; 4 / 5 / 90 ; 5 / 22 / 90 ; 9 / 5 / 90$

\section{DATA GAP STATUS}

Combined (chronic + onco) rat: No data gap, no adverse effect

Chronic sog: No data gap, no adverse effect

Onco rat: No data gad, no adverse effect

Onco mouse: No data gap, no adverse effiec:

Repro rat: No data gap, no adversa eiffec:

Terato rat: No data gap, no aoversa effect

Terato raboit: No data gad, no adverse efiect

Gene mutation: No data gad, no aoverse erffect

Chromosome: No data gap, no adverse effiec:

ONA damage: No data gao, no adverse erfect

Neurotox: No data gao, no adverse effec:

Note, Toxicology one-liners are attached

* indicates acceptable study

Bold face indicates possibie adverse effect

File name: T900905

Toxicology Summary by $G$. Chernoff, $9 / 5 / 90$

Rectified through volume $\# 125$, record $\$ 091230$ 


\section{TOXICOLOGY ONE-LINERS ANO OISCUSSION}

\section{COMBINED (CHROHIC + ONCO) RAT}

$\star \approx 067$ 014771, "The Evaluation of the Chronic Toxicity Effects of Cythion Administered in the Diet to Sprague-Dawley Rats for 24 Consecutive Months", (Food and Drug Research Laboratories, Inc., Laboratory \#5436, 5/13/80), Malathion, 92.1\%, Lot No. W70225-1; 50 Sprague-Dawley rats/sex/group were fed $0,100,1000$ or $5000 \mathrm{ppm}$ for 2 years; hematology at 12, 26, 53 and 104 weeks; sys NOEL = $100 \mathrm{ppm}$; chronic effects on liver and kidney by increased organ weight but this was not substantiated by microscopic findings; no oncogenic effect reported. No adverse effect. Acceptable. These results differ from those of NCI below in which adverse effects on the GI tract were reported. Rereview finds that the initial review noting adverse eifects in liver and kioney organ weight is not of biological significance in view of the pathology report in the supplemental. submission, volumes 79-81. Document 111-097 contains a rebuttal dated $6 / 19 / 87$. No change in status. (Gee, 8/5/85, $6 / 20 / 86$ and $5 / 3 / 88$ )

EPA One-liner: Systemic NOEL $=100$ pom (decroase in body weight, decreased brain chol inesterase), systemic $L E L=1000 \mathrm{ppm}$, onco $\mathrm{NOEL}$ - $>$ EOCO pom (HOT), guideline.

In the February 1988, "Guidence for Reregistration....", EPA has reversed its oecision and considers ine siudy. unacceptable upon reexamination sue to deficiencies in data reporting, slide reading and intercurrent gisease. A new sucy is being required in fisher 344 rats.

079, 080, $081037614,-15,-16$, (Food and Drug Res. Lab., 1980). Addenda to 067014771 . Summary tables of organ weights, blood choiinesterase values, inaividual body weignts and rood consumption, histopathology repor: making reevaluation and upgrading of 014771 possible (Gee, 12/26/85).

088 05i410, Addendum to 014771. Validation of andysis of fortified diets using 2 different detectors for GLC.

088 05i411, Addendum to 014771. Analysis of diets by week plus stability data - upgrades Record \#014771 to acseptable.

\section{CHRONIC RAT}

022.024554 , Summary only. Insufficient information to evaluate. Gee, $8 / 2 / 85$.

007 024211, (Hazleton, 1952.) Sumary only. Three formulations of malathion were given to $20 \mathrm{male}$ rats/group at 500,1000 or $5000 \mathrm{ppm}$. Survival daca only over 109 weeks. Unacceptable. (Gee, 8/2/85)

EPA 1-liner: No CORE grade. Systemic NOEL $=1000 \mathrm{pDm}$ (reduced food intake and weignt gain), oncogenic NOEL > $5000 \mathrm{ppm}$ (HDT), ChE NOEL $=100 \mathrm{ppm}$ (LDT).

\section{CHRONIC, DOE}

*098 058618, "One-Year Oral Toxicity Study in Purebred Beagle Dogs with AC $5,601 "$. (Tegeris Laboratories, Inc., report \#85010, 2-10-87). AC 6,601, lot no. W40515-0011, 25.0\%, was given to beagle dogs at $0,62.5,125$ and 250 $\mathrm{mg} / \mathrm{kg} /$ day by gelatin capsule, 7 days a week for 1 year, $6 / \mathrm{sex} / 00$ se. No mortalities, no interim sacrifices. Systemic NOEL $=125 \mathrm{mg} / \mathrm{kg} / \mathrm{day}$, body weignt depression, changes in hematological parameters and serum enzymes. ChE NOEL $<62.5 \mathrm{mg} / \mathrm{kg} / \mathrm{day}$. No adverse effect. Acceptable. (Shimer, 2-23-a8 and Gee $3 / 7 / 88$ ) 
EPA 1-liner: unacceptable because a NOEL was not established for increased liver and kidney weights, elevated platelet count, decreased creatinine, decreased BUN, inhibition of erythrocyte and plasma cholinesterases. A new study is required - see "Guidance for the Reregistration of Pesticide Products containing Malathion as an Active Ingredient", February, 1988.

Note: In a conversation with Or. 8. Dementi of EPA, COFA was informed that EPA is no longer requiring a new study with non-rodents at this time. (Gee, $4 / 6 / 90)$

\section{ONCOGENICITY, RAT}

068 014772, "Bioassay of Malathion for Possible Carcinogenicity", (NCI conducted at Guif South Research Institute, report (NIH) 78-824, December 1977). Malathion, >95* purity, lot SPS-10127; Osborne-ivendel rats; $10 / \mathrm{sex}$ in controls plus 40/sex pooled controls (from other studies conducted within the year at Gulf South Res. Inst.) and 50/sex/test group were fed 0,4700 or 8150 ppm (TWA) for 80 weeks and observed for 33 -- initial doses were 8000 and 12000 which were decreased at week 14 for low dose group to 4000 ppm and at week 3 for the high dose group from 12000 to 8000 ppm for 77 weeks. Unacceptable (no hematology, inadequate number of controls and no historical control data, problems with dose selection and drastic changes in dose part way chrougn study, missing data); not clear whether an oncogenic efiect. A later volume, 111-086, contains a publisned article in Environmental Research 37: 154-173 (1985), record 041972 , reyiewing the pathological finoings of this and 2 other NCI-sponsored onco studies. The authors conclude that malatnion had no effect on survival of Osborne-Mendei rats. They also concluded that no evidence of carcinogenicity was found. The review jy Remsen (aee) indicaced an oncogenic efrect in the thyroid of male racs. The reexamination of the slides resulted in the finding of an additional adenoma in the pooied control and one in the low dose group so the incidence as reportsd in the cited publication in males is: follicular cell adenoma/carcinoma -- $1 / 14,1 / 14$ (controi), 6/41, 2/41 (low dose) and $7 / 35$, $2 / 35$ (high dose); C-cell adenoma/carcinoma - 1/14, 0/14 (control), 3/41, 0/41 (low dose) and $1 / 35,0 / 35$ (high dose). By fisner's exact test, the $p$ value for the comoined adenomas/carcinomas is 0.22 for high dose compared with control incidence. Therefore, the original finding of oncogenicity is no longer evaiuated as significant in view of the aoded information. Oue to lack of individual data in the NCI report, it is not possible to identify either when or in which rats the findings were made. Also, the numbers in the publication do not match those in the NCI report for thyroid findings even considering the acded two adenomas. The numbers reporzad by $\mathrm{NCI}$ are:

Thyroid

follicular-cell adenoma

$\begin{array}{ccc}\text { Control } & \text { low dose } & \text { high cose } \\ 1 / 5 & 1 / 41 & 1 / 47 \\ & 2 / 41 & 6 / 47 \\ & 1 / 41 & 3 / 47\end{array}$

follicular-cell carcinoma

$1 / 41$ Report does not indicate any effect(s) on the stomach. NOEL cannot be
determined accurately due to dosage changes but on the basis of body weignt using the TWA, the NOEL would be $4700 \mathrm{ppm}$. Ho adverse effect. Document III097 contains a rebuttal dated 6/19/87. No change in status. (Gee, 8/9/85 and $5 / 3 / 88)$

EPA one-liner: onco NOEL > $8150 \mathrm{ppm}$ (HOT), minimum. 
086 041972, (Publication in Environmental Res. 37: 154-173 (1985) by Huff, J. $E$. et al.). Paper addresses the pachology of three NCI/NTP onco studies in the 1970's with reevaluation of the slides. Using the data presented in this publication, the rereview of the studies has resulted in some changes in the findings originally stated by Remsen (Gee) in 014772, 014773 and 024193. (Gee, 6/19/86)

068 014773, "Bioassay of Malathion for Possible Carcinogenicity", (NCI, No. 192, Publication No. 79-1748, conducted at Gulf South Research Inst., 1979), Malathion, 95\% purity, lot SPS-10127; $50 \mathrm{F344} \mathrm{rats} / \mathrm{sex} / \mathrm{group}$ were fed 0,2000 or $4000 \mathrm{ppm}$ for 103 weeks; dose selection based on 13-week study from 0 $16,000 \mathrm{ppm}$ with 100\% survival at $8000 \mathrm{ppm}$; decreased body weight in males only and decrease in survival at $4000<2000<$ control from toxicity. Adverse effects: Positive for chronic effects on gastrointestinal tract (forestomach: chronic inflammation, ulcers, others); the possible oncogenicity in the adrenals (pheochromocytoma) is not clear as the incidence is not dose dependent and occurred in males only at $2 / 49$ (control), 11/49 (10w dose) and $6 / 49$ (high dose). A publication in Environmental Research 37: 154-173 (1985), 111-086, \$041972, addressed the issue in a reexamination of the pathology slides and concluded that there was no oncogenicity effect but confirmed the chronic effect on the stomach. The numoer of animals, however, does not agres between the publication and the Report 192. The trend, however, is the same. In conclusion, the report shows a chronic effect with coubtful oncogenic effects. Unacceptable with missing individual data, doubtful nigh cose for females especially. Not upgradeable. NOEL < 2000 ppm. (Remsen, 8/9/85) EPA one-liner: onco NOEL > $4000 \mathrm{ppm}$ (HOT), Sys:emic NOEL < $2000 \mathrm{ppm}$, minimum.

058 034788, "Bioassay of Malaoxon for Possible Carcinogenicity", (NCI, No. 135. NIH publ. no. 79-1390, conducted at Gu?f South Research Inst., 1979), Malaoxon analog or malathion, >95\% purity; 50 F $244 \mathrm{rats} / \mathrm{sex} /$ groud were foo 0 , 500 or $1000 \mathrm{ppm}$ for 103 weeks; diet analyzed as within 2\% ố target ppm; dose selection based on subchronic study. Summary data only presented and no individual data, no third dose, no cholinesterase measurements, no hematology; eauivocal evicence for oncocenicity in male and female F344 rats for C-coil doenoma/carcinomas in inyroid; positive for chronic toxicity to sne gastrointestinal tract with dose-re?ated increased incidence in ulcars of the forestomach with male rats being more sensitive than iemales. A publication (111-086, 041972) addresses these findings in a reexamination of the pathology slides from this and two other studies. The numbers in 041972 do not agrae with those in this report although the trend is the same.

$\begin{array}{ccccc}\begin{array}{c}\text { Thyrojid } \\ \text { C-cell adenoma/ } \\ \text { Carcinoma }\end{array} & M & \begin{array}{c}\text { Control } \\ 2 / 49\end{array} & \text { low dose } & \text { high dose } \\ 4 / 49 & & \\ \text { Reexam } & F & & 1 / 49 & 5 / 47 \\ & M & 3 / 49 & 3 / 45 & 10 / 49 * \\ & F & 4 / 48 & 7 / 48 & 11 / 48 *\end{array}$

The values from this report are not significant by Fisher exact in males but are in females. The reexam values are significant in both sexes. The publication does not discuss why the numbers are so different. In conclusion, malaoxon shows chronic toxicity and marginal oncogenicity as does malathion. NOEL $<500 \mathrm{ppm}$ (body weight, behavior). Unacceptable. (Gee, 8/6/85)

EPA 1-liner: Minimum. Oncogenic NOEL > $1000 \mathrm{ppm}$ (HOT). EPA is requiring a new study in the Fister 344 rat with maldoxon to clarify the results in the above study - see February, 1988, "Guidance for the Reregistration...." 
- SUMMARY: From the above, it is concluded that malathion is not oncogenic at any of the doses tested in these studiesnor is it unequivocally ancogenic in the mouse (see below). The major effect is a chronic one on the gastrointestinal tract at levels in the diet of $2000 \mathrm{ppm}$ of malathion and of $500 \mathrm{ppm}$ malaoxon, an analog of malathion. An assessment of the chronic effects should be made also considering the negative findings in 014771 , listed above under COMBINED RAT, at diet levels up to $5000 \mathrm{ppm}$, much higher than that at which the NCl studies report seeing an effect. Considering all of the factors, collectively the multiple studies permit the decision that the rat oncogenicity data gap is filled in that chronic effects occur at levels in the diet which have not been demonstrated to be oncogenic in either of two species (rat and mouse). (Gee. 1986)

\section{ONCOGENICITY, MOUSE}

*068, 104 034789, 069632, "Bioassay of Malathion for Possible Carcirogenicity", (NCI conducted at Gulf South Research Institute, report : (NIH) 78-824, December 1977), Malathion, > 95\% purity, lot SPS-10127, icentity of compound was verified by Gulf South Res. Inst., 10/sex for concurrent control and 50/sex/group for test were fed 0, 8000 or 16000 pom for 20 weeks followed by 14 weeks observation; B6C3F I mice. Oncogenic effect in liver of males at $16000 \mathrm{ppm}$. NOEL < $8000 \mathrm{ppm}$ (body weight). Originally reviewed (Gee 8/9/85) unacceptable but possibly upgradeable with submission of missing data on histopathology, and as having a possible doverse effac: (male liver oncogenic effect). Risk assessment by CDFA Medical Toxicology (T.R. Hathaway, $7 / 31 / 87)$ found the liver effect to not be of biological significance, hence, no adverse effect indicated. Subsequently reviewed (Gee $5 / 3 / 88$ ) with no status change. Re-reviewed with submission of individual histcoatiology da:a (\# 069632). Status change to acceptable. (Green and Silva, $8 / 28 / 89$ )

EPA one-liner: OnCD NOEL > 16,000 ppm (HDT--questionable liver findings-not significant with Bonferroni criteria. However, rolated irench $\mid$ sic| $\mid J=$ 0.0191 and increase of tumors at high dose $[p=0.031]$ - a level EPA normally considers significant), minimum.

Note: According to the 1988 reregistration standard. EPA has requestad additional data addressing the equivocal effects seen in the mouse. In a conversation with Or. Dementi, COFA was informed that a new study with malathion in the mouse is being requested. (Gee, 4/1990)

058034788 , "Gioassay of Malaoxon for Possible Carcinogenicity", (HC!, No. 135, 1979, NIH publ. no. 79-1390, canducted at Gulf Scuth Researcn Institute). Malaoxon analog of malathion, > 95\% purity, 50 B6C3FI mice/sex/group were fed 0,500 or $1000 \mathrm{ppm}$ for 103 weeks; dose selection based on a subchronic study data not included; No evidence of oncogenicity is reported. Unacceptable with no individual data, two doses only, no hematology, marginal chronic toxicity at high dose on body weight, etc., so questionable if adequate. The initial review indicated chronic toxicity was reported. Rereview of the study (Gee, $6 / 19 / 86$ ) now indicaces the findings of behavior modification and mortality are not of biological significance, the latter only indicating adequacy of dose leve1. NOEL: 500 ppm. No adverse effect. (Gee, 8/6/85 and 6/19/86) EPA one-liner: onco NOEL > $1000 \mathrm{ppm}$ (HOT), systemic NOEL < $500 \mathrm{ppm}$ (decreased mean body. weights in F), minimum. No additional data are required. 
083. 088 037620, 051409, "Report on Malathion: Successive Generation Studies with Rats, Final Report", (American Cyanamid Co., report "68-64, 7/9/68), Malathion, 95\% purity, SPS-6111; data on F2 breeding for $F 3$ generations only - not on other generations; approximately 16 matings at each dose of $0,100,500$ or $2500 \mathrm{ppm}$ fed in the diet. Use of cedar shavings resulted in respiratory problems in F3b pups; reproduction, lactation, necropsy and histopath data for F3 pups; positive adverse effect identified for decrease in lactation index. Systemic NOEL $=500 \mathrm{ppm}$ (decreased body weight), repro NOEL $=500 \mathrm{ppm}$ (decreased lactation index). Unacceptable (no interim pup weights - days 1, 4,7 or 14, no necropsy on adults, no analys is of diet, intercurrent disease, husbandry problen, single body weight for adults prior to mating only), not upgradeable. Document $111-097$ contains a rebuttal dated $6 / 19 / 87$. No change in status.

(Gee, $12 / 26 / 85$ and $5 / 3 / 88$ )

EPA is requiring a new reproduction study. The above study is considered unacceptable based on insufficient number of animals, lacx of individual data and other dericiencies - see February, 1988, "Guidance for the Reregistration...."

*126091230, "A Two-Generation (Two Litters) Reproduction Study with AC 6,601 to Rats", (R.E. Schroeder, 8io/0ynamics Inc., Report 87-3243, June 28, 1990). Malatnion, 94\% surity, lot $\$ A C 5015-136$, was administered in the diet to grouos or 25 male and 25 female rats at cose levels of 0 (venicie cancrol), इ三o, 1700, 5000, or $7500 \mathrm{ppm}$ for two generations, two litters per generation. At i500 $\mathrm{pm}$, maternal gestational and lactacion weignts were consistently reduced in both littars of both generztions, with statistical significance being cotained in the first prograncy and both laciation periods of the p-i generation. Pup weaning weights on aay 21 post partum were consistentiy reduced at both 5000 and $7500 \mathrm{ppm}$, reaching statistical significance for all litters at $7500 \mathrm{pom}$, and the first $P-1$ and second $F-1$ litsers at $\$ 000$ oum. At $7500 \mathrm{pom}$, the postnatal growth retaraation persisted througn dquitrocd, with no indication of catch-up growth. Reproductive parameters were not adversely effected. Developmental NOEL $=1700 \mathrm{ppm} ;>200 \mathrm{mg} / \mathrm{kg} /$ day (postnatal growth retardation); Parental $N O E L=\$ 000 \mathrm{oom} ;>400 \mathrm{mg} / \mathrm{kg} /$ say (reducad body weight); Resrsductive NOAEL = $7500 \mathrm{zom} \mathrm{(HOT);} \mathrm{>} 600 \mathrm{mg} / \mathrm{kg} / \mathrm{day}$. The sisdy is ACCEPTABLE, and no adverse reproductive health effect is roted (G. Chernofi, $\overline{8} / 2 \overline{3} / 90)$

SUMMARY: In the initial unaccaptable rat reproduction study (racord $\#$ 's 037620 and 051409 ), a decrease in the lactation incex at 2500 pom was identified as a jossible acverse healih effect, with a NOEL $=500$ pom. This outcome was not replicated in the acceptable swo gereration, two littars per generation repeat siudy (record 091230 ). Given the suberior quality of the repeet study, along with the failure to replicate the earlier reported adverse effect, the finding of the acceptable study, no potential adverse reproouctive health eifects, should be used for risk assessment purposes (G. Chemoff, 9/30/90).

\section{TERATOLOGY, RAT}

-111 074764, "A Developmental Toxicity Study With AC 6,601 in Rats", (Argus Researeh Laboratories. Inc., Laboratory Project ID 101-005, 4/5/89). AC 6,601 (malathion), technical grade, purity $94.0 \%$, was administered to groups of 25 Crl:CD (SO) BR female rats by gavage on days 6 through 15 of gestation at coses of 0 (corn oil vehicle control), 200, 400 or $800 \mathrm{mg} / \mathrm{kg} / \mathrm{day}$. The only significant finding in the dams was an increased. incidence of urine stained dodominal fur at $800 \mathrm{mg} / \mathrm{kg} /$ day. Fetal parameters were unaffected by treatment and no adverse effect was noted. Macernal and Developmental NOEL $=>800$ $\mathrm{mg} / \mathrm{kg} / \mathrm{day}$ (the high dose tested). Originally reviewed as unacceptable (Kishiyama \& Chernoff, 12/89), but witn the subaission of the dose 
justification in CDFA Record No. 090478, the study is upgraded to ACCEPTABLE (G. Chernoff, $4 / 5 / 90)$.

111074765 , Supplement to 074764 ; dosing solution analyses. No Worksheet.

118090478, Pilot study for dose justification in record no. 074764.

068 014778, "Teratogenicity Studies on Linuron, Malathion and Methoxychlor in Rats", (Bureau of Chemical Safety, Canada, 8/25/77, Puolication in Toxicol. ADo1. Pharmacol. 45: 435-444 (1978), accepted in 1977, Khera, K. S. et al.), Malathion technical, no purity stated: $20 \mathrm{Wistar}$ rats/group were given 0 , 50 , 100,200 or $300 \mathrm{mg} / \mathrm{kg}$ by oral gavage, days $6-15$ of gestation. No adverse effect on reproduction or teratogenic effect is reported. Sacrificed on day 22 with $2 / 3$ of fetuses for skeletal exam and $1 / 3$ for visceral. One table only. Unacceptable (inadequate high dose) Sys NOEL > $300 \mathrm{mg} / \mathrm{kg} / \mathrm{day}$ (HDi), Dev. toxicity NOEL $\geq 300 \mathrm{mg} / \mathrm{kg} /$ day. (Gee, 8/9/85)

092053281 , Duplicate of publication, Record $\# 014778$, plus copies or raw data for malathion. Includes mating identification, indiviqual body weights and litter findings. Data from range-finding study to $600 \mathrm{mg} / \mathrm{kg} / \mathrm{day}-4$ per group.

TERATOLOGY, RABB!T

*089 051413, "A Teratology Study with AC 6,501 in Rabbits", (Food and Drug Research Laboratories, Inc., study \& $8171,2 / 28 / 85)$. Malathion, 92.4\%, was administered by gavage to groups of 20 inseminated New Zealand rabbits at doses of 0,25 , 30 or $100 \mathrm{mg} / \mathrm{kg} / \mathrm{day}$ on day $6-18$ of gestation. Maternal weight gain during dosing was statistically reduced at 50 and $100 \mathrm{mg} / \mathrm{kg} / \mathrm{day}$. Mean numbers and percent fetal resorptions were also elevated at these two doses. The number of unexplained unscheduled deaths were elevated above historical control values in the low dose group, but did not achieve statistical significance. In addition, there was no evidence for a dose response efiect. . Haternal NOEL $=25 \mathrm{mg} / \mathrm{kg} /$ day (rejucej weight gain during josing); Developmental NOEL $=25 \mathrm{mg} / \mathrm{kg} /$ day (increase in resorptions). The study is ACCEPTABLE, and no adverse developmental health effects are noted (Parker, 2/13/87; Chernoff, 9/3/90).

EPA nas accepted this study.

\section{GENE MUTATION}

068, 099 014776, 060150, "Microbiological Assays in: In vivo and in vitro Mutagens", (SRI for EPA, project LSU-3493, February 1977). Malathion, technical grade, 92-97\% purity, lot 40216006.300; tested in Saimonella tyohimurium strains TA153E, TA1537, TA1538 and TA100 (no TA98), single plate, several trials with and without activation at $0,1,5,10,50,100,500$ or $1000 \mathrm{ug} / \mathrm{plate.} \mathrm{Ho} \mathrm{increase} \mathrm{in} \mathrm{reversion} \mathrm{rate} \mathrm{is} \mathrm{reported.} 060150$ contains individual plate counts. Unacceptable (lacks TA98, some positive controls). (Gee $8 / 9 / 85$ and $3 / 3 / 88$ )

067 014770, "Mutagenicity Testing of Cythion Malathion in the Ames Bacterial Test", (American Cyanamid Co..6/2/78). Malathion, 92.8\% purity, Salmonella tyohimurium strains TA 1535, TA1537, TA98 and TA100 with and witnout activation at $0,10,100$ and $1000 \mathrm{ug} / \mathrm{plate;}$ also E. coli WP2. Unacceptable (too few plates, concentrations, inadequate controls). Ho adverse effect reported. Some suggestion of cytotoxicity at $1000 \mathrm{ug} / \mathrm{plate.} \mathrm{(Gee} \mathrm{8/2/85)}$ 
157-009 034551, "The Mutagenic Effect of Organophosphate Insecticides on Escherichia coli". (Tunstall Laboratory, 8/71). Malathion technical, 97.4\% purity, tested at an unspecified amount with $E_{\text {. coli }}$ B/r WP2 strain for tryptophan reversion in triplicate; result reported as "-". Unacceptable, no data. (Gee 2/20/87)

$\star 122086717$, "Evaluation of $\mathrm{CL} 6,601$ in the 8acterial/Microsome Mutagenicity Test", (Traul, K. A., American Cyanamid Company, Agricultural Research Division, Study No. 114, 3/9/87). Malathion ( $C L$ 6001, batch $A C$ 4870-548, 95.2\% purity) was tested by the plate incorporation assay with Salmonella tyon:murium strains TA1535, TA1537, TA1538, TA98 and TA100 as well as with Escherichia coli strain WP2 uvrA-. Concentrations Eested were 0 (DMSO), 100, $500,1000,2500$ or $5000 \mu \mathrm{g} / \mathrm{plate}$ with triplicate plates per concentration and two trials. Bacteria were plated with and without activation with $S-9$ prepared from livers of male Spraque-Dawley rats and purchased irom Microbiological Associates. Positive controls with and without activation for each strain were effective. No increases in revertants with any strain were reported. Ho adverse effect. Acceptable. (Gee, $5 / 18 / 90$ )

* SUMMARY: Aithough each study has deficiencies in design or reporting of dat3, wher examined collectively the studies provide sufficient inrormation is determine that malathion is not mutagenic in bacteria. The data gap is, therefore, filled for the gene mutation test type. (Gee, 1987) The mos: recent submission (Record 0867!7) is acceptable indepencent of the otner studies and confirms the negative results. (Gee, 5/90)

\section{CHROMOSOME EFFECTS}

$\approx 006$, 099, $108014774,060282,073931$, "Dominant Lethal Tes: in the Mousa," (SRI for EPA, project LSU-3493, February, 1977). Malathion, technical grade, 92-97\% pure was fed in the diet for 7 weeks to 20 ICR/SIM male mice/group at $0,1250,2500$ or $5000 \mathrm{mg} / \mathrm{kg}$, before the animals were mated $1: 2$ for one week over 8 intervals. Mo evidence of a dowinant lethal effect reported. Record 060282 concains the individual data and a statement addressing the purity of the technical malathion. Previously reviewed as unacaptable (Gee, 12/27/85 3 $3 / 3 / 88)$, the study has been upgraded to acceptable with submission of the requested diet analysis. (M. Silva, $8 / 29 / 89$. )

085037622 , Addendum with summary data by mating weex for 014774.

068. 014777, "Genetic and Cytogenetic Effects induced in the Mouse by an Organcohosonorus insecticide: Malatnion:, (Publication in Environmental Res. 34: $170-174$ (1984) by Degraeve and Moutschen.), Malathion, > 99\% purizy, jstrain male mice (number not stated) were given 0 or $300 \mathrm{mg} / \mathrm{kg} \mathrm{i.p.} \mathrm{with} 12$, 24 or 36 hour recovery periods; 500 metaonases from bone marrow and varying number of spermatogonia were analyzed for aberrations. No adverse effect is reported in the publication. Unacceptable as is - need the full rapor:. (Gee, 8/9/85)

$* 122$ 086718, "Acute Test for Chemical Induction of Chromosome Aberration in Rat Bone Marrow Cells in vivo with AC 6,601", (Gudi, R., SITEK Research Laboratories, Rockville, MD, $0125-1531,3 / 22 / 90)$. Malithion (AC 6,601, batch AC6015-1360; 94\%) was given by oral gavage to Sprague-0ailey rats as a single dose. Based on a preliminary trial, doses selected were 0 (corn $0 i 1), 0.4$, 0.8 and $1.6 \mathrm{ml} / \mathrm{kg}$, equivalent to $0.5,1.0$ and $2.0 \mathrm{~g} / \mathrm{kg}$ based on density of 1.25. There were $5 /$ sex/group for the definitive assay with sacrifices at 12 , 24 and 48 hours post-treatment. Mitotic indices as well as aberrations were 
scored. Fifty cells per animal per sex per group were evaiuated for aberrations excluding gaps. There was no effect on the incidence of aberrations and only a possible slight decrease in the $M I$ at 24 and 48 hours in the high dose groups. No adverse effect. Acceptable. (Gee, 5/18/90)

\section{ONA DAMAGE}

$\star * 068,099$ 014775, 060284, "Mammalian in vitro Unscheduled ONA Synthesis Assays", (SRI for EPA, project no. TSU-3493, February 1977). Malathion, technical grade, 92\%-97\% purity, unscheduled DNA synthesis in human diploid fibroblasts WI-38, passage 28 , tested with and without activation, 691 is were exposed for 3 hours in the presence of tritiated thymidine to $0,10^{-7}, 10^{-6}$, $10^{-5}, 10^{-4}$, or $10^{-3} \mathrm{M}, 6$ flasks without activation and 3 with activation; No cytotoxicity reported except possibly at the highest concentration. No evidence for unscheduled DNA synthesis is reported as increased OPM/ug ONA. Initially reviewed as unacceptable based on the lack of sufficienc details in the protocol and information on the test material. Record :060284 contains the detailed protocols including passage number of the WI-38. The study is upgraded to acceptable status with the supplementary information. (Gee, $3 / 9 / 85$ and $3 / 3 / 88)$

068 034790, "Microbiological Assays in: In vivo and in vitro Studies or Selected Pesticioes to Evaluate their Po:entiai as Chenicai Muiagens", (SRI for EPA, project LJU-3493, February 1977), Escrerichia coli. Malachion, no purity stated, 0 or $1 \mathrm{mg}$ added to a disc on piates witn E. Coi 13110 or p3478 -- also with Bacillus subtilis strains 417 and $m 45$. Zones of innibition were measured. Ho difference in growth between repair defective and repair erfective strains. Unacceptable (no justification for single concentration, single value only althougn report indicates tnree irials), Decause no cytotoxicity was cemonstrated, the result is a "no test." (Gee, 8/9/85)

068034791 , "Microbiological Assays, in: In vivo and in vitro Studies or Selecied Pesticides to Evaiuate their potential as Chemicai Mutagens", (SR! for EPA, projest LSU-3493, February 1977). Surmary data only. Malathion, no purity stated; Saccharomyces cerevisiae strain 03 measured for mitotic crossing-over at $50 \mathrm{mg} / \mathrm{ml}$ (5x) with and without activation, 4 hour exposure. No adverse effect reported. Unacceptable due to missing information. (Gee, $8 / 9 / 85)$

* 122 086716, "Test for Chemical Induction of Unscheduled ONA Synthesis in Rat Primary Hepatocyte Cultures by Autoradiogranhy with AC 6,601", (Pant, K. J., SITEK Research Laooratories, Rockville, MD, 1/24/1990, Study No. 0125-5100). Malathion (technical, batct AC 6,601, 94\%) was tested with primary hedatocytes from male Sprague-0awley rats. After a preliminary range-finding assay, the concentrations used in the UDS assay were 0 (DMSO, untreated or etnanol), $0.02,0.04,0.08,0,12$ or $0.16 \mu 1 / \mathrm{ml}$ with an 18 hour incubation in the presence of $10 \mu \mathrm{Ci} / \mathrm{ml} / \mathrm{H}$-thymidine. Incorporation of thymidine into nuclei was quantitated by autoradiography with 150 nuclei per concentration scored in morphologically normal cells in the 0.02 through $0.12 \mathrm{\mu T} / \mathrm{ml}$ groups. The positive control was $2-A A F$ and that treatment gave the anticipated results with 100\% of nuclei having $\geq 5$ net grains. Treatment with malathion did not induce an increase in unscheduled ONA synthesis. No adverse effect with hepatocytes. Acceptable. (Gee, 5/18/90) 


\section{NEUROTOXICITY}

*103 068075, "42-Day Neurotoxicity Study with AC 6,601 Technical in Mature White Leghorn Chickens", (Bio-Life Associates, Ltd., report " 87 ON 109, 4/1/88). AC 6,601 Technical (malathion), 93.6\% purity, administered by gavage with protection (intramuscular injection of atropine sulfate at $10.0 \mathrm{mg} / \mathrm{kg}$ ) at $1007.5 \mathrm{mg} / \mathrm{kg}$ to 60 hens. Survivors (2l hens) were redosed with protection at $852.5 \mathrm{mg} / \mathrm{kg}$ on day 21 . Negative control $(1.87 \mathrm{ml}$ and $1.15 \mathrm{ml}$ of tap water on day 1 and day 21 respectively) and positive control (TOTP at $500 \mathrm{mg} / \mathrm{kg}$ ) groups of 15 hens. 39 of the 60 hens dosed on day 1 at $1007.5 \mathrm{mg} / \mathrm{kg}$ died by day 15 , the remaining 21 birds survived through day 21.7 of the 21 birds re-dosed at $852.5 \mathrm{mg} / \mathrm{kg}$ on day 21 died by day 28. 14 survived through day 42 . Reversible moderate/severe ataxia to paralysis of legs and wings and inability to stand reported in all malathion treated hens through day 4 and again, after redosing on day. 21, through day 25. 10 hens/group for histopathology -unremarkable for malathion treated group. No adverse effect. Acseptable. (Green and Silva $8 / 29 / 89)$

\section{SUPPIEMENTAL STUOIES}

:21 086381, "Disposition and Metabolism of 14 C-Labeled Malatrion in Razs (Preliminary and Definitive Study)", (Reddy, V., T. Freeman and M. Cannon, Miowest Resaarch Laboratories, Projec: No. $9354-a, 12 / 20 / 89$ ). Maiathion (uniabeled at $94.6 \%$ and ${ }^{14} \mathrm{C}$-labeled at $98 \%$ ) was given by orai gavage to इ/sex/group of Sprague-Dawley ( $\mathrm{Cr}$ l:CD BR) rats at single doses of 40 or 800 $\mathrm{mg} / \mathrm{kg}$ or 15 doses of unlabeled malathion at $40 \mathrm{mg} / \mathrm{kg}$ followed by a $16 \mathrm{th}$ dose of radioactive malathion. Excretion was followed for 72 hours before sacrifice of the animals and measurement of tissue content. Most of the malatnion was excreted in the first 12 hours predominantly in the urine or Doth males and females. Less than 1\% was retained in the tissues with the level in the liver being the highest. Ten metabolites were identified by GC/MS of material eluted from HPLC. The major metadolites were the c and 3 isomers of the monocarooxylic acid derivative ano the dicarbcxylic acid derivative cf malathion. The intravenous route was not used due to the insoluoility of malathion in water or saline. Report is complete and acceptable. (Gee, 5/21/90)

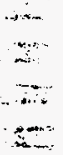


CALIFORNIA DEPARTMENT OF FOOO AND AGRICULTURE

MEDICAL TOXICOLOGY BRANCH

TOXICOLOGY STUDY EVALUATION WORKSHEET

(reproduction)

I. STUDY IDENTIFICATION

Active Ingredient: Malathion

Formulated Product Mane:

Cherical Code f: 00367

ID f: SBC-124284-E

Document f: $111-126$

EPA Reg. f: 241-0-

Record f: 091230

Study Type: 834, Rat Reproduction

SB 950 f: 343

Full Study Title: A Two-Generation (Two Litters) Reproduction Study with AC 6,601 to Rats

Comany Sponsor: American Cyanamid $C O$.

Conducting Laboratory: Bio/Dynamics Inc.

Final Report Date: June 28, 1990

\section{SUMMARY OF WORKSHEET}

A. STUDY STATUS: Is report complete? - YES

Is study acceptable? - YES

- Meets EPA guidelines

- Minor variances from guidelines

- Major variances from guidelines

- Could be upgraded with additional inforation (see VI-A)

- Has useful data

- Insufficient data

- Mon EPA validated study

- Other

B. Conclusions: Does this study as reported demonstrate a possible adverse health effect?: NO

If so, in wat area?

C. ONE LINER - SUmary of the study:

$\$ 126$ 091230, "A Two-Generation (Two Litters) Reproduction Study with AC 6,601 to Rats", (R.E. Schroeder, Bio/Dynamics Inc., Report 87-3243, June 28, 1990). Malathion, 94\% purity, lot \#AC6015-136, was administered in the diet to groups of $25 \mathrm{male}$ and 25 female rats at dose levels of 0 (vehicle control), 550, 1700, 5000, or $7500 \mathrm{ppm}$ for two generations, two litters per generation. At $7500 \mathrm{ppm}$, matemal gestational and lactation weights were consistently reduced in both litters of both generations, with statistical significance being obtained in the first pregnancy and both lactation periods of the $P-1$ generation. Pup weaning weignts on day 21 post partum were consistently reduced at both 5000 and $7500 \mathrm{ppm}$, reacting statistical significance for all litters at $7500 \mathrm{ppm}$, and the first P-1 and second F-1 litters at $5000 \mathrm{ppm}$. At $7500 \mathrm{ppm}$, the postnatal growth retardation persisted through adulthood, with no indication of catch-up growth. Reproductive parameters were not adversely effected. Developmental $\mathrm{NOEL}=1700 \mathrm{ppm} ;>200 \mathrm{mg} / \mathrm{kg} /$ day. (postnatal growth retardation); Parenta 1 NOEL $=5000 \mathrm{ppm;}>400 \mathrm{mg} / \mathrm{kg} /$ day (reduced body weight); Reproductive HOAEL $=7500 \mathrm{ppm}$ (HDT); > $>00 \mathrm{mg} / \mathrm{kg} / \mathrm{day}$. The study is ACCEPTABLE, and no adverse reproductive health effect is noted (G. Chernoff, $8 / 23 / 90)$.

D. ARE DATA ADEQUATE TO SUPPORT REGISTRATION (if applicable)?
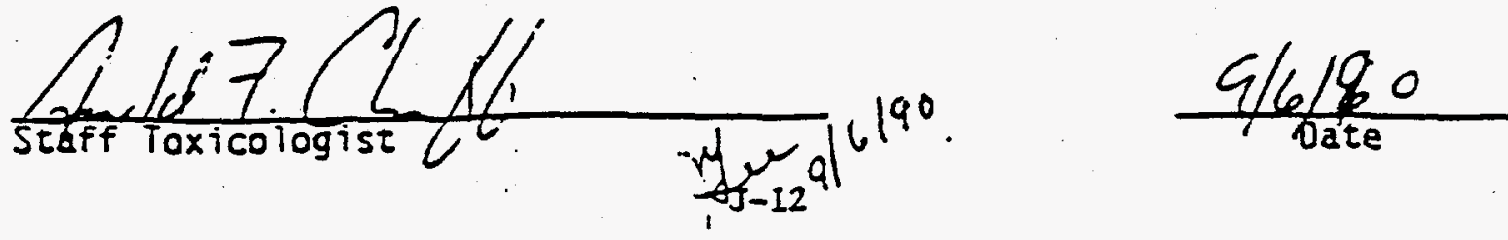
A. AHIMALS, ROUTE OF ADHIMISTRATION, AND' DURATION OF TREATMENT:

Species: Rat

Strain: COBS:CD (Sprague-Dawley derived)

Source of animals: Charles River Labs., Portage, MI

Age at start: 42 days

Route of administration: oral in feed

Vehicle: Purina Rodent Chow "5002

Period of treatment: continuous for 2 generations, 2 i itters/generation Study dates: $7 / 5 / 88-9 / 6 / 89$

8. BACKGROUHD (including relationship of this study to other studies): This is a replacement study submitted for consideration to fill the SE950 data gap for 'Reproduction, Rat'.

c. TREATMENT LEVELS AND GROUP SIZE

\begin{tabular}{|c|c|c|c|c|c|}
\hline & \multicolumn{5}{|c|}{ Malathion Treatmenc Level (PPM) } \\
\hline $\begin{array}{l}P \text { Generation } \\
\text { number of males on study } \\
\text { number of females on study } \\
\text { number of } F-1 \text { a litters } \\
\text { number of } F-1 b \text { litters } \\
F-1 \text { Generation }\end{array}$ & $\begin{array}{l}25 \\
26 \\
24 \\
24\end{array}$ & $\begin{array}{l}25 \\
25 \\
23 \\
22\end{array}$ & $\begin{array}{l}25 \\
26 \\
23 \\
23\end{array}$ & $\begin{array}{l}25 \\
25 \\
24 \\
24\end{array}$ & $\begin{array}{l}25 \\
25 \\
24 \\
22\end{array}$ \\
\hline $\begin{array}{l}\text { number of males on study } \\
\text { number of females on study } \\
\text { number of } F-2 a \text { litters } \\
\text { number of } F-2 b \text { litters }\end{array}$ & $\begin{array}{l}25 \\
25 \\
24 \\
17\end{array}$ & $\begin{array}{l}25 \\
25 \\
25 \\
20\end{array}$ & $\begin{array}{l}25 \\
25 \\
24 \\
17\end{array}$ & $\begin{array}{l}25 \\
25 \\
24 \\
16\end{array}$ & $\begin{array}{l}25 \\
25 \\
25 \\
20\end{array}$ \\
\hline
\end{tabular}

\section{STUDY DESIGN ANO CONDUCT EVALUATION}

A. STUDY PROCEDURES AND REMARKS (e.g., OK, specific parameters; asterisKs denote deficiencies. MA indicates not applicable or no conent).

1. Test article (assay, purity, lot \$, stability): OK; AC 6,601 (malathion); 94.0\%; lot \#AC6015-136.

2. Analysis of dosing aterial (stability, hoogeneity, coupound content): OK; compound content in the food samples over the course of the study averaged 99.6, 100.7, 98.3, and 96.5\% of nominal for the 550, 1700, 5000, and $7500 \mathrm{ppm}$ diets, respectively; homogeneity for the $\$ 50$ and $7500 \mathrm{ppm}$ diets ranged from 563-626 ppm and 6670-8010 ppm; stability at 7 and 14 days in the rat room averaged 102.0 and 94.9\% of nominal for the $550 \mathrm{ppm}$ diet, " and 102.3 and $96.6 \%$ of nominal for the $7500 \mathrm{ppm}$ diet: samples frozen for 7 and 14 days averaged 110.7 and $94.9 \%$, and 104.0 and $94.9 \%$ of nominal for the 550 and $7500 \mathrm{ppm}$ diets, respectively.

3. Anical selection (species, strain, age, sex): OK

4. Animal husbandry (housing, etc): OK; individually housed in suspended caging, except during mating and lactation, in an environmentally controlled room with a 12 hour light cycle; food and tap water available ad lib.

5. Mortality (and intercurrent disease): OK; two control females, two $550 \mathrm{ppm}$ group males, two $1700 \mathrm{ppm}$ females, two $5000 \mathrm{ppm}$ females, and one $7500 \mathrm{ppm}$ female. 
6. Number of animals (start and termination): OK; there were less than 20 litters per treatment group _ in the F-2b generation, however, since there were 2 litters per generation, the minimum number of total litters per dose group exceeded the number required by guidelines.

7. Randomization of animals: OK: computer randomization by weight.

8. Dose level selection (numer of groups and justification): OK; although no justification for the dose selection was provided, decreased parental weights were sufficient evidence for indicating the achievement of a parental MTO.

9. Route of administration (appropriate for test article): OK; in diet.

10. Exposure conditions (schedule and methods): OK; continuous for 2 generations, 2 litters per generation.

11. Controls (negative and positive): OK; negative venicle control.

12. Observations (cageside, body weight, physicals, etc): OK: clinica? observation twice daily; physical examination once weekly; body weights weekly througnout the study plus on gestational days 0,7 , 14, and 20 for dams, and on lactation days $0,4,7,14$, and 21 for pups and dans; food consumption weekly throughout the study plus gestational periods $0-7,7-14$, and 14-20 for dams.

13. Necropsies (required animals, tissues, or parameters): OK; male and female reproductive tissues plus any abnormal tissues for all parental animals; external and internal examinations of pups with detailed examination of one male and one female each, from the F-lo and $F-2 b$ litters.

14. Histopathology (tissues, groups, and number of animals): OK; reproductive plus any abnormal tissues in control and nigh dose animals.

15. Fetal examination: N/A

16. Appropriateness of rethods: OK.

17. Treatment of resuits (data sumarization and statistics): OK.

18. Study report (complete, reflects data, data cited but missing): OK.

19. Consistency (with other studies of this type): OK.

20. Good laboratory practice (internal audits, sign-offs): OK; Q.A. signoffs provioed.

21. Other:

B. ELABORATION OF METHODS OR PROTOCOL DESCRIPTION (if needed):

\section{RESULTS}

A. EFFECTS REPORTED:

1. Malathion Consumbtion During the Course of the Study: The estimated mean $\mathrm{mg} / \mathrm{kg} /$ day consumption of malathion for the pre-mating interval, post-mating intervals in males, and gestational intervals in females is shown in the table below (compiled from data listed on pages $31,34,35,37$, and 42 of the study report).

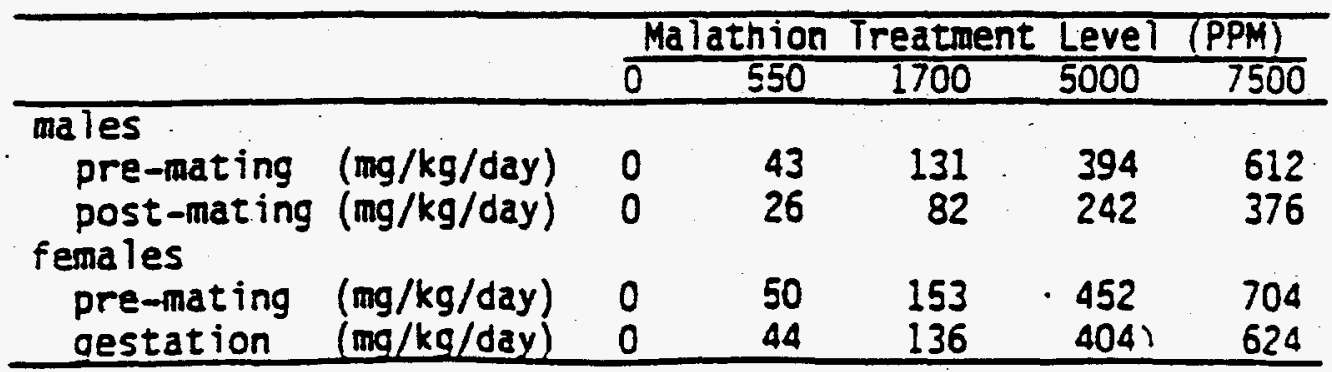


2. Parental Clinical Observations: Unscneduled deaths were limited to nine animals over the course of the study (Table 1 and text pages 26-27 of the Study Report). Seven were females (two each from the control, $1700 \mathrm{ppm}$, and $5000 \mathrm{ppm}$ groups, and one in the $7500 \mathrm{ppm}$ group), and 2 were males (both from the $500 \mathrm{ppm}$ group). None of these deaths were considered to be treatmentrelated. Similarly, there were no treatment-related clinical signs apparent from the data provided in Table 34 of the study report.

3. Parental Male Body Weiahts: Selected mean male body weights, compiled from data listed in Tables 2 to 7 of the Study Report, are shown in the table below. Differences from control values $(\Delta)$, as well as percent difference from control values $(\% \Delta)$ were calculated for the $7500 \mathrm{ppm}$ dose groups. In the P-1 generation, mean body weights of the high dose males were reduced 8 grams from control values following the first week of treatment. This reouction persisted through the pre-mating interval (week.9), post-mating intervals (week 10 to 27), and to termination (week 27). At no point was the decrease statistically significant. In contrast, high dose males from tne $F-1$ generation began the pre-mating interval at week 30 with a significant 27 gram booy weight deficit compared to controls. This oeficit increased to 48 grams by the end of the pre-mating interval (week 40), ano remained at approximately 55. grams through the mating intervals (week 41-57), to termination (week 57 ). $\mathrm{F}-1$ males from the $5000 \mathrm{ppm}$ group showed a similar, but not significant, reduction in body weight over the 30 to 57 week interval.

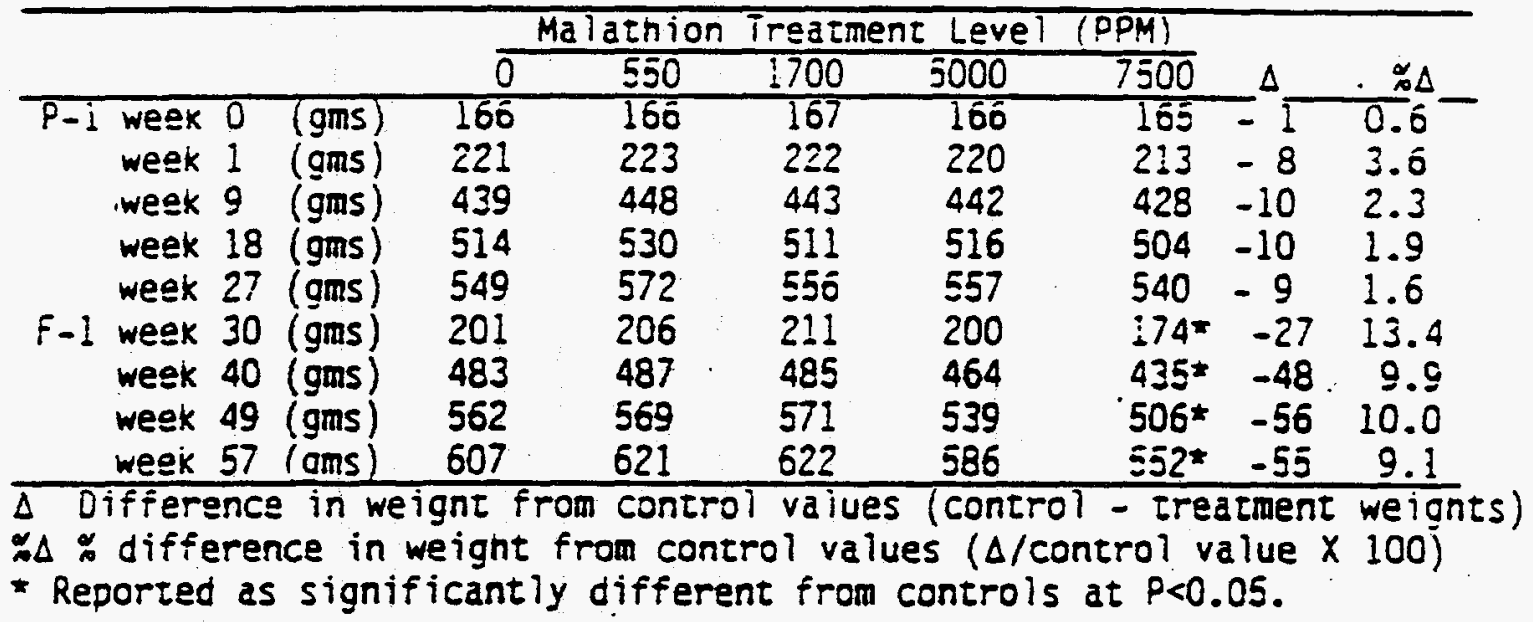

The findings from the P-1 generation suggest that the inhibitory effect of malathion on weight gain occurred shortly after the initiation of treatment. Once this initial decrease occurred, it remained relatively constant at approximately 98\% of control weight, without further reduction or catch-up growth. Food consumption in the first week of treatment was marginally reouced by 3 grams in males from the 7500 dose group (Table 10 of the Study Report). F-1 males differed from $P-1$ males in that they were exposed to malathion from the time of conception. The finding of reduced weight at week 30 indicates that the initial weight reduction in this generation occurred at an earlier point in the study. While the difference in weight increased between week 30 and 40 , from 27 to 48 grams, the percent decrease over the same time interval was reduced slightly from 13.4 to $9.9 \%$ of control values. Unlike the P-1, food consumption in the F-1 males tended to be greater than control values at the majority of the time points measured between week 30 and 57 (Tables 11 and 14 of the study report).

4. Parental Female Body Weights: Selected mean female body weights for the $P_{-}-1$ generation, compiled from data listed in Tables 2, 26, and 33 of the Study Report, are shown in the table below. Differences from control values $(\Delta)$, as well as percent difference from control values $(\approx \Delta)$ were calculated 
for the $7500 \mathrm{ppm}$ dose groups. Similar to the findings with P-1 males, the females demonstrated an early reduction in weight gain that reached 11 grams by week 5 of treatment and then remained relatively constant to the first pregnancy. During the first pregnancy and lactation intervals, maternal weights were significantly reduced compared to controls, with the percent reduction remaining around 7\% of control values. During the second pregnancy and lactation interval, the percent reduction was marginally reduced to approximately $6 \%$ of controls. With the exception of one occasion on day 0 of lactation 2, the difference in absolute weights did not reach statistical significance. Food consumption during the pre-mating period did not exhibit any consistent pattern, but rather, was greater than controls on some weeks, and less in others (Table 11 of the Study Report). During the first pregnancy food consumption was significantly decreased between days 0 and 7 , but returned to control vaiues for the remainder of the first pregnancy, and for the entire second pregnancy (Table 28 of the Study Report). Food. consumption was not monitored during lactation.

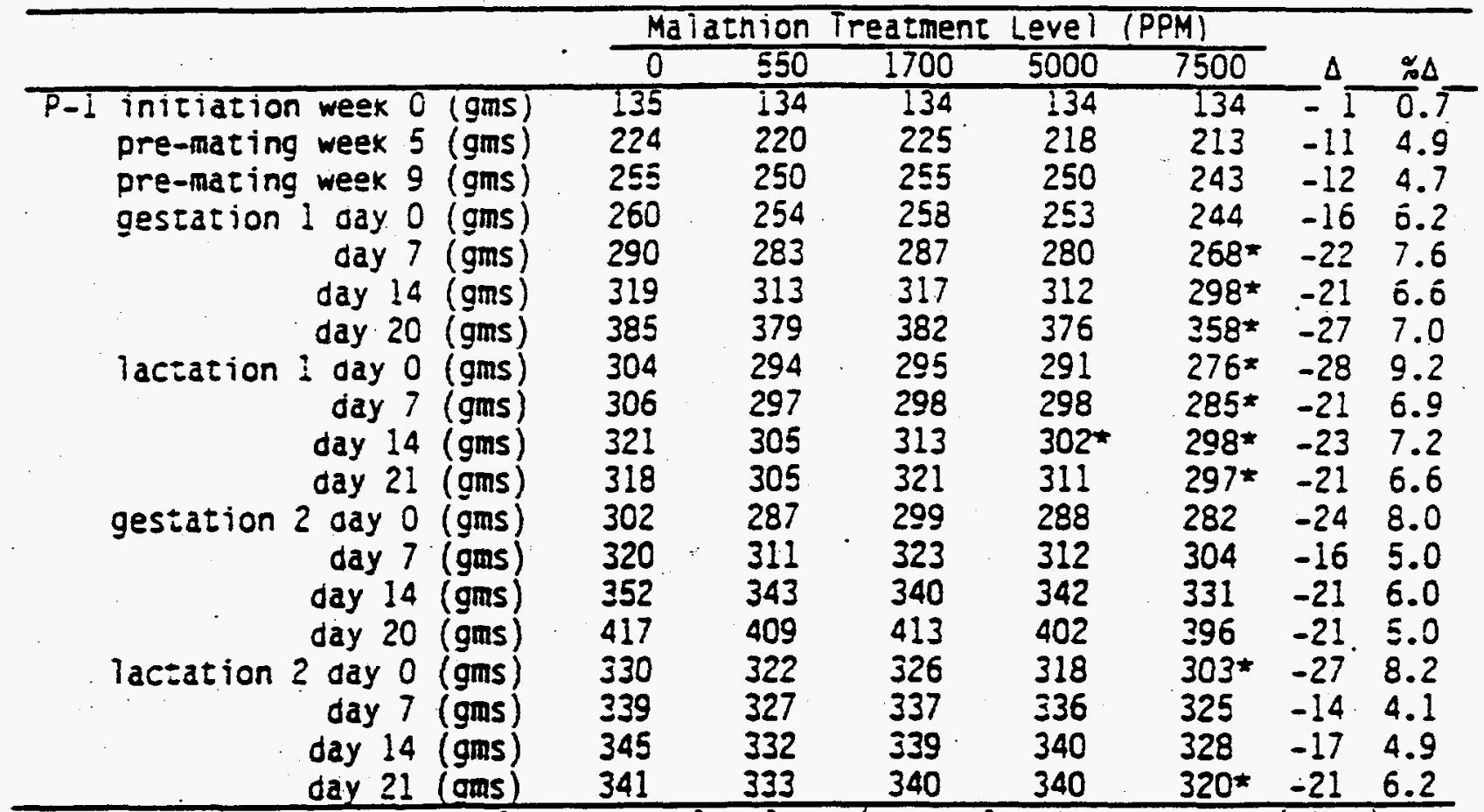

$\Delta$ Difference in weight from control values (control - treacment weights)

$₫ \Delta *$ difference in weight from control values ( $\Delta /$ control value $X 100$ )

* Reported as significantiy different from controls at $P<0.05$.

Selected mean female body weights for the F-1 generation, compiled from data Tisted in Tabies 3, 27, and 33 of the Study Report, are shown in the table below." Differences from control values $(\Delta)$, as well as percent difference from control values ( $\mathrm{x} \Delta$ ) were calculated for the $7500 \mathrm{ppm}$ dose groups. $F-1$ females were exposed to walathion from their conception through the delivery and weaning of 2 litters. At week 30, the initiation of the pre-mating interval, maternal weights were significantly reduced by 16 grams from the control value. This significant reduction in weight remained through to the end of the pre-mating interval in week 40 . Maternal body weights during the first pregnancy and lactation interval, as well as the second pregnancy, were reduced by approximately 5\% compared to controls. During lactation 2, the decrease was reduced to approximately $2 \%$ of the control value. Food consumption during the pre-mating period and 2 pregnancies was equal to, or greater than the control values (Tables 11 and 29 of the Study Report). At $5000 \mathrm{ppm}$, decreases in maternal weight during pre-mating, pregnancies 1 and 2 . and lactation intervals 1 and 2 were not statistically significant. 


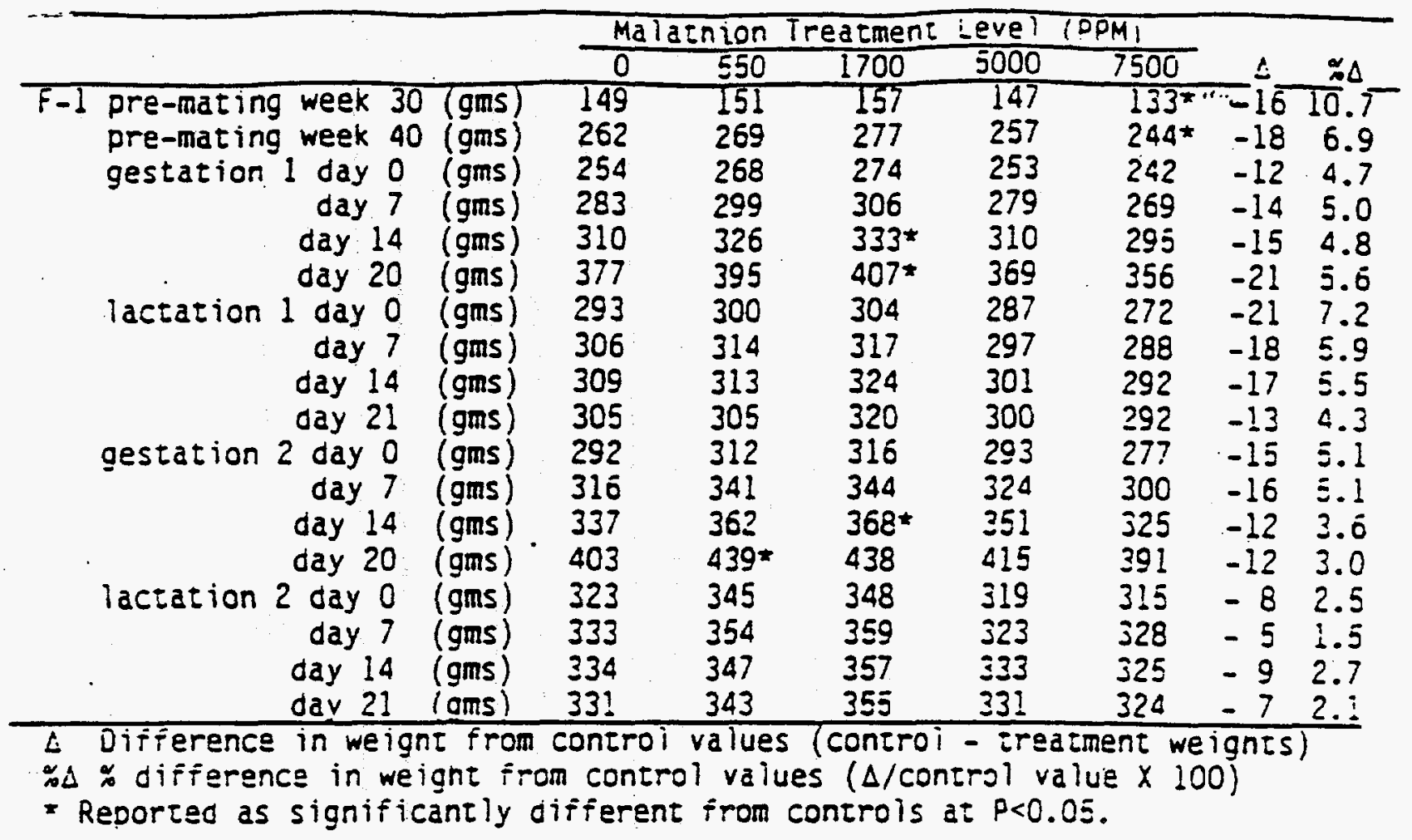

The results reported for the females are consistent with inose odserved in males. Based on these results, it appears that malathion at ocses of 7500 pom can cause a requction in weight, which persists witnout furtner significant reduction or catch-up, for the remaincer of the exposure period. Statistical significance of reduced body weight was reported for $F-1$ females in the premating period, and $P-1$ females ouring pregnancy and lacsasion interval' 1 . The percent decrease from control weights during these periocs exceeded $10 \%$ on one occasion, in pre-mating week 30 for the F-1 generation. For the significant cesrease in weight during gestation and lactation, the percent reduction ranged from 6.6 to 9.2 , with a medium of 7.2 .

5. Reoroductive Parameters: There were no apparant treatment-related effects reported for reproauctive parameters including masing, fertility, and gestation indices, and gestational length (Tables 35 and 36 of the study Report).

6. Mean Litter Size and Survival Indices: Based on the data provided in iable 36, there were no indications of a treatment-related effect on mean litter size. The F-2a total mean litter size at birth was statistically decreased at $5000 \mathrm{ppm}$ compared to the controls, however, since this was an isolated event in the absence of related findings, it was not considerad treatment related. In a similar manner, the observation of a decreased lactation survival index at $7500 \cdots \mathrm{pm}$ in the $\mathrm{F}-1 \mathrm{a}$ litter, and a decreased viability survival index at $5000 \mathrm{ppm}$ in the F-2b litter, were considered isolated events, and not related to the treatment.

7. Mean Puo Weiahts: Selected mean pup body weights, compiled from data listed in Table 37 of the Study Report, are shown in the table below. Differences from control values $(\Delta)$, as well as percent difference from control values $(\% \Delta)$ were calculated for the 5000 and $7500 \mathrm{ppm}$ dose groups. There was a consistent trend in both the 5000 and 7500 ppm groups towards decreased mean weights at weaning on day 21 of lactation. This decrease was statistically significant in each of the $7500 \mathrm{ppm}$ litters, and in F-la and F$2 b$ litters at $5000 \mathrm{ppm}$. At $550 \mathrm{ppm}$ the mean weight of. the F-1b litter was also significantly reduced on day 21 , but since this was an isolated event for this dose group, the finding was not considered treatment related. The same is true for the significant decrease in mean pup weight reported for day 0 in the 7500 ppm F-1b litter. The significant decreases noted in mean pup weights 
on days 7 and 14 in the $5000 \mathrm{ppm}$ F-2b litters also appear to be isolated events. This is based on the absence of significant reductions at these two time points in any of the other litters, including those from the higher 7500 ppm dose group.

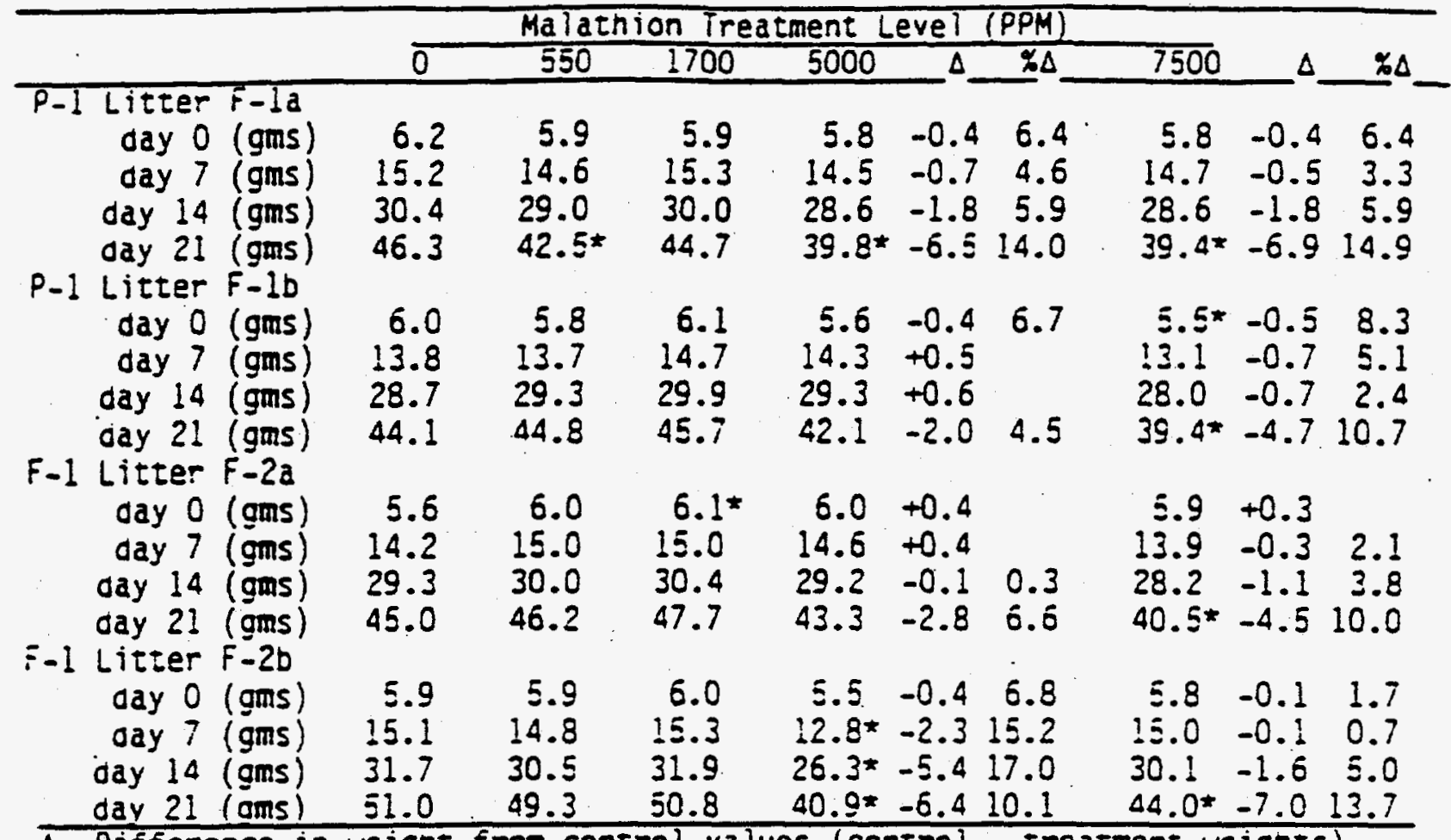

$\Delta$ Difference in weight from control values (control - treatment weignts)

$\approx \Delta *$ difference in weight from control values ( $\Delta$ /control value $X 100$ )

* Redorted as significantly different from controls at $P<0.05$.

These results indicate that continuous exposure to malathion at dose levels greater than 1700 ppm can result in postnatal growth retardation as determined by reduced weaning weights. Since the data provided do not allow for an exact oetermination of the time of onset, it is unclear if the reouced pup weight is the result of prenatal exposure, nutritional deficiencies in the perinatal period, or the direct action of malathion ingestion in the late lactation period. To further elucidate the etiology, a cross fostering study would be required.

8. Postmortem Findings: From the data reported in Appendix $U$ of the Study Report, there were no apparent treacment-related gross necropsy or histological findings observed in the study.

B. NO OBSERYED EFFECT LEVEL (MOEL):

Deve lopmental NOEL $=1700 \mathrm{ppm}$ (> $200 \mathrm{mg} / \mathrm{kg} /$ day)

Parental NOEL $=5000 \mathrm{ppm}(>400 \mathrm{mg} / \mathrm{kg} /$ day $)$

Reproductive KOAEL $=7500 \mathrm{ppm}(>600 \mathrm{mg} / \mathrm{kg} / \mathrm{day})$

\section{DISCUSSION}

A. MAJOR DEFICIENCIES (if present). What are they and can they be corrected with additional information? Be specific: No major deficiencies were noted.

B. OISCUSSION OF RESULTS (if necessary). Were there possible adverse health effects? Are there any recomendations specific to this study?

As snown in the summary table below, reduced weight was a consistent finding following dietary exposures to malathion. The time of onset, degree, and 
persistence of the weight reduction was dependent on the time and level of exposure.

\begin{tabular}{lccccccc}
\hline & \multicolumn{6}{c}{ Malathion Treatment Level } \\
\cline { 2 - 7 } & & 0 & 550 & 1700 & 5000 & 7500 \\
\hline Requced paternal weignt & - & - & - & - & + \\
Reduced maternal weight & - & - & - & - & + \\
Reduced dud weight & - & - & - & + & + \\
\hline
\end{tabular}

When the initial exposure occurred after weaning, as in the $P-1$ generacion, the effect was relatively mild in high dose males, with a greater imoac: during pregnancy and lactation in high dose females. After one week of treatment, there was a 4\% reduction in male body weight which persisted at 24\% of control values until termination after 27 weeks on study. The decreaseo body weignt was not statistically signiticant, and was not accompanied oy a notable reduction in food consumbtion. Females exhibited a similar pattern of decreased weignt through the pre-mating period. Ouring the first pregnancy anc lactation interval, the percent reduction increased from approximately 5 to $7 \%$ of control values, a statistically significant finding. Ouring the second pregnancy and lactation interval, the percent reduction was approximately $6 \%$, a statistically non-significant difference based on mean booy weights. No odvious association between the decreased body weignt and a decrease in fooc consumotion was nozed.

When exposure occurred from the :ime of conception as in the F-i generation, the weignt reouction was first ooserved in the eariy postnatal period, prior to weaning on day 21 post partum. At $7500 \mathrm{ppm}$, mean pup weights were reouceo approximately 5\% through day 14 post partum, and by day 21 were siatistically less than controls (approximately 13\%). This statistically significant decrease in body weignt was permanent, persisting into adulthood. During pregnancy and lactation, maternal mean body weignts increased to contro $i$ levels, and statistical significance was lost. At 5000 ppa, mean pup weignts were also reduced at day 21 , however, statistical significance was only attained in the F-la litter. Unlike the high dose group, the statistically significant weight reduction observed at 5000 ppm on aay 21 did not persis: into adulthood. There was no apparent association of aecreasec jood consumption with the decreased weight.

Mean pup weignt for litters from the $F-1$ matings (7itters $F-2 a$ and $F-2 b$ ) followed the same trend as those from the P-1 matings. At $7500 \mathrm{ppm}$, weignt reduction was approximately $2 \%$ of control througn day 14 , and mean booy weignts were - not statistically different from controls. On day 21, the reduction in weignt increased to approximately 11\%, and the decrease in mean body weight was statistically significant. Pups from the 5000 ppm matings also exnibited decreased weights on day 21 post partum, which reached statistical significance in the F-2b litters.

The exact etiology of the postnatal growth retardation, as measured by reduced weaning weight, could not be determined from the results obtained with the experimental design of the study. However, based on the timing of the intial weignt decrease, between days 14 and 21 of lactation, and the onset of weight reouction following initiation of treatment in the $p-1$ generation, it is reasonable to hypothesize that direct exposure to malathion via the diet was a contributing factor. In spite of the persistent postnatal growth retardation observed at 7500 ppm, no adverse reproductive effects were noted. Based on these findings, the developmental NOEL is set equal to $1700 \mathrm{ppm}$, the parenta] NOEL is set equal to $5000 \mathrm{ppm}$, and the reproductive NOAEL is set equal to 7500 $\mathrm{ppm}$, the high dose tested. 
Control and Eradication

$2895 \mathrm{~N}$. Iarkin, Suite A

Fresno, CA 93727

May 28, 1991

Mr. Gavin Wright

Bureau of Land Management

El Centro Resource Area

333 South Waterman

El Centro, CA. 92243

Dear Mr. Wright:

SUBJECT: Harvester Ant Survey April 22-29, 1991

Pre and post treatment monitoring of harvester ant colonies was conducted as prescribed in attached "Harvester Ant Monitoring" instruction sheet.

Two areas of public land were treated, one on the west side of the Imperial Valley, called "Superstition" and one on the east side called "East Mesa". On the west side, treatment to control beet leafhopper was confined to Township 13S, Range 12E, Sections

$7,8,16,17,18,19,20,21,22,27,28,29,32$ and 33 . Only in Section 21 was the entire section treated (see attached map).

On the east side (East Mesa), the treatment zone on public land comprised portions of Sections 24 and 25 in Township 13S, Range 16E; and portions of Sections 18, 19 and 30 in Township 13S, Range 17E..

Harvester ant colonies in both areas were located by survey on foot. A rough map was drawn to aid the observer in relocating colonies. Flags (wire with orange plastic flags) and flagging tape were used to mark locations.

No attempt was made to assure positive taxonomic identification of the harvester ants at the locations observed, but they appear to be Veromessor pergandei.

Foragers observed were gathering the majority of the seed from plantaco isularis and oligomeris linifolia. They were also observed returning with dead pentatomids and other insects. Foraging started shortly after sunup and ceased by 10:45 PDT.

Colonies outside the treatment areas were also located and monitored as control, live on the west side (Superstition) and five on the east side (East Mesa).

Measurements to colonies from road or between colonies are estimates. Measurements in miles on access roads are from the odometer of a 1990 chevrolet Blazer $4 \times 4$ and will vary from vehicle to vehicle. 
Mr. Gavin Wright

Page 2

May 28, 1991

This synopsis will address, first, the west side (Superstition) then the east side (East Mesa).

\section{SUPERSTITION:}

The monitoring sites related in the spray area are along the power Iine road that bisects the treatment area (see map). Mileage measurements begin at the south end of the area at a point where the extension of Andre Road intersects with the large power line in the NEI/4 of Section 28 (T13S R12E). All mileage is northwest from this point:

\section{Site 11 site $=1$ is at 9 mile}

This is a large, strong colony first monitored at 09:30 on 4/22/91 The foraging trail led to the north. Pre treatment count on the trail was 302 ants in a 5-minute period, or 60.4 ants per minute passing through ar approximately $4^{\prime \prime}$ space selected by the observer.

Treatment occursed on $4 / 23 / 91$. Post treatment observations of the colony occursed on $4 / 24 / 91 ; 4 / 25 / 91$ and $4 / 27 / 91$.

on 4/24/91, numerous dead ants were observed inside entrance. One lone ant was observed outside the colony. No foraging was observed on 4/25/91, no sign of activity was observed. On 4/27/91, no sign. of activity was observed.

\section{Site $\$ 2$ mile}

Site " 2 is a large colony foraging to the SE. The trail was about 6-10: wide. A pre treatment count of 390 ants, 78 per minute, were observed passing through a $4^{\prime \prime}$ section of trail in a 5-minute period" on $4722 / 91$.

Treatment occurzed on 4/23/91. Post treatment observations on $4 / 24 /$ found numerous dead ants inside entrance; five ants were observed. milling around on the mound and appeared to be very defensive. Foraging counts were zero. Observations on $4 / 25 / 91$ and $4 / 27 / 91$ founc no ants visible.

\section{Site $\$ 3 \quad 1.3$ mile}

Site $\$ 3$ is beyond site $\$ 2$ to the west. Pre treatment monitoring on 4/22/91, found a count of 151 ants per 5-minute or 30.2 ants per minute passing a 4" wide section of trail. Tbis is a small colony foraging west, down into a wash. 
Mr. Gavin Wright

Page 3

May 28,1991

Treatment occurzed on 4/23/91. Post treatment observations on $4 / 24 / 91,4 / 25 / 91$ and $4 / 27 / 91$ found no activity.

\section{Site $\$ 4 \quad 1.3$ mile}

Site $\# 4$ is west of sites $\# 2$ and $\# 3$. Pre treatment monitoring occurr on $4 / 22 / 91$. The pre treatment count was 230 ants per 5-minute or 86 per minute moving past a 4" wide point on the trail to the south.

Treatment occurred on 4/23/91. Post treatment monitoring on 4/24/91 found about 35 ants moving around a secondary entrance; no count or trail. Observations on 4/25/91, found two more entrances opered wit 25-30 ants at two openings and 10-12 ants at a third opening. High wind seemed to be keeping them from foraging; no count on trail. observations on 4/27/91, discovered a foraging trail to the southeast. The count on the trail was 59 ants in 5-minutes or 11.8 ants per minute.

\section{Site $\$ 5 \quad 1.7$ mile}

The colony at site $\# 5$ is of medium. size. The pre treatment monitori was conducted on $4 / 24 / 91$. The ants began forming a foraging trail a: 06:20. A count of 83 ants moving past a $4^{\prime \prime}$ section of trail in a 5-minute ( 16.6 per minute) period was observed.

This colony displayed an extremely sensitive behavior. The slightes: movement or vibration brought on a defensive behavior rippling throus the entire trail of foragers.

Treatment occurzed on 4/24/91. Post treatment observations were conducted on $4 / 25 / 91$ and $4 / 27 / 91$. On $4 / 25 / 91,6-8$ ants were visible inside opening; an ant was carrying a dead ant. They appeared to be reluctant to come out into the wind. No count was taken.

on 4/27/91, no count was taken; ants were out miliing around.' They were extremely sensitive and activity rapidiy decreased after being disturbed.

\section{Site 1.7 mile}

Pre spray monitoring was conducted on $4 / 24 / 91$. The colony at site $\# 6$ is $\mathrm{NE}$ of site $\# 5$. It is a large colony with a well defined trail to the NW by 07:00. The count was 202 ants per 5-minute or 40.4 ants per minute past a $4^{\prime \prime}$ wide point on the foraging trail. 
Mr. Gavin Wright

Page 4

May 28, 1991

Treatment occurred on $4 / 24 / 91$. Post treatment monitoring occurred, on $4 / 25 / 91$ and $4 / 27 / 91$. On $4 / 25 / 91$, the count was zero with only one ant observed. On $4 / 27 / 91$, the count was still zero.

\section{site 27 mile}

The pre treatment monitoring of site $\# 7$ was conducted on $4 / 22 / 91$ at 12:00. Ant activity had ceased for the day, thus the pre treatmen: count was zero. Several ants were, however, visible at the openins

rreatment on Site $\# 7$ occurred on $4 / 23 / 91$. Post treatment observations conducted on $4 / 24 / 91$, found one ant walking around. on $4 / 27 / 91$, Site $\# 7$ was observed and no ant activity was found.

Control (Superstition)

Site Ac-8 (Control) 4.5 mile

Site $f C-8$ is one of the control sites that receives no treatment. This and the following four sites are nearly a mile or more north the treatment zone.

Pre treatment monitoring occurred on $4 / 23 / 91$. This is a small color using a secondary entrance with a foraging trail to the SE. The count was 177 in 5-minute or 35.4 ants per minute.

Treatment occurred in the treatment zone south of the site on $4 / 23 /$ and $4 / 24 / 91$. Post treatment observations were conducted on $4 / 24 / 91$. and $4 / 27 / 91$.

On $4 / 24 / 91$, the ants were still using the secondary opening. The trail led to the east. The count of ants passing a point $4^{\prime \prime}$ wide of the trail was 291 in 5 -minutes or 58.2 ants per minute.

on $4 / 27 / 91$, site \#C-8 was observed for the third time. Activity was normal with the foraging trail heading east. The count was 109 per 5-minute or 21.8 per minute.

Site $A C-9$ (Control) 4.5 mile

Site \#C-9 is west of \#C-8. It is a small colony with a foraging trail to the NW. Pre treatment monitoring was conducted on $4 / 23 / 91$. The count was 55 per 5-minute or 11 ants per minute. 
Mr. Gavin Wright

Page 5

May 28, 1991

Treatment occurred on $4 / 23 / 91$ and $4 / 24 / 91$, with the nearest application over one mile to the south.

Post treatment observation occurred on $4 / 25 / 91$ and $4 / 27 / 91$. on 4/25/91, $100+$ ants were observed milling around the secondary entrance. There were bigh winds, no trail had formed and no count was made; on 4/27/91, a count of 161 ants per 5-minutes ( 32.2 per minute) was recorded.

\section{Site fC-10 (Control) 4.5 mile}

Site $\#-10$ is east of the pole Iine. Site \#C-10 is a large colony foraging to NW toward the road. The pre treatment count was 222 per 5-minutes of 44.4 per misute.

Treatment occurred on $4 / 23 / 91$ and $4 / 24 / 91$ over one mile to the south. post treatment observations were conducted on $4 / 25 / 91$ and $4 / 27 / 91$. on $4 / 25 / 91$, no count was made because of $25+m p h$ wind. We observed $50+$ ants milling around using a secondary entrance. on $4 / 27 / 91$, a good foraging trail was established and a count of 124 ants per 5-minutes was recorded (24.8 ants per minute) passing a $4^{\prime \prime}$ section of trail.

\section{Site 1 - 11 . (Control) $4.5 \mathrm{mile}$}

Site $\# C-I I$ is NE of $\# C-10$. It is a large colony with a large tzail ranning NW is the wash. Pre treatment monitoring occurred on $4 / 23 / 91$ The count was 230 ants per 5 -minutes (46 per minute) passing a $4^{\prime \prime}$ section of trail.

Treatment occurzed over one mile south on $4 / 23 / 91$ and $4 / 24 / 91$. Post treatment monitoring on 4/25/91, found a foraging trail in $25+m p h$ wind. The count was 68 ants in 5-minutes ( 13 per minute). The post treatment count on 4/27/91, yielded 23 ants per 5-minute period ( 4.6 ants per minute).

site fc-12 (Control) 5.5 mile

Site $\#$ C-12 is a large colony with a foraging trail heading NW into a wash. A pre treatment count of 211 ants per 5-minutes $(42.2$ ants per minute) was taken on $4 / 23 / 91$.

Treatment occurred on $4 / 23 / 91$ and $4 / 24 / 91$ over two miles to the south. 
Mr. Gavis Wright

Page 6

MaY 28, 1991

Post treatment monitoring was conducted on $4 / 25 / 91$ and $4 / 27 / 91$. The count on $4 / 25 / 91$ was 205 ants per 5 -minute period ( 41.8 ants $p$ minute) on trail to the east in $25+m p h$ wind.

on $4 / 27 / 91$, the count recorded was 48 ants per 5-minute period ( 9.6 ants per minute). Foraging was divided into two main trails to the west.

\section{EAST MESA}

We bad a difficult time locating viable colonies within the area scheduled to be treated. All colonies found were small, probably on: a year or so old. There was evidence of large, older colonies, but they were no longer active.

All mileage measurements were from the "Y" in the access road at the south edge of Section 19 in Township 13S, Range 17E (see map). The colonies in the treatment area (East Mesa 1-5) are in the SwI/4 of section 19 ; 0.5 mile west of "y" in the access road.

The colonies outside the treatment area (Control "Cl-c5) are $1.5 \mathrm{mile}$ SW of the "Y" in the access road, one mile outside the treatment are in Township 13S, Range 16E, Section 25.

All colonies in East Mesa were monitored twice, one pre treatment and one post treatment.

\section{Site $0.5 \mathrm{mile}$}

Site. 1 is on the soutb side, about 30 yards off the road. This is a-small colony with two foraging trails, one to the south and onf to the north. Pre treatment count taken on 4/25/91, recorded 189 ants per 5-minutes ( 37.8 per minute) on the north trail.

Treatment occurred on 4/26/91. Post treatment observations found ants milling around entrance. Four ants were found two feet from entrance mound dying. No trail had formed and a count of zero was recorded.

\section{site $\# 2 \quad 0.5$ mile}

Site \#2 is a small colony north of the road with foraging trail to the north. Pre treatment count was 70 ants per 5-minute interval (14 ants per minute). 
Mr. Gavin Wright

Page 7

May 28, 1991

Treatment occurred on $4 / 26 / 91$. Post treatment monitoring found the trail north was active. six ants were observed dying after being ou foraging. The count on the trail was 49 ants per 5-minutes (9.8 per minute).

Several colonies nearby were active.

Site $\$ 3 \quad 0.5$ mile

Site $\# 3$ is a small colony north and east of site $\# 2$. Pre treatment count was 137 ants per 5-minutes (27.4 per minute).

Treatment occurred on 4/26/91. Post treatment monitoring on $4 / 27 / 91$, found 4 ants dead on the mound. Foragers had formed a trail and a count of 96 ants per 5-minutes (19.2 ants per minute) was recorded.

Site 14 mile

Site $\# 4$ is a very small colony with a foraging trail to the north. Pre treatment count recorded 85 ants passing a point on the trail per 5-minute interval ( 17 ants per minute).

Treatment occurred on 4/26/91. Post treatment observations found returning foragers apparently showing ill effects of treatment. The count recorded on the trail was 27 ants per 5 -minutes $(5.4$ ants per minute).

Site $\neq 5$ o.5 mile

site $\# 5$ is a small colony with a trail to the noth and a smaller trail to the soutb. A wind of $20+m p h$ was blowing ants around. Pre treatment count of foragers on the trail to the north was 43 ants per 5-minutes ( 8.6 ants per minute).

Treatment occurzed on $4 / 26 / 91$. Post treatment coust was zero. ants foraging. There was light activity around the mound. Twelve to fifteen ants moved out one to two feet from the mound.

Control (East Hesa)

The control area for East Mesa is.in T13S, 1.5 miles southwest of the "Y" intersection of the south edge of section 19. The closest treatment to the control area was one mile to the northeast in Sections 19 and 30 (see map). 
Mr. Gavin Wright

Page 8

May 28, 1991

\section{Site $f C-1$ (Control) 1.5 mile}

Site $\# C-I$ is a small colony not forming a definitive trail. Ants moved out using a fan foraging strategy to the south. The pre tre ment count on $4 / 25 / 91$, recorded 90 ants per 5-minutes (18 ants per minute) passing a point at the most dense area of the far.

Treatment occursed one mile norbheast on $4 / 26 / 91$. Post treatment. observation on 4/27/91 recorded a count of 86 ( 17.2 ants per minut. at the most dense point in the fan shape foraging colun.

\section{Site $\#$ C-2 (Control) 1.5 mile}

Site \#C-2 is a small colony with a foraging trail to the west. Ih pre treatment count on $4 / 25 / 91$, was 96 ants per 5-minutes (19.2 an per minute).

Treatment of the area occurred one mile northeast on $4 / 26 / 91$. The post treatment monitoring count was 74 ants per 5-minute period (14.8 ants per minute) on the trail to the southeast.

\section{Site $\mathrm{AC}-3$ (Control) $1.5 \mathrm{mile}$}

Site \#C-3 is a small colony foraging to the northeast. Count on the trail was 207 ants in a 5-minute period (41.4 ants per minute) on $4 / 25 / 91$.

Treatment occurred on $4 / 26 / 91$ ane mile to the northeast.

The post treatment count on the trail to the north east on $4 / 27 / 91$, was 111 ants per 5-minutes (22.2 ants per minute).

\section{Site}

Site $\# C-4$ is a small colony along side the road with a trail to the east. The pre treatment count on the trail was 83 ants in a 5-minute period ( 16.6 ants per minute) on $4 / 25 / 91$.

mreatment occurred one mile to the northeast on $4 / 26 / 91$.

Post treatment observations found three trails, one to the east, west and south on 4/27/91. The count on the east trail was 75 ants in a 5-minute period ( 15 ants per minute). 
Mr. Gavin Wrighe

Page 9

May 28, 1991

\section{Sire \#C-5 (Control)}

Site \#C-5 is a small colony. The pre treatment monicoring found three trails too, one west, one east and one to the south. The count was taken on the east. The count on $4 / 25 / 91$ was 56 ancs per 5-minutes ( 11.2 ants per minute).

Treatment occurred on $4 / 26 / 91$ one mile to the nortieast. The post ereacment coune found 185 ants per 5-minutes ( 37 ants per minute) on a trail to the southwest on $4 / 27 / 91$. Another smaller trail meandered to the east.

On May 21, 1991, four of the harvester ant colonies in the Superstition (west side) area, Site \#'s 1, 2, 3 and 4 were observed to see how they were doing. Only the first four sites, which had been treated on April 23 , 1991, were observed.

S1te \#1 - The colony had moved its entrance about four feet to the southeast. The entrance is well established compared with the old entrance. Colony strength looks good. The ants had established a strong foraging trail.

The biggest change appears to be a decrease in the apparent number of major workers. Prior to ereacment, there was approximately 30 z majors (no actual counts were made). After treatment, there are only about 5 major workers on the trail.

When we were conducting the pre and post ereatment monitoring, we tried to be careful not to disturb the mounds or entrance or even step on the trail.

When observed on 5/21/91, it was noted there were lots of footprints (human, on and around the old mound). Perhaps that is why they opened a new entrance to the southeast.

Stee $\# 2$ - No harvester ant activity could be found within 50 feet of the original entrance. Again, footprints were near and on the mound.

Site \#3 - The colony has not moved fis entrance. Colony strength appears not to have dirlnished, except for the apparent reduction in the percencage of major workers as in site \#1.

At Site \#3, there are footprints evergwhere; someone also drove a vehicle out pasc size \#3 and on to site \#4. 
Mr. Gavin Wright

Page 10

May 28, 1991

Site 4 - The colony moved its entrance a couple of feet; otherwise it appears to be quite strong. By our estimates, as strong as wher first observed prior to treatment in the area. The small percentag of major workers is similar to sites $\# I$ and $\# 3$.

Because of time constraints, none of the other sites were observed th date; however, numerous other strong colonies were obsezved to be healthy and foraging.

There is no doubt that a treatment with malathion affected the coloni of harvester ants. There was mortality among the workers who were foraging when treatment occurred. It is also apparent that most of t. colonies have the ability to rapidly recover. From our limited observation, it is clear each colony reacts differently to the distur ance: some close off the entrance and shut down activity for several. days, others move their entrance, and yet others proceed with business usual after a very short period of time. In fact, as observed, some. colonies were out the following day.

sincereiy,

Robert I. Peterson

Entomologist-Project Leader

Curly Top virus Control Program

(209) $445-5472$

Enclosures

cc Imperial County Department of Agriculture Feblman 
0.9 mllos north of Intersection of pole lline and AMDRE Rood.

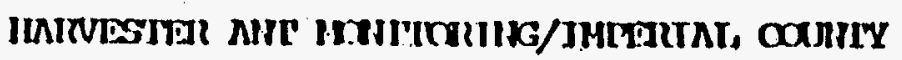

SUPERSIIIIIOIIHESSISI do

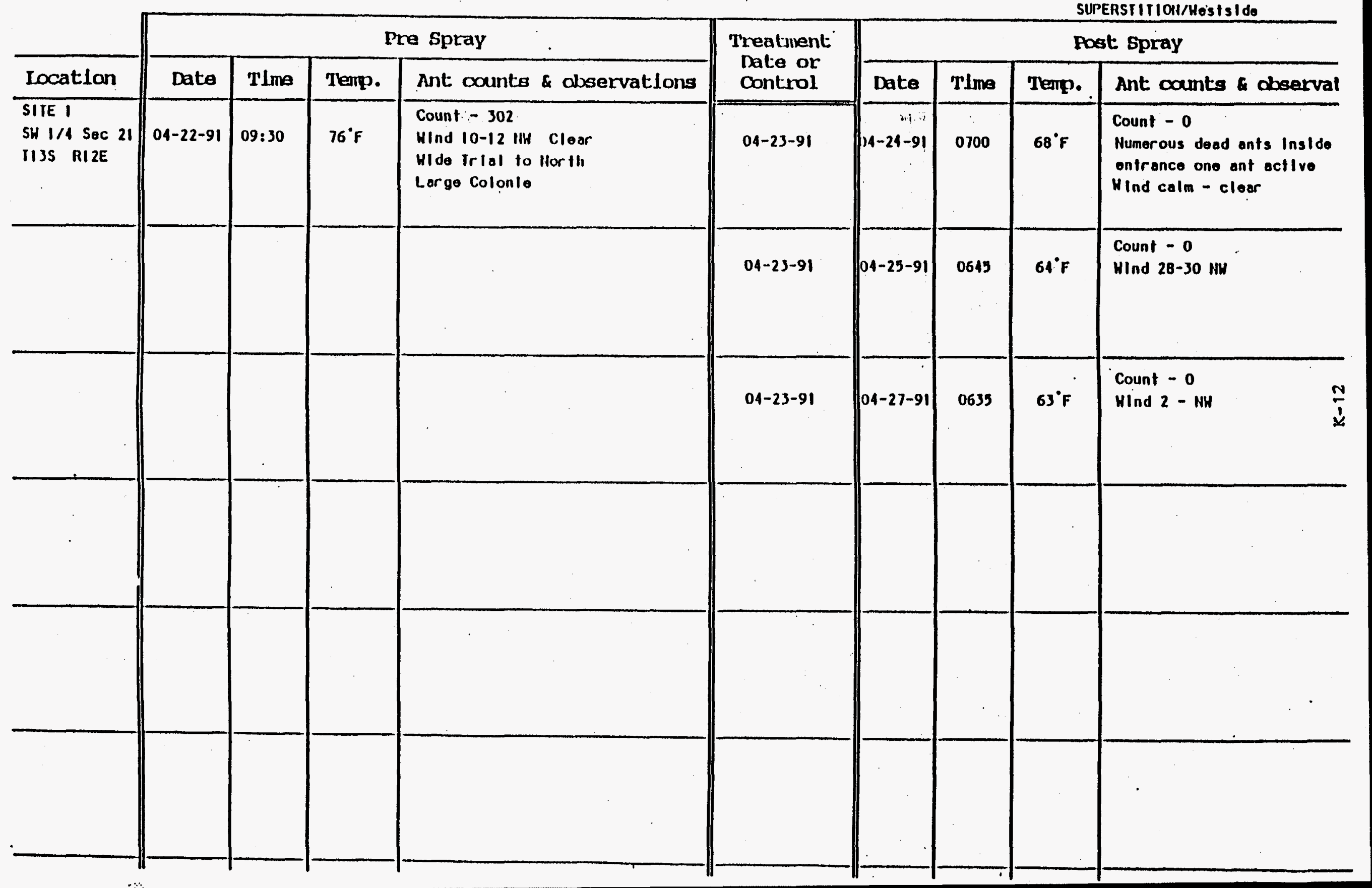


1.3 mllo" north of polo line and ARDRE Rood.

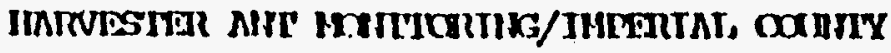

SUPERSIITIOH/WOStSI do

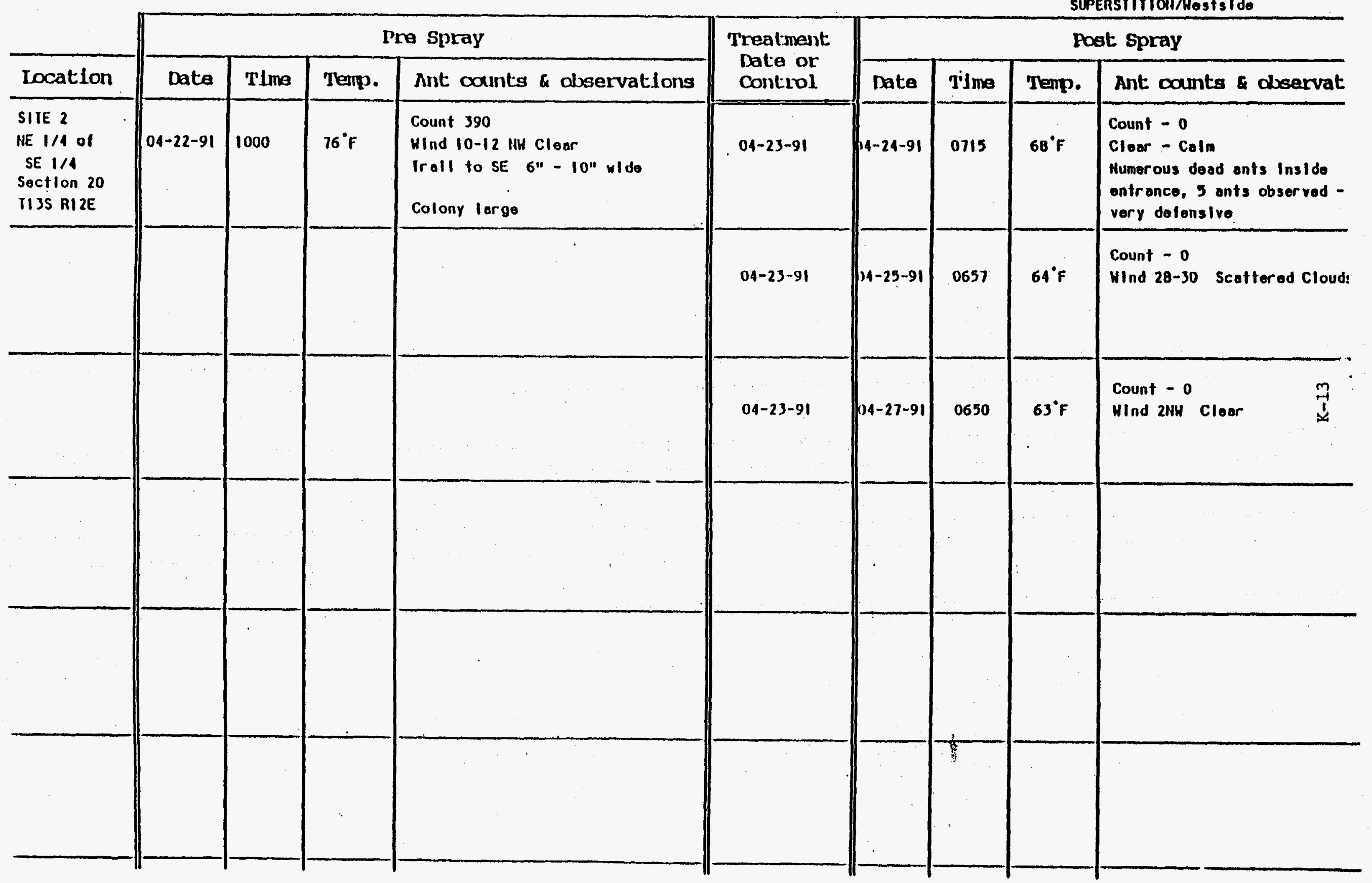


SUPERSTITIOH/Hes IsI do

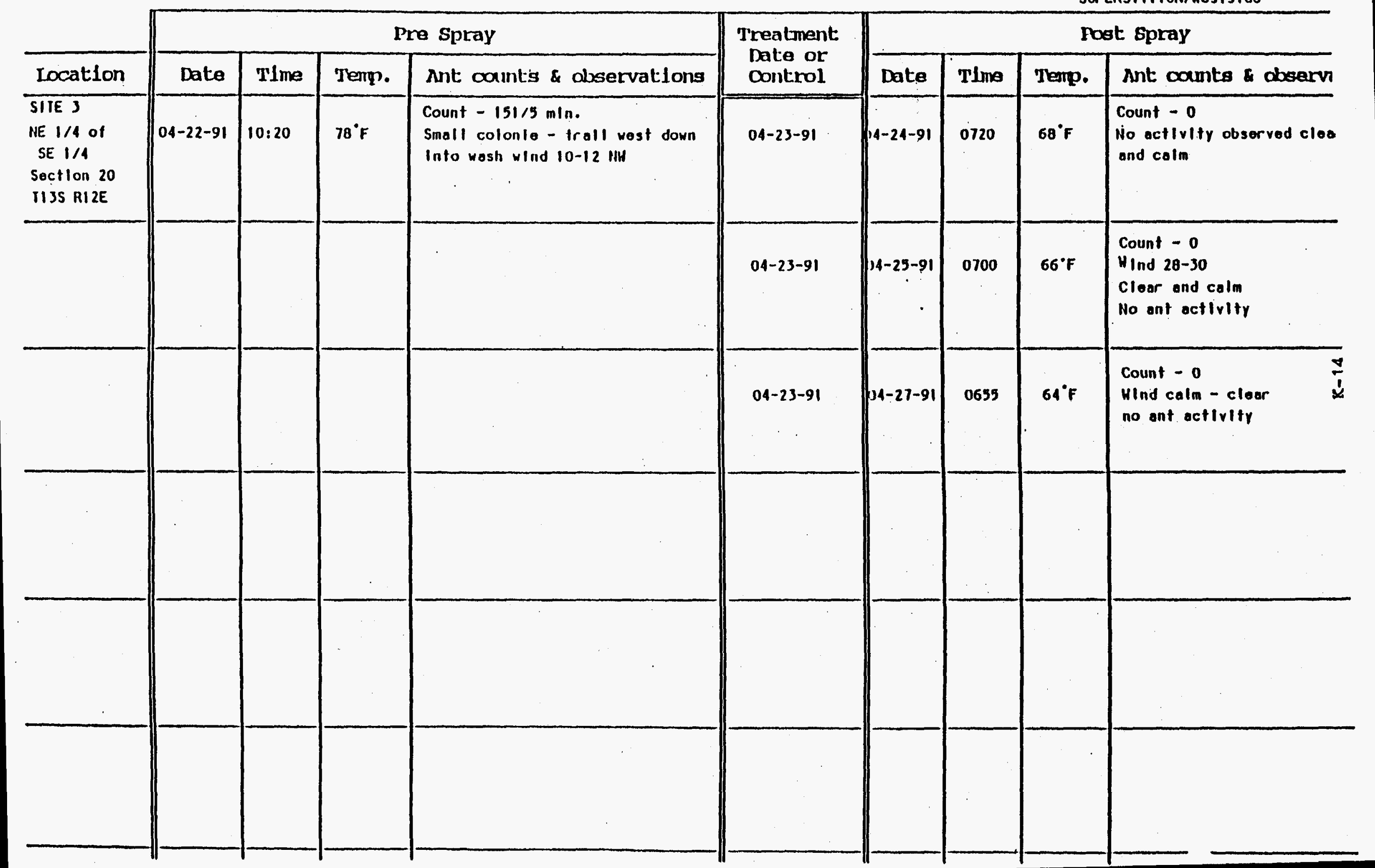




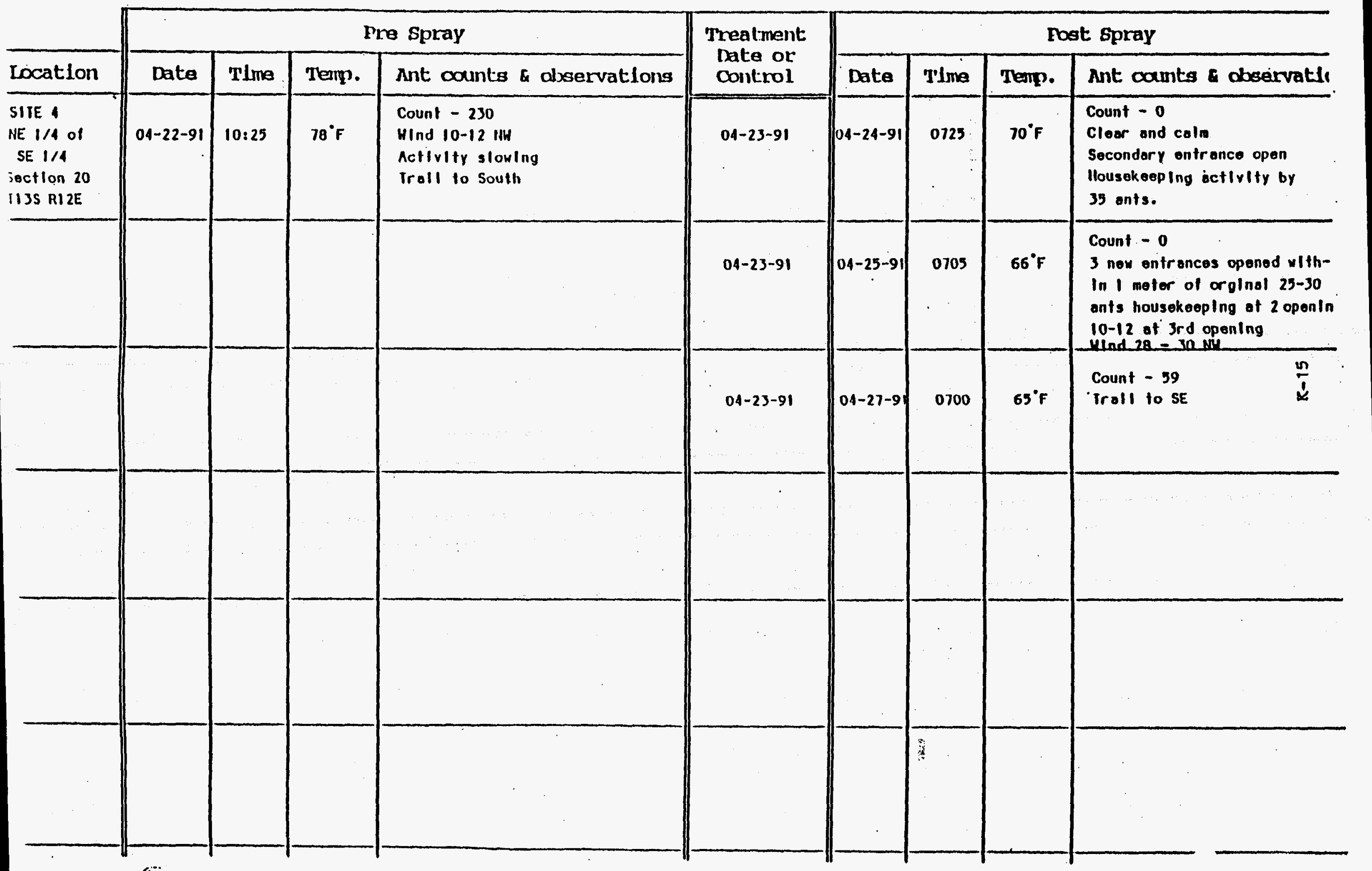


1.7 miles north of Intersection of pole lline and ANDRE Road.

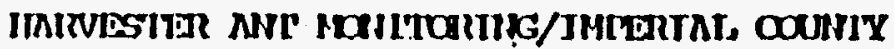

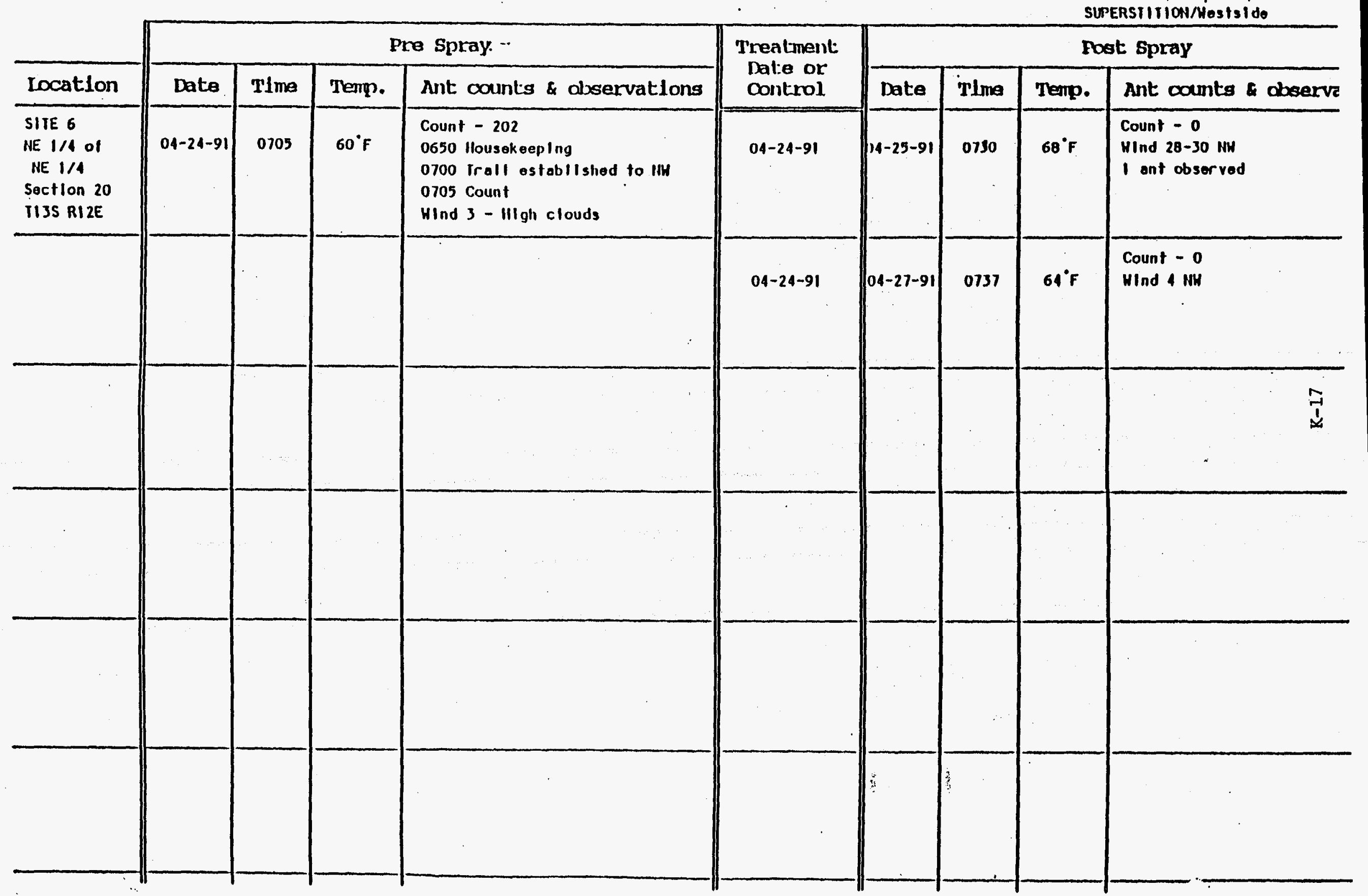




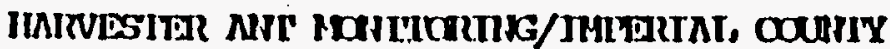

SUPERSIIIIOWI/Hostsido

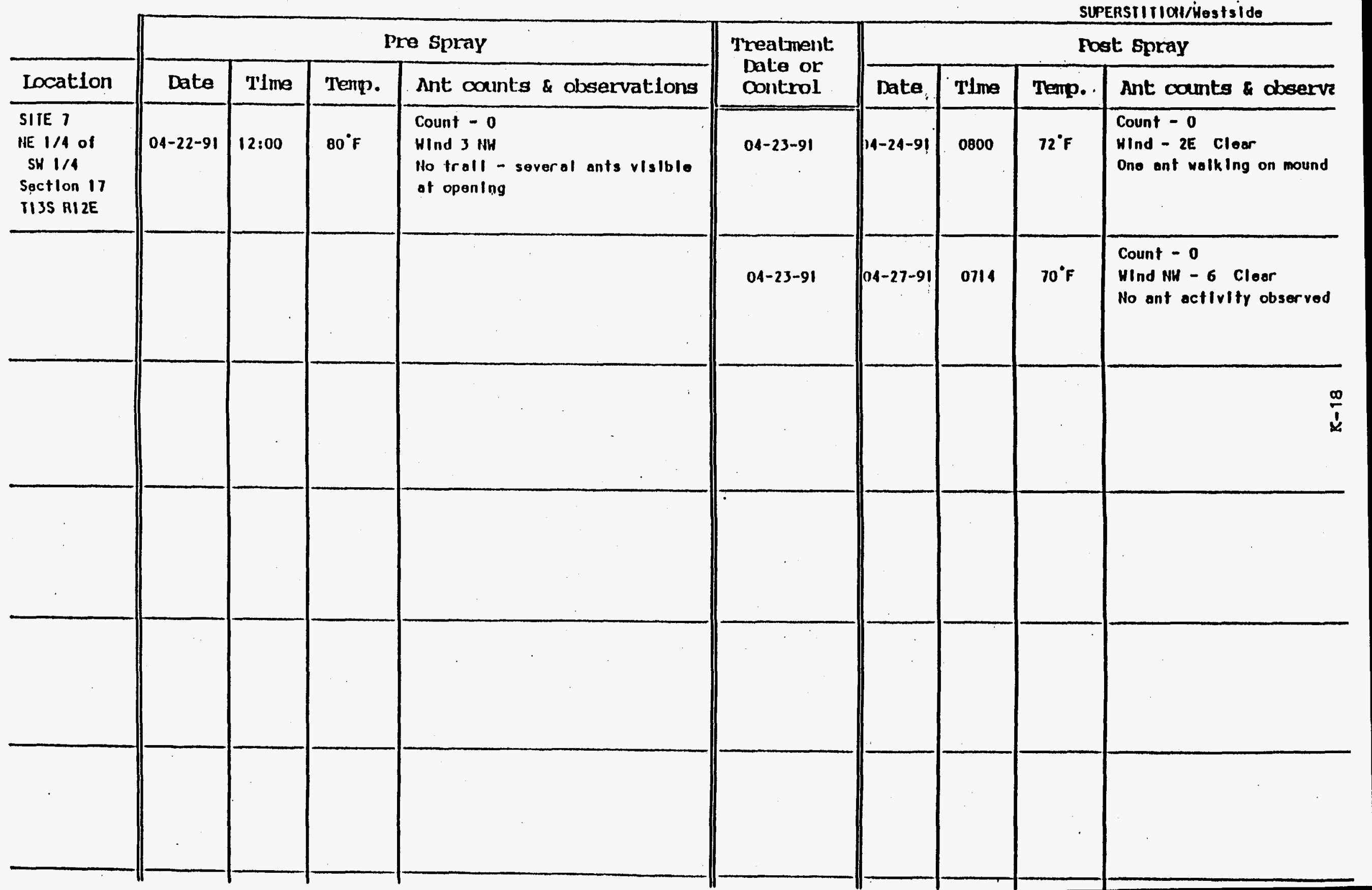


1.5 milles north of Intersectlon pole line and ANDRE Rood.

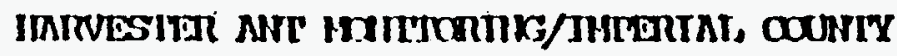

CONIRA.

SUPERSTITIOIIHOSts/do

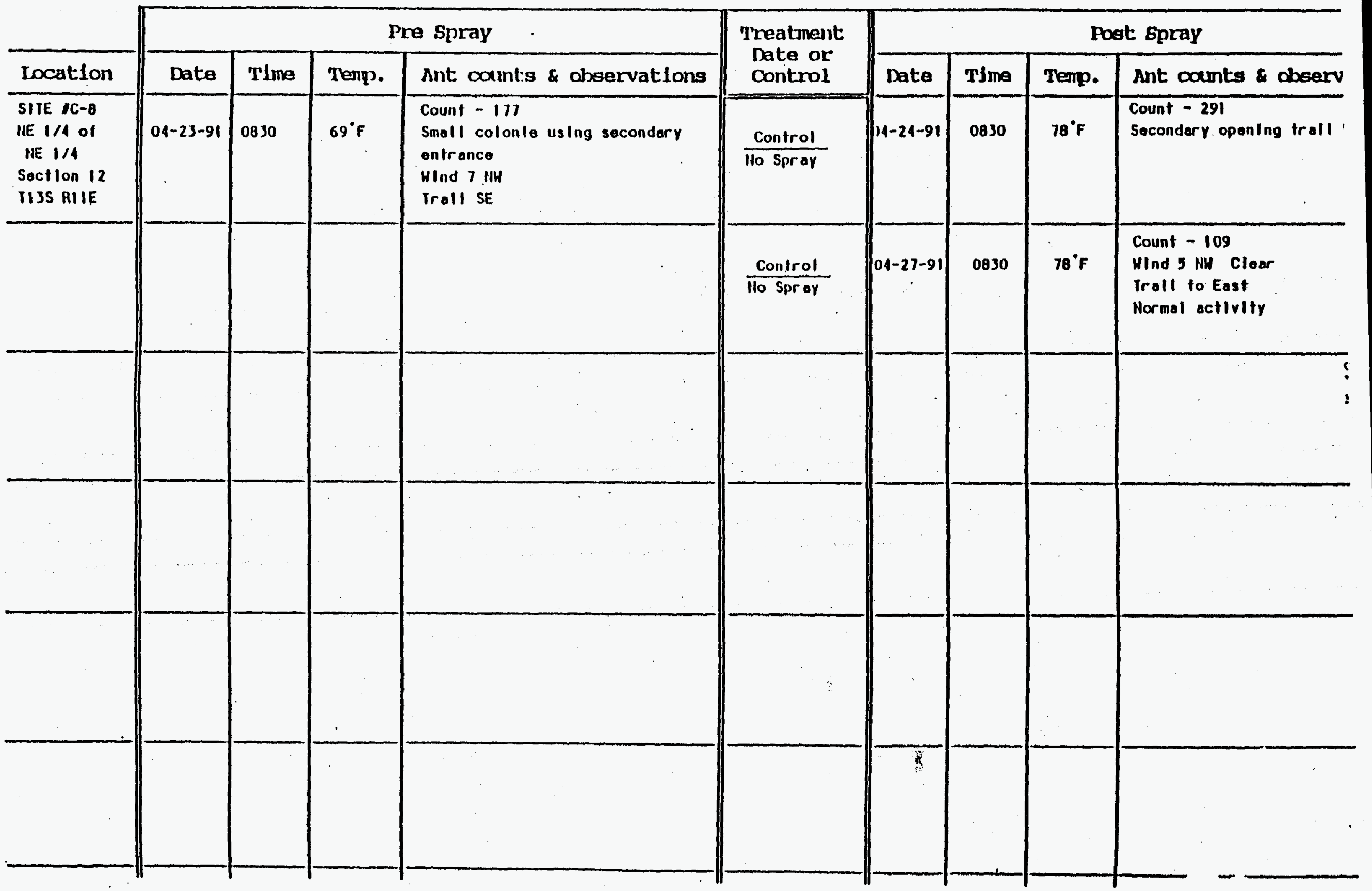


SUPERSTITIOW/HOSTSI do

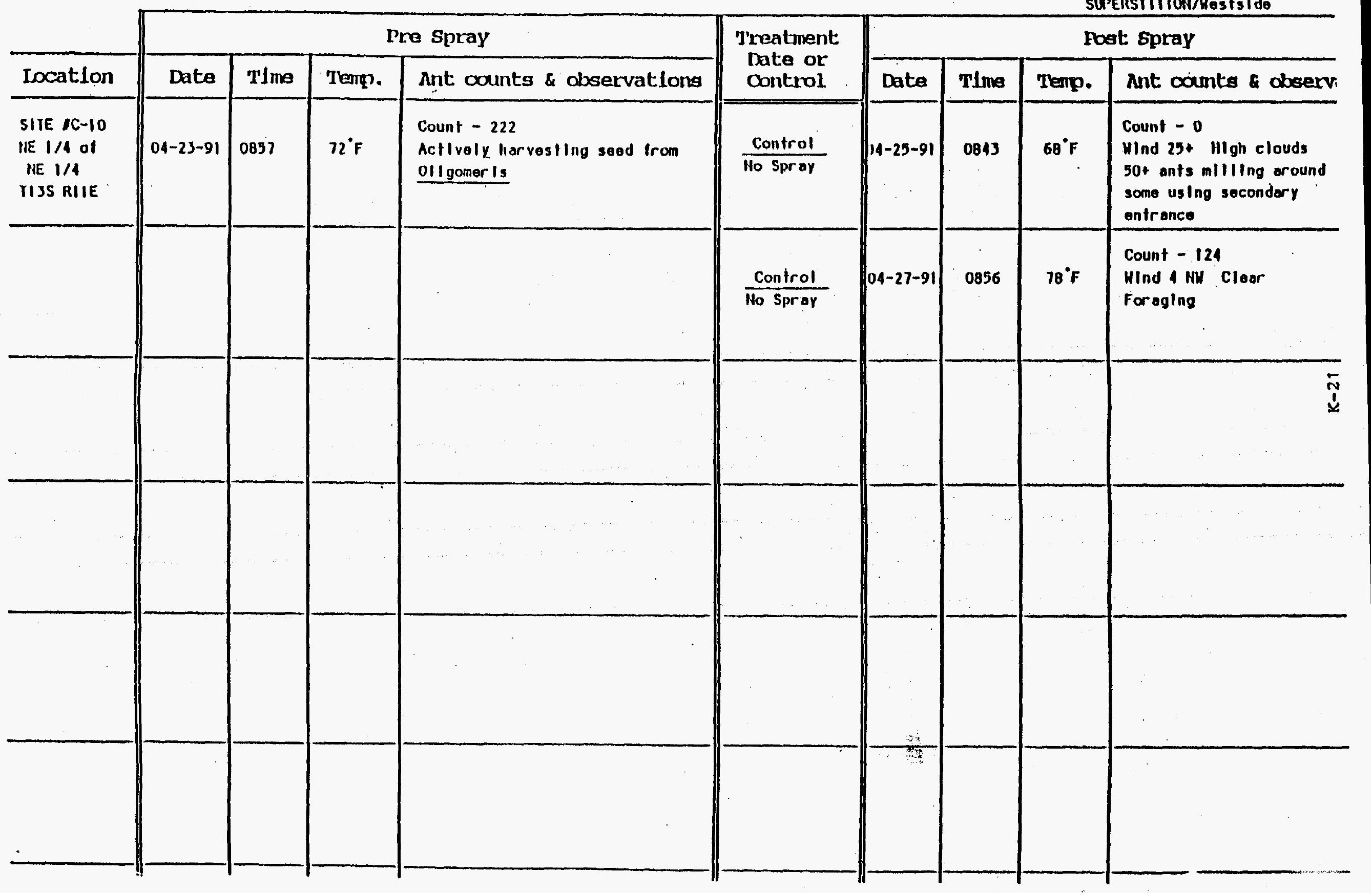




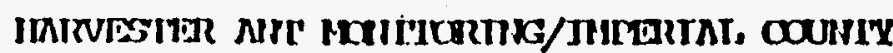

SUPERSTITION/HES I'sI do.

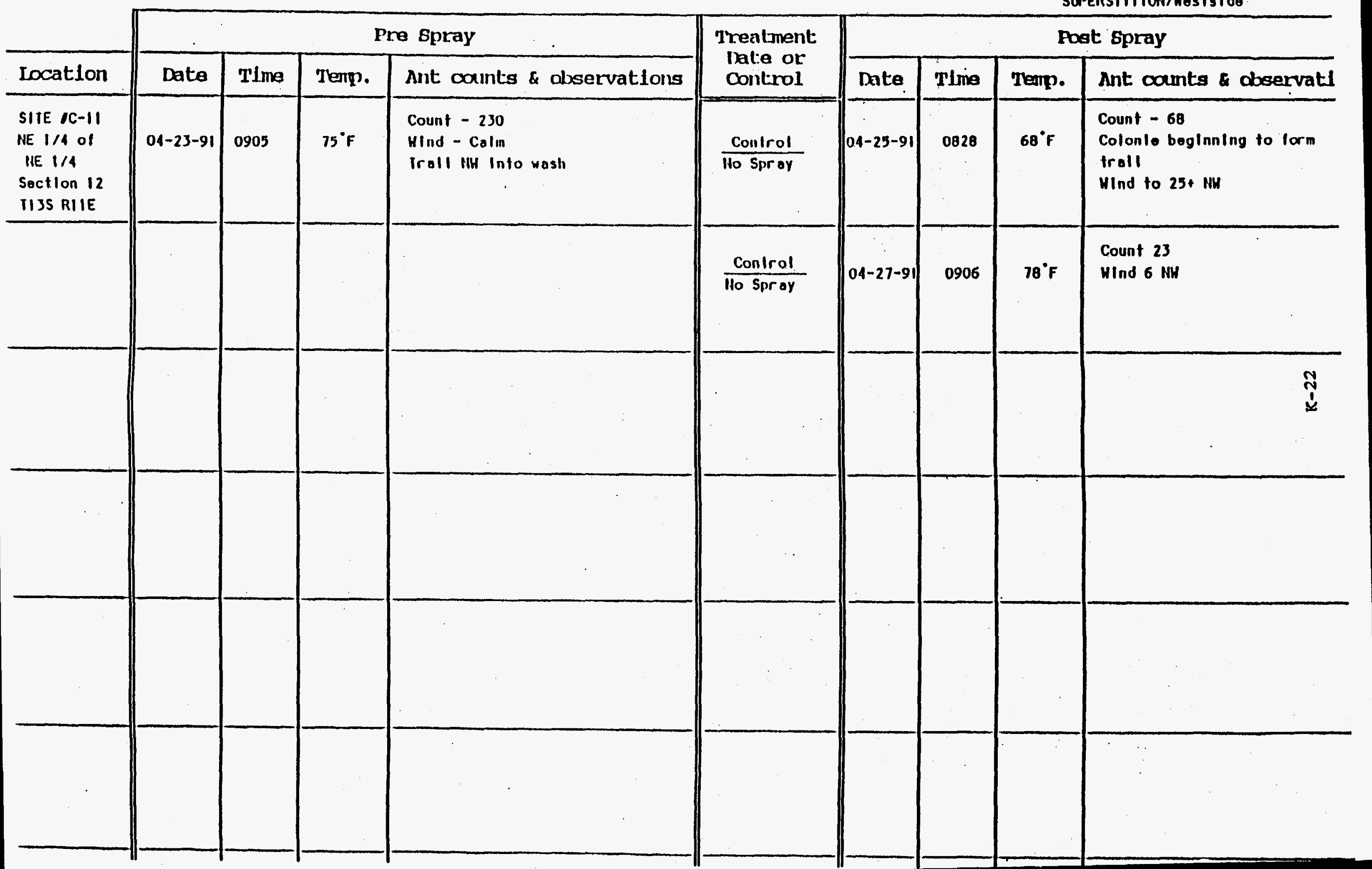




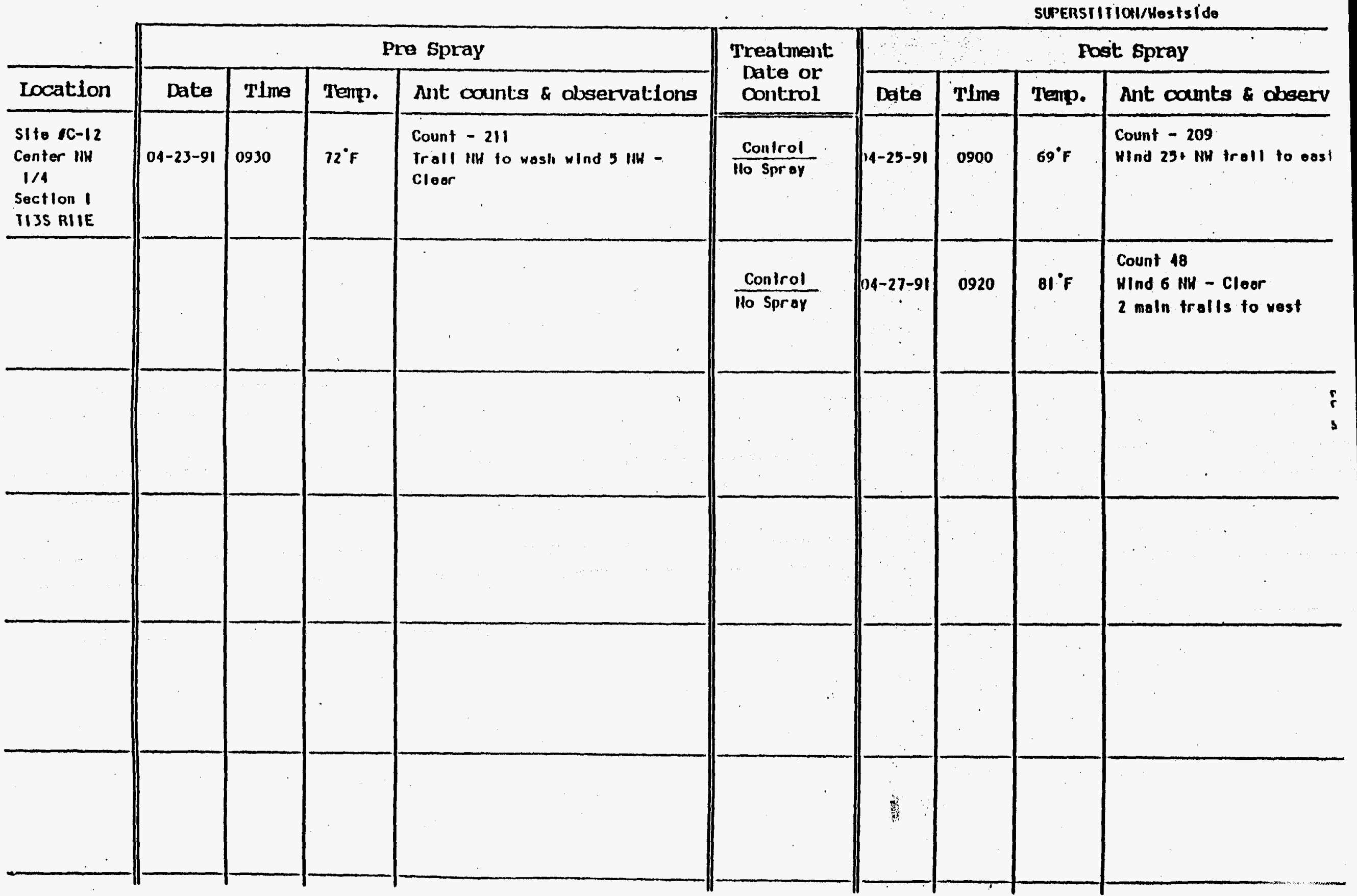


EAST MESA

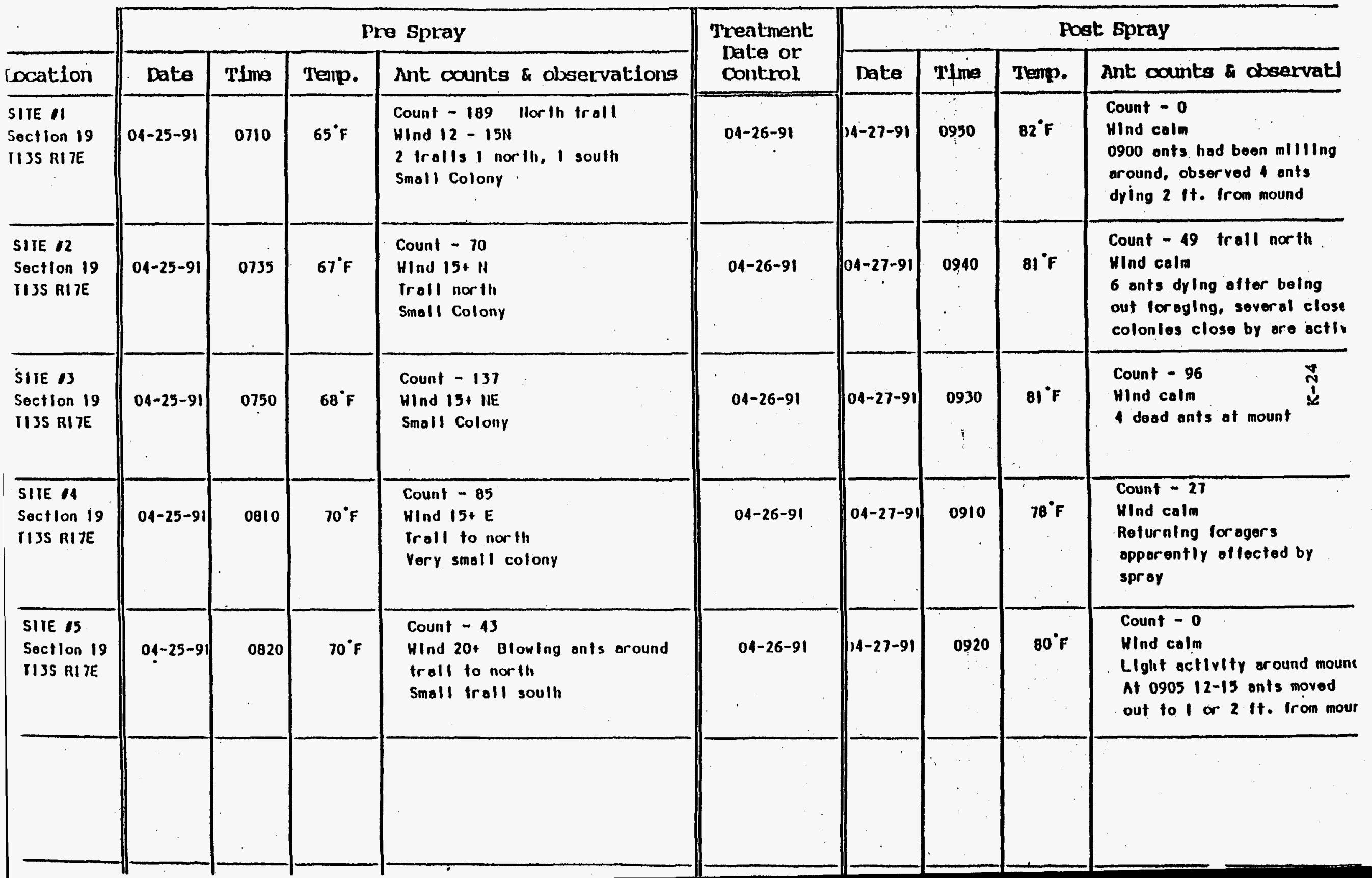




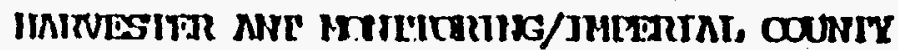

EAST MESA

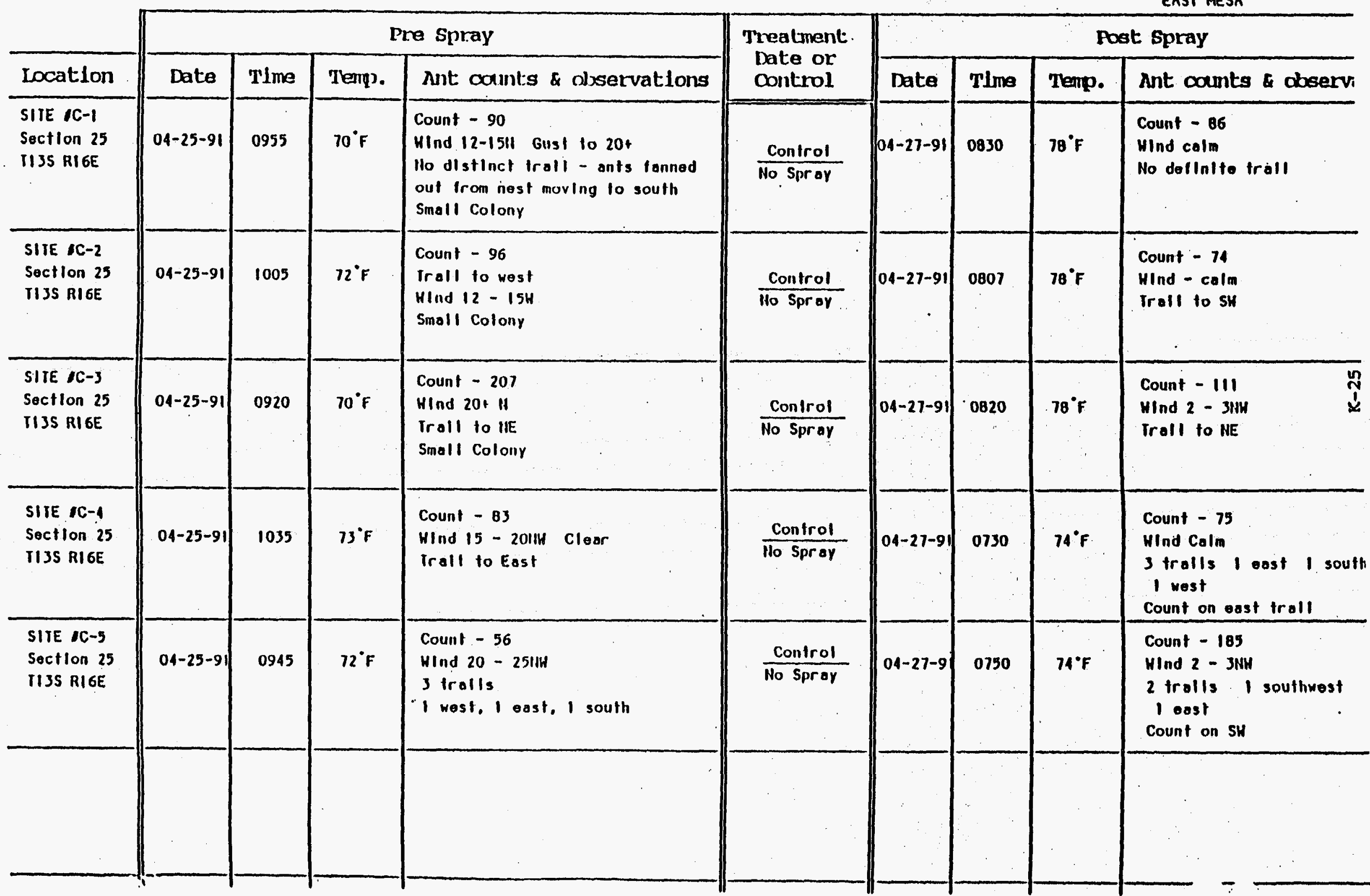


CHECKLIST OF CRITICAL HABITAT FOR SPECIES WHICH MAY BE FOUND IN OR NEAR CTVCP CONTROL BOUNDARIES

\begin{tabular}{|c|c|c|}
\hline specles & $\begin{array}{l}\text { Counties where Critical } \\
\text { Habltat has been Designated }\end{array}$ & $\begin{array}{l}\text { Critical Habltat } \\
\text { found within CIVCP } \\
\text { Control Boundaries }\end{array}$ \\
\hline $\begin{array}{c}\text { American Peregrine } \\
\text { falcon }\end{array}$ & Sonoma, Napa, Lake & None \\
\hline bonytail chub & $\begin{array}{l}\text { Moffat, Mesa, Co.; Mesa, } \\
\text { Garfield, San Juan, UT.; } \\
\text { Mohave, Nevada, Clark, AZ.; } \\
\text { San Bernardino, CA. }\end{array}$ & None \\
\hline Califormia condor & $\begin{array}{l}\text { Ventura, Los Angeles, Santa } \\
\text { Barbara, San Luis Obispo, } \\
\text { Kern, Tulare }\end{array}$ & None \\
\hline $\begin{array}{l}\text { Coachella Valley } \\
\text { fringed-toed lizard }\end{array}$ & Riverside & None \\
\hline Colorado squawfish & $\begin{array}{l}\text { Moffat, Rio Blanco, Mesa, } \\
\text { Garfield, Co.; Uintah, } \\
\text { Carbon, Grand, Emery, Wayne, } \\
\text { San Juan, UT.; San Juan, MM. }\end{array}$ & None \\
\hline desert pupfish & Imperial, $\mathrm{CA}$; Pima, $\mathrm{AZ}$. & None: \\
\hline desert tortoise & $\begin{array}{l}\text { Washington, UT.; Mohave, AZ.; } \\
\text { Lincoln, Clark, NV.; San } \\
\text { Bernardino, Imperial, Kern, } \\
\text { Riverside, Los Angeles, CA. }\end{array}$ & None \\
\hline Fresno kangaroo rat & Fresno & None \\
\hline $\begin{array}{l}\text { large-flowered } \\
\text { fiddleneck }\end{array}$ & San Joaquin & None \\
\hline least Bell's vireo & $\begin{array}{l}\text { Santa Barbara, Ventura, } \\
\text { Riverside, San Bernardino, } \\
\text { San Diego }\end{array}$ & None \\
\hline razorback sucker & $\begin{array}{l}\text { Moffat, Pelta, Mesa, } \\
\text { Garfield, Co.; Uintah, } \\
\text { Carbon, Grand, Emery, Wayne, } \\
\text { San Juan, UT.; San Juan, NM.; } \\
\text { Coconino, Mohave, La Paz, } \\
\text { Yuma, Graham, Greenlee, Gila, } \\
\text { Pinal, Yavapai, AZ.; } \\
\text { Clark, NV. }\end{array}$ & None \\
\hline $\begin{array}{l}\text { southwestern willow } \\
\text { flycatcher } \\
\text { (proposed habitat) }\end{array}$ & $\begin{array}{l}\text { Riverside, San Bernardino, } \\
\text { San Diego, CA. ; Cochise, } \\
\text { Pima, Pinal, Yavapai, Gila, } \\
\text { Coconino, Apache, AZ.; } \\
\text { Bernalillo, Catron, Grant, } \\
\text { Hidalgo, MM. habitat) }\end{array}$ & None \\
\hline $\begin{array}{l}\text { valley elderberry } \\
\text { longhorn beetle }\end{array}$ & Sacramento & None \\
\hline
\end{tabular}

(Fed. Code of Reg. 17.95\& 17.96; Fed. Register, 7/23/93, Vol.58, \# 140) 